\title{
PHOTODEGRADATION AND PHOTOSTABILIZATION OF WEATHERED WOOD FLOUR FILLED POLYETHYLENE COMPOSITES
}

Dissertation for the Degree of Ph.D. Michigan Technological University

Nicole M. Stark

2003 



\section{PHOTODEGRADATION AND PHOTOSTABILIZATION OF WEATHERED WOOD FLOUR FILLED POLYETHYLENE COMPOSITES}

By

Nicole M. Stark

A dissertation submitted in partial fulfillment of the requirements for the degree of

Doctor of Philosophy

(Forest Science)

at

Michigan Technological University

2003 

This dissertation "PHOTODEGRADATION AND PHOTOSTABILIZATION OF WEATHERED WOOD FLOUR FILLED POLYETHYLENE COMPOSITES”, is hereby approved as partial fulfillment of the requirements for the degree of Doctor of Philosophy in Forest Science.

School of Forestry Resources \& Environmental Science

Laurent M. Matuana, Ph.D., Dissertation Advisor

Glenn Mroz, Ph.D., Dean

Date 



\section{TABLE OF CONTENTS}

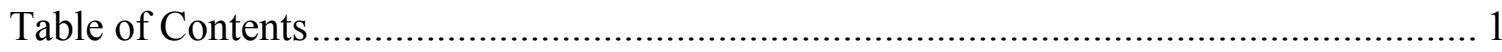

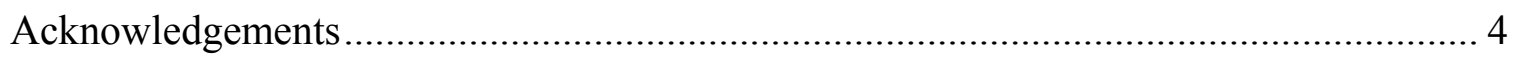

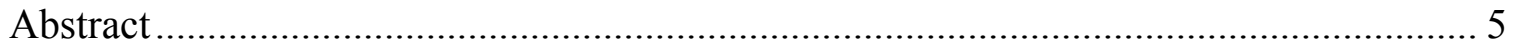

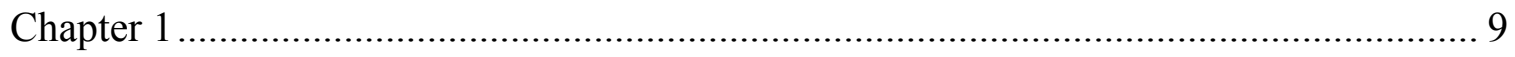

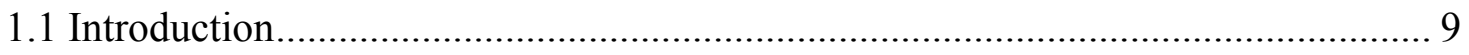

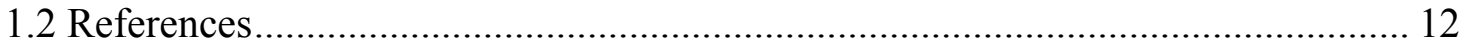

Chapter 2 - Background Information and Literature Review ..................................... 15

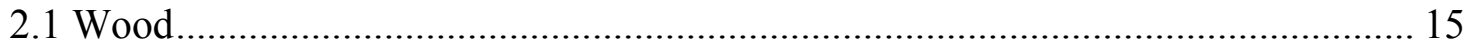

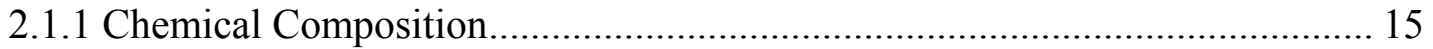

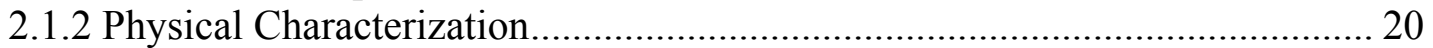

2.1.3 Engineering Properties.......................................................................... 23

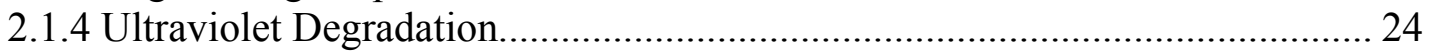

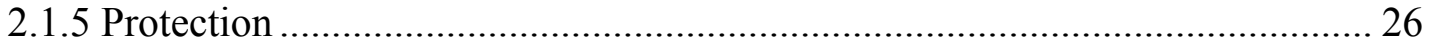

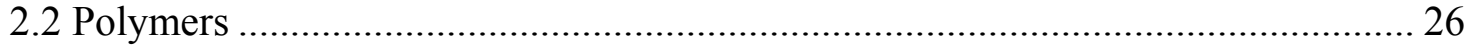

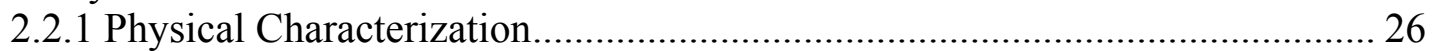

2.2.2 Chemical Composition - Polyethylene...................................................... 28

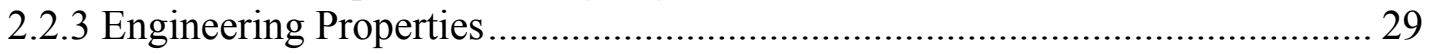

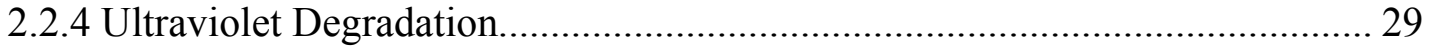

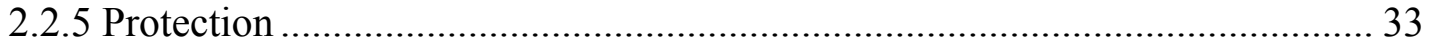

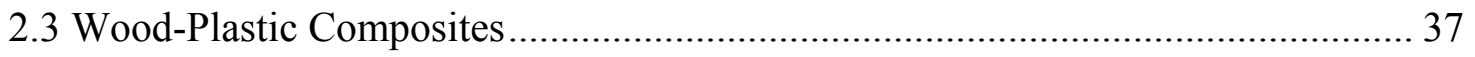

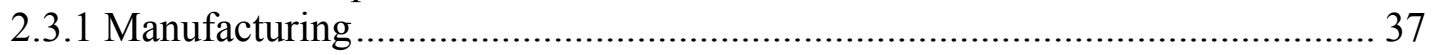

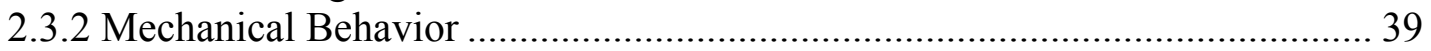

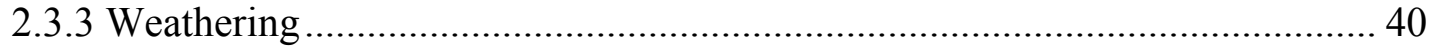

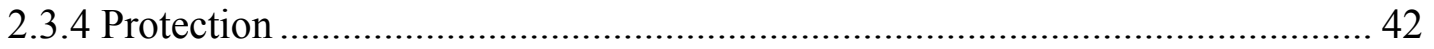

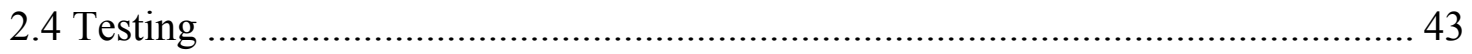

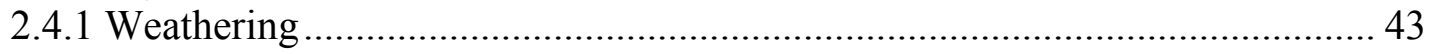

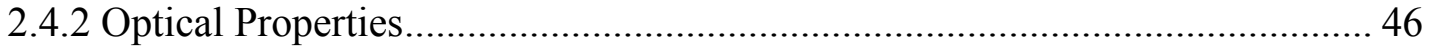

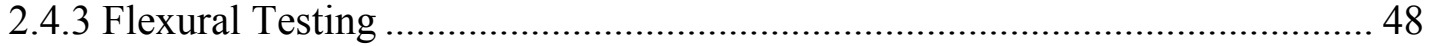

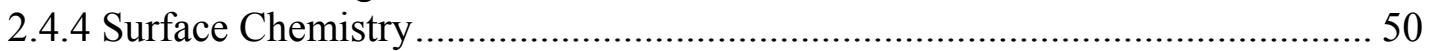

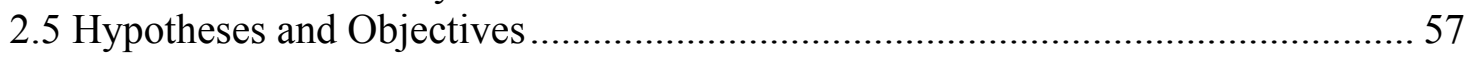

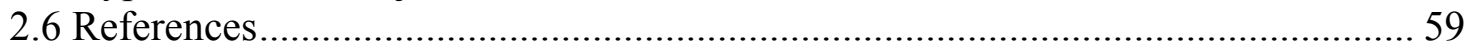

Chapter 3 - Effect of Processing Method on Accelerated Weathering of Wood

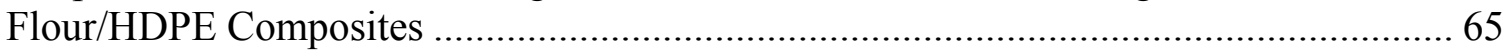

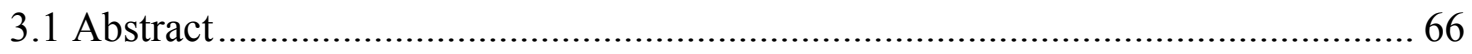

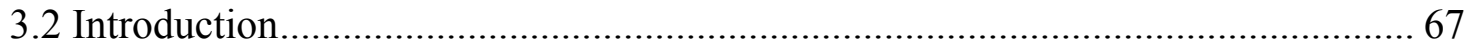




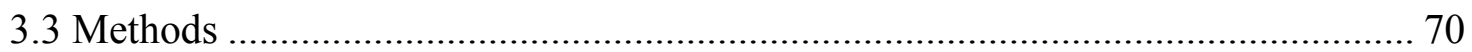

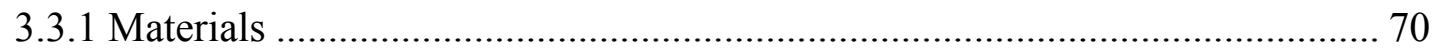

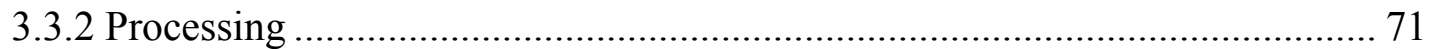

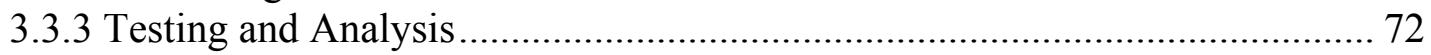

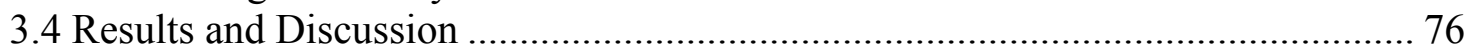

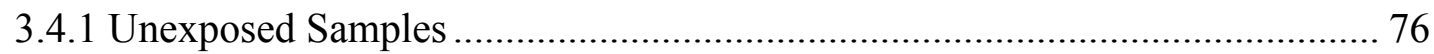

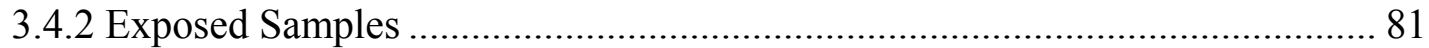

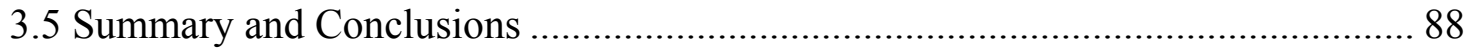

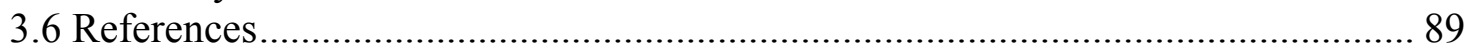

Chapter 4 - Surface Chemistry Changes of Weathered Wood Flour/HDPE Composites

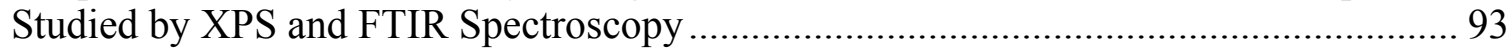

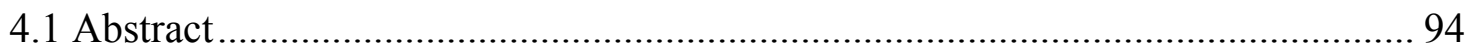

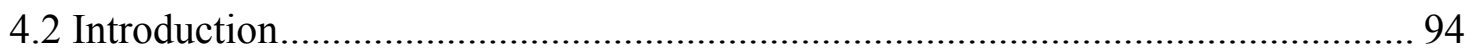

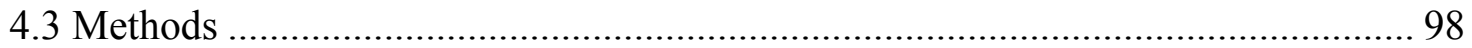

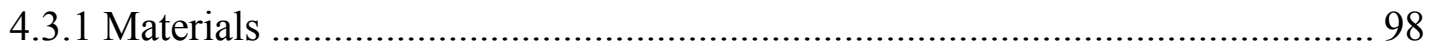

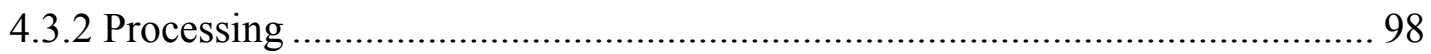

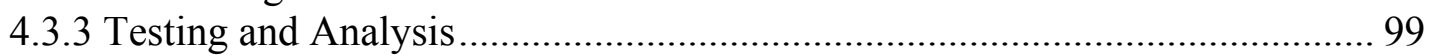

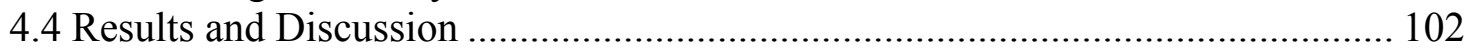

4.4.1 X-Ray Photoelectron Spectroscopy ........................................................... 102

4.4.2 Fourier Transform Infrared Spectroscopy ……………………………........ 106

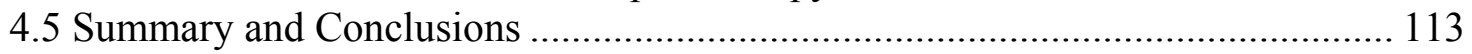

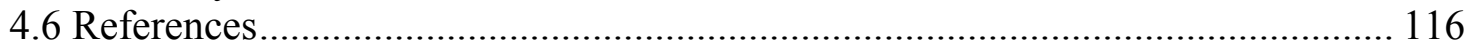

Chapter 5 - Ultraviolet Weathering of Photostabilized Wood Flour/HDPE Composites

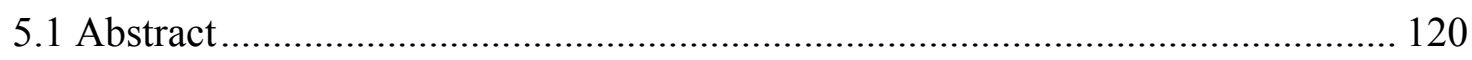

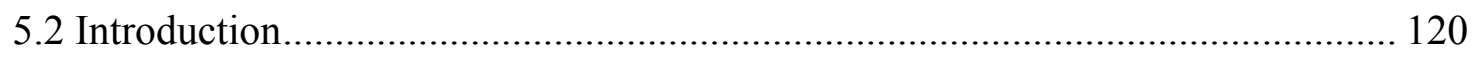

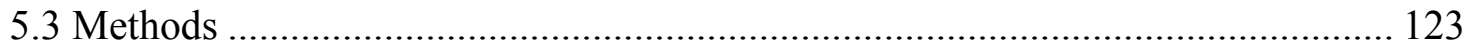

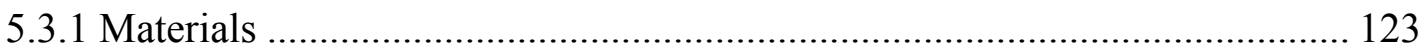

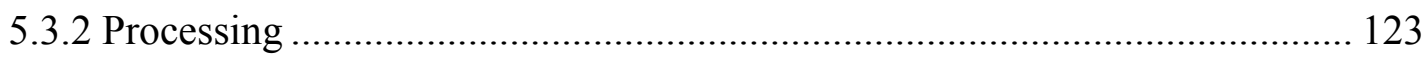

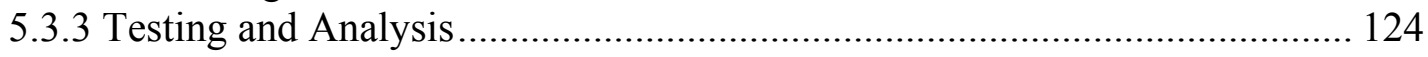

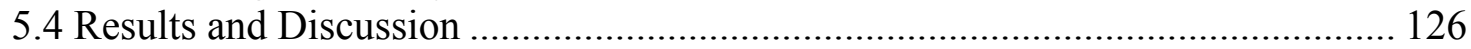

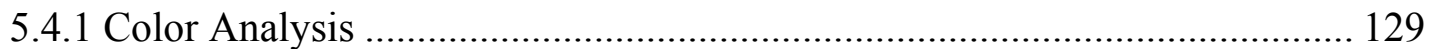

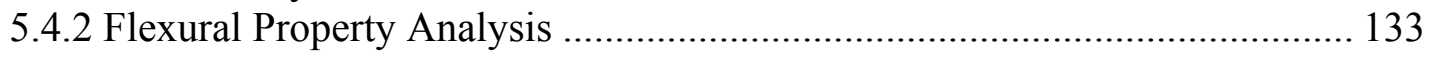

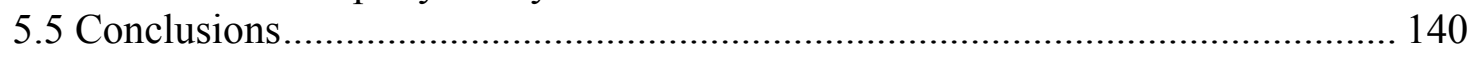

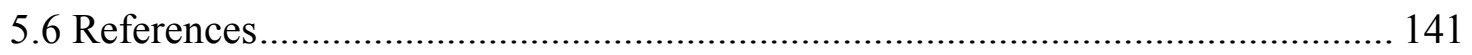

Chapter 6 - Color Fade and Mechanical Properties of Photostabilized Wood Flour/HDPE Composites Exposed to Accelerated Ultraviolet Weathering.......................................... 143

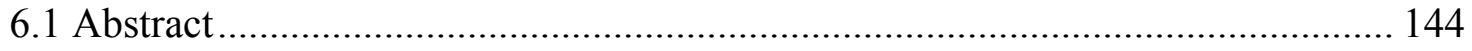

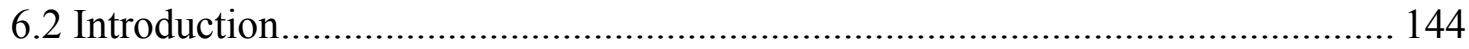

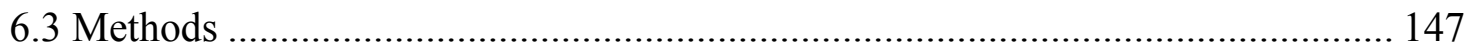




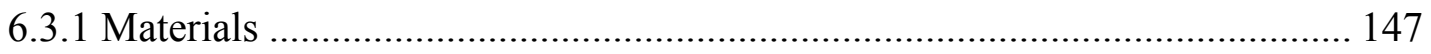

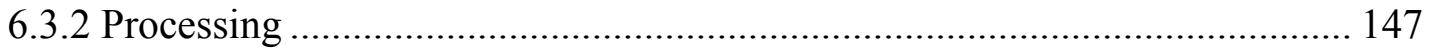

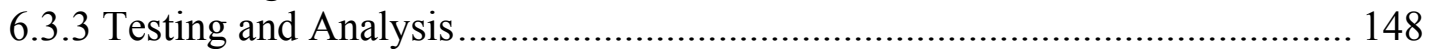

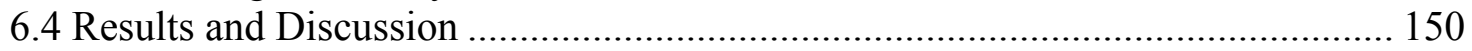

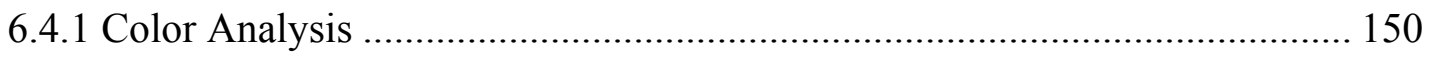

6.4.2 Flexural Property Analysis ................................................................... 152

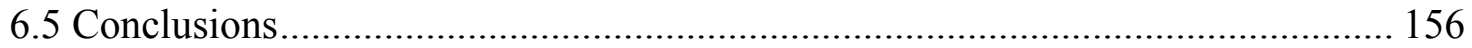

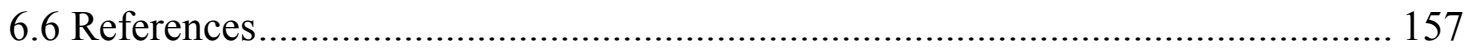

Chapter 7 - Structural and Mechanical Property Changes of Wood Flour/HDPE Composites After Accelerated Weathering …………………………….......................... 161

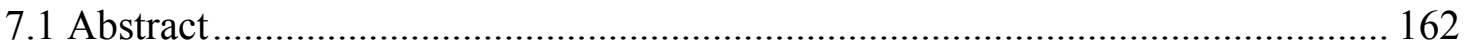

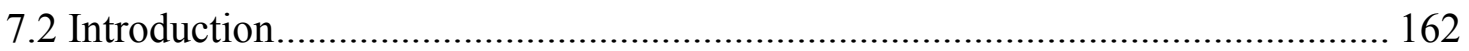

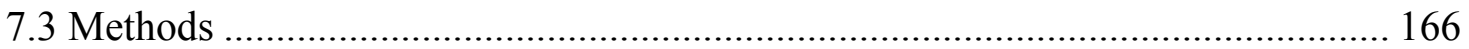

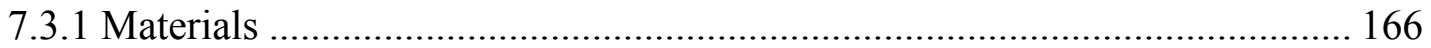

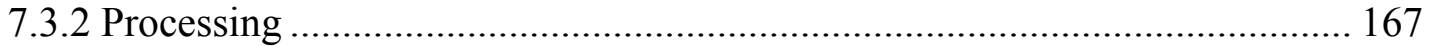

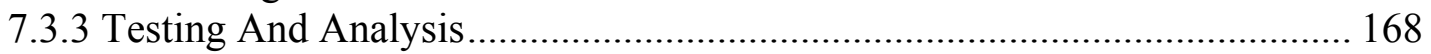

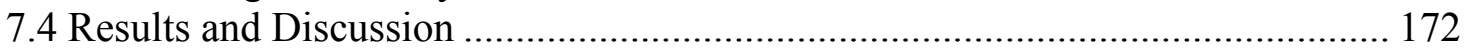

7.4.1 Scanning Electron Microscopy ................................................................. 172

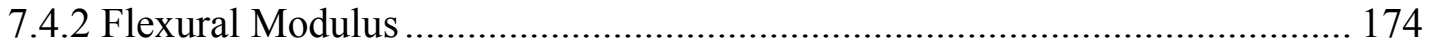

7.4.3 Fourier Transform Infrared Spectroscopy ………………………….......... 176

7.4.4 Structure-Property Relationships ………………....................................... 183

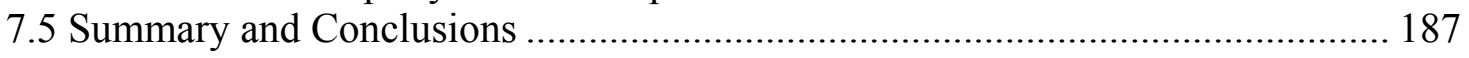

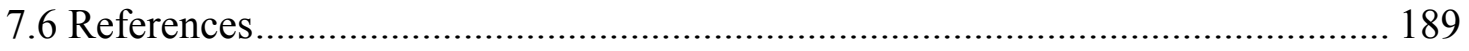

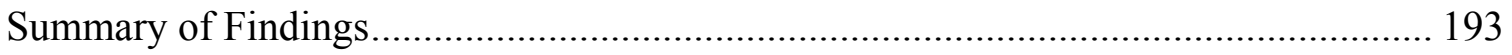

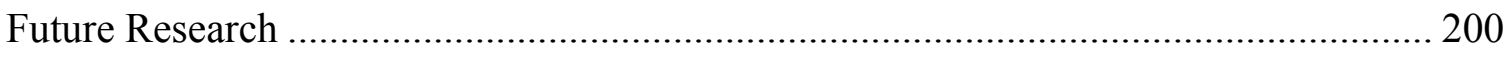

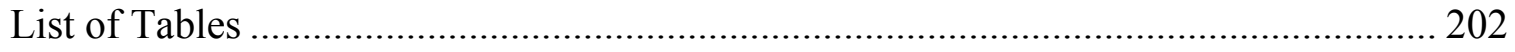

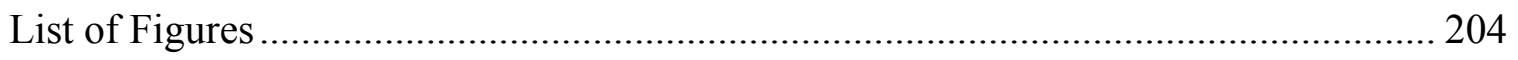

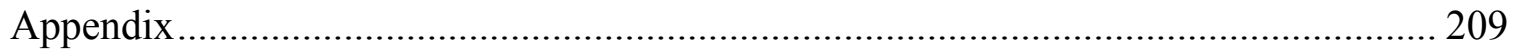




\section{ACKNOWLEDGEMENTS}

The research presented in this thesis was completed in cooperation with the United States Department of Agriculture Forest Products Laboratory (FPL) and the School of School of Forestry Resources \& Environmental Science, Michigan Technological University. It was partially funded by a grant from the Partnership for Advancing Technologies in Housing.

I would like to express my sincere gratitude to my academic advisor, Dr. Laurent M. Matuana for his guidance and support during the past three years. What I learned from him will be beneficial in my future. I also appreciate my committee members Dr. Peter Laks, Dr. Patricia Heiden, and Dr. Jaroslaw Drelich for spending time reading drafts and providing valuable feedback.

I would also like to thank my colleagues at FPL: the Performance-Engineered Composites Group for all their encouragement and help, those working in the melt-blend lab who kept things running during my absences, the mechanical shops for making custom sample holders, and Tom Kuster for use of the microscopes. My sincere gratitude also goes to Dr. John Youngquist and Dr. Jerrold E. Winandy whose backing and commitment were necessary for me to succeed.

Finally, I would like to thank my family and friends. Without aid and encouragement from my parents the "little things" would not have got done. Without the support of my friends I may have become entirely too serious. 


\section{ABSTRACT}

Wood plastic composites (WPCs) have gained popularity as building materials because of their usefulness in replacing solid wood in a variety of applications. These composites are promoted as being low-maintenance, high-durability products. However, it has been shown that WPCs exposed to weathering may experience a color change and/or loss in mechanical properties. An important requirement for building materials used in outdoor applications is the retention of their aesthetic qualities and mechanical properties during service life. Therefore, it is critical to understand the photodegradation mechanisms of WPCs exposed to UV radiation and to develop approaches to stabilize these composites against ultraviolet light. In this dissertation, the surface chemistries of weathered composites (both unstabilized and stabilized) as well as the effect of weathering on the color fade and the retention of mechanical properties were characterized.

Since different methods of manufacturing WPCs lead to different surface characteristics, which can influence weathering, the effect of manufacturing method on the photodegradation of WPCs was investigated first. Wood flour (WF) filled highdensity polyethylene (HDPE) composite samples were either injection molded, extruded, or extruded and then planed. Fourier transform infrared (FTIR) spectroscopy was used to monitor the surface chemistry of the manufactured composites. The spectra showed that the surface of planed samples had more wood component than extruded and injection molded samples, respectively. After weathering, the samples were analyzed for color fade, and loss of flexural properties. The final lightness of the composites was not dependent upon the manufacturing method. However the mechanical property loss was 
dependent upon manufacturing method. The samples with more wood component at the surface (planed samples) experienced a larger percent of total loss in flexural properties after weathering due to a greater effect of moisture on the samples.

The change in surface chemistry of HDPE and WF/HDPE composites after weathering was studied using spectroscopic techniques. X-ray photoelectron spectroscopy (XPS) was used to characterize the occurrence of surface oxidation whereas FTIR spectroscopy was used to monitor the development of degradation products, such as carbonyl groups and vinyl groups, and to determine changes in HDPE crystallinity. Surface oxidation occurred immediately after exposure for both the neat HDPE and WF/HDPE composites. After weathering, the surface of the WF/HDPE composites was oxidized to a greater extent than the neat HDPE after weathering. This suggests that photodegradation is exacerbated by the addition of the carbonyl functional groups of the wood fibers within the HDPE matrix during composite manufacturing. While neat HDPE may undergo cross-linking in the initial stages of accelerated weathering, the WF may physically hinder the ability of the HDPE to cross-link resulting in the potential for HDPE chain scission to dominate in the initial weathering stages of the WF/HDPE composites.

To determine which phototstabilizers are most effective for WF/HDPE composites, factorial experimental designs were used to determine the effects of adding two hindered amine light stabilizers, an ultraviolet absorber, and a pigment on the color fade and mechanical properties of both unweathered and UV weathered samples. Both the pigment and ultraviolet absorber were more effective photostabilizers for WF/HDPE composites than hindered amine light stabilizers. The ineffectiveness of hindered amine 
light stabilizers in protecting WPCs against UV radiation was attributed to the acid/base reactions occurring between the WF and hindered amine light stabilizer.

The efficiency of an ultraviolet absorber and/or pigment was also examined by incorporating different concentrations of an ultraviolet absorber and/or pigment into WF/HDPE composites. Color change and flexural properties were determined after accelerated UV weathering. The lightness of the composite after weathering was influenced by the concentration of both the ultraviolet absorber and pigment. The pigment exerted more of an influence than the ultraviolet absorber by masking the bleaching wood component as well as blocking UV light. Flexural MOE loss was influenced by an increase in ultraviolet absorber concentration, but increasing pigment concentration from 1 to $2 \%$ had little influence on MOE loss. However, increasing both ultraviolet absorber and pigment concentration resulted in improved strength properties over the unstabilized composites after $3000 \mathrm{~h}$ of weathering.

Finally, the change in surface chemistry due to weathering of WF/HDPE composites that were either unstabilized or stabilized with an ultraviolet absorber and/or pigment was analyzed using FTIR spectroscopy. The samples were tested for loss in modulus of elasticity, carbonyl and vinyl group formation at the surface, and change in HDPE crystallinity. It was concluded that structural changes in the samples; carbonyl group formation, terminal vinyl group formation, and crystallinity changes cannot reliably be used to predict changes in modulus of elasticity using a simple linear relationship. The effect of cross-linking, chain scission, and crystallinity changes due to ultraviolet exposure as well as the interfacial degradation due to moisture exposure are inter-related factors when weathering HDPE and WF/HDPE composites. 


\section{CHAPTER 1}

\subsection{Introduction}

Wood-plastic composites (WPCs) represent a rapidly growing industry in the United States for both plastic processors and forest products industries. To plastic processors, wood and other lignocellulosic fibers (e.g., agrofibers) represent a vast supply of readily available raw materials (filler or reinforcement) for all types of WPCs. Forestproducts companies, on the other hand, see plastics as a way to expand sustainable forest resource utilization through the use of wood waste, fibers from under-utilized species, and reclamation and recycling of wood, other agricultural species and waste, and paper materials from municipal solid waste streams (1), as well as a way to make new construction materials with attributes that wood does not have (2).

Fillers are commonly used in the thermoplastic industry to provide stiffness and strength to platics. In 2001 in North American, 5.5 billion lb of fillers were used, with the most important fillers being inorganic materials ( 5.1 billion $1 \mathrm{~b})$ such as calcium carbonate (2.2 billion $\mathrm{lb}$ ), glass fiber (1.7 billion $\mathrm{lb})$, and other mineral fillers such as clay, talc, mica (1.2 billion $\mathrm{lb}$ ). Only 400 million $\mathrm{lb}$ were natural fibers (3). Although inorganic fillers currently dominate the thermoplastic industry, wood-derived fillers have become more accepted in recent years. Growth of WPCs has averaged more than 25\% a year since 1998, no segment of the plastics industry has grown faster (4). To a great extent, the use of wood fibers in plastics is due to the recent acceptance of WPCs into the construction industry for applications such as decking, siding, roof tiles, and window and door frames (5). It is predicted that for building products alone, approximately 1.1 billion 
lb (500,000 tons) of WPCs will be used in North America in 2006 (3). Construction, transportation, industrial, and consumer applications are also on the rise. Currently, nearly $70 \%$ of WPCs are polyethylene matrix composites (3).

The growth in exterior applications for WPCs has resulted in a concern about their durability. WPC products are susceptible to degradation when exposed to long-term outdoor solar ultraviolet radiation (photodegradation), rain, snow, pollutants, and decay. Photodegradation of WPCs is a combination of degradation of the thermoplastic matrix and wood component and is of special concern for the use of these composites for outdoor applications.

In spite of the work to improve its weatherability, plastic still undergoes photochemical degradation when exposed to natural weathering (6-12). Degradation results in changes in chemical, physical, and mechanical properties of the plastic $(6,8,9)$. Some of the degradative effects of the products are manifested through the development of a colored and brittle material of lower elasticity and impact resistance. Color change is primarily a surface phenomenon but is unacceptable from an aesthetic perspective. On the other hand, mechanical failure is a devastating phenomenon. For example when fracture occurs in the construction industry, the building unexpectedly becomes vulnerable to wind (poor insulation) and/or water infiltration through cracks and materials must be replaced.

Similarly, wood exposed outdoors undergoes photochemical degradation caused by ultraviolet light (13-18). This degradation takes place primarily and preferentially in the lignin component, which is responsible for color changes and causes the surface of the wood to become more hydrophilic and rougher (18). 
The photochemical degradation of both plastics and wood causes millions of dollars of material damage every year in the United States and high material cost may be involved to replace damaged products just a few short years after installation (19). This is one of the most important practical problems that may limit the use of WPCs in exterior building construction applications where long-term performance is of prime importance. Ultimate consumer acceptance of WPCs will depend on their ability to retain their physical, mechanical and aesthetic qualities over long periods of time, ranging from 15 to 30 years. Since materials used for exterior applications are exposed to sunlight, understanding the photodegradation mechanism for these lower cost products is the only way to improve their quality and durability.

While considerable information is available on the mechanisms of photodegradation and approaches to improve the durability of either thermoplastics (7-12) or wood (13-17), prior research has not extensively examined the performance of wood-fiber filled plastic composites exposed to ultraviolet (UV) radiation. Very few articles have been published on the durability of these composites. Degradation due to fungal attack has been examined (20-22). Others have investigated the photodegradation of polyvinyl chloride (PVC) and wood composites (23-24) exposed to accelerated laboratory UV tests. There has yet to be a fundamental understanding of the degradation of wood filled polyethylene (PE) composites. Fundamental research is needed in order to elucidate the photodegradation mechanism occurring in WPCs during weathering and to increase their durability.

This thesis outlines a plan to gain an in-depth understanding of the photodegradation mechanism of WPCs exposed to accelerated ultraviolet radiation and 
develop approaches to stabilize these composites against UV radiation in order to

enhance their outdoor performance.

\subsection{References}

1. J.J. Balatinecz and R.T. Woodhams, "Wood-Plastic Composites: Doing More With Less," Journal of Forestry, 91(11), 22-26, 1993.

2. J. Patterson, "New Opportunities with Wood-Flour-Foamed PVC," Journal of Vinyl \& Additive Technology, 7(3), 138-141, 2001.

3. M. DeFosse, "Wood Composites Are Expanding Among Sectors," Modern Plastics, 80(1), 25-30, 2003.

4. J. Morton, "Current and Emerging Applications for Natural \& Wood Fiber Composites," in Proceedings, $7^{\text {th }}$ International Conference on Woodfiber-Plastic Composites, Madison,WI, May 19-20, 2003.

5. C. Eckert, "Opportunities for Natural Fibers in Plastic Composites," in Proceedings, Progress in Wood Fiber-Plastic Composites Conference, Toronto, May 25-26, 2000.

6. T.A. Osswald and G. Menges, Materials Science of Polymers for Engineers, Hanser Publishers, New York, 1995.

7. F. Gugumus, "Light Stabilizers," in Plastics Additives Handbook, Chapter 3, 129262, R. Gächter and H. Müller, Eds., Hanser Publishers, New York, 1990.

8. S. A. Jabarin and E. A. Lofgren, "Photooxidative Effects on Properties and Structure of High-Density Polyethylene," Journal of Applied Polymer Science, 53(4), 411-423, 1994.

9. G. Wypych, Handbook of Material Weathering, ChemTec Publishing, TorontoScarborough, 1995.

10. F. Gugumus, "The Performance of Light Stabilizers in Accelerated and Natural Weathering," Polymer Degradation and Stability, 50(1), 101-116, 1995.

11. F. Gugumus, "Re-evaluation of The Stabilization Mechanism of Various Light Stabilizer Classes," Polymer Degradation and Stability, 39(1), 117-135, 1993.

12. A. Tidjani, "Comparison of Formation of Oxidation Products During PhotoOxidation of Linear Low Density Polyethylene Under Different Natural and Accelerated Weathering Conditions," Polymer Degradation and Stability, 68(3), 2000, 465-469.

13. D.V. Plackett, E.A. Dunningham and A.P. Singh, "Weathering of Chemically Modified Wood," in Chemical Modification of Lignocellulosic Materials, D.N.S. Hon, Ed., 277-294, Marcel Dekker, Inc., New York, 1996.

14. R.M. Rowell, "Physical and Mechanical Properties of Chemically Modified Wood," in Chemical Modification of Lignocellulosic Materials, D.N.S. Hon, Ed., 295-310, Marcel Dekker, Inc., New York, 1996.

15. W.C. Feist, "Weathering Characteristics of Finished Wood Based Panel," Journal of Coatings Technology, 54(686), 43-50, 1982. 
16. P.D. Evans, A.F.A. Wallis and N.L. Owen, "Weathering of Chemically Modified Wood Surfaces: Natural Weathering of Scots Pine Acetylated to Different Weight Gains," Wood Science and Technology, 34(2), 151-165, 2000.

17. S. Grelier, A. Castellan and D.P. Kamdem, "Photoprotection of Copper-AmineTreated Pine," Wood and Fiber Science, 32(2), 196-202, 2000.

18. D.N.-S. Hon, "Weathering and Photochemistry of Wood," in Wood and Cellulosic Chemistry, Chapter 11, 513-546, D.N.-S. Hon and N. Shiraishi, Eds, Marcel Dekker, Inc., New York, 2001.

19. Plastic Design Library Staff, The Effect of UV Light and Weather on Plastics and Elastomers, William Andrew, Inc., Society of Plastics Engineers, 1994.

20. P.E. Laks and S.A. Verhey, "Decay and Termite Resistance of Thermoplastic/Wood-Fiber Composites," in Proceedings, $5^{\text {th }}$ Pacific Rim BioBased Composites Symposium, 644-651, Canberra, Australia, December 10-14, 2000.

21. B. Naghipour, "Effects of Extreme Environmental Conditions and Fungal Exposure on the Properties of Wood-Plastic Composites," Masters of Science Thesis, Forestry, University of Toronto, 1996.

22. C.M. Clemons and R.E. Ibach, "The Effects of Processing Method and Moisture History on the Laboratory Fungal Resistance of Wood-HDPE Composites," submitted to Forest Products Journal, December 2002.

23. L.M. Matuana, D.P. Kamdem and J. Zhang, "Photoaging and Stabilization of Rigid PVC/Wood-Fiber Composites," Journal of Applied Polymer Science, 80(11), 19431950, 2001.

24. L.M. Matuana and D.P. Kamdem, "Accelerated Ultraviolet Weathering of PVC/Wood-Flour Composites," Polymer Engineering and Science, 42(8), 16571666, 2002. 


\section{CHAPTER 2 - BACKGROUND INFORMATION AND LITERATURE REVIEW}

\subsection{Wood}

\subsubsection{Chemical Composition}

Wood is classified as a lignocellulosic material. It is made up of major constituents (cellulose, hemicellulose, and lignin) and minor constituents (ash and extractives) (1). The major constituents are structural components with a high molecular weight. Wood is approximately $60-75 \%$ cellulose, $20-30 \%$ lignin, $1-10 \%$ extractives and $0-0.5 \%$ ash (2). The chemical composition of wood varies between species.

\section{Cellulose}

Cellulose is the most abundant and the main structural component of wood. The cellulose molecule is largely linear. Three elements, namely carbon, hydrogen, and oxygen are organized into $\beta$-D-glucose units and linked together to form long linear chains that are arranged in one plane. The molecular weight of cellulose varies between 50,000 and 2.5 million depending on the origin of the sample (3). Figure 2.1 shows a combination of four cellulose building blocks.

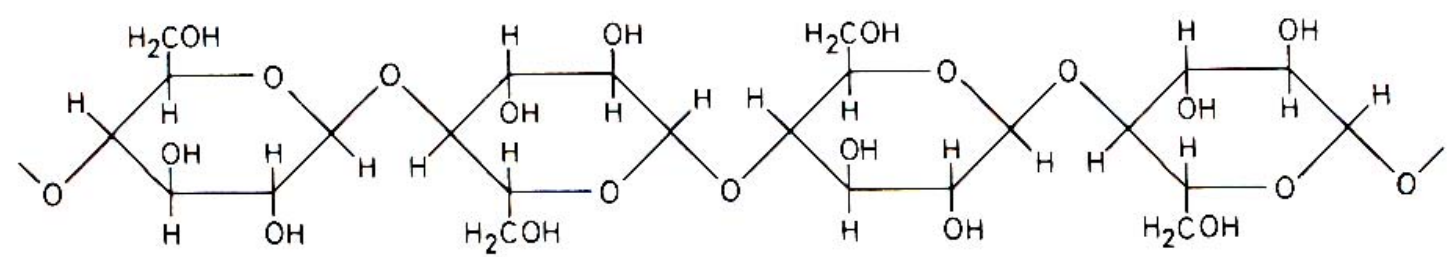

Figure 2.1. A combination of four cellulose building blocks (3). 
The formation of supramolecular cellulose structures originates from functional groups that are able to interact. The arrangement of molecular cellulose is due largely to the surface hydroxyl groups. A high proportion of cellulose is crystalline, held together by intermolecular hydrogen bonding (Fig. 2.2). The hydroxyl groups can be between glucose units in the same molecule (intramolecular linkages) or between two adjacent molecules (intermolecular linkages). The degree of crystallinity is approximately $60 \%-$ $70 \%$ for pulp wood (3).

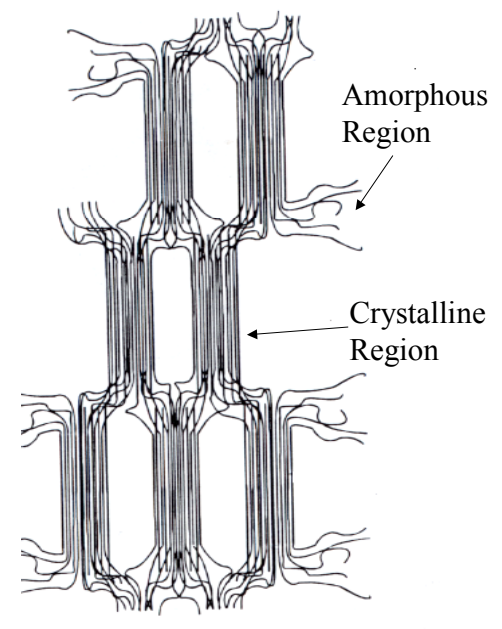

Figure 2.2. Cellulose molecular arrangement (2).

The hydroxyl groups on cellulose are also largely responsibly for its reactive nature. Hydrogen bonds exist not only between cellulose hydroxyl groups, but also between cellulose and water. Cellulose is hygroscopic (attractive to water) because it is a polar molecule and easily undergoes hydrogen bonding (2). The absorption of water by cellulose depends on the number of free hydroxyl groups, not those linked with each other. Therefore water cannot enter crystallites, only amorphous regions are accessible by 
water. The amount of swelling due to moisture absorption is limited because chain movement is limited. In addition, only hydroxyl groups present in amorphous cellulose are available for chemical reactions (4).

\section{$\underline{\text { Hemicellulose }}$}

Hemicellulose is similar to cellulose in that it is arranged in 5 or 6 carbon sugars in chains. However chains are relatively short, therefore are soluble or easily degraded to be soluble (2). The degree of polymerization may be only tens or hundreds of repeating units (4). Hardwoods contain more hemicellulose than softwoods.

\section{Lignin}

Lignin can be thought of as a matrix that holds cellulose fibers together. It is a brittle, relatively inert material that acts as both a bonding agent and stiffening agent. Diffusion of lignin into the fiber wall increases stiffness and allows for stress transfer between matrix and fiber. While the nature of the bond between cellulose and lignin is still in dispute, they are difficult to separate which indicates the bond is an efficient one (2). Generally softwoods have a larger percentage of lignin than hardwoods, accounting for $23 \%-33 \%$ in softwoods and $16 \%-25 \%$ in hardwoods, respectively (3).

Lignin is also comprised of carbon, hydrogen, and oxygen. The basic precursor is a phenolic material (Fig. 2.3). Lignin combines in many ways to form a highly branched, 3-dimensional network (Fig. 2.4). The result is an isotropic substance. The six member rings of lignin are made up of only carbon atoms forming a stable benzene ring. In addition, there is a low occurrence of hydroxyl sites. Therefore lignin is not as reactive as cellulose. 

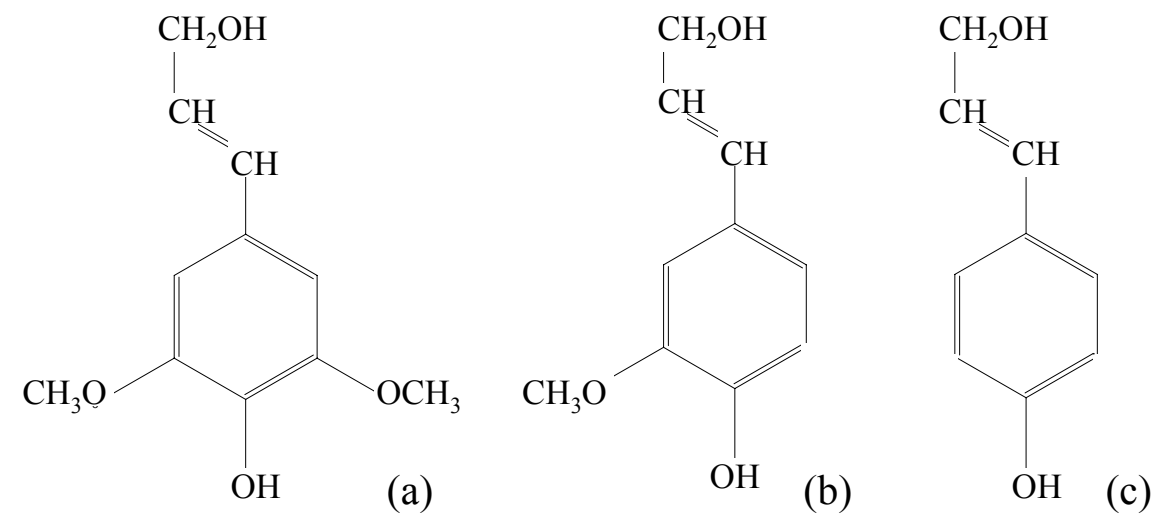

Figure 2.3. Lignin precursors for (a) syringyl, (b) guaiacyl, (c) p-hydroxyphenyl lignin.

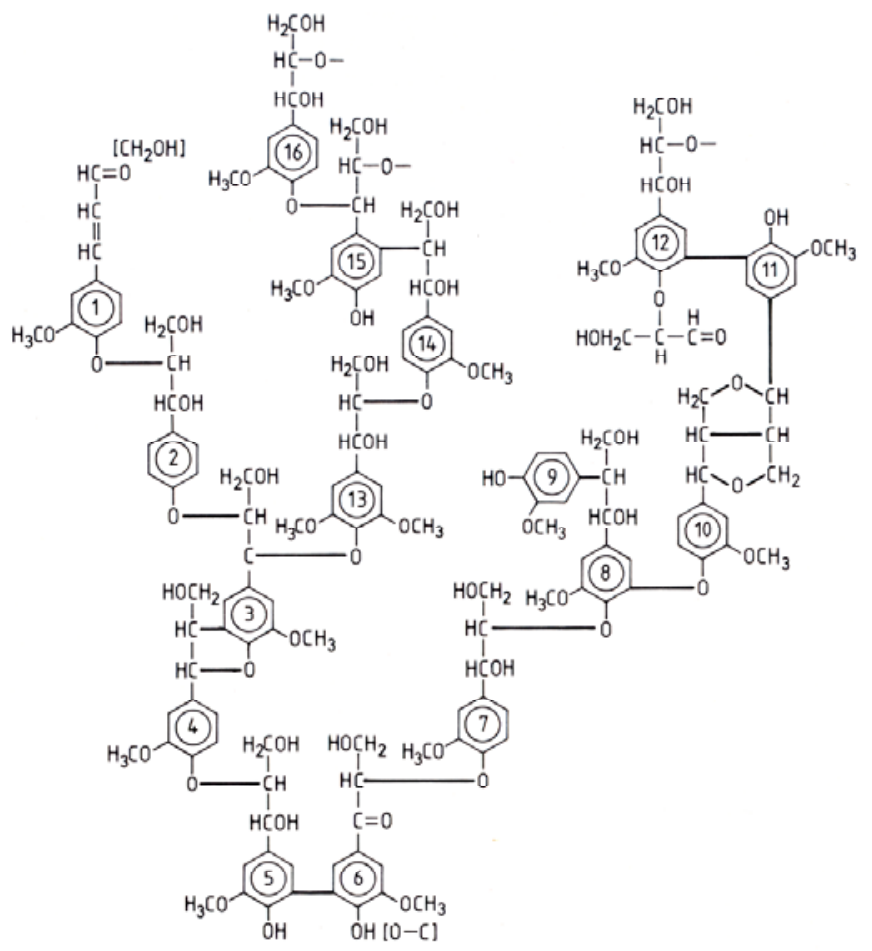

Figure 2.4. Structural scheme of spruce (Picea spp.) lignin (5). 
There are three different lignin precursors found in hardwoods and softwoods that correspond with three types of lignin: guaiacyl (G), syringyl (S), and p-hydroxyphenol (H) (Fig. 2.3). Lignins found in softwoods and hardwoods can be characterized based on the amount of each type of lignin present. Softwoods generally have a much higher percentage of G lignin. For example, the G:S:H ratio for loblolly pine (Pinus taeda) is $86: 2: 13$ (3). The variability in hardwoods is much greater. The $\mathrm{S}$ lignin content of hardwood can vary between $20 \%$ and $60 \%$ (3).

\section{$\underline{\text { Extractives }}$}

Wood extractives are organic substances than can be removed from wood with solvents. Extractives can include organic waxes, oils, fats, tannins, carbohydrates, acids, gums, and resins. Their greatest effects are on hygroscopicity, permeability, and durability of wood. They are deposits, meaning they are not strongly bound in the wood and are free to move (2). Extractives are concentrated in resin canals and ray parenchyma cells (3).

There are three types of wood extractives; aliphatic compounds, terpenes and terpenoids, and phenolic compounds. Aliphatic compounds include n-alkanes, fatty alcohols, fatty acids, fats (esters) and waxes. Terpenoids include turpentine and resin acids. Phenolic compounds include tannins, flavonoids, lignans, stilbenes, and tropolones (4). Extractives are typically removed through steam distillation, ether extraction, alcohol extraction, or water extraction. Steam distillation is used to remove terpenes and ether extraction is used to remove fatty alcohols, fatty acids, and waxes. Tannins are alcohol soluble while other carbohydrates and inorganic materials are water soluble $(1,3)$. 


\subsubsection{Physical Characterization}

The familiar concentric ring pattern apparent on the stump of a tree is due to annual growth rings. The lighter material associated with the early growing season is called earlywood. Latewood is the darker ring, and is formed later in the growing season. Earlywood is lighter in weight, softer, and weaker than latewood (6).

Wood is composed of several different types of specialty cells. The majority of wood cells are elongated, pointed at the end, and are oriented with the stem axis. These cells are referred to as fibers or tracheids. Cell sizes are different for earlywood and latewood. Earlywood cells typically have relatively large cavities and thin walls. In contrast, latewood cells have smaller cavities and thicker walls (Fig. 2.5). The length of wood fibers varies within a single tree and among species, hardwood fibers are generally shorter than softwood fibers. Hardwood fibers are on average $1 \mathrm{~mm}$ in length while softwood fibers can range from 3-8 mm (6).

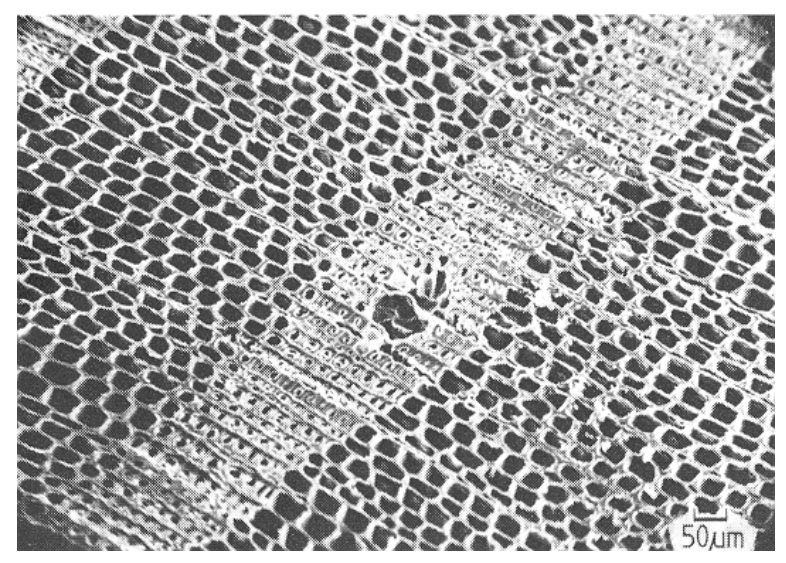

Figure 2.5. Transverse section showing earlywood and latewood cells for a softwood (3). 
Softwoods consist of $90 \%-95 \%$ tracheids (3). In softwoods, the latewood tracheids provide strength while the earlywood tracheids conduct water and minerals. Radial transport occurs in cells arranged in rays, parenchyma cells.

In contrast, hardwoods have shorter tracheids, on average $1 \mathrm{~mm}$ (6). Hardwoods have developed specialized cells for transporting sap. The large diameter cells in hardwoods are called vessel elements. The vessels can range from a few centimeters to several meters in length (3). The difference between earlywood and latewood tracheids is not as extreme as in softwood. Hardwoods also have parenchyma cells to radially transport water. However the number of parenchyma cells is higher in hardwoods than softwoods.

Cells walls are layered structures arranged concentrically and characterized by differences in chemical composition and orientation (Fig. 2.6).

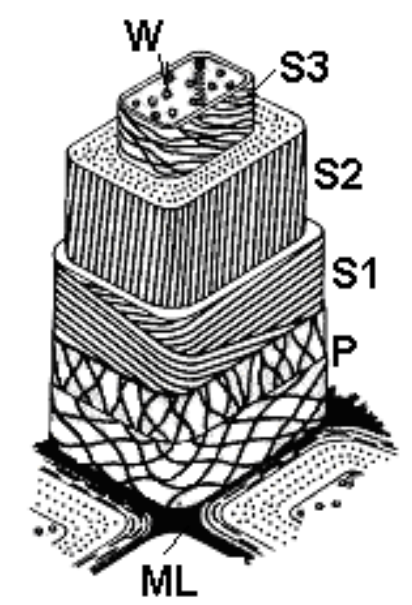

Figure 2.6. Wood cell wall structure (3). 
Individual cells are glued together by the middle lamella (ML), which is generally free of cellulose. The primary wall (P), secondary wall 1 (S1), secondary wall 2 (S2) and secondary wall 3 (S3), are distinguished by the orientation of cellulose fibrils in the walls. In P, cellulose fibrils are arranged in thin crossing layers, in S1 the fibrils are arranged in a slight slope perpendicular to the fiber direction, and S2 the fibrils are roughly aligned with the fiber direction (3). The P and S3 layers have less cellulose present than the S1 and S2 layers. The S3 layer has a high concentration of non-structural substances. The cavity bound by the cell wall is referred to as the lumen. The change in wall thickness between earlywood and latewood is mainly due to changes in S2 thickness, which is also where the majority of cellulose is found. The density of the cell wall is approximately $1.49 \mathrm{~g} / \mathrm{cm}^{3}(2)$.

Mechanical forces as well as seasonal forces influence the shape of cells. This leads to development of abnormal wood known as compression and tension wood, a result of strain acting on the stem. Angiosperm trees develop tension wood while Gymnosperm trees develop compression wood. The result is cells that are different than neighboring cells. Compression wood cells are characterized by a relatively high lignin content. The alignment of fibrils in S2 is about $45^{\circ}$. Tension wood contains smaller and fewer vessels than normal wood, and cells compensate by the addition of a new wall layer, termed a gelatinous layer (G layer). This layer may be present instead of S2 or the tertiary wall, or may be an additional layer. The gelatinous layer consists of highly crystalline cellulose aligned in the direction of the fiber axis (3). 


\subsubsection{Engineering Properties}

Wood is an orthotropic material. The tensile strength of wood is in the fiber direction, or parallel the grain. For example, the tensile strength of ponderosa pine (Pinus ponderosa) is $57,900 \mathrm{kPa}$ parallel to the grain and 2,100 $\mathrm{kPa}$ perpendicular to the grain (6). Mechanical properties and changes in dimension due to moisture or temperature are affected by the alignment of the grain.

Wood shrinks or swells upon changes in moisture content below the fiber saturation point. The amount of water absorbed or released is predictable based on relative humidity and temperature of the environment, leading to equilibrium moisture content in wood (6). Wood shrinks most in the direction of the annual growth rings (tangentially), about half as much across the rings (radially), and only slightly along the grain (longitudinally) (6). Ponderosa pine shrinks volumetrically from green wood to oven-dry by about $9.7 \%(2)$.

When wood is heated, the production of volatiles begins at processing temperatures exceeding $200^{\circ} \mathrm{C}(7)$. While wood starts degrading at $210^{\circ} \mathrm{C}$, this is mainly due to extractives and hemicelluloses. Cellulose does not begin to degrade until $270^{\circ} \mathrm{C}$ (8) and lignin at $280^{\circ} \mathrm{C}(7)$. Wood also expands and contracts upon heating and cooling.

The coefficient of thermal expansion for ponderosa pine is $4 \times 10^{-6}$ parallel to the grain and $35 \times 10^{-6}$ perpendicular to the grain (2).

A common wood filler for thermoplastics is wood flour. Wood flour is typically derived from post-industrial waste such as planer shavings and sawdust. The production method often leads to fiber bundles rather than individual fibers. Moisture, particle size 
distribution, and density are monitored for consistent physical and chemical properties during processing. It is available commercially in a variety of size distributions and species.

\subsubsection{Ultraviolet Degradation}

All wood chemical components are susceptible to degradation by sunlight or ultraviolet light. This reaction leads to changes in wood's appearance such as discoloration, loss of gloss and lightness, roughening, and checking of surfaces, and destruction of mechanical and physical properties (6). While some species may lighten or become gray, others may darken or redden. The effects of UV degradation are largely surface phenomena.

Pure cellulose is not a good light absorber; absorption that does occur may be due to the presence of carbonyl groups accidentally introduced into cellulose during its isolation and purification. Lignin is a better light absorber. Of the total amount of UV light absorbed by wood, lignin absorbs $80 \%-95 \%$ (3). Chromophoric functional groups present in lignin can include phenolics, hydroxyl groups, double bonds, and carbonyl groups. In addition, lignin can form free radicals as intermediates. Because lignin preferentially absorbs light, the result is more degradation than cellulose. In addition, photon energy absorbed by cellulose is likely to transfer to lignin (9). Degradation of wood begins with an attack on the lignin rich middle lamella. The result is often a fibrous appearance at the wood surface. Longer exposure leads to a degradation of secondary walls (3). 
UV light cannot penetrate deeper than $75 \mu \mathrm{m}$ into wood. However, studies investigating depth of degradation show that degradation occurs deeper than this. The result is a proposed mechanism where wood components at the surface initially absorb UV light, and then an energy transfer process from molecule to molecules dissipates excess energy to create new free radicals. In this way free radicals migrate deeper into wood and cause discoloration reactions (9). Studies have shown that lignin content after 10 years of exposure of southern pine (Pinus spp.) changes gradually through the discolored surface layer, with less lignin at the surface and more in the center portion (9).

The primary mechanism of oxidation of wood is the formation of hydroperoxide groups. Oxidation of wood is a slow process, accelerated by exposure to ultraviolet light and heat. Photooxidation of wood can be divided into three separate processes: initiation, propagation, and termination, shown in Scheme 1 (9).

$$
\begin{array}{ll}
\text { Initiation: } & \mathrm{RH} \rightarrow \mathrm{R}^{\cdot}+\mathrm{H}^{\cdot} \text { in the presence of light } \\
\text { Propagation: } & \mathrm{R}^{\cdot}+\mathrm{O}_{2} \rightarrow \mathrm{RO}_{2}{ }^{\bullet} \\
& \mathrm{RO}_{2}+\mathrm{RH} \rightarrow \mathrm{ROOH}+\mathrm{R}^{\cdot} \\
& \\
\text { Termination: } & \mathrm{RO}_{2}^{\cdot}+\mathrm{RO}_{2}^{\cdot} \rightarrow \text { non-radical product } \\
& \mathrm{R}^{\cdot}+\mathrm{RO}_{2}{ }^{\cdot} \rightarrow \text { non-radical product } \\
& \mathrm{R}^{\cdot}+\mathrm{R}^{\cdot} \rightarrow \text { non-radical product }
\end{array}
$$

Scheme 1. Sequence of oxidation reactions in wood. 


\subsubsection{Protection}

An UV absorber can be used to prevent photodegradation. The general treatment is to coat the wood surface with organic solvents or paint in which a UV absorber is dissolved. However, if the topcoat is removed the protection disappears (10). A better method is to use a UV absorber with functional groups that will react with wood (6). Chromophoric groups (carbonyl groups, phenolic hydroxyl groups) can be modified to reduce discoloration. The treatment of the hydroxyl group by acetylation, methylation, and benzoylation decreases photo-induced discoloration (10).

\subsection{Polymers}

\subsubsection{Physical Characterization}

Polymers are molecules of very high molecular weight $\left(\mathrm{M}_{\mathrm{W}}\right)$ made up of many repeating units of low molecular weight, called monomers. They may be generated synthetically or through natural processes.

Synthetic polymers are generated through either addition polymerization or condensation polymerization. The simplest method, addition polymerization, occurs when monomers are added to each other by breaking double-bonds that exist between carbon atoms. The addition mechanism is used to make polymers from monomers with ring structures or double bond by a chain reaction. The extra bond of the monomer is used to form the bond between monomers; this means that no molecules are lost during polymerization. There is no change in the $\mathrm{M}_{\mathrm{W}}$ of the monomer incorporated into the polymer. Addition polymers are characterized by high $\mathrm{M}_{\mathrm{W}}$ average. In condensation 
polymerization, two components with end-groups that react with each other are mixed. The result is a polymer with repeating units that are smaller than the monomer from which they are formed (11). Water is a common by-product of condensation polymerization (12). Condensation polymers are characterized by relatively low $M_{W}$ number averages. The macromolecular configuration of polymer chains may be linear or branched.

Polymers are classified as being thermoset, thermoplastic, or elastomers. Thermosets harden as they cure, and do not flow upon reheating. This is due to the formation of cross-links during the curing process, which limit polymer mobility. This contrasts with thermoplastics, which solidify when cooled, and flow again upon reheating. Thermoplastics can be further classified as amorphous or semi-crystalline. The molecular chains of amorphous thermoplastics remain in disorder when the thermoplastic cools, leading to a material with a fairly random molecular structure. A portion of the molecular chains of a semi-crystalline remain in disorder when the thermoplastic cools, with the remainder arranging themselves into ordered regions (12). Semi-crystalline polymers exhibit a glass transition point, $\mathrm{T}_{\mathrm{g}}$, where the amorphous regions begin to flow, and a melting point, $T_{m}$, where the crystalline regions melt. Below $T_{g}$ the polymer is brittle, above $\mathrm{T}_{\mathrm{g}}$ the polymer is relatively flexible. Elastomers are polymers exhibiting long range elasticity at room temperature, i.e., polymers having low initial Young's modulus (stiffness) but high extensibility. 


\subsubsection{Chemical Composition - Polyethylene}

Polyethylene (PE) is a semi-crystalline thermoplastic polymer consisting of a carbon backbone with hydrogen sidegroups (Fig. 2.7). Although PE is a linear molecule, the macromolecular structure may be a linear molecule with branches. High-density PE (HDPE) has approximately 5-10 short branches for every 1000 carbon atoms. In contrast low-density PE (LDPE) has the same number of branches, but they are much longer. Linear low-density PE (LLDPE) also has short branches but they are more numerous, approximately 10-35 per 1000 carbon atoms (12).

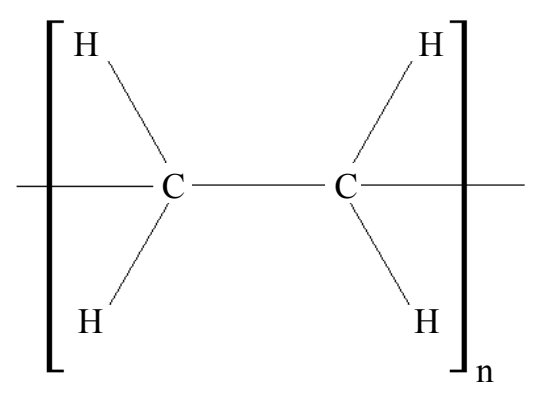

Figure 2.7. PE repeating unit.

The branches can influence density and crystallinity of the polymeric material. Low-density PE ranges from $0.91-0.925 \mathrm{~g} / \mathrm{cm}^{3}$ while high-density PE ranges from 0.941 $0.965 \mathrm{~g} / \mathrm{cm}^{3}$. The crystallinity of low-density PE can range from $42 \%-53 \%$ while that of high-density PE ranges from 64\%-80\% (12). 


\subsubsection{Engineering Properties}

Polymers are viscoelastic materials, meaning they may behave as solids or liquids. The response of viscoelastic materials to an applied stress or strain is dependent upon deformation rate and time (11). This is arguably the most distinctive polymeric characteristic in terms of engineering properties. When polymers undergo small deformations, linear viscoelasticity theory is valid. However non-linear viscoelasticity must be used if deformations are large (12). At low strain rates or high temperatures ductile failure can be expected. At high strain rates or low temperatures brittle failure occurs.

Semi-crystalline polymers experience both plastic and elastic deformation. Plastic deformation is a result of changing morphology in the crystalline and amorphous regions of the polymer. The elastic deformation is related to crystallinity of the polymer when the temperature is between the $\mathrm{T}_{\mathrm{g}}$ and $\mathrm{T}_{\mathrm{m}}$. The crystalline component of PE has a higher modulus than the amorphous component; therefore increasing crystallinity increases modulus of elasticity (MOE) of PE (11). The results can be extrapolated to show that $100 \%$ crystalline PE would have an MOE of approximately $5 \mathrm{GN} / \mathrm{m}^{2}$ (11). Increasing the crystallinity of PE also increases the strength (12).

\subsubsection{Ultraviolet Degradation}

The energies of photons in the ultraviolet region $(290-400 \mathrm{~nm})$ are significantly higher than bond energies typically found in polyolefins (e.g., C-C and C-H bonds) (13). However, the excitation of single bonds requires an amount of energy that is also significantly higher than the corresponding bond energy. Often, energy is locally 
absorbed and distributed to nearby domains. This lowers the probability of chain scission. Therefore photodegradation of polyolefins is caused mainly by the presence of chromophores, functional groups that readily absorb UV light, that are introduced during polymer manufacturing, processing, or storage. They can include catalyst residues, hydroperoxide groups, carbonyl groups, and double bonds (13). The result is free radicals that initiate the photooxidation process as shown in Scheme $2(\mathrm{Ga})$. During the initiation stage, free radicals are formed. The free radicals attack the polymer or react with oxygen to form new free radicals during the propagation stages. Finally, termination occurs when two free radicals combine with one another.

$$
\begin{array}{ll}
\text { Initiation: } & \text { Chromophores } \rightarrow \text { Free Radicals }\left(\mathrm{P}^{\bullet}, \mathrm{PO}^{\bullet}, \mathrm{HO}^{\bullet}, \mathrm{HO}_{2} \ldots\right) \\
\text { Propagation: } & \mathrm{P}^{\bullet}+\mathrm{O}_{2} \rightarrow \mathrm{PO}_{2}^{\bullet} \\
& \mathrm{PO}_{2}^{\bullet}+\mathrm{PH} \rightarrow \mathrm{POOH}+\mathrm{P}^{\bullet} \\
& \\
\text { Termination: } & \mathrm{PO}_{2}^{\bullet}+\mathrm{PO}_{2}^{\cdot} \rightarrow \mathrm{POOP}+\mathrm{PO}_{2}, \text { other nonradical products } \\
& \mathrm{P}^{\bullet}+\mathrm{PO}_{2}^{\bullet} \rightarrow \text { POOP } \\
& \mathrm{P}^{\bullet}+\mathrm{P}^{\bullet} \rightarrow \mathrm{PP}
\end{array}
$$

Scheme 2. Sequence of oxidation reactions in polymers. P represents the polymer chain

The degradation of PE exposed to UV light (photodegradation) has been extensively studied (13-34). It has been postulated that carbonyl groups are the main light absorbing species responsible for photochemical initiation reactions of UV-exposed PE 
(14). Degradation reactions proceed from carbonyl group precursors according to Norrish type I and II reactions (14-16). If degradation of carbonyl groups proceeds according to Norrish I (Fig. 2.8a), the resulting free radicals formed can attack the polymer via scheme 2. Free radical attack may lead to termination via cross-linking or chain scission (15). If degradation proceeds according to Norrish II (Fig. 2.8b), carbonyl groups and terminal vinyl groups are produced and chain scission occurs. In addition, the carbonyl group formed is capable of further degradation. During the course of PE photodegradation two mechanisms, chain scission and cross-linking, are competing (14-18). However, chain scission is more predominant in natural weathering than accelerated weathering $(14,17)$.

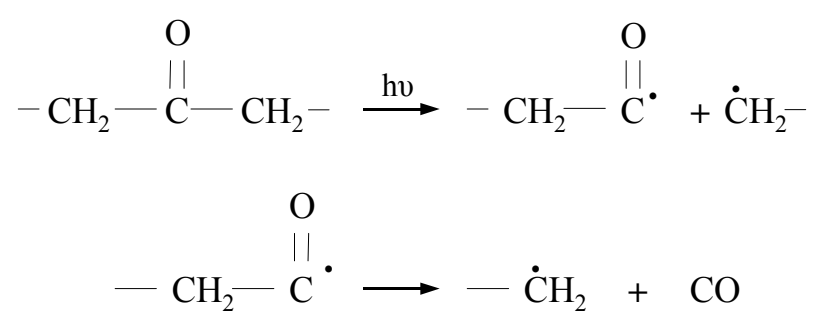

(2.8a) Norrish I

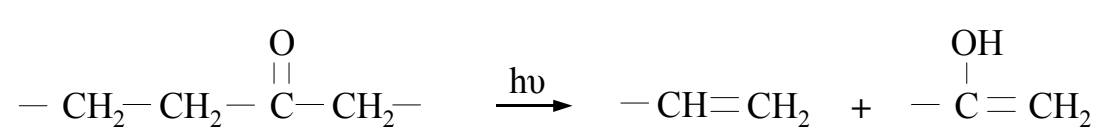

$$
\begin{aligned}
& \stackrel{\mathrm{OH}}{\mathrm{I}} \underset{\mathrm{C}=\mathrm{CH}_{2}}{\longrightarrow} \stackrel{\mathrm{O}}{\mathrm{II}}-\mathrm{CH}_{3}
\end{aligned}
$$

(2.8b) Norrish II

Figure 2.8. Norrish degradation mechanisms from carbonyl precursors: (a) Norrish I, and (b) Norrish II. 
As a semi-crystalline polymer, the packing of crystalline phase in PE is much tighter than that of the amorphous phase and is impermeable to oxygen (13). Therefore, the degradation reactions occur predominantly in the amorphous region and are controlled by the diffusion of oxygen in this region (15). While chain scission occurs in the amorphous phase of the polymer, imperfect crystalline regions degrade due to crosslinking (19). Tie molecules, chains traversing the amorphous phase from one crystalline lamella to another, can also be affected during photodegradation $(18,20)$. Formation of carbonyl groups and vinyl groups can be studied as a direct indication of main chain scission (21-23). An increase in PE crystallinity after weathering also indicates that chain scission has occurred. The shorter chains produced during chain scission are more mobile and are able to crystallize more readily, resulting in an increased crystallization and associated embrittlement $(14,15)$.

The effects of UV radiation, moisture, and extreme temperatures are detrimental to the mechanical properties of PE. Photodegradation manifests itself by destroying strength properties and embrittling the material. Monitoring mechanical properties is one method to determine if photodegradation has occurred. The embrittlement of PE is routinely studied as a decrease in tensile elongation at break $(14,21,22,24,25)$, or decrease in strength and modulus of elasticity. Sometimes the energy required to reach $50 \%$ of elongation at break or impact strength is reported $(26,27)$.

The photodegradation of PE is a surface phenomena $(28,29)$. Photodegradation can lead to undesirable surface characteristics such as the formation of surface cracks. Surface cracks are a result of a development of surface stresses during the aging process (28). The degradation profile throughout the thickness of the sample has been studied by 
obtaining a microtomed slice of a weathered sample and testing properties, such as penetration depth (28) and carbonyl formation (29). It was found that surfaces of weathered sample were higher in hardness and had more carbonyl groups than the interior of the samples.

\subsubsection{Protection}

Compounds have been developed to inhibit or delay degradative changes in polymers upon ultraviolet (UV) exposure. These photostabilizers are generally classed according to the degradation mechanism they hinder. Three main types of photostabilizers are UV absorbers, quenchers, and free radical scavengers. In addition, pigments, while not technically photostabilizers, are often used as photo-blockers to inhibit photodegradation of polymers.

The first option for protection is to absorb UV light before the polymer is affected. Ultraviolet absorbers (UVAs), preferentially absorb UV light. The most studied UVAs are hydroxybenzophenones and hydroxyphenylbenzotriazoles. These compounds are self-regenerating, returning to their original form after use, thereby avoiding photosensitization $(13,15,27)$. Figure 2.9 shows the absorption mechanism of a typical hydroxyphenylbenzotriazole.

Upon absorption of energy, a rapid internal hydrogen transfer occurs. The energy dissipates as heat and the UVA returns to its ground state (5). A fundamental flaw is that they need a certain sample thickness for good protection $(13,27)$. Normal usage levels are $0.10 \%-1.0 \%$ based on the weight of the matrix (35). In theory, UVAs would not be consumed during exposure of the polymer. 


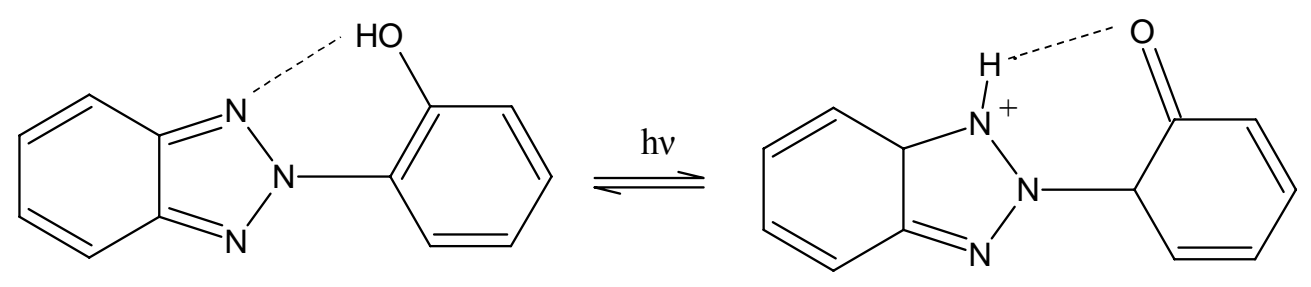

Figure 2.9. UVA mechanism of photostabilization.

A second possibility is to deactivate the excited states of the polymer. This is done with quenchers. Quenchers take over energy absorbed by chromophores and dissipate it as heat or as fluorescent or phosphorescent radiation $(13,15)$. Fortunately, hydroxybenzophenones and hydroxyphenylbenzotriazoles also act as quenchers.

The scavenging of free radical intermediates produced during degradation is a third option for photostabilization. Free radical scavengers such as hindered amine light stabilizers (HALSs) have been extensively studied in the past several years $(16,24,26,30,31)$. The protection HALSs offer comes from two mechanisms. HALSs are able to form stable radicals in the presence of oxygen to form a nitroxyl radical (Fig. 2.10a) (15). This decreases the amount of oxygen available to degrade the polymer chain. In addition, the nitroxyl radical is very stable and will not remove hydrogen from polymer molecules, yet it will react with another polymer radical in a termination reaction which de-activates free-radicals and breaks the chain reaction process (Fig. 2.10b) (15). Typical concentrations are $0.05 \%-0.6 \%$ for thick PE sections and $0.1 \%-1 \%$ for thin polymeric tapes based on the weight of the polymer (35). 

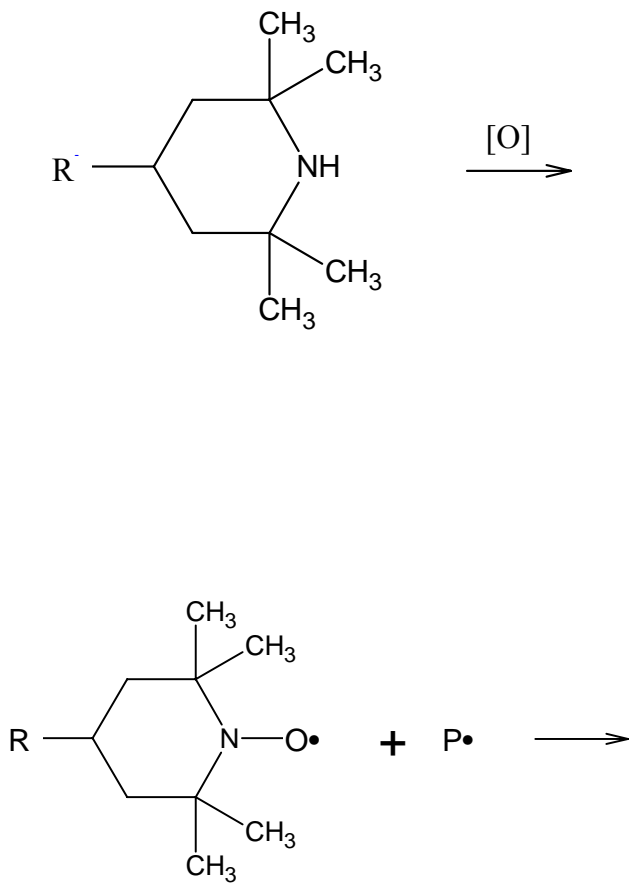

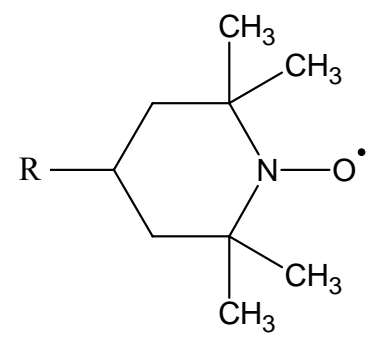

(2.10a)

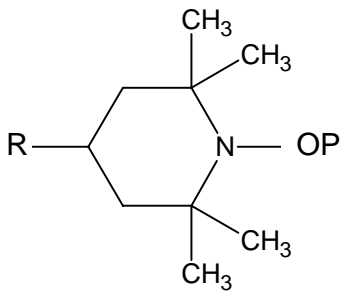

Figure 2.10. Protection mechanisms of HALS: (a) formation of nitroxyl radical in the presence of oxygen and (b) deactivation of polymer free radical by nitroxyl radical.

Unlike UVAs, a decrease in HALSs is observed over time as the photostabilizer is consumed. The relative concentration after exposure time is independent of the initial HALS concentration, and can be expressed by Equation 2.1 (31):

$$
(\mathrm{HALS})=(\mathrm{HALS})_{0} \exp (-\mathrm{at})
$$

where $\mathrm{a}$ is a rate constant and is independent of initial concentration (HALS) ${ }_{0}$ and $\mathrm{t}$ is time. In an experiment conducted in Florida, the concentration of HALS in an injection 
molded sample was followed using gas chromatography. The parameter $\ln \left((\right.$ HALS $\left.) /(\text { HALS })_{0}\right)$ decreased linearly as a function of time for all initial HALS concentrations. It could be extrapolated that a concentration of 0.1 (HALS) $)_{0}$ would be reached after approximately 6 years $(31)$.

While both UVAs and HALSs are routinely used in the photostabilization of PE, HALSs are more efficient. In one study, PE plaques were stabilized with a hydroxybenzophenone UVA and a polymeric HALS. The control PE sample lost $50 \%$ of its tensile strength after 0.68 year of equivalent exposure in the Florida sun. Stabilization with UVA and HALS increased this to 1.89 and 5.00 years, respectively (30). When titanium dioxide was added to each of the blends the time it took for the sample to lose $50 \%$ of their tensile strength was an equivalent of 2.36 and 11.43 years for a UVA/titanium dioxide and HALS/titanium dioxide blends, respectively (30).

Pigments are not technically photostabilizers. Pigments work to shield light, and prevent UV exposure of the polymer. Their protective action depends on concentration and particle size. Generally speaking, if the particle size is $1 \mu \mathrm{m}$ or less, larger particle sizes are more effective at reducing the amount of UV light the polymer is exposed to (15). Common pigments included titanium dioxide, iron oxide, and carbon black. Concentrations are typically $1 \%-10 \%$, depending upon the intensity of color desired. The degradation of photostabilized HDPE after accelerated weathering was similar for HDPE containing pigments and HDPE containing a higher amount of HALS (25). 


\subsection{Wood-Plastic Composites}

\subsubsection{Manufacturing}

Manufacturing of wood-plastic composites (WPCs) is generally a two-step process: compounding or blending raw materials and forming composite blends into a product (36). Thermal energy is required to melt the polymer and allow it to flow. When wood fiber is added to plastic, mechanical energy also needs to be put into the system to insure that the wood is evenly distributed and dispersed in the molten polymer, resulting in a homogeneous composite. Processing in this way is called melt-blending.

A popular and efficient method of melt-blending wood-plastic composites involves the use of twin screw extruders. During this type of continuous processing material is conveyed down a heated barrel along two rotating screws inside the barrel. The screws may be co-rotating or counter-rotating. Kinetic energy generated by the rotating screws as well as the heated barrel aids in melting the plastic, while the action of the screws mixes in the wood.

Compounding extruders are used solely to mix wood and plastic together. The material exiting the extruder, the extrudate, takes the form of spaghetti-like strands. These strands are cut into pellets to be used in other processing methods. More recently, in-line or direct extrusion has become popular for producing WPC profiles. Window sashes, door jambs, and decking can be manufactured by attaching a die at the end of the extruder and directly forming the cross-section desired.

Complex three-dimensional shapes can be formed using injection molding. Injection molding involves heating WPC pellets and forcing the molten composite into a 
mold, often with a plunger action. The mold is usually cool, and after the part cools the mold opens and ejects it.

Temperature, pressure, and flow are some parameters that can change based on processing method. Both processing methods and processing variables greatly influence the morphology and the physical properties of the composite.

Injection molded composite plaques result in a skin-core morphology. In short fiber polymeric composites, fibers in the core layer are oriented perpendicularly to flow while those in the skin layer are oriented parallel to flow $(37,38)$. Processing variables can affect the relative thickness of these layers. A low mold temperature can lead to a large skin thickness (37). Increasing barrel temperature, screw speed, and injection speed decrease skin thickness (37). Not only does the morphology of the injection molded composites change from the skin to core region, but the volume fraction of the fiber can change as well. It has been shown that fiber volume fraction for injection molded cellulose fiber filled polypropylene is slightly higher in the core layer than the surface layer (38). In addition, a polymer-rich surface layer is often present for injection molded composites (39).

Extruding short fiber reinforced polymeric composite can also lead to a skin-core morphology. Extruded polypropylene filaments filled with short glass fiber were studied. The circular profiles were analyzed for density and orientation differences. It was found that at the surface of the extrudate, the composites had a higher density and the fibers were more aligned in the flow direction than for the core of the extrudate (40). 


\subsubsection{Mechanical Behavior}

Mechanical performance of a composite is dependent upon several variables. The content and geometry of the wood flour, the properties of the polymer matrix, the quality of the composite and the fiber/polymer interface, and the processing method may all influence the mechanical properties of the composite.

Adding wood flour generally improved stiffness of the composite over that of the unfilled polymer. Increasing wood flour content from $20 \%$ to $50 \%$ increases flexural modulus $(41,42)$. However increasing wood flour content decreases tensile strength and elongation at break $(41,42)$. Therefore increasing wood flour content results in a WPC that is stiffer and more brittle.

Wood fillers can sometimes reinforce the polymer, improving the strength of the composites. At a critical fiber length, stress is transferred from the matrix to the fiber (2). Stress transfer is more efficient if adhesion between the fiber and the matrix is good. Wood flour is a particulate filler. If wood fiber, with a longer aspect ratio, is used as a filler in plastics, the strength properties of the composite are improved. When wood fiber (aspect ratio of 14) was added to polypropylene at $40 \%$ instead of wood flour (aspect ratio 2-4), the flexural strength increased $8 \%(43)$.

Hydrophilic wood flour is not compatible with hydrophobic polymers. To improve interfacial bonding between two components, a coupling agent can be used. Maleic anhydride grafted polymers are efficient coupling agents for WPCs $(36,43)$. Adding a coupling agent to $40 \%$ wood flour filled polypropylene resulted in an increase in flexural strength of $20 \%$. When a wood fiber was used with a coupling agent instead of 
wood flour, the increase in flexural strength was 51\% (43). Adding a coupling agent results in more efficient stress transfer from the fiber to matrix, which increases the strength of the composite. However a coupling agent has little effect on composite stiffness.

\subsubsection{Weathering}

Two variables are of concern when weathering wood-plastic composites: 1) UV exposure and 2) water exposure. Articles have been published that have examined weathering of WPCs (44-47) as well as the influence of moisture on WPCs $(39,48-52)$.

Different concentrations of wood flour were added to polyvinyl chloride (44). The samples underwent accelerated weathering and color fade, surface chemistry, and tensile properties were followed. It was found that after weathering, the surface of the sample became more hydrophilic regardless of the addition of wood flour. Using x-ray photoelectron spectroscopy to follow surface oxidation, it was found that surface oxidation increased with increasing wood flour content. Surface oxidation also increased with accelerated weathering. The composites retained all of their tensile properties after weathering (44).

The effect of color fade and flexural properties of wood flour (WF) filled polyethylene (PE) and polypropylene composites after accelerated weathering has been investigated (45). After $1500 \mathrm{~h}$ of weathering, the composite samples exhibited fading. The authors claim the composites faded more between 0 and $400 \mathrm{~h}$ of weathering than between 1000 and $1500 \mathrm{~h}$ of weathering. The results indicated that polypropylene based 
composites fade more than PE based composites. The composite samples also lost bending strength and stiffness after $1500 \mathrm{~h}$ of weathering.

Other lignocellulosic material, such as coir, jute, and sisal, as well as wood flour, have been added to PE at 50\% and weathered (46). The samples were tested for color fade after weathering. While all composites faded after weathering, the sisal and wood flour filled composites faded least, followed by the jute and the coir, respectively (46). Coir, jute, and sisal filled PE composites were also weathered and tested for mechanical property loss. The mechanical property loss of the sisal composites was highest, followed by coir and jute, respectively (46). For example, sisal, coir, and jute composites lost 54\%, $44 \%$, and $33 \%$ of their initial flexural MOE after $1500 \mathrm{~h}$ of weathering (46).

Moisture exposure is a component of the accelerated weathering process. The mechanical properties of wood flour filled polymer composites are negatively affected by moisture $(39,48-52)$. When the composite is exposed to moisture, the hydrophilic fiber swells. Cracks may form in the polymer matrix, which can also contribute to the penetration of water into the composite (48). Exposing wood filled polymer composites to moisture results in a drop in flexural MOE and strength by degrading the woodpolymer interfacial quality (48-50). The amount of moisture absorbed can be influenced by wood flour content and wood particle size $(48,51)$.

The method of manufacturing wood-plastic composites also affects moisture absorption. Clemons and coworkers looked at 50\% wood flour filled HDPE composites manufactured via extrusion, compression molding, and injection molding. It was reported that extruded composites absorbed the most moisture while injection molded composites absorbed the least (39). It was presumed that this was due to a polymer rich surface layer 
and lower void content attributable to the higher density of injection molded composites (39).

\subsubsection{Protection}

The protection of WPCs has revolved around adding a pigment to the composite or adding a hindered amine light stabilizer.

Wood flour filled poly vinyl chloride composites have been analyzed after weathering (47). The composites were either unpigmented, or pigmented with titanium dioxide. The samples were assessed using contact angle measurement, infrared analysis and color measurement. It was found that after weathering, color change of the unpigmented composite was 16.57 while that of the pigmented composite was only 4.34 (47). Additionally, adding pigment afforded some protection to the samples by slowing the formation of polyene linkages (47).

The effect of red and black colorants on color fade and flexural properties of wood flour (WF) filled polyethylene (PE) and polypropylene composites after accelerated weathering has been investigated (45). The researchers determined that colorants can be used effectively to lessen color fade of WF/PE composites after accelerated weathering. The results showed that after $1500 \mathrm{~h}$ of accelerated weathering, unpigmented $50 \%$ WF/PE composites lightened 32\%. With red pigment added the composites lightened $13.1 \%$ and with black pigment added the composites did not lighten. Similarly, pigments affected flexural properties. The flexural property loss of 50\% WF/PE composites was not as great when black pigment was added to the composite compared to unpigmented composite. While this study clearly showed that pigments are effective for preventing 
color fade and mechanical property loss of WF/PE composites, the effect of pigment concentration is not known.

In another study, a hindered amine light stabilizer (HALS) was added to $50 \% \mathrm{WF}$ filled PE composites at $0.25 \%$ and $0.5 \%$ by weight (46). The composites were then weathered for $1500 \mathrm{~h}$ and monitored for color fade and mechanical property change. The addition of HALS to the composite did not affect color change caused by accelerated weathering. The modulus of the composites decreased between $26 \%$ and $30 \%$ regardless of the addition of HALS. The loss in flexural strength of the composite was reduced 3\% when $0.5 \%$ HALS was added to the composite, but the significance of this is not known.

\subsection{Testing}

\subsubsection{Weathering}

Weathering can include a combination of exposure to UV radiation, rain, and temperature differences. Variables such as seasonal and latitudinal variations, sun elevation, pollutant composition, cloudiness, and scattering of particles can cause the composition of solar radiation reaching earth to vary (5). As the wavelength of a photon decreases, its energy increases. Therefore, shorter wavelengths of UV radiation are the most destructive. However, not all wavelengths of UV radiation reach earth. Seasonal variations dictate the shortest wavelength to reach earth, the solar cut-off wavelength. This is generally $295 \mathrm{~nm}$ in summer and $310 \mathrm{~nm}$ in winter (5). It is important during weathering to avoid exposure to light with wavelengths below the solar cut-off wavelength to avoid degradation mechanisms that may not occur naturally. 


\section{Accelerated Weathering}

Typical accelerated weathering equipment involves a combination of UV exposure and water spray. Commercially available UV chambers can be used to expose samples to UV light. Four common light sources for UV radiation include carbon arc lamps, xenon arc lamps, fluorescent UV lamps and mercury lamps. Xenon arc lamps, and fluorescent UV lamps are the most popular today. The oldest source of artificial radiation is carbon arc lamps. They have strong radiation below $300 \mathrm{~nm}$, therefore, do not simulate natural light well and can cause unrealistic degradation of materials (5). Mercury lamps have main emissions at 254, 290, and $365 \mathrm{~nm}$, which excludes it from sources that simulate natural conditions. Fluorescent lamps used by industry are often UV-A lamps or UV-B lamps. The radiation of UV-B lamps is not comparable with natural conditions, but UV-A lamps simulate natural radiation well in a certain range. However, some wavelengths that are known to degrade materials are missing in the UV-A spectrum (5). Xenon-arc lamps most closely resemble natural UV radiation when properly filtered. They do not contain radiation below the daylight cut-off and the intensity is similar to that of daylight radiation (5).

The test standard commonly used to weather plastics using a xenon-arc lamp is ASTM D2565, Standard Practice for Xenon-Arc Exposure of Plastics Intended for Outdoor Applications (53). This test requires the use of a filtered xenon-arc lamp, which is generally mounted in the middle of a weathering chamber with the samples attached to a drum that rotates around it. The revolution of the drum is $1 \mathrm{rpm}$. The most common weathering cycle consists of 102 minutes of light only followed by 18 minutes of light and water spray. The irradiance should be $41.5 \mathrm{~W} / \mathrm{m}^{2}$ between 300 and $400 \mathrm{~nm}(53)$. The 
voltage to the bulb controls the irradiance. If irradiance is not measured the voltage should be adjusted according to the bulb manufacturer's recommendations to compensate for decay of the bulb. The humidity is maintained at $50 \%$ during the light only interval and the black panel temperature is $63^{\circ} \mathrm{C}(53)$.

\section{Accelerated versus Natural Weathering}

While xenon-arc lamps are spectrally similar to that of natural light, they emit a substantial amount of energy. Therefore, the temperature of the exposed specimens tends to be high relative to the temperature of similar specimens observed outdoors (54). It is thought that the cause of the lack of repeatability and reproducibility of xenon arc UVchambers is the lack of temperature control (54). Because natural weathering is time consuming and involves several external factors such as sunlight, temperature, humidity, and atmospheric pollutants, it would be beneficial to accurately predict the service-life of weathered PE using short-term accelerated weathering tests. However, at this point, natural weathering is still needed to obtain a reliable prediction of service life $(11,54)$.

Nevertheless, there have been several attempts to correlate natural weathering with accelerated weathering. By following carbonyl group formation in weathered PE, it has been shown that 1 hour of accelerated weathering is almost equivalent to $10.73 \mathrm{~h}$ of natural weathering (7). While accelerated weathering is an appropriate method for comparing the performance of different materials, some mechanistic differences in the degradation reaction of PE have been noted between accelerated and naturally weathered samples (5).

Sebaa, et al., examined the rate of oxidation of PE during natural and artificial weathering (8). They found that the rate of oxidation was similar in natural weathering 
and accelerated weathering. They concluded that UV light is a more predominant factor than temperature in the PE degradation process (8).

Tidjani examined carbonyl group formation and vinyl group formation of PE during accelerated and natural weathering (11). He also found that regardless of weathering mode, comparable amounts of carbonyl groups were formed. However, vinyl groups were produced in higher amounts under accelerated conditions than under natural conditions. The explanation is that under accelerated weathering, cross-linking reactions occur which decreases the concentration of radicals taking part in the oxidation process. He concluded that there is still much to be understood about the links between natural and accelerated weathering. Further elaboration shows that chain scission reactions outweigh cross-linking reactions in natural weathering of PE (12). It is still thought that investigation of natural photoaging of polymers is a necessity to minimize errors of prediction of polymer life service (55).

\subsubsection{Optical Properties}

Color is perceived as three dimensions, hue, chroma, and lightness. Two common color systems for measuring the color of a material are the CIE $\mathrm{L}^{*} \mathrm{a}^{*} \mathrm{~b}^{*}$ color system and the CIE $\mathrm{L}^{*} \mathrm{C}^{*} \mathrm{H}^{\circ}$ system. In the $\mathrm{CIE} \mathrm{L}^{*} \mathrm{C}^{*} \mathrm{H}^{\circ}$ system $\mathrm{L}^{*}$ is the lightness factor, $\mathrm{C}^{*}$ is chroma and $\mathrm{H}^{\circ}$ is the hue angle. The $\mathrm{CIE} \mathrm{L}^{*} \mathrm{C}^{*} \mathrm{H}^{\circ}$ uses cylindrical coordinates to describe a color space. Converting to Cartesian coordinates results in the CIE L*a*b* color system (Fig. 2.11). 


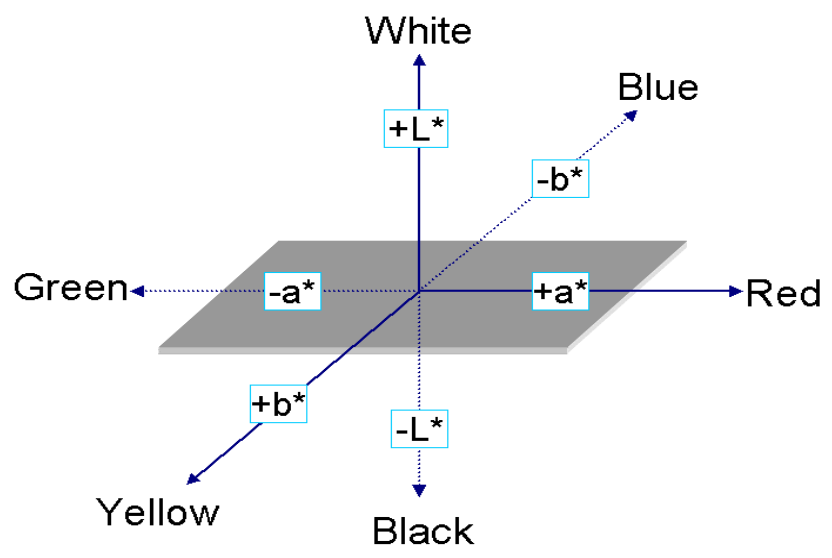

Figure 2.11. CIE L*a*b* color space.

In the CIE $\mathrm{L}^{*} \mathrm{a} \mathrm{b}^{*}$ color system, the value $L^{*}$ can be thought of as a lightness factor. $L^{*}$ can range from 0 to 100 , representing the amount of light reflected from the sample. An increase in $L^{*}$ means the sample is lightening (i.e., $+\Delta L$ for lightening and $-\Delta L$ for darkening); $+\Delta a$ signifies a color shift towards red, $-\Delta a$ towards green, $+\Delta b$ towards yellow, and $-\Delta b$ towards blue.

The calculation of color differences is often determined according to ASTM D2244, Standard Test Method for Calculation of Color Differences from Instrumentally Measured Color Coordinates (56). If color is determined using the CIE Lab color space, the difference in color between two samples is determined using Equation 2.2:

$$
\Delta E_{a b}=\left(\Delta L^{2}+\Delta a^{2}+\Delta b^{2}\right)^{1 / 2}
$$


where $\Delta L, \Delta a$, and $\Delta b$ represent the difference between initial and final values of $L^{*}, a^{*}$, and $b^{*}$, respectively.

\subsubsection{Flexural Testing}

A three-point bending test set-up to measure flexural properties consists of a sample on two stationary supports with load applied in the middle of the sample (Fig. 2.12). The strength of the material is a function of applied force and sample cross-section. The stiffness of the material is a function of the applied force, the resulting deflection, and the sample cross-section. If two materials have the same cross-section and are subjected to the same applied force, the one that deflects the least is considered to be the stiffest.

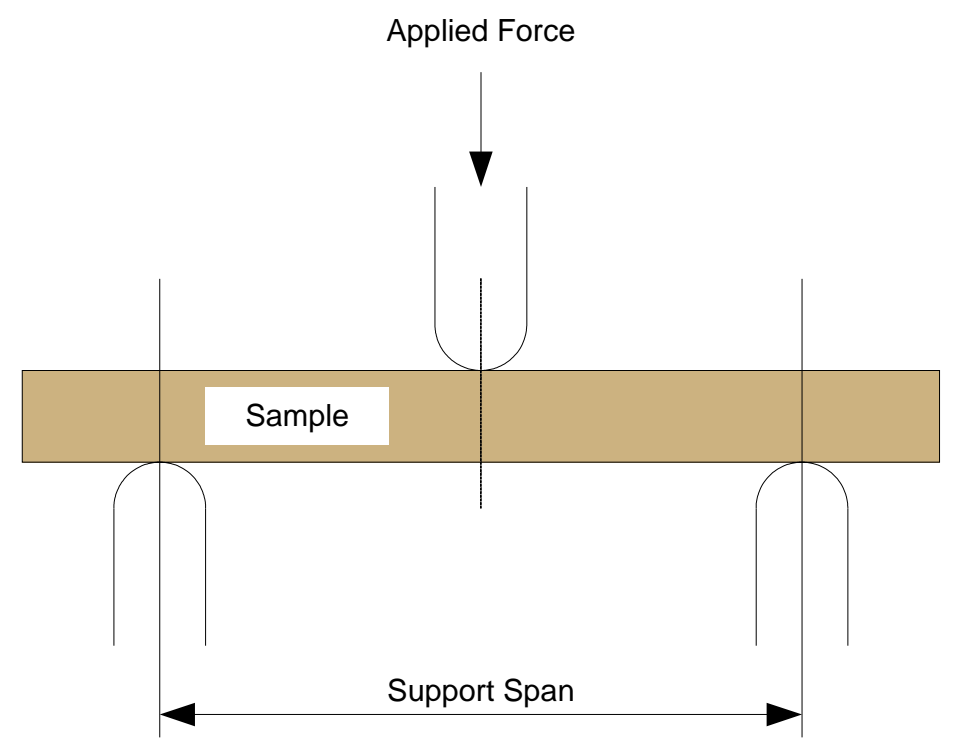

Figure 2.12. Three-point bending set-up. 
Flexural testing for strength and stiffness can be carried out according to ASTM D790 (57), Standard Test Method for Flexural Properties of Unreinforced and Reinforced Plastics and Electrical Insulating Materials. According to this standard, a load is applied and the deflection of the sample is measured. At any given time the stress of the sample is determined using Equation 2.3 while the strain at the outer edge is determined using Equation 2.4 (57).

$$
\begin{aligned}
& \text { Stress }=\frac{3 P L}{2 b d^{2}} \\
& \text { Strain }=\frac{6 D d}{L^{2}}
\end{aligned}
$$

where $\mathrm{P}=$ applied load, $\mathrm{L}=$ support span, $\mathrm{b}=$ sample width, $\mathrm{d}=$ sample depth, and $\mathrm{D}=$ displacement of cross-head.

The strength and modulus of elasticity (MOE) of the sample are reported. The strength is the maximum stress the sample sustains during testing. The MOE is found by plotting the stress-strain curve and obtaining the initial slope. Figure 2.13 shows typical stress-strain curves for HDPE and WF/HDPE composites. The initial slope is represented by a dotted line. It is apparent that WF/HDPE composites have a higher MOE than the HDPE. 


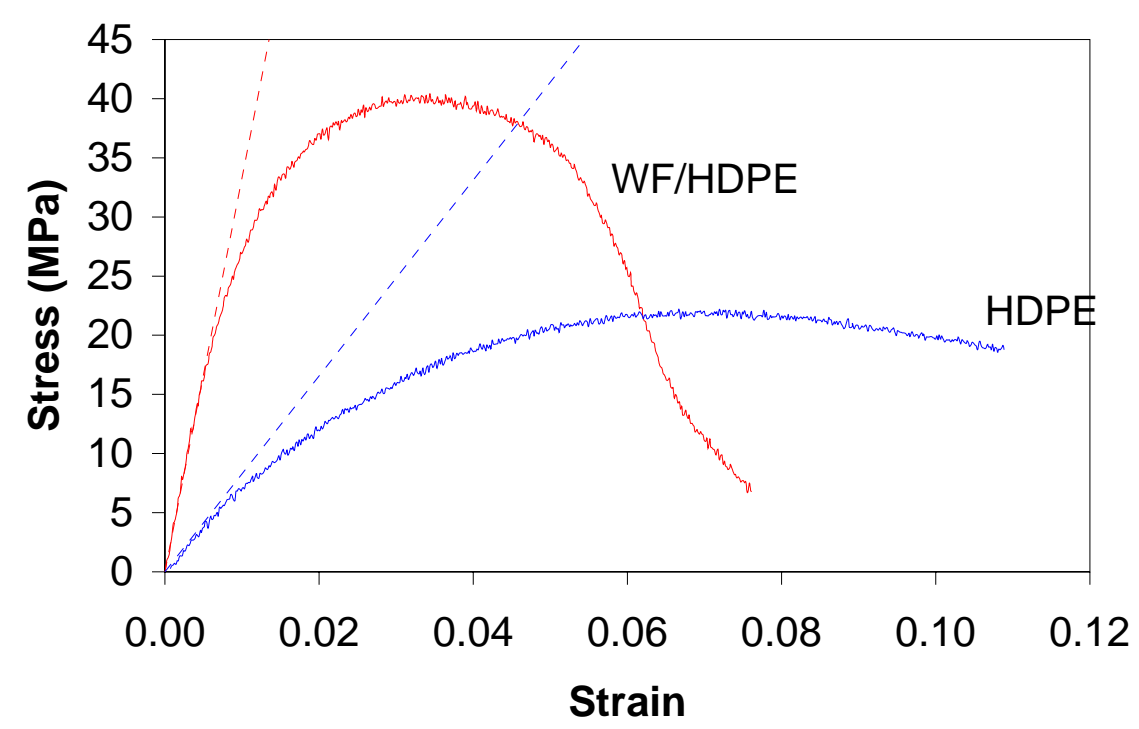

Figure 2.13. Representative stress-strain curves for an unfilled HDPE sample and a WF/HDPE composite.

\subsubsection{Surface Chemistry}

\section{$\underline{\text { X-Ray Photoelectron Spectroscopy }}$}

X-ray photoelectron spectroscopy (XPS) is a surface analysis technique that can give the elements and types of bonds present at the surface. XPS analysis involves the beaming of a photon to a sample. According to Einstein's Photoelectric effect, an electron is emitted from the surface. The binding energy $\left(\mathrm{E}_{\mathrm{b}}\right)$ of this electron is recorded and analyzed. Each element has a characteristic $E_{b}$. Therefore XPS can be used to ascertain surface elemental composition. It also provides information about the chemical surface with a spatial resolution of a few millimeters and a depth resolution of $5 \mathrm{~nm}$, depending on the take-off angle (58). 
In XPS, the incident beam is an x-ray, and electrons originating from external atoms are emitted. The maximum beam penetration depth is $74-100 \AA$ (59). The electrons have a characteristic kinetic energy, $\mathrm{E}_{\mathrm{k}}$, given by Equation 2.5 (59):

$$
E_{k}=E_{x}-\left(E_{b}+E_{C}^{\prime}+\varphi^{\prime}\right)
$$

where $E_{x}$ is the energy of the incident $x$-ray, $E_{b}$ is the binding energy of the electron, $E_{C}^{\prime}$ is the energy lost in counteracting the potential associated with the steady charging of the surface, and $\varphi^{\prime}$ is the work function of the spectrometer.

Different scan resolutions yield different information. A survey scan will give the elements present at the surface. A low-resolution scan gives the percent of each element present, the atomic concentrations are calculated through their peak intensities. A highresolution scan gives the types of bonds and concentrations present, each peak shifts depending on which atoms the analyzed atom is bound to. For example, in the case of carbon $\left(\mathrm{C}_{1 \mathrm{~s}}\right)$, the high-resolution spectra may consist of four components peaks around $285.0 \mathrm{eV}, 286.9 \mathrm{eV}, 288.7 \mathrm{eV}$, and $289.3 \mathrm{eV}$. These subpeaks correspond with $\mathrm{C} 1(\mathrm{C}-\mathrm{C}$ or $\mathrm{C}-\mathrm{H}), \mathrm{C} 2(\mathrm{C}-\mathrm{OH}$ or $\mathrm{C}-\mathrm{O}-\mathrm{C}), \mathrm{C} 3(\mathrm{O}-\mathrm{C}-\mathrm{O}$ or $\mathrm{C}=\mathrm{O})$, and $\mathrm{C} 4(\mathrm{O}-\mathrm{C}=\mathrm{O})$, respectively (58). A disadvantage of XPS is that it cannot detect $\mathrm{H}$. This may lead to problems in differentiating a carboxylic acid from an ester for example. Nevertheless, XPS is straightforward, easy to use, and non-destructive, which partly accounts for its extensive use in recent years. It has most frequently been employed to confirm polymer or fiber modification after treatment $(15,60-65)$. 
The surface layers of modified polyolefins can be analyzed using XPS. An investigation of the oxidation of surface layers of low-density PE treated with corona discharge was conducted using XPS. Three different take-off angles of $10^{\circ}, 30^{\circ}$, and $90^{\circ}$ were used which corresponded to penetration depths of $0.6,1.9$, and $3.7 \mathrm{~nm}$. XPS was used to determine the $\mathrm{O} / \mathrm{C}$ ratio at the three different layers in the sample after treatment. It was found that the $\mathrm{O} / \mathrm{C}$ ratio generally decreased with increasing depth (60). Exposure to UV light also modifies the polymer surface. XPS has been used in conjunction with elongation at break and gel content data to determine the effects of antioxidants, HALS, and pigments on the stability of $\mathrm{PE}$ by monitoring $\mathrm{O} / \mathrm{C}$ ratios. Using these methods it was also found that the $\mathrm{O} / \mathrm{C}$ ratio was higher at the surface of pigmented systems before any weathering took place (15).

Pulp analysis is important for the paper industry as the quality of fiber-to-fiber bonding depends largely on the chemical nature of the fiber surface. XPS can be used to monitor differences on lignocellulosic surfaces. The increase in sulfur content of chemithermomechanical (CTMP) and the polyacrylonitrile grafting levels has been followed using XPS $(61,62)$. The oxygen-to carbon ratio of steam exploded CTMP pulps has also been followed (63).

Fibers modified to improve fiber/polymer compatibilities are of interest. XPS has been used extensively to analyze surface characteristics of chemically treated lignocellulosics. By analyzing carbon and oxygen peaks formation, it has been shown that plasma fluorination of cellulose increases surface hydrophobicity (64). Angle resolved XPS was also used to determine whether aminosilane was being adsorbed to newsprint fibers by a terminated amine or by an ether linkage. This led to the conclusion 
that an ether linkage was one of the mechanisms by which aminosilane couples to newsprint fibers (65).

\section{Fourier Transform Infrared Spectroscopy}

Fourier Transform Infrared (FTIR) spectroscopy is a powerful method for determining functional groups at surfaces. IR spectroscopy is a measurement of the absorption of IR frequencies placed in the path of a beam of light. A proton beam in the form of a laser bombards the surface, and a photon is emitted after excitation. The radiation emitted is in the vibrational IR region, and is also referred to in terms of wavenumbers (v), which is the number of waves per centimeter (59). IR radiation is electromagnetic radiation with frequencies between 4000 and $400 \mathrm{~cm}^{-1}$.

Chemical bonds absorb light of varying intensities and varying frequencies. The frequencies at which absorption occurs can be directly correlated to chemical bonds. FTIR spectroscopy identifies the chemical groups by measuring the energy absorbed by the vibrations of the chemical groups (66).

There are several techniques that can be employed to obtain FTIR spectra. Attenuated total reflectance (ATR) is a method that does not alter the original surface of the sample. In ATR-FTIR, there is intimate contact between the sample surface to be analyzed and a crystal (Fig. 2.14). The beam enters the crystal at one end, travels through the crystal and excites the surface of the sample. The wavelengths of the photons emitted by the sample are recorded. Peaks occur at wavelengths that correspond with known functional groups. The penetration depth of the incident beam is dependent upon the index of refraction of the crystal and sample, and also the wavelength of the photon, 
however it is on the order of $0.5-3 \mu \mathrm{m}$. The exact penetration depth, $\mathrm{d}_{\mathrm{p}}$, can be calculated using Equation 2.6 as follows:

$$
d_{p}=\frac{\lambda}{2 \pi n_{1}\left(\sin ^{2} \theta-\left(n_{2} / n_{1}\right)^{2}\right)^{1 / 2}}
$$

where $\mathrm{n}_{1}=$ index of refraction of crystal, $\mathrm{n}_{2}=$ index of refraction of sample, $\lambda=$ wavenumber, and $\theta=$ angle of crystal.

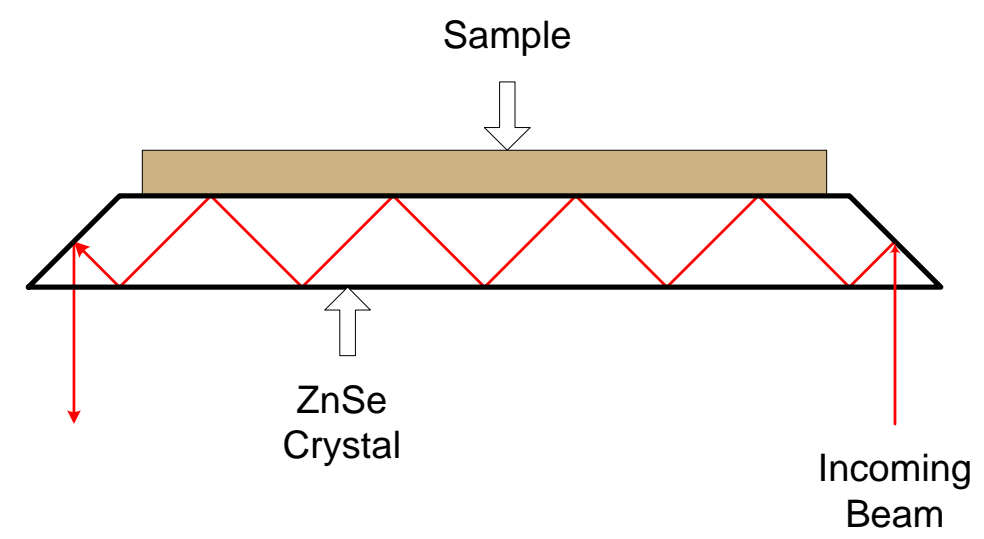

Figure 2.14. Schematic of attenuated total reflectance FTIR set-up.

FTIR spectroscopy has also been used in varied applications where surface chemistry analysis is desired. Recently, FTIR spectroscopy has been employed to study changes in surface chemistry of PE after weathering. Several papers have been published where FTIR spectroscopy was used to monitor carbonyl group formation $(4,6,7,9-13,19)$, vinyl group formation $(4,6,9,11)$, and changes in crystallinity (22-24) of weathered PE. 
The majority of FTIR work on degradation has been to monitor the generation of carbonyl groups, to verify surface oxygenation.

The role of tie molecules, which exist between the crystalline lamellae, in the photostabilization of PE has been investigated. Four different PE samples underwent photoirradiation with a medium pressure mercury (MPM) lamp. FTIR spectra were examined to monitor oxygenated products at the surface. The results were used in part to conclude that tie molecules play an important role in determining embrittlement time. Tie molecules present in high density PE (HDPE), which is more crystalline than linear low density PE (LLDPE), were reported to undergo more damage from a small amount of oxidation products formation than in LLDPE (10). Another study has also investigated the stability of several different types of PE using FTIR spectroscopy to monitor carbonyl group formation. Again it was found that polymer stability, evaluated by elongation at break, is superior in LLDPE than HDPE. It was concluded that segmental motion of the polymer chain affected polymer stability (67).

Classes of materials have been developed to protect polymers from photodegradation. FTIR spectroscopy is commonly used to analyze and compare the surface chemistry of unstabilized and stabilized polymers before and after weathering through the monitoring of carbonyl group generation $(14,68)$. While photostabilization of polymers is a concern, other additives may influence the degradation of the polymer. Flame retardants can reduce the photostability of polymer materials. FTIR was used to verify that formation of carbonyl groups by photoirradiation is accelerated by the addition of flame retardants in PE (10). 
In some cases photodegradable polymers are of interest. A study was undertaken to examine photodegradation, under natural weathering conditions, of PE films containing various commercial photoinitiator systems. This study employed FTIR spectroscopy to monitor the formation of carbonyl groups. The formation of carbonyl groups indicates main chain scission rather than cross-linking has occurred, which is desirable for photodegradable polymers. The group compared the results for samples exposed to both natural and accelerated weathering. They determined that cross-linking is much more important when irradiation is performed with the xenon lamp, and this can be easily explained by the difference in exposure temperature with is much higher for the xenon lamp (13).

Fiber surfaces can also be studied using FTIR techniques. To improve the interface of the fiber/polymer matrix, coupling agents are added. FTIR spectroscopy has been used to confirm an esterification reaction between wood fibers and maleated polypropylene. The FTIR studies showed that bleached Kraft cellulose and thermomechanical pulp reacted with maleic anhydride to form ester links (69).

The introduction of a fiber into a polymer matrix changes the crystallinity of the matrix. Following a different approach, FTIR can be used to determine the crystallinity changes of the matrix. HDPE samples with $10 \%, 20 \%, 30 \%$, and $40 \%$ aspen fibers were formed and exposed to environmental conditions for different time periods, and the FTIR spectra were obtained. The method used assumes that the spectral bands at 1474 and 730 $\mathrm{cm}^{-1}$ are associated with crystalline phase flexural vibrations, while the spectra bands at 1464 and $720 \mathrm{~cm}^{-1}$ are associated with the amorphous phase. The crystallinity was 
determined using empirical relations. The authors determined that the crystallinity decreases with increasing fiber content, and also with increasing exposure time (70).

\subsection{Hypotheses and Objectives}

Despite this initial work, there is not a fundamental understanding of the photostabilization of wood flour filled PE composites. The work that has been done examining surface oxidation of WPCs has been conducted on poly-vinyl chloride, the photodegradation mechanisms of PE can be quite different. While it has become apparent that the processing method of WPCs influences their moisture absorption, how this affects weathering is not known. Additionally, there are several classes of photostabilizers that are available for use to protect WPCs. While some work has been

done looking at pigments and HALS for WPCs, how these photostabilizers work for WPCs either in combination with one another or at different concentrations is not known.

\section{Based on the present state of knowledge, the following hypotheses are brought forward:}

i. Manufacturing WPC samples using different processing methods will influence weatherability.

ii. Adding wood flour to HDPE will change the mechanism of UV degradation.

iii. Photodegradation can be delayed by using several types of photostabilizers in combination with each other. 
The main goal of the proposed study is to characterize the changes in color fade, mechanical properties, and surface chemistry that occur in WF/HDPE composites as a result of accelerated weathering and to determine the effects of photostabilizers on weathering WF/HDPE composites. The specific objectives that must be achieved to fulfill this goal are:

i. Characterize the surface of $\mathrm{WF} / \mathrm{HDPE}$ composites produced using different manufacturing methods.

ii. Understand how manufacturing methods affect the weathering of WF/HDPE composites.

iii. Study how weathering changes the structure and surface chemistry of HDPE blends and WF/HDPE composites.

iv. Determine the effectiveness of various photostabilizers and their interactions on the weathering of WF/HDPE composites.

v. Determine the effect of stabilizer concentration on the color fade and mechanical property loss of WF/HDPE composites after weathering.

vi. Characterize the mechanical properties and surface chemistry change of stabilized HDPE blends and WF/HDPE composites after weathering. 


\subsection{References}

1. J. Baeza and J. Freer, "Chemical Characterization of Wood and Its Components," in Wood and Cellulosic Chemistry, Chapter 8, 275-384, D.N.-S. Hon and N. Shiraishi, Eds, Marcel Dekker, Inc., New York, 2001.

2. A.A. Marra, Technology of Wood Bonding, Van Nostrand Reinhold, New York, 1992.

3. D. Fengel and G. Wegener, Wood, Walter de Gruyter, New York, 1983.

4. M. Kazayawoko, "Surface Characterisation and Mechanisms of Adhesion in Wood Fibre-Polypropylene Composites," Ph.D. Thesis, Department of Forestry, University of Toronto, 1996.

5. E. Adler, "Lignin Chemistry-Past, Present, and Future," Wood Science and Technology, 11(3), 169-218, 1977.

6. Anonymous, Wood Handbook-Wood as an Engineering Material, United States Department of Agriculture, Forest Products Laboratory, FPL-GTR-113, 1999.

7. D.N. Saheb and J.P. Jog, "Natural Fiber Polymer Composites: A Review," Advances in Polymer Technology, 18(4), 351-363, 1999.

8. K.D. Sears, R. Jacobson, D.F. Caulfield and J. Underwood, "Reinforcement of Engineering Thermoplastics with High Purity Wood Cellulose Fibers," in Proceedings, $6^{\text {th }}$ International Woodfiber-Plastics Composites Conference, 27-34, Madison, Wisconsin, May 15-16, 2001.

9. D.N.-S. Hon, "Weathering and Photochemistry of Wood," in Wood and Cellulosic Chemistry, Chapter 11, 513-546, D.N.-S. Hon and N. Shiraishi, Eds, Marcel Dekker, Inc., New York, 2001.

10. D.N.-S. Hon and N. Minemura, "Color and Discoloration," in Wood and Cellulosic Chemistry, Chapter 9, 385-442, D.N.-S. Hon and N. Shiraishi, Eds, Marcel Dekker, Inc., New York, 2001.

11. R.J. Young and P.A. Lovell, Introduction to Polymers, Second Edition, Chapman \& Hall, London, 1991.

12. T.A. Osswald and G. Menges, Materials Science of Polymers for Engineers, Hanser Publishers, New York, 1995.

13. F. Gugumus, "Light Stabilizers," in Plastics Additives Handbook, Chapter 3, 129262, R. Gächter and H. Müller, Eds., Hanser Publishers, New York, 1990.

14. S.A. Jabarin and E.A. Lofgren, "Photooxidative Effects on Properties and Structure of High-Density Polyethylene," Journal of Applied Polymer Science, 53(4), 411423, 1994.

15. G. Wypych, Handbook of Material Weathering, ChemTec Publishing, TorontoScarborough, 1995.

16. M. Kaci, T. Sadoun and S. Cimmino, "HALS Stabilization of LDPE Films Used in Agricultural Applications," Macromolecular Materials and Engineering, 278(1), $36-42,2000$.

17. B.Y. Zhao, X.W. Yi, R.Y. Li, P.F. Zhu and K.A. Hu, "Characterization to the Weathering Extent of LLDPE/LDPE Thin Film," Journal of Applied Polymer Science, 88(1), 12-16, 2003. 
18. M. Sebaa, C. Servens and J. Pouyet, "Natural and Artificial Weathering of LowDensity Polyethylene (LDPE): Calorimetric Analysis," Journal of Applied Polymer Science, 47(11), 1897-1903, 1993.

19. S.H. Hamid and M.B. Amin, "Lifetime Prediction of Polymers," Journal of Applied Polymer Science, 55(10), 1385-1394, 1995.

20. A. Torikai, H. Shirakawa, S. Nagaya and K. Fueki, "Photodegradation of Polyethylene: Factors Affecting Photostability," Journal of Applied Polymer Science, 40(9-10), 1637-1646, 1990.

21. A. Tidjani, "Comparison of Formation of Oxidation Products During PhotoOxidation of Linear Low Density Polyethylene Under Different Natural and Accelerated Weathering Conditions," Polymer Degradation and Stability, 68(3), 465-469, 2000.

22. A. Tidjani, R. Arnaud and A. Dasilva, "Natural and Accelerated Photoaging of Linear Low-Density Polyethylene: Changes in Elongation at Break," Journal of Applied Polymer Science, 47(2), 211-216, 1993.

23. C. David, M. Trojan and A. Daro, "Photodegradation of Polyethylene: Comparison of Various Photo initiators in Natural Weathering Conditions," Polymer Degradation and Stability, 37(3), 233-245, 1992.

24. P. Gijsman and A. Dozeman, "Comparison of the UV-Degradation Chemistry of Unstabilized and HALS-Stabilized Polyethylene and Polypropylene," Polymer Degradation and Stability, 53(1), 45-50, 1996.

25. M.A. Maatoug, P. Anna, G. Bertalan, I. Ravadits, G. Marosi, I. Csontos, A. Márton and A. Tóth, "Role of Pigments in the Stability of Polyethylene Systems," Macromolecular Materials and Engineering, 282(9), 30-36, 2000.

26. F. Gugumus, "Aspects of the Impact of Stabilizer Mass on Performance in Polymers 3. Performance of HALS in Polyethylene," Polymer Degradation and Stability, 69(1), 93-104, 2000.

27. F. Gugumus, "Possibilities and Limits of Synergism with Light Stabilizers in Polyolefins 2. UV absorbers in Polyolefins," Polymer Degradation and Stability, 75(2), 309-320, 2002.

28. A.C. Tavares, J.V. Gulmine, C.M. Lepienski and L. Akcelrud, "The Effect of Accelerated Aging on the Surface Mechanical Properties of Polyethylene," Polymer Degradation and Stability, 81(2), 367-373, 2003.

29. J.V. Gulmine, P.R. Janissek, H.M. Heise and L. Akcelrud, "Degradation Profile of Polyethylene After Artificial Accelerated Weathering," Polymer Degradation and Stability, 79(1), 385-397, 2003.

30. F. Gugumus, "The Performance of Light Stabilizers in Accelerated and Natural Weathering," Polymer Degradation and Stability, 50(1), 101-116, 1995.

31. F. Gugumus, "Current Trends in the Mode of Action Hindered Amine Light Stabilizers," Polymer Degradation and Stability, 40(2), 167-215, 1993.

32. M. Kaci, T. Sadoun, and S. Cimmino, "Crystallinity Measurements of Unstabilized and HALS-Stabilized LDPE Films Exposed to Natural Weathering by FT-IR, DSC, and WAXS Analyses," International Journal of Polymer Analytical Characterization, 6(5), 455-464, 2001. 
33. G. Zerbi, G. Gallino, N. Del Fanti and L. Baini, "Structural Depth Profiling in Polyethylene Films by Multiple Internal Reflection Infra-red Spectroscopy," Polymer, 30(12), 2324-2327, 1989.

34. W. Camacho and S. Karlsson, "Simultaneous Determination of Molecular Weight and Crystallinity of Recycled HDPE by Infrared Spectroscopy and Multivariate Calibration," Journal of Applied Polymer Science, 85(2), 321-327, 2002.

35. Ciba Specialty Chemicals, Platics Additives Division Website, http://www.cibasc.com/view.asp?id=890

36. B. English, C.M. Clemons, N. Stark and J.P. Schneider, "Waste-Wood-Derived Fillers for Plastics," Forest Service General Technical Report, FPL-GTR-91, 1996.

37. S.-Y. Fu, X. Hu and C.-Y. Yue, "Effects of Fiber Length and Orientation Distributions on the Mechanical Properties of Short-Fiber-Reinforced Polymers," Materials Science Research International, 5(2), 74-83, 1999.

38. C.M. Clemons, D.F. Caulfield and A.J. Giacomin, "Dynamic Fracture Toughness of Cellulose-Fiber-Reinforced Polypropylene: Preliminary Investigation of Microstructural Effects," Journal of Elastomers and Plastics, 31(4), 367-378, 1999.

39. C.M. Clemons and R.E. Ibach, "The Effects of Processing Method and Moisture History on the Laboratory Fungal Resistance of Wood-HDPE Composites," submitted to Forest Products Journal, December 2002.

40. S.E. Barbosa and J.M. Kenny, "Processing of Short-Fiber Reinforced Polypropylene," Polymer Engineering and Science, 40(1), 11-22, 2000.

41. M.J. Zaini, M.Y.A. Fuad, Z. Ismail, M.S. Mansor and J. Mustafah, "The Effect of Filler Content and Size on the Mechanical Properties of Polypropylene/Oil Palm Wood Flour Composites," Polymer International, 40(1), 51-55, 1996.

42. M.J. Berger and N.M. Stark, "Investigations of Species Effects in an InjectionMolding-Grade, Wood-Filled Polypropylene," in Proceedings, $4^{\text {th }}$ International Woodfiber-Plastic Composites, 19-25, Madison, WI, May 12-14, 1997.

43. N.M. Stark, "Wood Fiber Derived From Scrap Pallets Used in Polypropylene Composites," Forest Products Journal, 49(6), 39-46, 1999.

44. L.M. Matuana and D.P. Kamdem, "Accelerated Ultraviolet Weathering of PVC/Wood-Flour Composites," Polymer Engineering and Science, 42(8), 16571666, 2002.

45. R.H. Falk, T. Lundin and C. Felton, "The Effects of Weathering on WoodThermoplastic Composites Intended for Outdoor Applications," in Proceedings, Durability and Disaster Mitigation in Wood-Frame Housing, Madison, WI, Nov. 6$8,2000$.

46. T. Lundin, "Effect of Accelerated Weathering on the Physical and Mechanical Properties of Natural-Fiber Thermoplastic Composites," M.S. Thesis, University of Wisconsin-Madison, 2001.

47. L.M. Matuana, D.P. Kamdem and J. Zhang, "Photoaging and Stabilization of Rigid PVC/Wood-Fiber Composites," Journal of Applied Polymer Science, 80(11), 19431950, 2001.

48. K. Joseph, S. Thomas and C. Pavithran, "Effect of Ageing on the Physical and Mechanical Properties of Sisal-Fiber-Reinforced Polyethylene Composites," Composites Science and Technology, 53(1), 99-110, 1995. 
49. N. Stark, "Influence of Moisture Absorption on Mechanical Properties of Wood Flour-Polypropylene Composites," Journal of Thermoplastic Composites, 14(5), 421-432, 2001.

50. S.V. Rangaraj and L.V. Smith, "Effects of Moisture on the Durability of a Wood/Thermoplastic Composite," Journal of Thermoplastic Composite Materials, 13(3), 140-161, 2000.

51. Q. Lin, X. Zhou and G. Dai, "Effect of Hydrothermal Environment on Moisture Absorption and Mechanical Properties of Wood Flour-Filled Polypropylene Composites," Journal of Applied Polymer Science, 85(14), 2824-2832, 2002.

52. J.J. Balatinecz and B.-D. Park, "The Effects of Temperature and Moisture Exposure on the Properties of Wood-Fiber Thermoplastic Composites", Journal of Thermoplastic Composite Materials, 10(9), 476-487, 1997.

53. American Society for Testing and Materials, "D2565 Standard Practice for XenonArc Exposure of Plastics Intended for Outdoor Applications," in Annual Book of ASTM Standards, 8.02, 2000.

54. J.W. Martin, J.W. Chin, W.E. Byrd, E. Embree and K.M. Kraft, "An Integrating Sphere-Based Ultraviolet Exposure Chamber Design for the Photodegradation of Polymeric Materials," Polymer Degradation and Stability, 63(2) 297-304, 1999.

55. A. Tidjani, "Photooxidation of Polypropylene Under Natural and Accelerated Weathering Conditions," Journal of Applied Polymer Science, 64(13), 2497-2503, 1997.

56. American Society for Testing and Materials, "D2244 Standard Test Method for Calculation of Color Differences From Instrumentally Measured Color Coordinates," in Annual Book of ASTM Standards, 6.01, 2000.

57. American Society for Testing and Materials, "D790 Standard Test Method for Flexural Properties of Unreinforced and Reinforced Plastics and Electrical Insulating Materials," in Annual Book of ASTM Standards, 8.01, 2000.

58. D.P. Kamdem, B. Riedl, A. Adnot and S. Kaliaguine, "ESCA Spectroscopy of Poly (Methyl Methacrylate) Grafted onto Wood Fibers," Journal of Applied Polymer Science, 43(10), 1901-1912, 1991.

59. L.M. Matuana, "Wood Fiber/Polyvinyl Chloride Composites and Their Microcellular Foams," Ph.D. Thesis, University of Toronto, 1997.

60. M. Zenkiewicz, "Investigation on the Oxidation of Surface Layers of Polyolefins Treated with Corona Discharge," Journal of Adhesion Science Technology, 15(1), 63-70, 2001.

61. A.O. Barry and Z. Koran, "Surface Analysis by ESCA of Sulfite Post-Treated CTMP," Journal of Applied Polymer Science, 39(1), 31-42. 1990.

62. A.O. Barry, B. Riedl, A. Adnot and S.C. Kaliaguine, "X-Ray Photoelectron Spectroscopy of Chemithermomechanical Pulp Grafted with Polyacrylonitrile," Journal of Electron Spectroscopy and Related Phenomena, 57(1), 47-59, 1991.

63. X. Hua, S. Kaliaguine, B.V.Kokta and A. Adnot, "Surface Analysis of Explosion Pulps by ESCA, Part 1, Carbon (1s) Spectra and Oxygen-to-Carbon Ratios," Wood Science and Technology, 27(6), 449-459, 1993.

64. S. Sapieha, M. Verreault, J.E. Klemberg-Sapieha, E. Sacher and M.R. Wertheimer, "X-Ray Photoelectron Study of the Plasma Fluorination of Lignocellulose," Applied Surface Science, 44(2), 165-169, 1990 
65. L.M. Matuana, J.J. Balatinecz, C.B. Park and R.N.S. Sodhi, "X-Ray Photoelectron Spectroscopy Study of Silane-Treated Newsprint-Fibers," Wood Science and Technology, 33(4), 259-270, 1999.

66. Q. Li, "Extrusion Foaming of Polyolefin/Wood-Flour Composites," Ph.D. Thesis, Michigan Technological University, 2002.

67. A. Torikai, "Photo- and Radiation-Induced Degradation of Synthetic Polymers: Polymer Structure and Stability," Die Angewandte Makromolekulare Chemie, 216(March), 225-241, 1994.

68. P. Gijsman, J. Hennekens and D. Tummers, "The Mechanism of Action of Hindered Amine Light Stabilizers," Polymer Degradation and Stability, 39(2), 225233, 1993.

69. M. Kazayawoko, J.J. Balatinecz and R.T. Woodhams, "Diffuse Reflectance Fourier Transform Infrared Spectra of Wood Fibers Treated with Maleated Polypropylenes," Journal of Applied Polymer Science, 66(6), 1163-1173, 1997.

70. X. Colom, J. Cañavate, P. Pagès, J. Saurina and J. Carrasco, "Changes in Crystallinity of the HDPE Matrix in Composites with Cellulosic Fibers Using DSC and FTIR," Journal of Reinforced Plastics and Composites, 119(10), 818-830, 2000 . 


\section{Chapter 3 - EfFect of Processing Method on ACCELERATED WEATHERING OF WOOD FLOUR/HDPE COMPOSITES}

This chapter has been submitted to the Journal of Applied Polymer Science (September 2003). It is co-authored by N.M. Stark, L.M. Matuana, and C.M. Clemons 


\subsection{Abstract}

Wood-plastic lumber is promoted as being a low-maintenance high-durability product. However, it has been shown that wood-plastic composites exposed to accelerated weathering may experience a color change and/or loss in mechanical properties. Different methods of manufacturing wood-plastic composites lead to different surface characteristics, which can influence weathering. In this study, 50\% wood flour filled high-density polyethylene (HDPE) composite samples were either injection molded, extruded, or extruded and then planed. Different processing methods produced composites with different surface components. Fourier transform infrared spectroscopy was used to chemically show these differences. The surface of the planed samples exhibited more of a wood component than the extruded and injection molded samples, respectively. The samples underwent accelerated weathering in a xenon-arc weathering apparatus and were removed after 1000,2000 , and $3000 \mathrm{~h}$ of accelerated weathering. The samples were analyzed for color fade, and loss of flexural modulus of elasticity and strength. It was shown that the final lightness of the samples after weathering was not dependent upon the manufacturing method. However the mechanical property loss due to weathering was dependant upon manufacturing method. The samples with more of wood component at the surface experienced a larger percentage of total loss in flexural modulus of elasticity and strength after weathering. This was likely due to the greater effect of moisture on the samples with the more hydrophilic wood at the surface. 


\subsection{Introduction}

In recent years, wood-derived fillers have made significant inroads into the thermoplastic industry. Much of this has been due to the emergence of wood-plastic composites in the construction industry. Exterior non-structural or semi-structural building products such as decking, fencing, siding, and roof tiles are being introduced into the marketplace. It is predicted that for building products alone, approximately 1.1 billion $\mathrm{lb}(500,000$ tons) of wood-plastic composites will be used in North America in 2006 (1). Construction, transportation, industrial and consumer applications are also on the rise. Currently, nearly $70 \%$ of wood-plastic composites are polyethylene matrix composites (1). Polypropylene and polyvinyl chloride are also common matrix materials used by the wood-plastic composites industry.

Wood-plastic lumber is promoted as being a low-maintenance high-durability product (2). However, the use of wood-plastic composites by the construction industry has resulted in concern about the durability of these products exposed to outdoor environments. Ultraviolet (UV) durability is of particular concern. It has been shown that wood-plastic composites exposed to accelerated weathering experience color change (38) and a loss in mechanical properties $(3-6,8)$. The changes in mechanical properties after weathering can be due to a combination of changes such as composite surface oxidation, matrix crystallinity changes, and interfacial degradation due to moisture absorption (9).

While the effect of weathering on wood-plastic composites has been consistently reported, the rate of change has not. Samples of $50 \%$ wood flour filled HDPE have been 
tested for color fade after accelerated weathering. Some have reported that the majority of color fade occurs in the first $700 \mathrm{~h}$ of 1500 total $\mathrm{h}$ of weathering (4), while others have shown that color fade continues through $2000 \mathrm{~h}$ of weathering (6). Even more disparity can be found in the literature regarding mechanical properties. Some have shown that for $50 \%$ wood flour filled HDPE the flexural modulus of elasticity (MOE) and strength decrease during the first $1000 \mathrm{~h}$ of $2000 \mathrm{~h}$ total exposure time (3). Others showed that for the same formulation the flexural MOE and strength change very little during the first $1000 \mathrm{~h}$ of accelerated weathering and the majority of change occurs during the second $1000 \mathrm{~h}$ of weathering (6).

Injection molding, compression molding, and extrusion are processing methods commonly used for the manufacture of wood-plastic composites. Temperature, pressure, and flow are some parameters that can change based on the processing method. Both processing methods and processing variables greatly influence the morphology and the physical properties of the composite.

Injection molded composite plaques result in a skin-core morphology. In short fiber polymeric composites the fibers in the core layer are oriented perpendicularly to flow while those in the skin layer are oriented parallel to flow $(10,11)$. Processing variables can affect the relative thickness of these layers. A low mold temperature can lead to a large skin thickness (10). Increasing the barrel temperature, screw temperature, and injection speed decrease the skin thickness (10). Not only does the morphology of the injection molded composites change from the skin to core region, but the volume fraction of the fiber can change as well. It has been shown that the fiber volume fraction for injection molded cellulose fiber filled polypropylene is slightly higher in the core layer 
than the surface layer (11). In addition, a polymer-rich surface layer is often present for injection molded composites (12).

Extruding short fiber reinforced polymeric composite can also lead to a skin-core morphology. Extruded polypropylene filaments filled with short glass fiber were studied. The circular profiles were analyzed for density and orientation differences. It was found that at the surface of the extrudate, the composites had a higher density and the fibers were more aligned in the flow direction than for the core of the extrudate (13).

The method of manufacturing wood-plastic composites also affects moisture absorption. Clemons and Ibach (12) looked at 50\% wood flour filled HDPE composites manufactured via extrusion, compression molding, and injection molding. It was reported that extruded composites absorbed the most moisture while injection molded composites absorbed the least (12). It was presumed that this was due to the polymer rich surface layer and lower void content attributable to the higher density of injection molded composites (12).

The mechanical properties of wood flour filled polymer composites are negatively affected by moisture $(12,14-18)$. When the composite is exposed to moisture, the hydrophilic fiber swells. Cracks may form in the polymer matrix, which can also contribute to the penetration of water into the composite (14). Exposing wood filled polymer composites to moisture results in a drop in flexural MOE and strength by degrading the wood-polymer interfacial quality (14-16). The amount of moisture absorbed can be influenced by wood flour content and wood particle size $(14,17)$.

Despite the known effects of manufacturing methods on moisture absorption and mechanical properties of composites, research has not been extensively carried out to 
examine the influence of composite production methods on ultraviolet degradation. This study had two main objectives: 1) to characterize the surface of 50\% wood flour/HDPE composites produced using different manufacturing methods, and 2) to understand how manufacturing methods affect the weathering of wood flour /HDPE composites.

Fourier Transform Infrared (FTIR) spectroscopy was utilized to study the surface characteristics of wood flour/HDPE composites manufactured using different processing techniques because of its effectiveness to analyze the functional groups present in a material. FTIR methods have been extensively used to study weathered polyethylene (1924). In addition, FTIR has been employed to study the functional groups present in wood $(25-27)$.

The results of the study reported here will aid in the development of an understanding of how processing methods affect the color fade and mechanical properties of WF/HDPE composites after weathering.

\subsection{Methods}

\subsubsection{Materials}

The materials used in this study were wood flour (WF) and high-density polyethylene (HDPE). The WF was a 40 mesh ponderosa pine supplied by American Wood Fibers (Schofield, WI). The HDPE was a virgin material with a melt index of 0.72 $\mathrm{g} / 10 \mathrm{~min}$ and density of $0.963 \mathrm{~g} / \mathrm{cm}^{3}$ supplied by Solvay Polymers, Inc. (Fortiflex A6070-162, Houston, TX). A lubricant was added to aid in the extrusion (Struktol TR016). 


\subsubsection{Processing}

\section{Injection Molded}

The WF was dried for $24 \mathrm{~h}$ at $105^{\circ} \mathrm{C}\left(221^{\circ} \mathrm{F}\right)$, and then the composites were dryblended at 50\% WF. Compounding was accomplished using a 32-mm Davis Standard (Pawcatuck, CT) twin-screw extruder to produce homogeneous WF/HDPE composite pellets. The melt temperature at the die was $200^{\circ} \mathrm{C}\left(392^{\circ} \mathrm{F}\right)$ and the melt pressure was 2.96 $\mathrm{MPa}(430 \mathrm{psi})$. The pellets were dried at $105^{\circ} \mathrm{C}\left(221^{\circ} \mathrm{F}\right)$ for at least $24 \mathrm{~h}$ prior to injection molding into flexural bar test samples. The HDPE samples were injection molded using a 33-ton (30 metric tones) Cincinnati Milacron (Batavia, OH) injection molder. The mold nozzle temperature was $204^{\circ} \mathrm{C}\left(400^{\circ} \mathrm{F}\right)$ and the injection pressure reached a peak of 12.4 MPa (1800 psi). The American Society for Testing and Materials mold cavity used for the flexural samples is $120 \times 3 \times 12 \mathrm{~mm}$ (28).

\section{Extruded}

Extruded samples were run at University of Maine's Advanced Engineered Wood Composite Center. The composition of the composite was $49 \%$ by weight WF, $8 \%$ by weight lubricant, and the remainder HDPE. A Davis Standard $94 \mathrm{~mm}$ twin-screw extruder was used with a die that produced a $1.2 " \times 5.5 "$ radius edge profile. The die temperature was $180^{\circ} \mathrm{C}\left(356^{\circ} \mathrm{F}\right)$ and the die pressure was $2.1 \mathrm{MPa}(300 \mathrm{psi})$. Flexural samples $(120 \times 3 \times 12 \mathrm{~mm})$ were cut from the deck boards to be used for testing (Fig. 3.1). The extruded surface was left in tact. 


\section{Planed}

The surface of the extruded samples were planed to remove any surface characteristics due to the extrusion processing method. The samples were cut from the deck board just below the planed surface to minimize any difference from the extruded samples that may result from the thickness of the board (Fig. 3.1).

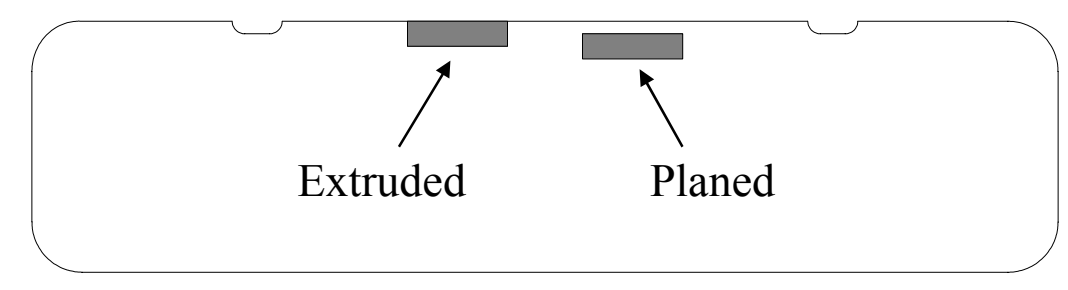

Figure 3.1. Extruded profile showing where extruded and planed samples were cut from.

\subsubsection{Testing and Analysis}

\section{$\underline{\text { Density }}$}

The unexposed samples were dried for $24 \mathrm{~h}$ at $105^{\circ} \mathrm{C}\left(221^{\circ} \mathrm{F}\right)$ to remove moisture before being tested for density according to ASTM D792 (28). The sample size tested was approximately $60 \times 3 \times 12 \mathrm{~mm}$. Twenty replicates for each processing method were tested.

The density of the wood flour in the composites was calculated. The rule of mixtures can be written in weight fractions as follows: 


$$
\frac{1}{\rho_{c}}=\left(\frac{w_{f}}{\rho_{f}}\right)+\left(\frac{w_{m}}{\rho_{m}}\right)
$$

where $\rho=$ density, $w=$ weight fraction, and the subscripts $c, f, m$ refer to composite, fiber, matrix, respectively. Rearrangement of Equation 3.1 allows for the calculation of the fiber density in the composite $\left(\rho_{f}\right)$.

\section{Color Measurement}

A Minolta CR-200 Chroma Meter (Minolta Corporation, Ramsey, New Jersey) was used to measure color using the CIELAB color system. Lightness $(L)$ was measured for at least five replicate samples. In the CIELAB color system, the value $L$ can be thought of as a lightness factor. $L$ represents the reflectance of a sample. An $L$ of 0 means the sample does not reflect light, an $L$ of 100 means the sample reflects $100 \%$ of light. An increase in $L$ means the sample is lightening (i.e., $+\Delta L$ for lightening and $-\Delta L$ for darkening).

\section{Mechanical Properties}

Samples were oven dried at $105^{\circ} \mathrm{C}$ for $24 \mathrm{~h}$ before testing. This ensured the same conditioning for samples before and after weathering. Flexural tests were carried out according to ASTM D790 (28) on an Instron Universal Testing machine. The three-point loading system was utilized with a crosshead speed of $1.3 \mathrm{~mm} / \mathrm{min}$. The exposed surface was placed away from the center load to place that part of the sample in tension. At least five replicate specimens were tested for each formulation. The modulus of elasticity (MOE) and maximum strength were calculated according to the standard. 


\section{Fourier Transform Infrared Spectroscopy}

FTIR spectroscopy was conducted on a Mattson Genesis II spectrophotometer to provide knowledge of the functional groups present at the surface of the samples. The penetration depth is dependent upon the wavelength and index of refraction of the WF and HDPE and ranges from 0.5 to $3 \mu \mathrm{m}$. Scans were run at a resolution of $4 \mathrm{~cm}^{-1}$. Each sample recorded consisted of 100 scans recorded in absorbance units from $4000-700 \mathrm{~cm}^{-1}$. The spectra were obtained using attenuated total reflectance (ATR). The surfaces of the samples analyzed were in contact with a $\mathrm{ZnSe}$ crystal that has a $45^{\circ}$ angle of incidence. At least five replicate samples were analyzed.

Cellulose spectra have a strong peak due to hydroxyl groups at $1023 \mathrm{~cm}^{-1}(25)$. A wood index was calculated using Equation 3.2:

$$
\text { Wood Index }=\frac{I_{1023}}{I_{2912}} \times 100
$$

where I represents the peak intensity. The peak intensity was normalized using the peak at $2912 \mathrm{~cm}^{-1}$, which corresponds to methyl group vibrations.

\section{Weathering}

The samples were placed in a xenon arc-type light exposure apparatus which was operated according to ASTM D2565 (29). Samples were mounted in four rows on a drum that rotated around the xenon arc bulb at $1 \mathrm{rpm}$. The weathering cycle consisted of 108 min UV exposure and 12 min simultaneous water spray and UV exposure (29). An irradiance sensor was used to measure the light intensity for wavelengths from 300 to 400 
$\mathrm{nm}$. The irradiance was monitored and the voltage to the bulb was changed periodically in order to maintain a constant irradiance. The dosage, or amount of light energy the samples were subjected to was calculated (irradiance $\mathrm{x}$ time). The dosage at 500-hour time increments is shown in Table 3.1. We can be confident that samples were exposed to consistent energy dosages for each thousand hours of weathering. To understand the effect of time on weathering, samples were removed for analysis after 1000, 2000, and $3000 \mathrm{~h}$.

\begin{tabular}{|c|c|}
\hline Time Increment (Hours) & $\begin{array}{c}\text { Dosage } \\
\left(\mathrm{kW}-\mathrm{hr} / \mathrm{m}^{2}\right)\end{array}$ \\
\hline $0-500$ & 29.4 \\
\hline $500-1000$ & 29.1 \\
\hline $1000-1500$ & 27.9 \\
\hline $1500-2000$ & 28.2 \\
\hline $2000-2500$ & 28.7 \\
\hline $2500-3000$ & 28.8 \\
\hline
\end{tabular}

\section{Scanning Electron Microscopy}

Molded surfaces were sputtered with gold and analyzed with a scanning electron microscope (SEM) (JSM-840, JEOL USA, Inc., Peabody, MA) at a working distance of approximately $25 \mathrm{~mm}$, a voltage of $15 \mathrm{kV}$, and a probe current of $1 \times 10^{-9} \mathrm{amps}$.

\section{$\underline{\text { Statistics }}$}

To determine the effects of weathering on properties, Student's two-tailed $t$-tests were carried out at $\alpha=0.05$ for each blend, testing the data for significant differences within a manufacturing method due to weathering. 


\subsection{Results and Discussion}

\subsubsection{Unexposed Samples}

WF/HDPE composites were manufactured by either injection molding or extrusion. Furthermore, the extruded samples were either cut to leave the original surface intact or the surface was planed. The physical properties of the molded, extruded, and planed composites without UV weathering are summarized in Table 3.2. The processing pressures during injection molding were much higher than during extrusion. The result was a higher density for molded samples than for extruded or planed samples. During processing the wood cells can either be compressed or filled. If the PE is assumed to be incompressible, the density of the wood flour can be calculated by rearranging Equation 3.1. The density of the wood flour in the injection molded composites was higher than for the extruded and planed samples. This was also due to the larger processing pressures the composite experienced during injection molding than extrusion. The density of the wood flour in the molded samples approached that of wood cell walls, approximately 1.49 $\mathrm{g} / \mathrm{cm}^{3}(30)$.

Table 3.2. Physical properties of unexposed $50 \%$ wood flour filled HDPE composites.

\begin{tabular}{cccccc}
\hline Samples & $\begin{array}{c}\text { Composite } \\
\text { Density }\left(\rho_{\mathrm{c}}\right) \\
\left(\mathrm{g} / \mathrm{cm}^{3}\right)\end{array}$ & $\begin{array}{c}\text { Wood Flour } \\
\text { Density }\left(\rho_{\mathrm{f}}\right) \\
\left(\mathrm{g} / \mathrm{cm}^{3}\right)\end{array}$ & Lightness & $\begin{array}{c}\text { MOE } \\
(\mathrm{GPa})\end{array}$ & $\begin{array}{c}\text { Strength } \\
(\mathrm{MPa})\end{array}$ \\
\hline Molded & $1.135(0.002)$ & $1.40(0.01)$ & $49.0(0.7)$ & $3.6(0.2)$ & $39.6(0.7)$ \\
Extruded & $1.087(0.008)$ & $1.27(0.02)$ & $57.0(0.8)$ & $3.3(0.2)$ & $24.5(0.9)$ \\
Planed & $1.085(0.019)$ & $1.26(0.05)$ & $62.1(1.0)$ & $3.4(0.2)$ & $27.2(0.7)$ \\
HDPE & $0.953(0.001)$ & $\mathrm{na}$ & $76.4(0.2)$ & $0.9(0.1)$ & $22.3(0.2)$ \\
\hline
\end{tabular}

Numbers in parentheses represents one standard deviation. 
The lightness of the composites also varied with manufacturing method (Table 3.2). The molded samples were the darkest. The processing temperatures were higher for the molded samples, which resulted in a darker composite as the wood began to degrade. Comparing the extruded to the planed composites, the planed composites were lighter in color. The polymeric surface layer on the extruded composite effectively wet the wood flour. When wetting occurs at the wood surface light is transmitted deeper in the cell, resulting in an apparent darkening of the wood (31).

Generally, the flexural MOE of the composites were similar. However, the flexural strength of the molded samples was greater than for the extruded and planed samples. This is most likely due to the difference in densities. The higher densities of the molded samples result in more intimate contact between the HDPE matrix and WF. The improvement in interfacial quality led to a more efficient stress transfer between the matrix and fiber, leading to increased strength.

The surface of each sample was analyzed using FTIR spectroscopy. Figure 3.2 shows two spectra, the top one of unfilled HDPE and the bottom one of a solid piece of southern yellow pine (SYP, Pinus spp.). The broad peak at $3318 \mathrm{~cm}^{-1}$ is associated with mixed hydroxyl groups originating mainly from cellulose. The peak at $2912 \mathrm{~cm}^{-1}$ is due to - $\mathrm{CH} 2$ - groups and appears as a very strong peak in HDPE and a much weaker peak in SYP. A relatively large proportion of HDPE is - $\mathrm{CH} 2$ - groups compared to SYP. The peak at $1023 \mathrm{~cm}^{-1}$ is assigned to a hydroxyl group associated with cellulose (25). 


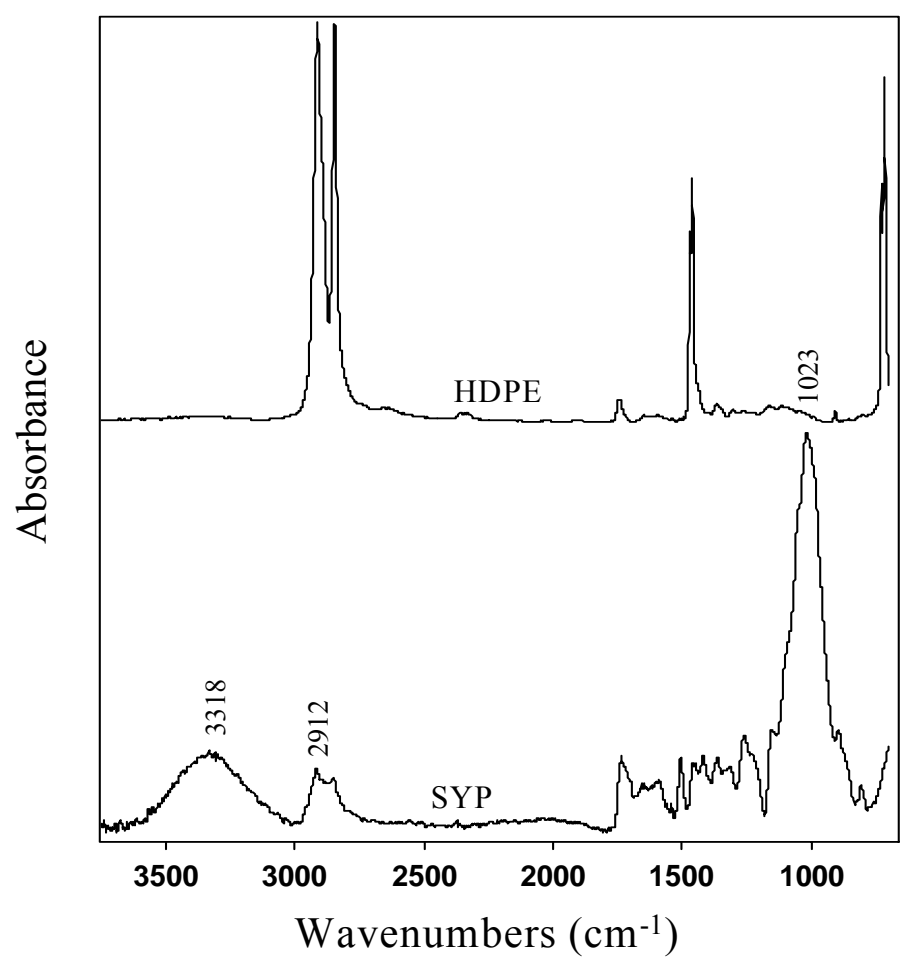

Figure 3.2. FTIR spectra of HDPE and SYP.

Figure 3.3 shows the FTIR spectra obtained for molded, extruded, and planed composites. The increase in hydroxyl groups at the surface was clearly seen as an increase in the broad peak at $3318 \mathrm{~cm}^{-1}$ and the strong peak at $1023 \mathrm{~cm}^{-1}$. A wood index was calculated to relate the hydroxyl group peak at $1023 \mathrm{~cm}^{-1}$ to the methyl group peak at $2912 \mathrm{~cm}^{-1}$ (Eq. 3.2). The results are shown in Table 3.3. The planed samples had the highest wood index, followed by the extruded and the injection-molded samples. It was expected that the planed composites would exhibit stronger peaks due to the wood component because wood particles were exposed during the planing. The differences between molded and extruded samples are probably due to processing differences. During processing, the pressure causes a thin layer of polymer to be formed at the 
surface. The increased pressure attributable to injection molding lead to a composite with a thicker polymer rich surface layer.

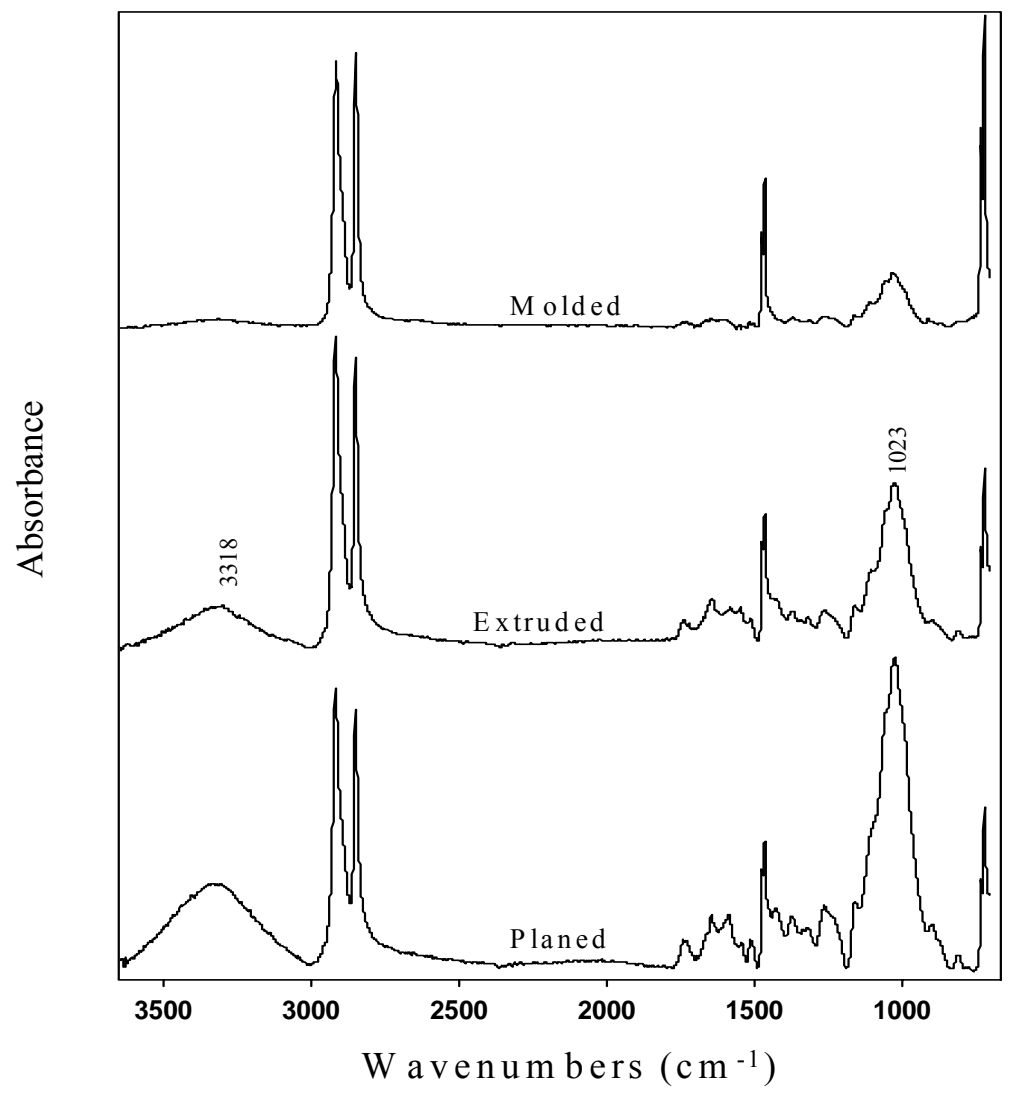

Figure 3.3. FTIR spectra of molded, extruded, and planed WF/HDPE composites.

Table 3.3. Wood Index determined from the cellulose peak at $1023 \mathrm{~cm}^{-1}$.

\begin{tabular}{cc}
\hline & Wood Index \\
\hline Molded & $0.24(0.02)$ \\
Extruded & $0.44(0.09)$ \\
Planed & $2.74(1.39)$ \\
SYP & 7.58
\end{tabular}

Numbers in parentheses represents one standard deviation. 
Micrographs of the unexposed surfaces of the molded, extruded and planed composites are shown in Figures 3.4a, 3.5a, and 3.6a, respectively. The micrographs visually confirm the FTIR data. The surface of the molded sample (Fig. 3.4a) is relatively smooth and flow of the polymer over wood particles can be seen. The surface of the extruded sample (Fig. 3.5a) has many voids where the polymer failed to encapsulate the wood particle. The lower processing pressure and temperature does not allow for the polymer to flow at the surface as well as for the injection-molded composites. The planed samples (Fig. 3.6a) also have a relatively smooth surface. However, it is visually apparent that the wood fibers are exposed at the surface.

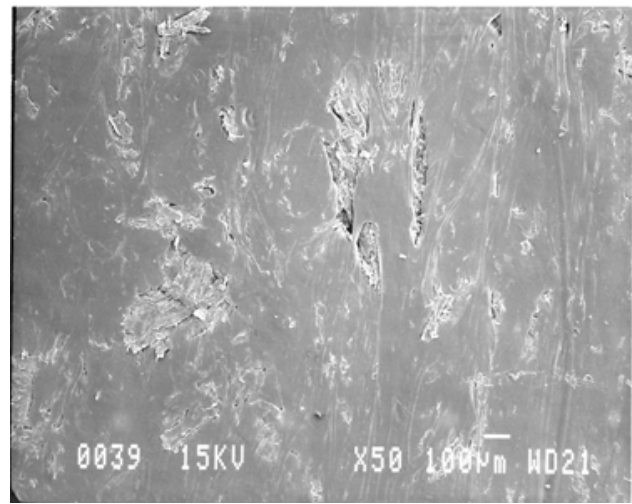

(3.4a)

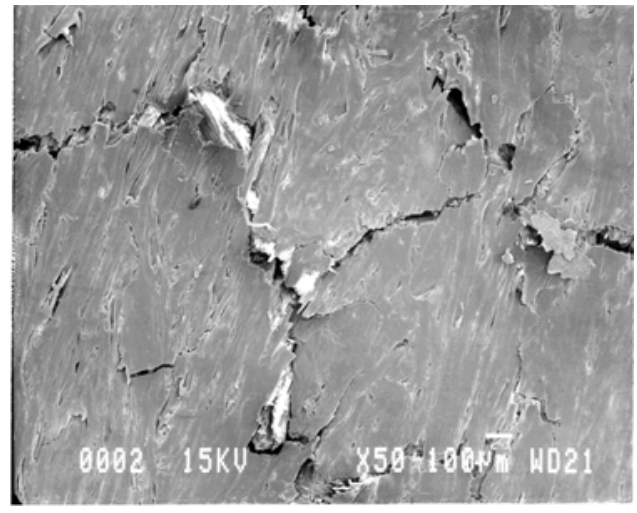

(3.4c)

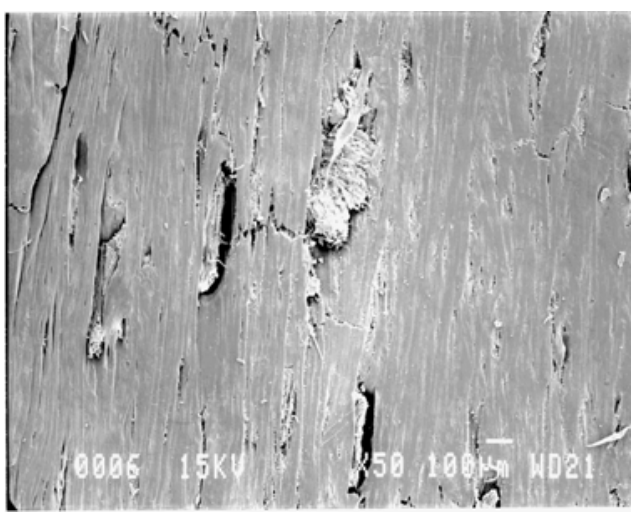

$(3.4 b)$

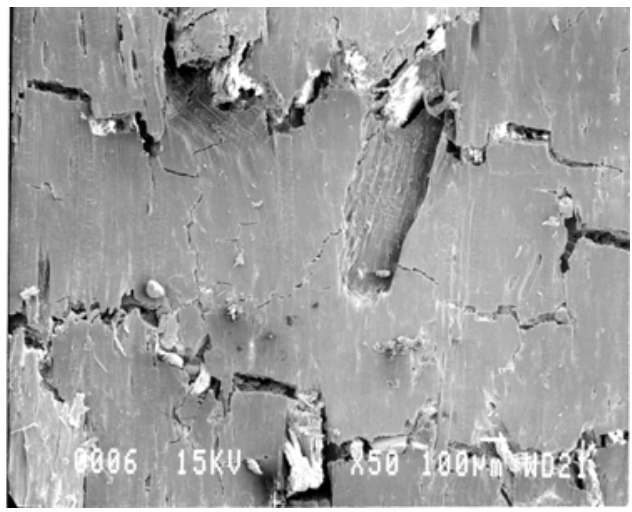

$(3.4 d)$

Figure 3.4. Micrographs of molded WF/HDPE composites: (a) before weathering and after (b) 1000, (c) 2000, and (d) $3000 \mathrm{~h}$ of weathering. 


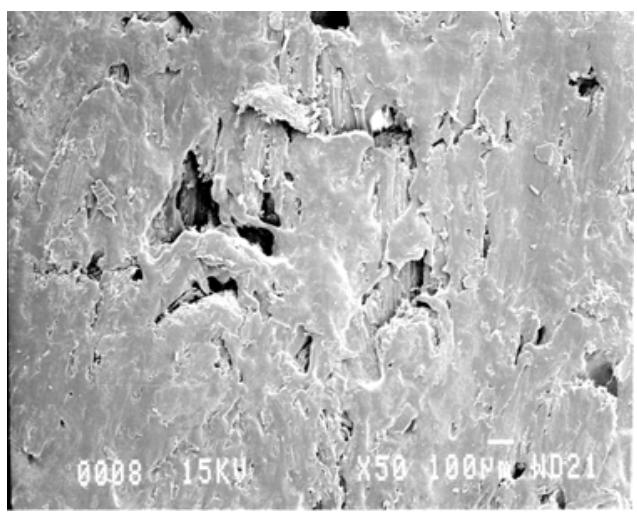

(3.5a)

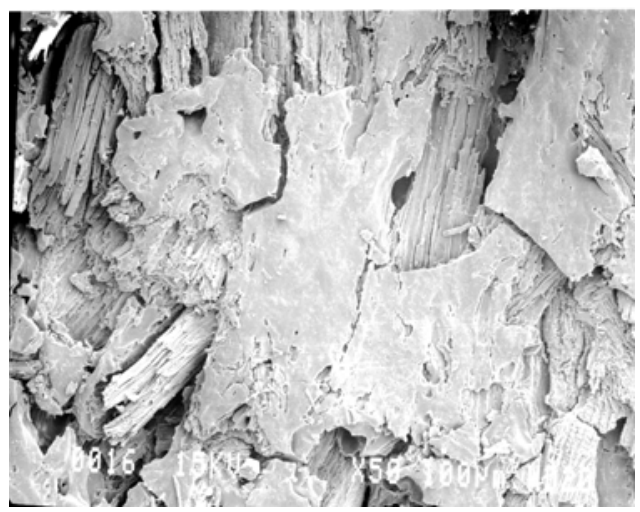

$(3.5 \mathrm{c})$

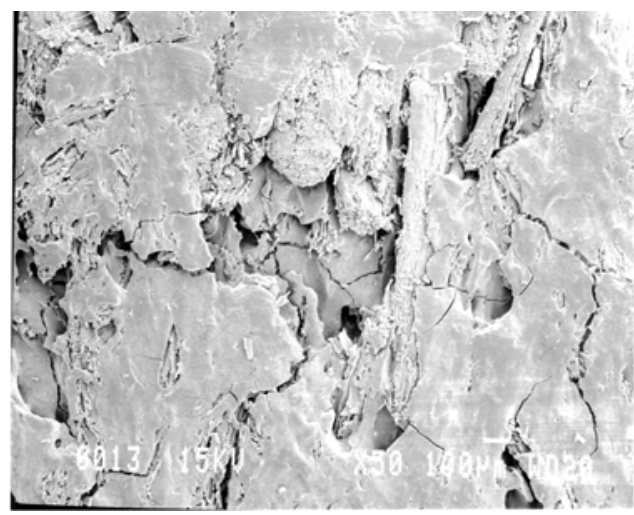

$(3.5 b)$

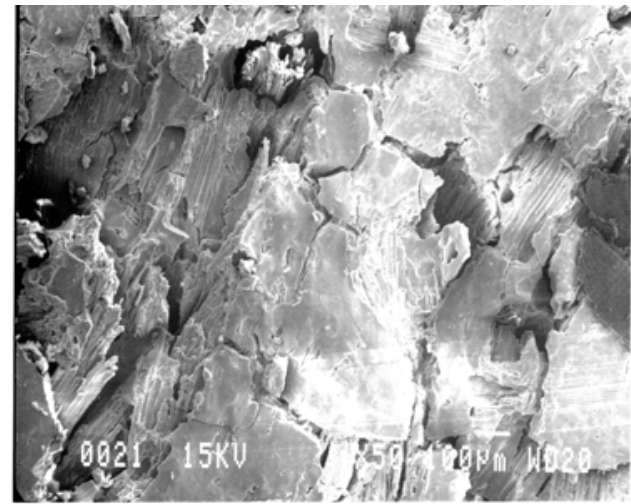

$(3.5 \mathrm{~d})$

Figure 3.5. Micrographs of extruded WF/HDPE composites: (a) before weathering and after (b) 1000, (c) 2000, and (d) $3000 \mathrm{~h}$ of weathering.

\subsubsection{Exposed Samples}

The molded, extruded, and planed samples underwent accelerated weathering in a xenon-arc weathering apparatus. The samples were removed after 1000, 2000, and 3000 $\mathrm{h}$ of weathering. Micrographs of the unexposed and weathered surfaces are shown in Figures 3.4-3.6. The composites were then tested for lightness, flexural MOE, and flexural strength. These results are shown in Figures 3.7-3.9, respectively. Each manufacturing method is shown on the x-axis. It should be mentioned that comparison between manufacturing methods was not performed. Instead, comparison was performed 
within each manufacturing method between unweathered and weathered samples. Therefore, statistically significant differences within each manufacturing method were represented with separate letters in Figures 3.7-3.9. If the difference between two means is not statistically significant, the same letter denotes each bar.

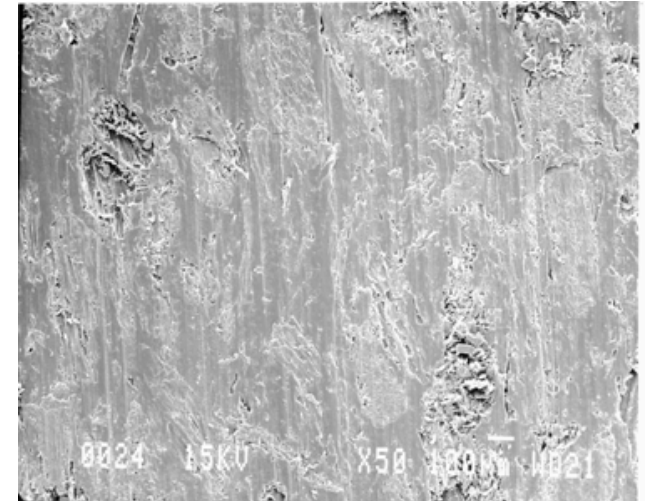

(3.6a)

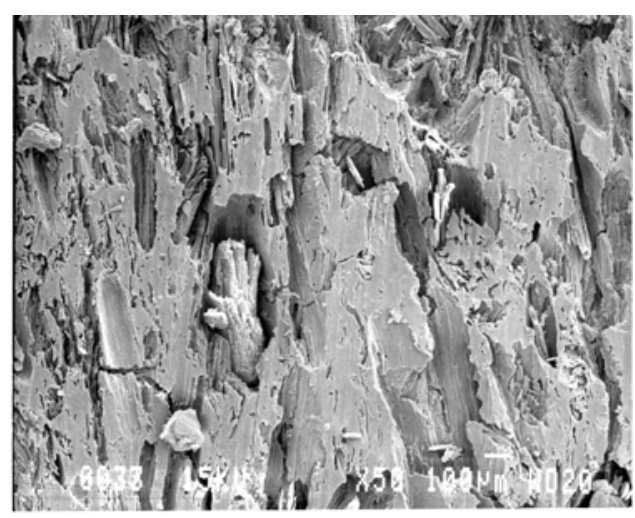

(3.6c)

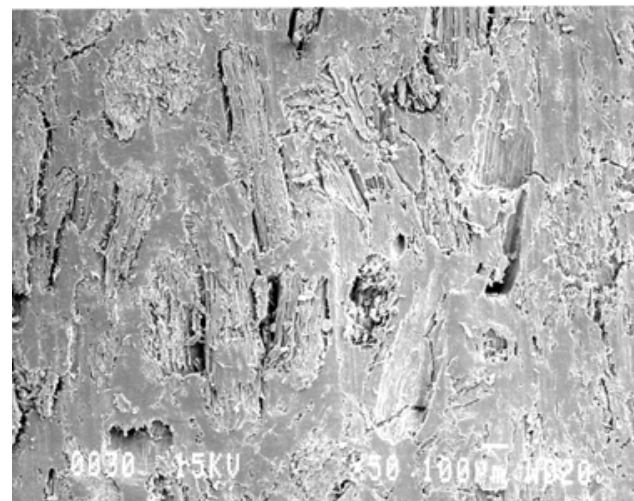

$(3.6 b)$

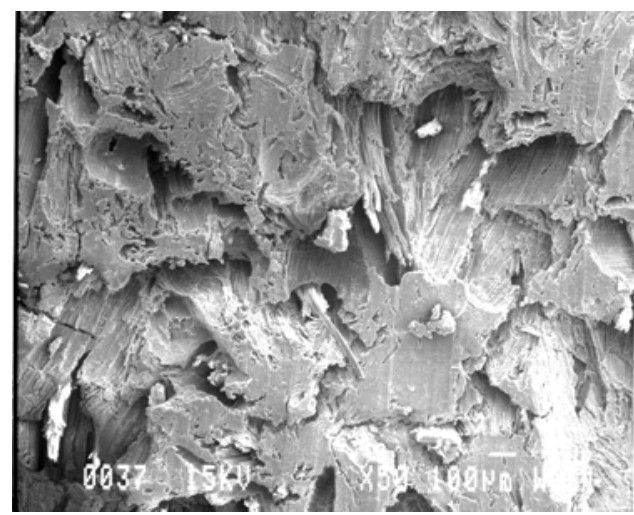

(3.6d)

Figure 3.6. Micrographs of planed WF/HDPE composites: (a) before weathering and after (b) 1000, (c) 2000, and (d) $3000 \mathrm{~h}$ of weathering.

All of the samples show surface cracking of the polymer matrix after weathering. In addition it is apparent that the swelling and shrinking of the wood particles after 
absorbing and desorbing moisture has resulted in voids at the wood flour/HDPE interface. The surface cracking and destruction of the interfacial properties continues as weathering time increases. It appears that the surface of the composite begins to flake off. This has occurred after $3000 \mathrm{~h}$ of weathering for the molded samples (Fig. 3.4d), and after $2000 \mathrm{~h}$ of weathering for the extruded and planed composites, (Figs. $3.5 \mathrm{c}$ and 3.6c, respectively). The composites surface of the extruded and planed composites are more drastically degraded after weathering than the molded composites due to their high wood index (Table 3.3).

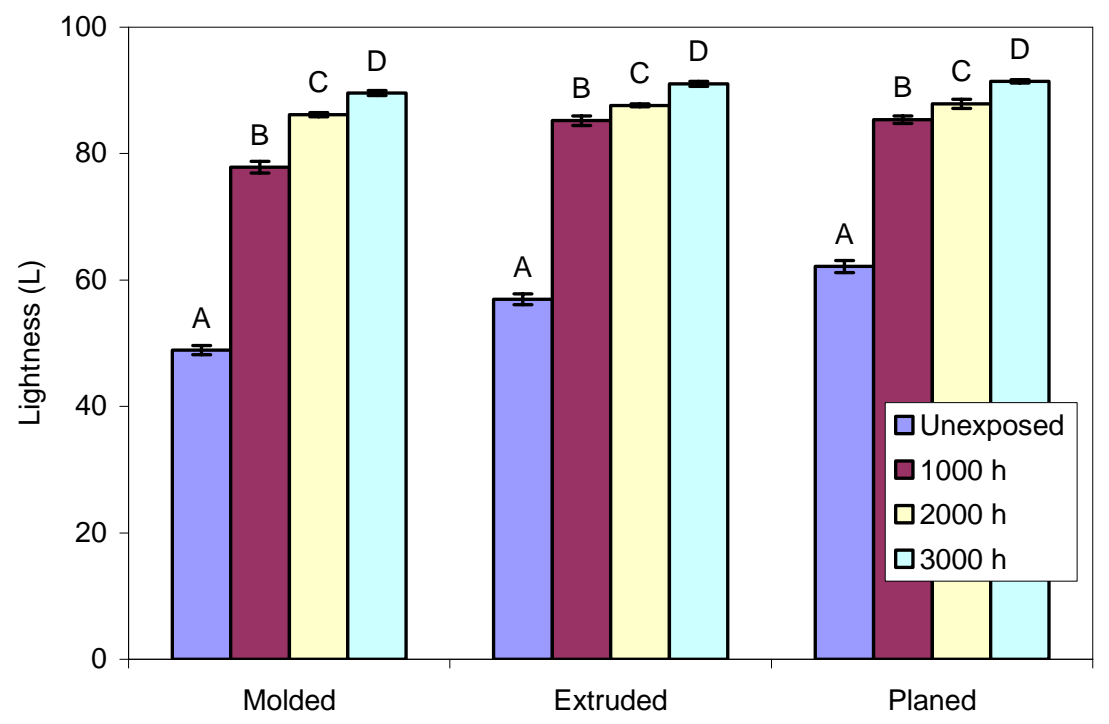

Figure 3.7. Lightness (L) values for molded, extruded, and planed WF/HDPE composites before and after 1000, 2000 and $3000 \mathrm{~h}$ of weathering.

The effect of weathering on composite lightness, $L$, is shown in Figure 3.7. It is clear that weathering resulted in a lightening of the composite. For each production method, the change in $L$ after each time period was significant. Regardless of the 
manufacturing method, the greatest increases in $L$ occurred in the first $1000 \mathrm{~h}$ and all of the samples reached a similar lightness value after $3000 \mathrm{~h}$ of weathering. The lightening of the composite originates mainly from the wood flour bleaching, and is a composite surface phenomenon. Lundin (3) characterized this depth after $2000 \mathrm{~h}$ of weathering and found it to be $0.3 \mathrm{~mm}$ for $50 \%$ wood flour filled HDPE. Because the final values of $L$ are similar for the composites regardless of manufacturing method, we can conclude that the lightened layer is deeper than the depth of the polymer rich layers in the molded and extruded samples. Therefore production method has little effect on total lightness after $3000 \mathrm{~h}$ of weathering.

It is also evident that after $1000 \mathrm{~h}$ of weathering the planed and extruded samples were closer to the their final lightness than the composites with more of a polymer influence at the surface, the molded samples. After $1000 \mathrm{~h}$ of weathering, the molded samples reached $71 \%$ of their total lightening while the extruded and planed samples reached $80 \%$ and $83 \%$, respectively. This illustrates that the samples with more wood component at the surface will experience a larger percentage of the total lightening in the early stages of weathering.

The flexural MOE and strength generally decreased after accelerated weathering. The decrease in MOE for the molded samples was significant for each $1000 \mathrm{~h}$ of weathering (Fig. 3.8). For the extruded samples the decrease in MOE was not significant between 2000 and $3000 \mathrm{~h}$ of weathering, and for planed samples the decrease was not significant for 1000,2000 , and $3000 \mathrm{~h}$ of weathering. 


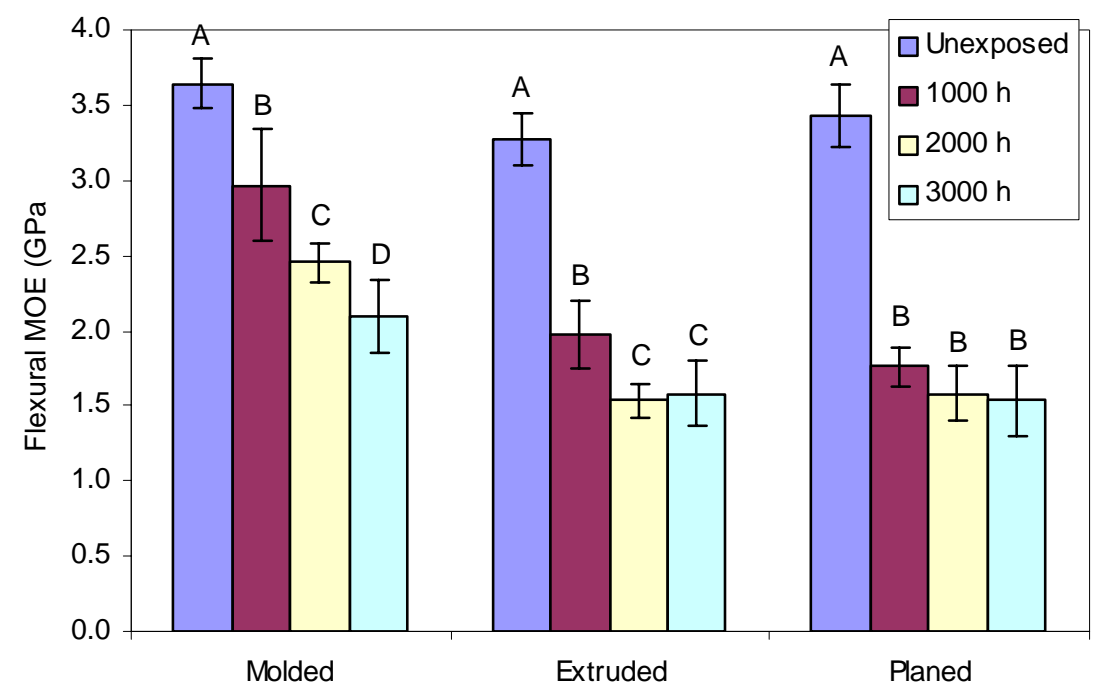

Figure 3.8. Flexural modulus of molded, extruded, and planed WF/HDPE composites before and after 1000, 2000 and $3000 \mathrm{~h}$ of weathering.

The decrease in flexural strength for the molded samples was not significant between 1000 and $2000 \mathrm{~h}$ of weathering (Fig. 3.9). The same significant changes in strength after weathering were observed for the extruded and planed samples as shown for MOE. After $3000 \mathrm{~h}$ of weathering the MOE and strength were both similar for the extruded and planed samples, and lower than the molded samples. Unlike $L$ after $3000 \mathrm{~h}$ of weathering, the manufacturing method did appear to affect final flexural properties, with the molded composites having higher flexural properties after weathering than the extruded and planed composites. It is expected that increased weathering times would cause the mechanical properties to reach similar values regardless of manufacturing method. The difference in the rate of mechanical property degradation is likely due to a combination of differences in density as well as surface characteristics. 


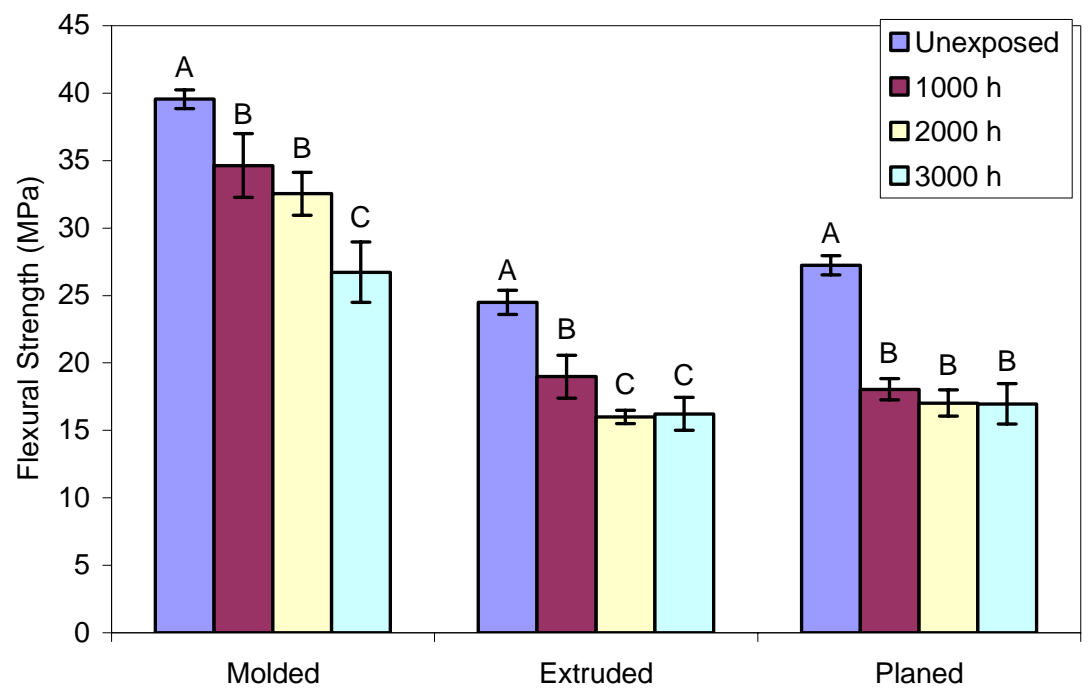

Figure 3.9. Flexural strength of molded, extruded, and planed WF/HDPE composites before and after 1000, 2000, and $3000 \mathrm{~h}$ of weathering.

Similar to the trend observed for lightness, after $1000 \mathrm{~h}$ of weathering the extruded and planed samples were closer to their final MOE and strength than the molded samples. After $1000 \mathrm{~h}$, the molded, extruded, and planed samples reached 44, 77, and $88 \%$, respectively, of their total MOE loss. Similarly, molded, extruded, and planed samples reached 38,67 , and $89 \%$, respectively, of their total loss in strength after $1000 \mathrm{~h}$ of weathering. These results imply that composites with more wood component at the surface will lose a large percentage of the total property loss in the initial weathering stages. Conversely, the samples with a large polymer characteristic at the surface will lose a smaller percentage of their total property loss in the initial stages.

This explains the apparently conflicting data reported by other researchers. Table 3.4 shows the loss in MOE and loss in strength for 50\% wood flour filled HDPE 
composites after weathering. The molded, extruded and planed samples are compared to the results found in two research papers where the samples were also injection molded. Lundin (3) weathered 50\% wood flour/HDPE composites for $2000 \mathrm{~h}$. They found that the yield stress and bending stiffness decreased through $1000 \mathrm{~h}$, and then leveled off. Conversely, Stark et al weathered 50\% wood flour filled HDPE samples for $2000 \mathrm{~h}$ (6). The samples were removed periodically. After $1000 \mathrm{~h}$ the MOE did not significantly drop. After $2000 \mathrm{~h}$ the drop was $26 \%$. In addition to differences between samples surface differences, comparing weathering effects based on weathering times may have an apparent error. The energy received by the samples also needs to be taken into consideration, and may be different for each study.

Table 3.4. Loss in MOE and loss in strength after accelerated weathering for 1000, 2000, and $3000 \mathrm{~h}$ for $50 \%$ WF filled HDPE composites compared with values found in the literature.

\begin{tabular}{ccccccc}
\hline Samples & \multicolumn{3}{c}{$\begin{array}{c}\text { MOE Loss } \\
(\%)\end{array}$} & \multicolumn{3}{c}{$\begin{array}{c}\text { Strength Loss } \\
(\%)\end{array}$} \\
& $1000 \mathrm{~h}$ & $2000 \mathrm{~h}$ & $3000 \mathrm{~h}$ & $1000 \mathrm{~h}$ & $2000 \mathrm{~h}$ & $3000 \mathrm{~h}$ \\
\hline Molded & 19 & 33 & 43 & 12 & 18 & 32 \\
Extruded & 40 & 53 & 52 & 22 & 35 & 34 \\
Planed & 49 & 54 & 55 & 34 & 37 & 38 \\
Molded [3] & 29 & 33 & --- & 17 & 20 & --- \\
Molded [15] & 3 & 26 & --- & 6 & 22 & -- \\
\hline
\end{tabular}

The color fade of the composites is due mainly to the effect of UV exposure on wood flour. While it needs to be studied further, the degradation of mechanical properties of WF/HDPE composites after weathering is thought to be largely due to moisture effects. This would most likely be due to a degradation of interfacial properties as a result of exposure to moisture. During weathering the samples cycle through environments of $35^{\circ} \mathrm{C}$ and $100 \%$ relative humidity during the water spray cycle, and $40^{\circ} \mathrm{C}$ and $30 \%$ 
relative humidity during the dry cycle. Moisture has been shown to adversely affect the properties of wood-plastic composites. Injection molded HDPE composites filled with $40 \%$ wood fiber exposed to a water bath for $2000 \mathrm{~h}$ experienced a $39 \%$ loss in flexural MOE (15). Similarly, 30\% WF/HDPE injection molded samples lost approximately 25\% of their flexural modulus after being exposed to boiling water for $50 \mathrm{~h}$ (18). Processing method has also been shown to influence moisture sorption properties. After soaking $50 \% \mathrm{WF} / \mathrm{HDPE}$ composites for two weeks, the more dense injection molded composites absorbed only 4\% moisture while the less dense extruded composites absorbed $17 \%$ (12).

\subsection{Summary and Conclusions}

FTIR can be used to examine the surface characteristics of wood-plastic composites manufactured using different processing techniques. By following peaks associated with functional groups present in polyethylene and cellulose, the differences in surface chemistries between manufacturing methods become apparent. In this study, injection molded, extruded, and planed samples were analyzed. The injection molded samples had more of a polymer influence at the surface than the extruded and planed samples. The planed samples exhibited a strong wood component as a result of removing polymer rich surface layer to expose the wood particles.

The higher processing pressures the molded samples experience result in a composite with a higher density than the extruded and planed samples. The higher density results in improved strengths over the extruded and planed samples through improved interfacial quality. 
The manufacturing method of wood-plastic composites greatly influences their durability. The molded samples have more of a polymer influence on the surface than the extruded and planed samples. This results in increased color fade for the extruded and planed samples in the initial stages of weathering, which is due to a bleaching of the wood fiber. However, after a sufficient weathering time period, the lightened degradation layer reaches deeper into the composite than the depth of the polymer rich layer. Therefore manufacturing method does not influence the total lightness of the composite after $3000 \mathrm{~h}$ of weathering.

The retention of flexural properties, however, is greatly influenced by processing method. Generally, the molded samples show an improved retention of flexural MOE and strength over extruded and planed samples after $3000 \mathrm{~h}$ of weathering. In addition, the extruded and planed samples lose a larger percentage of their total mechanical property loss during the first $1000 \mathrm{~h}$ of exposure than molded samples. This is likely due directly to the loss in properties due to moisture exposure. The planed samples provide a pathway for the absorption of moisture due to the strong hydrophilic wood characteristic at the surface.

\subsection{References}

1. M. DeFosse, "Wood Composites Are Expanding Among Sectors," Modern Plastics, 80(1), 25-30, 2003.

2. C. Clemons, "Wood-Plastic Composites in the United States, The Interfacing of Two Industries," Forest Products Journal, 52(6), 10-18, 2002.

3. T. Lundin, "Effect of Accelerated Weathering on the Physical and Mechanical Properties of Natural-Fiber Thermoplastic Composites," M.S. Thesis, University of Wisconsin-Madison, 2001.

4. R.H. Falk, T. Lundin and C. Felton, "The Effects of Weathering on WoodThermoplastic Composites Intended for Outdoor Applications," in Proceedings, 
Durability and Disaster Mitigation in Wood-Frame Housing, 175-179, Madison, WI, November 6, 2000.

5. N.M. Stark and L.M. Matuana, "Photostabilization of Wood Flour Filled HDPE Composites," in Proceedings, ANTEC, 2, 2209-2213, San Francisco, CA, May 5-9, 2002.

6. N.M. Stark and L.M. Matuana, "Ultraviolet Weathering of Photostabilized Wood Flour-HDPE Composites," accepted in Journal of Applied Polymer Science, February 2003.

7. L.M. Matuana, D.P. Kamdem and J. Zhang, "Photoaging and Stabilization of Rigid PVC/Wood-Fiber Composites," Journal of Applied Polymer Science, 80(11), 1943 1950, 2001.

8. L.M. Matuana and D.P. Kamdem, "Accelerated Ultraviolet Weathering of PVC/Wood-Flour Composites," Polymer Engineering and Science, 42(8), 1657 1666, 2002.

9. N.M. Stark and L.M. Matuana, "Structural and Mechanical Property Changes of Wood-Flour/HDPE Composites After Accelerated Weathering," submitted to Journal of Applied Polymer Science, August 2003.

10. S.-Y. Fu, X. Hu and C.-Y. Yue, "Effects of Fiber Length and Orientation Distributions on the Mechanical Properties of Short-Fiber-Reinforced Polymers," Materials Science Research International, 5(2), 74-83, 1999.

11. C.M. Clemons, D.F. Caulfield and A.J. Giacomin, "Dynamic Fracture Toughness of Cellulose-Fiber-Reinforced Polypropylene: Preliminary Investigation of Microstructural Effects," Journal of Elastomers and Plastics, 31(4), 367-378, 1999.

12. C.M. Clemons and R.E. Ibach, "The Effects of Processing Method and Moisture History on the Laboratory Fungal Resistance of Wood-HDPE Composites," submitted to Forest Products Journal, December 2002.

13. S.E. Barbosa and J.M. Kenny, "Processing of Short-Fiber Reinforced Polypropylene," Polymer Engineering and Science, 40(1), 11-22, 2000.

14. K. Joseph, S. Thomas and C. Pavithran, "Effect of Ageing on the Physical and Mechanical Properties of Sisal-Fiber-Reinforced Polyethylene Composites," Composites Science and Technology, 53(1), 99-110, 1995.

15. N. Stark, "Influence of Moisture Absorption on Mechanical Properties of Wood Flour-Polypropylene Composites," Journal of Thermoplastic Composites, 14(5), 421-432, 2001.

16. S.V. Rangaraj and L.V. Smith, "Effects of Moisture on the Durability of a Wood/Thermoplastic Composite," Journal of Thermoplastic Composite Materials, 13(3), 140-161, 2000.

17. Q. Lin, X. Zhou and G. Dai, "Effect of Hydrothermal Environment on Moisture Absorption and Mechanical Properties of Wood Flour-Filled Polypropylene Composites," Journal of Applied Polymer Science, 85(14), 2824-2832, 2002.

18. J.J. Balatinecz and B.D. Park, "The Effects of Temperature and Moisture Exposure on the Properties of Wood-Fiber Thermoplastic Composites," Journal of Thermoplastic Composite Materials, 10(9), 476-487, 1997.

19. S.A. Jabarin and E.A. Lofgren, "Photooxidative Effects of Properties and Structure of High-Density Polyethylene," Journal of Applied Polymer Science, 53(4), 411423, 1994. 
20. S.H. Hamid and M.B. Amin, "Lifetime Prediction of Polymers," Journal of Applied Polymer Science, 55(10), 1385-1394, 1995.

21. A. Torikai, H. Shirakawa, S. Nagaya and K. Fueki, "Photodegradation of Polyethylene: Factors Affecting Photostability," Journal of Applied Polymer Science, 40(9-10), 1637-1646, 1990.

22. A. Tidjani, "Comparison of Formation of Oxidation Products During PhotoOxidation of Linear Low Density Polyethylene Under Different Natural and Accelerated Weathering Conditions," Polymer Degradation and Stability, 68(3), 465-469, 2000.

23. C. David, M. Trojan, A. Daro and W. Demarteau, "Photodegradation of Polyethylene: Comparison of Various Photoinitiators in Natural Weathering Conditions," Polymer Degradation and Stability, 37(3), 233-245, 1992.

24. A. Tidjani, R. Arnaud and A. Dasilva, "Natural and Accelerated Photoaging of Linear Low-Density Polyethylene: Changes of the Elongation at Break," Journal of Applied Polymer Science, 47(2), 211-216, 1993.

25. J. Baeza and J. Freer, "Chemical Characterization of Wood and Its Components," in Wood and Cellulosic Chemistry, Chapter 8, 275-384, D.N.-S. Hon and N. Shiraishi, Eds, Marcel Dekker, Inc., New York, 2001.

26. X. Colom, F. Carrillo, F. Nogués, P. Garriga, "Structural Analysis of Photodegraded Wood by Means of FTIR Spectroscopy," Polymer Degradation and Stability, 80(3), 543-549, 2003.

27. K.K. Pandey, "A Study of Chemical Structure of Soft and Hardwood and Wood Polymers by FTIR Spectroscopy," Journal of Applied Polymer Science, 71(12), 1969-1975, 1999.

28. American Society for Testing and Materials, "D790 Standard Test Method for Flexural Properties of Unreinforced and Reinforced Plastics and Electrical Insulating Materials," in Annual Book of ASTM Standards, 8.01, 2000.

29. American Society for Testing and Materials, "D2565 Standard Practice for XenonArc Exposure of Plastics Intended for Outdoor Applications," in Annual Book of ASTM Standards, 8.02, 2000.

30. A.A. Marra, Technology of Wood Bonding, Van Nostrand Reinhold, New York, 1992.

31. D.N.-S. Hon and N. Minemura, "Color and Discoloration," in Wood and Cellulosic Chemistry, Chapter 9, 385-442, D.N.-S. Hon and N. Shiraishi, Eds, Marcel Dekker, Inc., New York, 2001. 


\section{Chapter 4 - Surface Chemistry Changes of Weathered WOOD FLOUR/HDPE COMPOSITES STUDIED BY XPS AND FTIR SPECTROSCOPY}

This chapter has been submitted to Polymer Degradation and Stability (July 2003). It is co-authored by N.M. Stark and L.M. Matuana. 


\subsection{Abstract}

Samples of $100 \%$ high-density polyethylene (HDPE) and HDPE filled with 50\% wood flour (WF) were weathered in a xenon arc-type accelerated weathering apparatus for $2000 \mathrm{~h}$. Changes in surface chemistry were studied using spectroscopic techniques. Xray photoelectron spectroscopy (XPS) was used to verify the occurrence of surface oxidation. Fourier transform infrared (FTIR) spectroscopy was used to monitor the development of degradation products, such as carbonyl groups and vinyl groups, and to determine changes in the HDPE crystallinity. The results indicate that surface oxidation occurs immediately after exposure for both the neat HDPE and WF/HDPE composites. However, the surface of the WF/HDPE composites is oxidized to a greater extent than the neat HDPE after weathering. This suggests that the addition of WF to HDPE matrix results in more weather related damage. The results also show that while neat HDPE may undergo cross-linking in the initial stages of accelerated weathering, the WF may physically hinder the ability of the HDPE to cross-link resulting in the potential for HDPE chain scission to dominate in the initial weathering stages of the WF/HDPE composites.

\subsection{Introduction}

Although inorganic fillers currently dominate the thermoplastic industry, the use of wood-derived fillers is growing. The growth has been fueled in part by the use of wood fiber thermoplastic composites (WTPC) in the non-structural (siding, roofing, etc.) or semi-structural (decking) construction market. This is apparent as WTPC make 
dramatic inroads into the residential decking market. In 2000, WTPC made up $8 \%$ of the decking market. This is projected to increase to $19 \%$ by 2005 (1). Other residential construction applications, such as windows, siding, and roof tiles are quickly entering the market or under development.

The use of WTPC by the construction industry has resulted in concern about the durability of WTPC exposed to outdoor environments. Of particular concern is the durability of WTPC after ultraviolet (UV) exposure. Scientists have begun to investigate the UV durability of WTPC (2-7). However the work that has been done with wood flour filled polyolefin composites has focused mainly on changes in appearance and mechanical properties (2-5). There has been little work that has provided insight into the surface chemistry changes of wood flour filled polyolefins after UV exposure.

The photodegradation of polyolefins is caused mainly by chromophores introduced during polymer manufacturing such as catalyst residues, hydroperoxide groups, carbonyl groups and double bonds (8). It has been postulated that carbonyl groups are the main light absorbing species responsible for the photochemical-induced degradation reactions of UV exposed polymers (9). The degradation reactions proceed from carbonyl group precursors according to Norrish type I and II reactions (9-10). If degradation of the carbonyl groups proceeds according to Norrish I, the resulting free radicals formed can attack the polyolefin (Fig. 4.1a). Which may lead to termination via either cross-linking or chain scission (10). If the degradation proceeds according to Norrish II, carbonyl groups and terminal vinyl groups are produced (Fig. 4.1b) and chain scission occurs. In addition, the carbonyl group formed is capable of further degradation. During the course of accelerated polyethylene photodegradation the two mechanisms, 
chain scission and cross-linking, are competing (9-11). While chain scission results in a lower molecular weight, cross-linking results in an increased molecular weight by increasing the bonding between polymer chains.

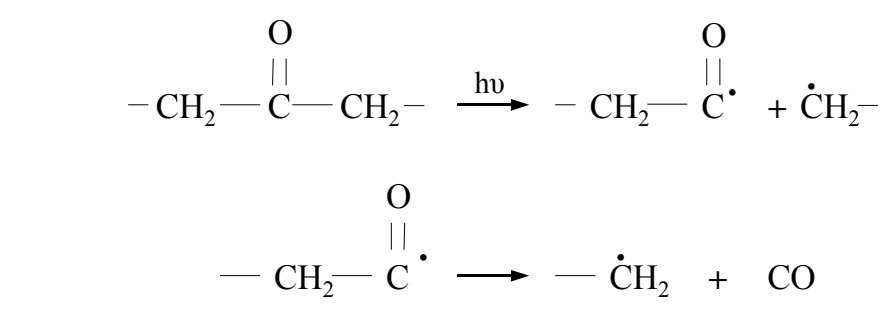

(4.1a) Norrish I

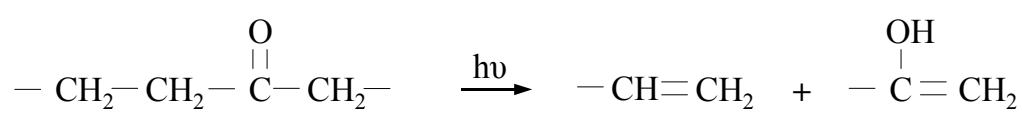

$$
\begin{aligned}
& \begin{array}{l}
\stackrel{\mathrm{OH}}{\mathrm{O}} \\
-\mathrm{C}=\mathrm{CH}_{2} \longrightarrow-\stackrel{\mathrm{I}}{\mathrm{C}}-\mathrm{CH}_{3}
\end{array}
\end{aligned}
$$

(4.1b) Norrish II

Figure 4.1. Norrish degradation mechanisms from carbonyl precursors: (a) Norrish I, and (b) Norrish II.

Ketones, carboxylic acids, and vinyl groups are the three major functional groups that accumulate as the photodegradation of polyethylene occurs (10). The formation of carbonyl groups and vinyl groups can be studied as a direct indication of main chain scission $(11,12)$. The weathering of polyethylene results in an increase in crystallinity (13), which also indicates that chain scission has occurred. The shorter chains produced during chain scission are more mobile and are able to crystallize more readily, resulting 
in an increased crystallization and associated embrittlement $(9,10)$. Contrarily, crosslinking does not affect polymer crystallinity.

Polyethylene is a semi-crystalline polymer. The packing of crystalline phase is much tighter than that of the amorphous phase and is impermeable to oxygen (8). Therefore the degradation reactions occur predominantly in the amorphous region and are controlled by the diffusion of oxygen in this region (10). While chain scission occurs in the amorphous phase of the polymer, UV induced cross-linking occurs in imperfect crystalline regions (14).

Recently Fourier Transform Infrared (FTIR) spectroscopy has been employed to study the changes in surface chemistry of polyethylene after weathering. Numerous papers have been published where FTIR spectroscopy was used to monitor carbonyl group formation $(9,11,12,14-17)$, vinyl group formation $(9,11,14)$, and changes in crystallinity $(13,18-21)$ of weathered polyethylene. X-ray photoelectron spectroscopy (XPS) has also been found useful to study the concentration of carbon to oxygen atoms of aged polyethylene $(22,23)$ and wood flour filled polyvinyl chloride (7).

In this study, XPS and FTIR spectroscopy were used to monitor the changes in surface chemistry of high-density polyethylene (HDPE) and wood flour (WF)/HDPE composites after accelerated weathering. In addition, crystallinity changes were also monitored using FTIR spectroscopy. Comparing surface chemistry changes of the neat HDPE samples to the WF/HDPE composites will allow for an understanding as to how the addition of wood flour to HDPE changes the mechanisms of UV degradation. 


\subsection{Methods}

\subsubsection{Materials}

The materials used in this study were WF and HDPE. The WF was a 40 mesh ponderosa pine supplied by American Wood Fibers (Schofield, WI). The HDPE was a virgin material with a melt index of $0.72 \mathrm{~g} / 10 \mathrm{~min}$ and density of $0.963 \mathrm{~g} / \mathrm{cm}^{3}$ supplied by Solvay Polymers, Inc. (Fortiflex A60-70-162, Houston, TX).

\subsubsection{Processing}

The HDPE samples were molded into flexural bar test samples using a 33-ton (30 metric tones) Cincinnati Milacron (Batavia, $\mathrm{OH}$ ) injection molder. The mold nozzle temperature was $204^{\circ} \mathrm{C}\left(400^{\circ} \mathrm{F}\right)$ and the injection pressure reached a peak of $12.4 \mathrm{MPa}$ (1800 psi). The American Society for Testing and Materials mold cavity used for the flexural samples is $120 \times 3 \times 12 \mathrm{~mm}(24)$.

The WF was dried for $24 \mathrm{~h}$ at $105^{\circ} \mathrm{C}\left(221^{\circ} \mathrm{F}\right)$, and then dry-blended with HDPE at $50 \%$ by weight. Compounding was accomplished using a 32-mm Davis Standard (Pawcatuck, CT) twin-screw extruder to produce homogeneous WF/HDPE composite pellets. The melt temperature at the die was $200^{\circ} \mathrm{C}\left(392^{\circ} \mathrm{F}\right)$ and the melt pressure was $2.96 \mathrm{MPa}(430 \mathrm{psi})$. The pellets were dried at $105^{\circ} \mathrm{C}\left(221^{\circ} \mathrm{F}\right)$ for at least $24 \mathrm{~h}$ prior to injection molding into flexural bar test samples. The injection molding conditions were the same as for the neat HDPE manufacture. 


\subsubsection{Testing and Analysis}

\section{Weathering}

Both the neat HDPE and WF/HDPE composite samples were placed in a xenon arc-type light-exposure apparatus and operated according to ASTM D2565 (25). Samples were mounted on a drum that rotated around the xenon arc lamp at $1 \mathrm{rpm}$, in four rows. The samples were rotated periodically to ensure that all samples were exposed to the same irradiance. The exposure cycle consisted of 108 minutes of light exposure and 12 minutes of simultaneous water spray and light exposure (25). Samples were removed after $250,500,1000$, and $2000 \mathrm{~h}$ of exposure for analysis.

\section{$\underline{\text { X-Ray Photoelectron Spectroscopy }}$}

X-ray photoelectron spectra were collected using a Leybold MAX-200 X-ray Photoelectron Spectrometer. Three types of spectra were collected, a survey spectra, a low resolution spectra from 0 to $1100 \mathrm{eV}$ binding energy, and a high resolution spectra of the $\mathrm{C}_{1 \mathrm{~s}}$ region from $280-300 \mathrm{eV}$. The samples were analyzed at a take-off angle of $90^{\circ}$. From the low-resolution spectra the ratio of elemental oxygen to carbon $(\mathrm{O} / \mathrm{C})$ was determined. To determine the types of oxygen-carbon bonds present, chemical bond analysis of carbon was accomplished by curve fitting the $\mathrm{C}_{1 \mathrm{~s}}$ peak from the highresolution spectra and deconvoluting it into 4 subpeaks corresponding to $\mathrm{C} 1, \mathrm{C} 2, \mathrm{C} 3$, and C4 using ESCA Tools (version 4.2, Mountain View, CA). An oxidized to unoxidized carbon ratio $\left(\mathrm{C}_{\mathrm{ox} / \mathrm{unox}}\right)$ was calculated using Equation 4.1 (6).

$$
C_{\text {ox/unox }}=\frac{C_{\text {oxidized }}}{C_{\text {unoxidized }}}=\frac{C 2+C 3+C 4}{C 1}
$$




\section{Fourier Transform Infrared Spectroscopy}

FTIR spectroscopy was conducted on a Mattson Genesis II spectrophotometer to provide a detailed knowledge of the functional groups present at the surface of the samples. Scans were run at a resolution of $4 \mathrm{~cm}^{-1}$. Each sample recorded consisted of 100 scans recorded in absorbance units from 4000-700 $\mathrm{cm}^{-1}$. The spectra were obtained using attenuated total reflectance (ATR). The surfaces of the samples analyzed were in contact with a $\mathrm{ZnSe}$ crystal that has a $45^{\circ}$ angle of incidence. Both carbonyl index and vinyl index were calculated using the following equations:

$$
\begin{gathered}
\text { Carbonyl Index }=\frac{I_{1715}}{I_{2912}} \times 100 \\
\text { Vinyl Index }=\frac{I_{908}}{I_{2912}} \times 100
\end{gathered}
$$

where I represents the peak intensity. The peak intensities were normalized using the peak at $2912 \mathrm{~cm}^{-1}$, which corresponds to methyl group vibrations.

The crystallinity of the HDPE was determined using the method described by Zerbi et al. (18). The doublet peaks observed at $1474-1464 \mathrm{~cm}^{-1}$ and $730-720 \mathrm{~cm}^{-1}$ correspond to polyethylene crystalline content $\left(1474 \mathrm{~cm}^{-1}\right.$ and $\left.730 \mathrm{~cm}^{-1}\right)$ and amorphous content $\left(1464 \mathrm{~cm}^{-1}\right.$ and $\left.720 \mathrm{~cm}^{-1}\right)$. The percentage of the crystalline content, $\mathrm{X}$, can be calculated using Equation 4.4 (18):

$$
X=100-\frac{\frac{1-I_{a} / I_{b}}{1.233}}{1+I_{a} / I_{b}} \times 100
$$


where $I_{a}$ and $I_{b}$ can be determined from the bands at either $1474 \mathrm{~cm}^{-1}$ and $1464 \mathrm{~cm}^{-1}$ or 730 $\mathrm{cm}^{-1}$ and $720 \mathrm{~cm}^{-1}$ respectively (18). Colom et al. (19) examined the crystallinity changes of aspen fiber filled HDPE composites using the FTIR method and differential scanning calorimetry (DSC). They determined that the bands at $730 \mathrm{~cm}^{-1}$ and $720 \mathrm{~cm}^{-1}$ were the most appropriate bands to study because a peak from cellulose fibers at $1430 \mathrm{~cm}^{-1}$ interferes with the $1474 \mathrm{~cm}^{-1}$ and $1464 \mathrm{~cm}^{-1}$ peaks (19). In addition Kaci et al. (13) studied the crystallinity changes of low-density polyethylene films after weathering using FTIR and DSC. They concluded that using the bands at $1474 \mathrm{~cm}^{-1}$ and $1464 \mathrm{~cm}^{-1}$ to determine crystallinity leads to unreliable results because they are asymmetric (13). In this paper, the crystallinity was calculated using the doublet peaks at $730 \mathrm{~cm}^{-1}$ and $720 \mathrm{~cm}^{-1}$.

\section{$\underline{\text { Statistics }}$}

Statistical analysis was conducted on the FTIR data to determine the significance of the changes in carbonyl index, vinyl index, and crystallinity after weathering. Five replicate samples were analyzed and an average and standard deviation were calculated to represent the data. In addition, significant changes between the exposed and unexposed samples were determined by conducting a One-tail t-test assuming equal variance at a level of $\alpha=0.05$. 


\subsection{Results and Discussion}

\subsubsection{X-Ray Photoelectron Spectroscopy}

A low-resolution scan was run to determine the percentages of the elements present at the surface. The relative elemental compositions of the samples are presented in Table 4.1. The main elements detected using XPS were oxygen and carbon. Small amounts of sodium, nitrogen, and silicon were also detected possibly arising from the additives introduced during polymer manufacturing or contamination during sample preparation. An oxygen to carbon $(\mathrm{O} / \mathrm{C})$ atomic ratio was calculated as an initial indication of surface oxidation. The $\mathrm{O} / \mathrm{C}$ ratio was slightly higher for the unexposed WF/HDPE samples than for the HDPE samples. This is primarily due to the hydroxyl and some carbonyl groups present in the wood flour. An increase in the concentration of oxygen atoms occurred after weathering. As a result, after $2000 \mathrm{~h}$ of weathering the $\mathrm{O} / \mathrm{C}$ ratio increased for both the neat HDPE and WF/HDPE samples, indicating that the surface of the material had oxidized.

Table 4.1. The relative amount of atoms present at the surface of the sample determined using low-resolution XPS scan and the calculated oxygen-to-carbon atomic ratio.

\begin{tabular}{ccccc}
\hline Elements & \multicolumn{2}{c}{ HDPE } & \multicolumn{2}{c}{ WF/HDPE } \\
& $0 \mathrm{Hr}$ & $2000 \mathrm{Hrs}$ & $0 \mathrm{Hr}$ & $2000 \mathrm{Hrs}$ \\
\hline $\mathrm{Na}$ & 0.58 & 0.29 & 0.57 & 0.00 \\
$\mathrm{O}$ & 13.28 & 25.44 & 14.12 & 29.99 \\
$\mathrm{~N}$ & 1.41 & 1.26 & 1.07 & 0.62 \\
$\mathrm{C}$ & 82.96 & 63.63 & 82.59 & 66.67 \\
$\mathrm{Si}$ & 1.78 & 9.38 & 1.64 & 2.71 \\
\hline $\mathrm{O} / \mathrm{C}$ & 0.160 & 0.400 & 0.171 & 0.450 \\
\hline
\end{tabular}


A high-resolution scan was conducted on the $\mathrm{C}_{1 \mathrm{~s}}$ region for each unexposed sample and for each sample weathered for $2000 \mathrm{~h}$ to determine the types and amounts of carbon-oxygen bonds present. The $\mathrm{C}_{1 \mathrm{~s}}$ peak was deconvoluted into four subpeaks, corresponding to $\mathrm{C} 1, \mathrm{C} 2, \mathrm{C} 3$, and $\mathrm{C} 4$. The theoretical binding energy and corresponding bond type are shown in Table 4.2. The $\mathrm{C} 1$ bond does not consist of carbon bonded to oxygen, while $\mathrm{C} 2, \mathrm{C} 3$, and $\mathrm{C} 4$ all posses a carbon-oxygen bond. The corresponding graphs and deconvolution peaks for the unexposed and exposed neat HDPE and WF/HDPE samples are presented in Figures 4.2 and 4.3, respectively. A drop in the C1 peak height is clearly seen for the neat HDPE samples weathered for $2000 \mathrm{~h}$ (Fig. 4.2), indicating a decreased concentration of unoxidized carbon atoms. This drop was even more apparent for the WF/HDPE composites. As illustrated in Figure 4.3, the peak intensity corresponding to $\mathrm{C} 1$ decreased dramatically while an increase in $\mathrm{C} 2$ was observed as a shoulder peak. This trend implied that surface oxidation has occurred. To quantify the degree of surface oxidation, the area under each peak was integrated and an oxidixed to unoxidized carbon $\left(\mathrm{C}_{\mathrm{ox} / \mathrm{unox}}\right)$ ratio was calculated (Eqn 4.1). These results are presented in Table 4.3.

Table 4.2. Deconvoluted peak assignments with corresponding theoretical binding energy and bond type for a high-resolution XPS scan of the $\mathrm{C}_{1 \mathrm{~s}}$ region.

\begin{tabular}{ccc} 
Carbon Group & Binding Energy $(\mathrm{eV})$ & Bond \\
\hline C1 & 285 & C-C or C-H \\
C2 & 286.5 & C-OH \\
C3 & 288 & O-C-O or C $=\mathrm{O}$ \\
C4 & 289.5 & O-C $=\mathrm{O}$ \\
\hline
\end{tabular}




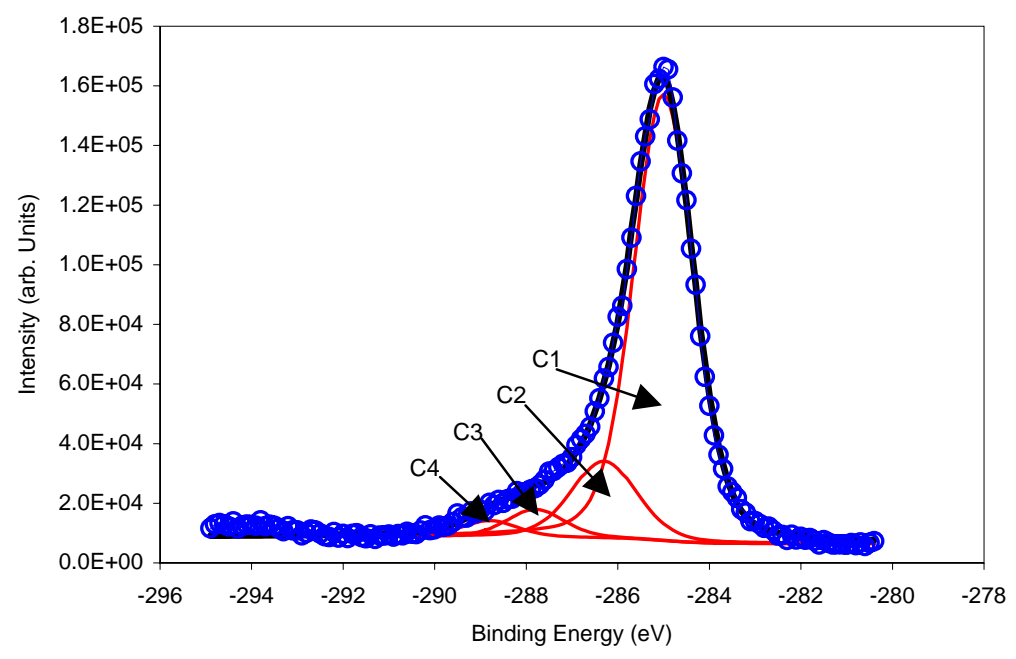

$(4.2 \mathrm{a})$

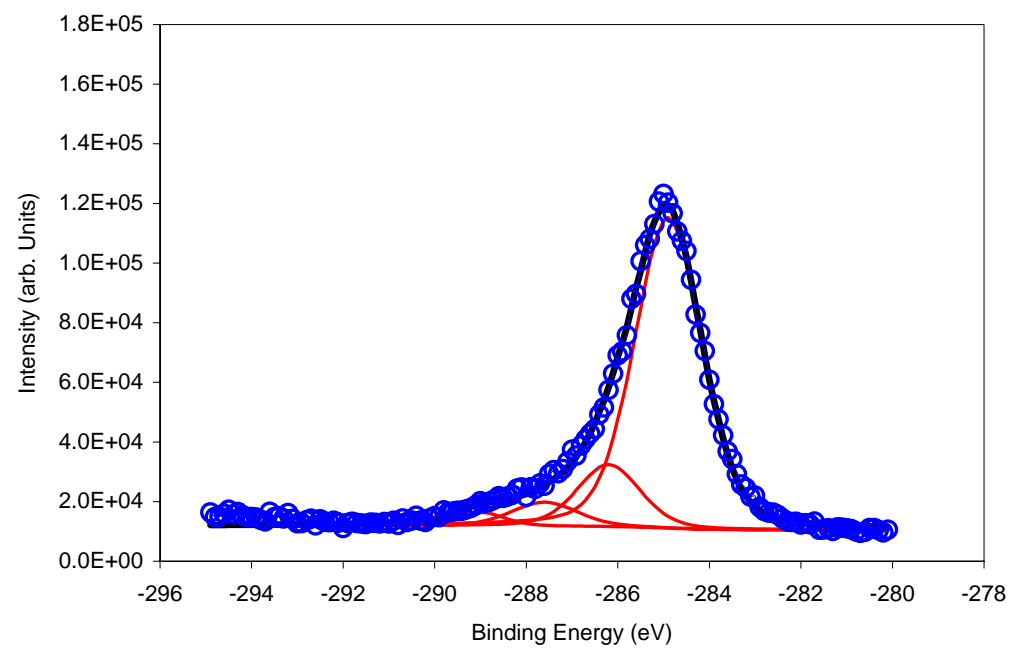

Figure 4.2. XPS Scan of $\mathrm{C}_{1 \mathrm{~s}}$ region for neat HDPE: (a) unexposed samples and (b) samples subjected to $2000 \mathrm{hrs}$ UV/water spray cyclic exposures.

Differences in the oxidized-to-unoxidized carbon ratio for the unweathered samples $(0 \mathrm{hr})$ were apparent (Table 4.3). The addition of WF into HDPE matrix increased the concentration of carbon-oxygen bonds $(\mathrm{C} 2+\mathrm{C} 3+\mathrm{C} 4)$ in the samples. This was expected since the major components of wood, i.e., cellulose, hemicelluloses, and 
lignin, have a larger percentage of oxidized carbon in their chemical structure than manufactured neat HDPE. Hydroxyl groups are the main carbon-oxygen functional group present in wood (26). This is most evident as a larger $\mathrm{C} 2$ value for the WF/HDPE composites than the neat HDPE before weathering (Table 4.3).

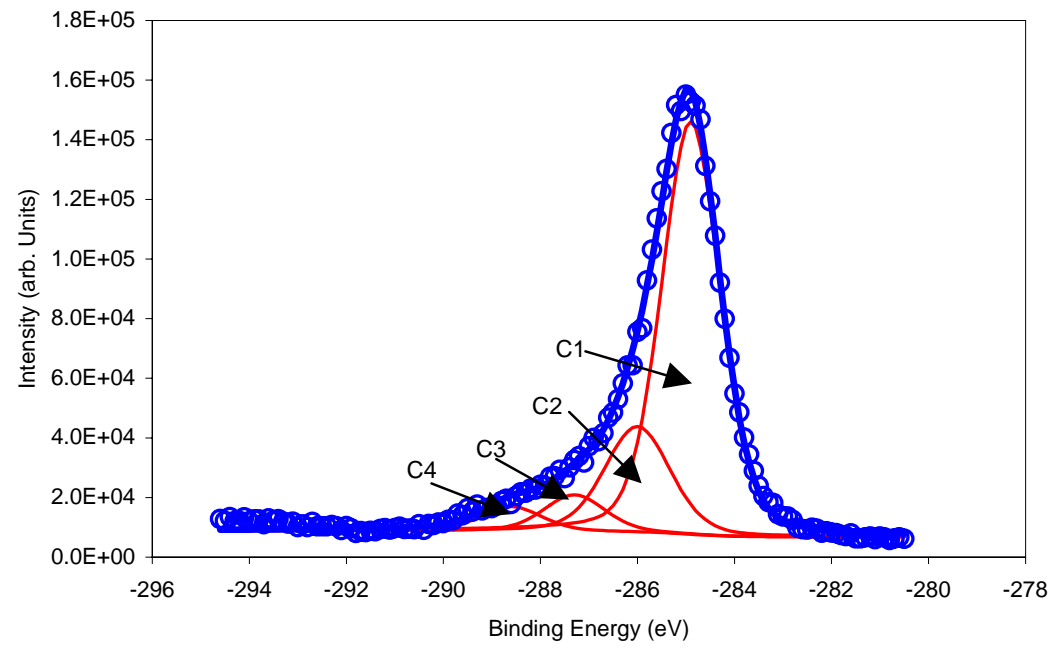

(4.3a)

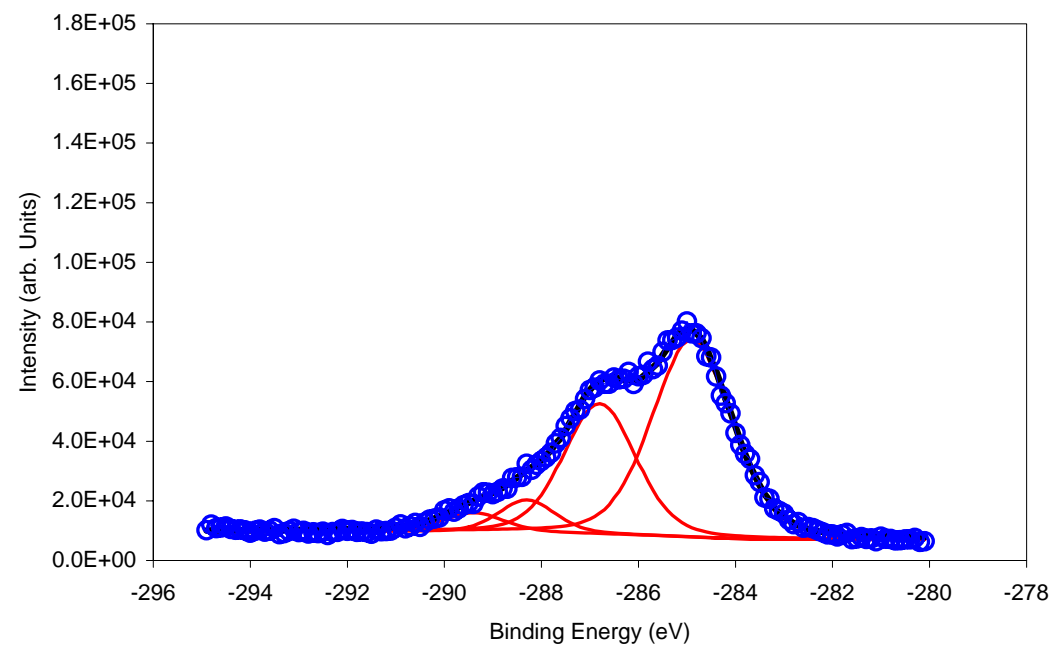

$(4.3 b)$

Figure 4.3. XPS Scan of $\mathrm{C}_{1 \mathrm{~s}}$ region for $\mathrm{WF} / \mathrm{HDPE}$ composites: (a) unexposed samples and (b) samples subjected to $2000 \mathrm{hrs} \mathrm{UV/water} \mathrm{spray}$ cyclic exposures. 
Table 4.3. The relative amount of different carbon-to-oxygen bonds present at the surface of the sample determined using high-resolution XPS.

\begin{tabular}{ccccc}
\hline & \multicolumn{2}{c}{ HDPE } & \multicolumn{2}{c}{ WF/HDPE } \\
& $0 \mathrm{Hr}$ & $2000 \mathrm{Hrs}$ & $0 \mathrm{Hr}$ & $2000 \mathrm{Hrs}$ \\
\hline $\mathrm{C} 1$ & 78.01 & 77.23 & 69.54 & 55.85 \\
$\mathrm{C} 2$ & 14.74 & 15.55 & 19.9 & 33.49 \\
$\mathrm{C} 3$ & 4.63 & 5.08 & 6.34 & 6.52 \\
$\mathrm{C} 4$ & 2.62 & 2.14 & 4.22 & 4.14 \\
$\mathrm{C}_{\text {ox/unox }}$ & 0.282 & 0.295 & 0.438 & 0.791 \\
\hline
\end{tabular}

As expected, weathering has significantly increased the oxidized-to-unoxidized carbon ratio $\left(\mathrm{C}_{\mathrm{ox} / \mathrm{unox}}\right)$ for both neat HDPE and WF/HDPE composite (Table 4.3), proving that substantial surface oxidation has occurred after $2000 \mathrm{~h}$. The increase in the oxidized to unoxidized carbon ratio for both the neat HDPE and the WF/HDPE composites appears to be mainly due to an increase in hydroxyl groups (i.e., increase in C2). These results confirm the trend observed with the low-resolution data, which showed an increase in elemental oxidation $(\mathrm{O} / \mathrm{C}$ ratio) after weathering (Table 4.1). It should also be mentioned that surface oxidation due to weathering was more pronounced for the WF/HDPE composite samples than for the pure HDPE samples. The $\mathrm{C}_{\mathrm{ox} / \mathrm{unox}}$ ratio increased dramatically for WF/HDPE composites after weathering, resulting in an $80 \%$ increase versus a $5 \%$ increase for neat HDPE samples suggesting that the addition of WF into HDPE matrix exacerbates the photo-oxidation of the surface of the sample. The surface of the entire composite sample was analyzed for oxidation. These methods cannot differentiate between oxidation of the HDPE or the WF independently.

\subsubsection{Fourier Transform Infrared Spectroscopy}

FTIR spectroscopy was used to verify the occurrence of surface oxidation of the samples through the investigation of a carbonyl group change. In addition, structural 
changes in the matrix after weathering were investigated by following vinyl group formation and crystallinity changes of both HDPE and WF/HDPE composite samples. Table 4.4 shows the peaks monitored with their corresponding functional groups and vibrational types. Figure 4.4 gives an example of the carbonyl band shape and location after exposure to various weathering times for WF/HDPE composite samples. In the carbonyl region $\left(1750 \mathrm{~cm}^{-1}-1700 \mathrm{~cm}^{-1}\right)$ a sharp peak formed at $1715 \mathrm{~cm}^{-1}$ with a shoulder peak at $1735 \mathrm{~cm}^{-1}$ corresponding carboxylic acid and ester groups, respectively (11). Figures 4.5-4.7 summarize the FTIR results for both HDPE and WF/HDPE composite samples.

Table 4.4. Wavenumbers of the peaks used for FTIR analysis and the corresponding functional groups and vibrational types $(9,21)$.

\begin{tabular}{ccc}
\hline $\begin{array}{c}\text { Wavenumber } \\
\left(\mathrm{cm}^{-1}\right)\end{array}$ & Functional Group & Vibrational Type \\
\hline 2912 & $-\mathrm{CH}_{2}-$ & $\mathrm{C}-\mathrm{H}$ stretching \\
1715 & $\mathrm{R}(\mathrm{C}=\mathrm{O}) \mathrm{OH}$ & $\mathrm{C}=\mathrm{O}$ stretching \\
1474 & $-\mathrm{CH}_{2-}$ & $\mathrm{C}-\mathrm{H}$ bending, crystalline \\
1464 & $-\mathrm{CH}_{2-}$ & $\mathrm{C}-\mathrm{H}$ bending, amorphous \\
908 & $\mathrm{RCH}=\mathrm{CH}_{2}$ & $\mathrm{C}-\mathrm{CH}_{2}$ out of plane bending \\
730 & $-\mathrm{CH}_{2-}$ & $\mathrm{C}-\mathrm{H}$ rocking, crystalline \\
720 & $-\mathrm{CH}_{2-}$ & $\mathrm{C}-\mathrm{H}$ rocking, amorphous \\
\hline
\end{tabular}

\section{Carbonyl Group Formation}

The increase in carbonyl group concentration (Eq. 4.2) over exposure time is plotted in Figure 4.5. Initially, the carbonyl index was higher for WF/HDPE samples than the pure HDPE composite samples. This supports the XPS data, as the addition of WF into the HDPE matrix increases the amount of oxygen in the sample including carbonyl functionality. As the exposure time increased, the carbonyl index increased at approximately the same rate for WF/HDPE composite samples and neat HDPE samples. 
The increase in carbonyl group formation for polyethylene after weathering is known to be proportional to the number of chain scissions that occurs in the polyethylene (10). Our results indicate that chain scission may have occurred immediately upon exposure, and that the number of chain scissions increases with increasing exposure time (Fig. 4.5).
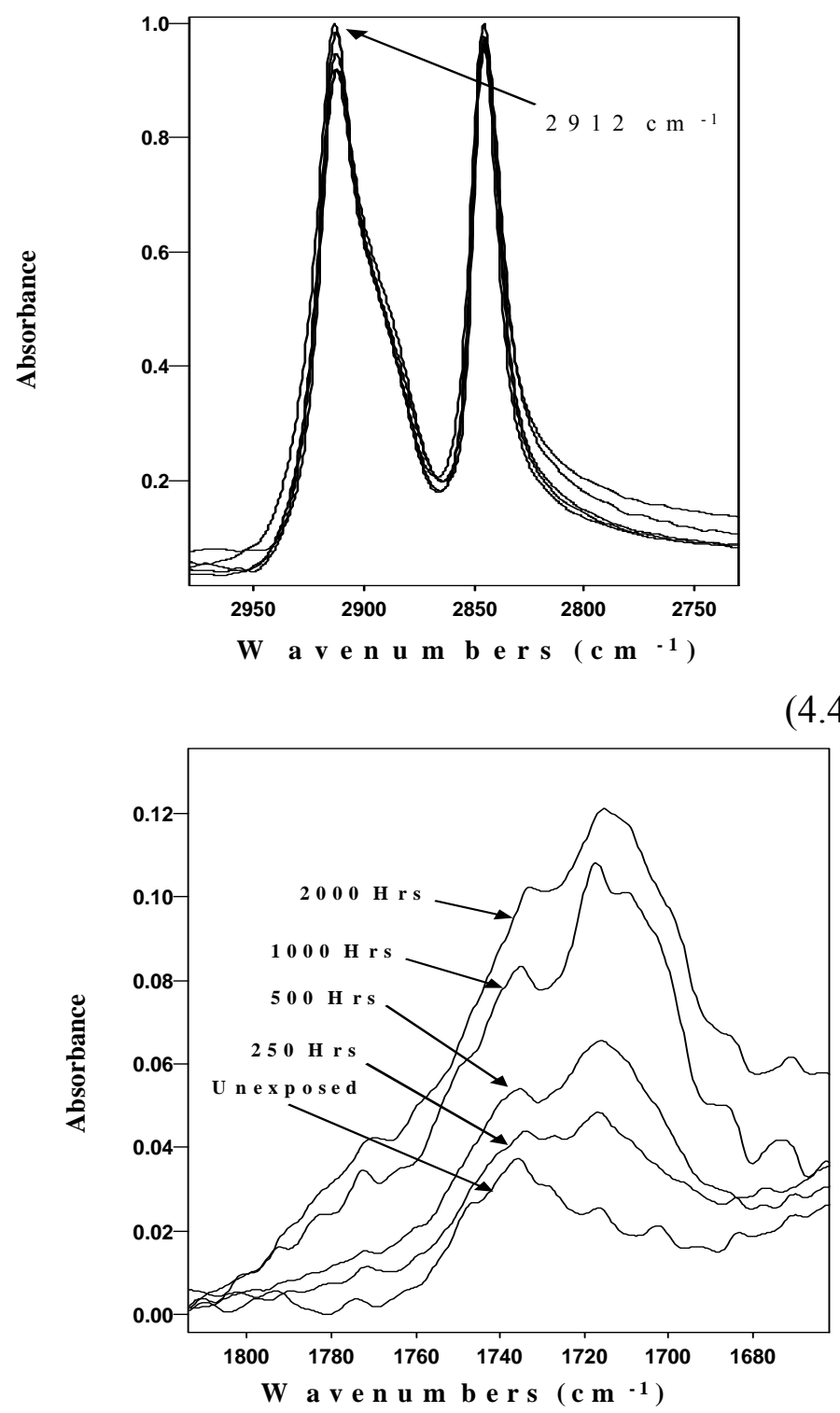

Figure 4.4. Size, shape and location of FTIR spectra of WF/HDPE composite samples exposed to various weathering times: (a) methyl group and (b) carbonyl group region. 


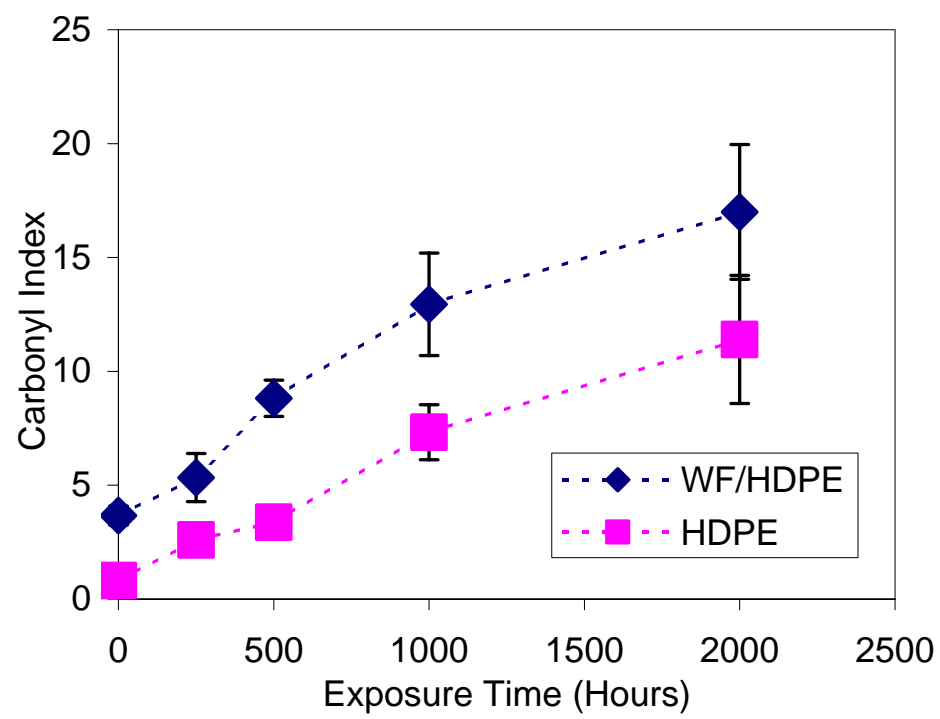

Figure 4.5. Carbonyl group formation versus exposure time for both neat HDPE and WF/HDPE composite samples. An outlined symbol indicates that the data point at that exposure level was not significantly different from the data point corresponding to the unexposed sample.

\section{Vinyl Group Formation}

Like carbonyl group formation, vinyl group formation is also an indication of polymer chain scission (9) of either the HDPE or WF, which occurs solely as a result of carbonyl degradation via Norrish II. Figure 4.6 shows the increase in vinyl groups concentrations based on the peak at $908 \mathrm{~cm}^{-1}$. The concentration of vinyl groups is generally much larger for the neat HDPE than the WF/HDPE composite samples. This suggests that vinyl group formation may be important only for the degradation of the polymer, and not of the wood.

There was no significant vinyl group formation during exposure of pure HDPE through the initial $250 \mathrm{~h}$ (Fig. 4.6). After $250 \mathrm{~h}$ the vinyl group formation significantly increased with UV exposure time and leveled off after $1000 \mathrm{~h}$. Other investigators have also found an initial delay in vinyl group formation in the early stages of naturally 
weathered HDPE (9), followed by a steep increase as weathering progressed. The plateau experienced in the production of vinyl groups at longer exposure times (1000-2000 h) is thought to be due to degradation via the Norrish type II mechanism, where degradation causes vinyl groups to be the major products in the first stage, followed by a slower conversion to carbonyl groups (9).

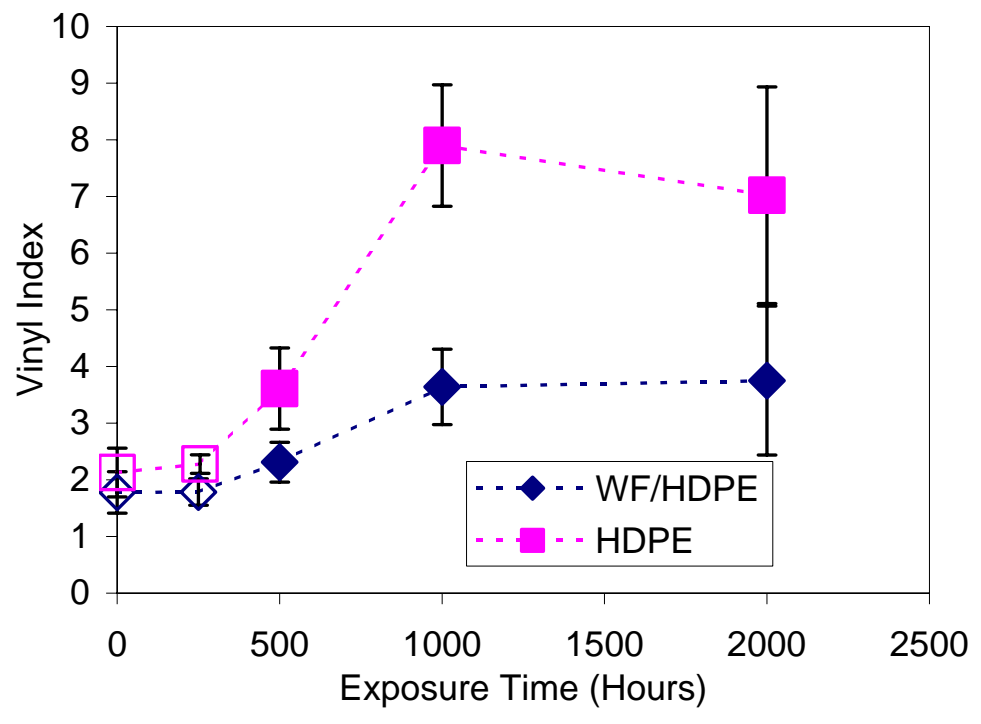

Figure 4.6. Vinyl group formation versus exposure time for both neat HDPE and WF/HDPE composite samples. An outlined symbol indicates that the data point at that exposure level was not significantly different from the data point corresponding to the unexposed sample.

Similarly, for WF/HDPE composites the vinyl group concentration was not significantly larger than that of the unexposed sample through $250 \mathrm{~h}$ of exposure, followed by an increase in concentration through $1000 \mathrm{~h}$. Again the concentration appeared to remain level between 1000 and $2000 \mathrm{~h}$ of exposure. The change in vinyl group concentration is though to be due mainly to degradation of the HDPE matrix as a component of WF/HDPE composites. 


\section{Crystallinity Changes}

The addition of WF to a HDPE matrix changes the crystallinity of the HDPE. The crystallinity of the HDPE in the unweathered samples was higher for neat HDPE samples than the WF/HDPE composites (Fig. 4.7). Although wood fiber can act as nucleating sites for crystallization, the wood fiber has been found to physically hinder crystal growth, resulting in lower polymer crystallinity (27). Colom et al. (19) studied the changes in crystallinity of aspen fiber filled HDPE matrix and reported that increasing the fiber content from 10 to $40 \%$ decreased the matrix crystallinity (19). Similar effect has also been shown in sisal fiber/polypropylene composites. When the sisal content is low $(<20 \%)$, the sisal fiber acts as a nucleating site resulting in an increased crystallinity. However, when the sisal content is above $20 \%$ the crystallinity decreases as the fibers begin to hinder the molecular motion of polypropylene and retard crystallization (27).

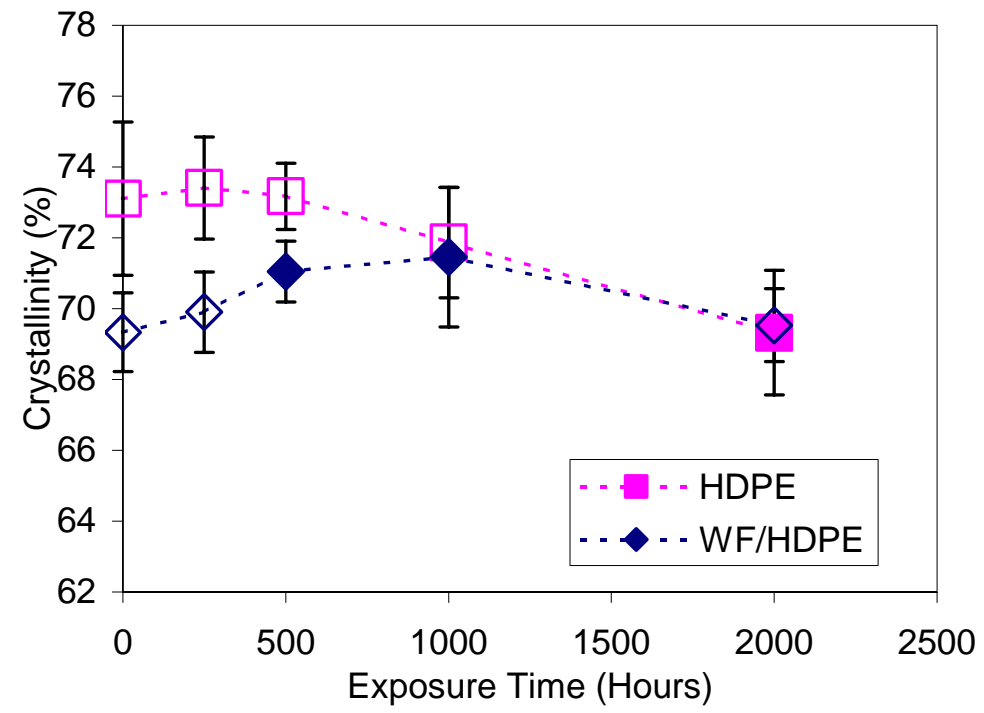

Figure 4.7. Crystallinity versus exposure time for both neat HDPE and WF/HDPE composite samples. An outlined symbol indicates that the data point at that exposure level was not significantly different from the data point corresponding to the unexposed sample. 
Crystallinity increases can also be used as an indicator of polyethylene chain scission during photodegradation. Chain scissions resulting from degradation via Norrish I and II reactions reduce the density of the entanglements in the amorphous phase allowing shorter molecules to crystallize due to higher mobility (9). Therefore secondary crystallization takes place in the amorphous phase of polyethylene. The effect of UV exposure time on the crystallinity of the neat HDPE and WF/HDPE composites is shown in Figure 4.7. As the samples undergo photodegradation, differences in crystallinity changes of the neat HDPE samples and WF/HDPE composite samples become apparent. The crystallinity of the HDPE appears to remain constant through $500 \mathrm{~h}$ at which point it begins to decrease, resulting in a significant decrease at 2000 h (Fig. 4.7). Alternatively, the crystallinity of HDPE matrix in the WF/HDPE composite increases with increasing exposure time through $1000 \mathrm{~h}$ at which point the crystallinity drops (Fig. 4.7).

Because chain scission has occurred during exposure, as evidenced by the growth of carbonyl and vinyl groups, it is expected that the crystallinity would increase. Indeed others have found increases in crystallinity after weathering. Kaci et al. (13) determined the crystallinity of low-density polyethylene using FTIR after natural weathering. They reported that the crystallinity increases with increasing exposure time until a plateau is reached after 400 days, and attributed this to secondary crystallization in the amorphous phase (13).

While chain scission may be an important mode of polyethylene degradation, crosslinking begins to predominate as the temperature increases $(10,12)$. In accelerated weathering, the temperatures are elevated above that of the exposure temperatures of natural weathering. Hamid et al. (14) studied both natural and accelerated weathering of 
LDPE. They concluded that the cross-linking and chain scission reactions take place simultaneously. Tidjani (11) adds that under accelerated weathering, cross-linking reactions occur that reduce the concentration of free radicals taking part in the oxidation process. Oxidation damage can also occur at the tie molecule region. Tie molecules are polymer molecules that a part of a folded crystalline region and extend through an amorphous region into another crystalline region. It has been shown that a small amount of oxidation products in polyethylene can cause great damage to the tie molecules (17), resulting in a breakdown of crystallization.

However, the WF/HDPE composite did experience an increase in crystallinity due to chain scission, rather than a decrease in crystallinity and cross-linking, which was the preferred method for neat HDPE degradation. While we do not know the reasons for this difference in the degradation mechanism, we believe that the WF particles may physically hinder cross-linking in the composite during the initial stages of accelerated weathering. This would allow for more chain scission, and a corresponding increase in crystallinity. As with the unfilled HDPE samples, chain scission in the HDPE matrix of the composite eventually affects the tie molecules, and the crystallinity is decreased.

\subsection{Summary and Conclusions}

Both XPS and FTIR spectroscopy can be used to effectively study the surface oxidation of weathered WF/HDPE composites. A low-resolution XPS scan quickly demonstrated that the concentration of oxygen atoms was increasing at the surface of both the HDPE samples and WF/HDPE samples after $2000 \mathrm{~h}$ of weathering. A highresolution scan was used to determine the types and amounts of carbon-oxygen bonds 
formed after $2000 \mathrm{~h}$ of weathering. Through the calculation of an oxidized-to-unoxidized carbon ratio, the results point toward an increase in oxidized carbon atoms. In addition, the oxidized-to-unoxidized carbon ratio increased dramatically more for the WF/HDPE composites versus unfilled HDPE ( $80 \%$ versus $5 \%$, respectively). This is evidence of the damaging effect of adding wood to HDPE, effectively increasing the surface oxidation of the composite samples after weathering.

FTIR spectroscopy was used to determine the carbonyl group formation, vinyl group formation, and crystallinity changes of the samples during weathering. An increase in the calculated carbonyl index denotes an increase in polymer chain scission. Initially, the carbonyl index is higher for the WF/HDPE composite samples but increases at approximately the same rate for the WF/HDPE composite and neat HDPE samples. The calculated vinyl group index can also be used to indicate polymer chain scission. The vinyl index remains constant through $250 \mathrm{~h}$ of exposure time, increases through $1000 \mathrm{~h}$, and then reaches a plateau for both WF/HDPE composite and neat HDPE samples. The concentration of vinyl groups is much larger for neat HDPE than WF/HDPE composites, suggesting that vinyl group formation takes place mainly in the polymer component of the composite. Increases in the matrix crystallinity can occur if chain scission occurs. The shorter, more mobile chains recrystallize in the amorphous phase of the polymer. Our data show differences between the crystallinity changes for neat HDPE and WF/HDPE composites. The crystallinity of the HDPE samples remains statistically unchanged through $1000 \mathrm{~h}$ of exposure after which time it decreases. Conversely, the crystallinity of the HDPE matrix in the WF/HDPE composites increases with exposure time through $1000 \mathrm{~h}$ before experiencing a drop. 
The neat HDPE samples may be undergoing cross-linking predominantly versus chain scission during the initial stages of accelerated weathering. This would be the result of Norrish I degradation mechanism favored over Norrish II (Fig. 4.1). The free radicals produced during Norrish I are free to react with free radicals on other chains to terminate and cross-link the polymer chains. While there is some chain scission occurring initially, the delay in vinyl group formation suggests that the Norrish II degradation mechanism is not as important until later stages in weathering. The favoring of cross-linking over chain scission results in no change in overall crystallinity. However, as the exposure increases the vinyl group formation increases, confirming an increase in polymer chain scission. The chain scissions begin to affect the tie molecules, resulting in a net decrease in crystallinity.

The WF/HDPE composite initially has a higher surface oxygen concentration over unfilled HDPE due to the hydroxyl groups on the wood surface. The rate of carbonyl group formation is similar for the WF/HDPE composites and unfilled HDPE samples. This suggests that each component of the WF/HDPE composite is oxidizing. While the initial crystallinity in the polymer matrix of the WF/HDPE composite is lower than the crystallinity of the neat HDPE due to the wood fiber hindering crystal growth, the crystallinity increases through $1000 \mathrm{~h}$ of exposure time. At $2000 \mathrm{~h}$ of exposure time the crystallinity has dropped off somewhat. This implies that chain scission in the polymer phase may predominate over cross-linking almost immediately. This may be a result of the wood fiber hindering cross-linking of the matrix as well as crystal growth. 


\subsection{References}

1. P. Smith, "WPC Product/Market Opportunities," in Proceedings, Progress in Wood Fiber-Plastic Composites, Toronto, Canada, May 23-24, 2002.

2. T. Lundin, "Effect of Accelerated Weathering on the Physical and Mechanical Properties of Natural Fiber Thermoplastic Composites," M.S. Thesis, University of Wisconsin-Madison, 2001.

3. R.H. Falk, C. Felton and T. Lundin, "Effects of Weathering on Color Loss of Natural Fiber-Thermoplastic Composites," in Proceedings, $3^{\text {rd }}$ International Symposium on Natural Polymers and Composites, 382-385, São Paulo, Brazil, May 14-17, 2000.

4. R.M. Rowell, S.E. Lange and R.E. Jacobson, "Weathering Performance of PlantFiber/Thermoplastic Composites," Molecular Crystals and Liquid Crystals, 353, 85-94, 2000.

5. N.M. Stark and L.M. Matuana, "Ultraviolet Weathering of Photostabilized Wood Flour-HDPE Composites," accepted in Journal of Applied Polymer Science, February 2003.

6. L.M. Matuana, D.P. Kamdem and J. Zhang, "Photoaging and Stabilization of Rigid PVC/Wood-Fiber Composites," Journal of Applied Polymer Science, 80(11), 19431950, 2001.

7. L.M. Matuana and D.P. Kamdem, "Accelerated Ultraviolet Weathering of PVC/Wood-Flour Composites," Polymer Engineering and Science, 42(8), 1657 1666, 2002.

8. F. Gugumus, "Light Stabilizers," in Plastics Additives Handbook, Chapter 3, 129262, R. Gächter and H. Müller, Eds., Hanser Publishers, New York, 1990.

9. S.A. Jabarin and E. A. Lofgren, "Photooxidative Effects on Properties and Structure of High-Density Polyethylene," Journal of Applied Polymer Science, 53(4), 411423, 1994.

10. G. Wypych, Handbook of Material Weathering, ChemTec Publishing, TorontoScarborough, 1995.

11. A. Tidjani, "Comparison of Formation of Oxidation Products During PhotoOxidation of Linear Low Density Polyethylene Under Different Natural and Accelerated Weathering Conditions," Polymer Degradation and Stability, 68(3), 465-469, 2000.

12. C. David, M. Trojan, A. Daro and W. Demarteau, "Photodegradation of polyethylene: Comparison of Various Photoinitiators in Natural Weathering Conditions," Polymer Degradation and Stability, 37(3), 233-245, 1992.

13. M. Kaci, T. Sadoun and S. Cimmino, "Crystallinity Measurements of Unstabilized and HALS-Stabilized LDPE Films Exposed to Natural Weathering by FT-IR, DSC, and WAXS Analyses," International Journal Polymer and Analytical Characterization, 6(5), 455-464, 2001.

14. S.H. Hamid and M.B. Amin, "Lifetime Prediction of Polymers," Journal of Applied Polymer Science, 55(1), 1385-1394, 1995. 
15. A. Tidjani, R. Arnaud and A. Dasilva, "Natural and Accelerated Photoaging of Low-Density Polyethylene: Changes of the Elongation at Break," Journal of Applied Polymer Science, 47(2), 211-216, 1993.

16. P. Gijsman and A. Dozeman, "Comparison of the UV-Degradation Chemistry of Unstabilized and HALS-Stabililzed Polyethylene and Polypropylene," Polymer Degradation and Stability, 53(1), 45-50, 1996.

17. A. Torikai, H. Shirakawa, S. Nagaya and K. Fueki, "Photodegradation of Polyethylene: Factors Affecting Photostability," Journal of Applied Polymer Science, 40(9-10), 1637-1646, 1990.

18. G. Zerbi, G. Gallino, N. Del Fanti and L. Baini, "Structural Depth Profiling in Polyethylene Films by Multiple Internal Reflection Infra-Red Spectroscopy," Polymer, 30(12), 2324-2327, 1989.

19. X. Colom, J. Canavate, P. Pagès, J. Saurina and F. Carrasco, "Changes in Crystallinity of the HDPE Matrix in Composites with Cellulosic Fiber Using DSC and FTIR," Journal of Reinforced Plastics and Composites, 19(10), 818-830, 2000.

20. W. Camacho and S. Karlsson, "Simultaneous Determination of Molecular Weight and Crystallinity of Recycled HDPE by Infrared Spectroscopy and Multivariate Calibration," Journal of Applied Polymer Science, 85(2), 321-327, 2002.

21. P. Pagès, F. Carrasco, J. Saurina and X. Colom, "FTIR and DSC study of HDPE Structural Changes and Mechanical Properties Variation When Exposed to Weathering Aging During Canadian Winter," Journal of Applied Polymer Science, 60(2), 153-159, 1996.

22. M.A. Maatoug, P. Anna, G. Bertalan, I. Ravadits, G. Marosi, I. Csontos, A. Márton and A. Tóth, "Role of Pigments in the Stability of Polyethylene Systems," Macromolecular Materials Engineering, 282(9), 30-36, 2000.

23. I. Banik, K.S. Kim, Y.I. Yun, D.H. Kim, C.M. Ryu and C.E. Park, "Inhibition of Aging in Plasma-Treated High-Density Polyethylene," Journal of Adhesion Science and Technology, 16(9), 1155-1169, 2002.

24. American Society for Testing and Materials, "D790 Standard Test Method for Flexural Properties of Unreinforced and Reinforced Plastics and Electrical Insulating Materials," in Annual Book of ASTM Standards, 8.01, 2000.

25. American Society for Testing and Materials, "D2565 Standard Practice for XenonArc Exposure of Plastics Intended for Outdoor Applications," in Annual Book of ASTM Standards, 8.02, 2000.

26. D.N.-S. Hon, "Weathering and Photochemistry of Wood," in Wood and Cellulosic Chemistry, Chapter 11, 513-546, D.N.-S. Hon and N. Shiraishi, Eds, Marcel Dekker, Inc., New York, 2001.

27. X.L. Xie, R.K.Y. Li, S.C. Tjong and Y.-W. Mai, "Structural Properties and Mechanical Behavior of Injection Molded Composites of Polypropylene and Sisal Fiber," Polymer Composites, 23(3), 319-328, 2002. 


\section{Chapter 5 - Ultraviolet Weathering OF PhOtostabilized WOOD FLOUR/HDPE COMPOSITES}

This chapter is in press, Journal of Applied Polymer Science (February 2003). It is coauthored by N.M. Stark and L.M. Matuana. 


\subsection{Abstract}

Ultraviolet exposure of wood-plastic composites can lead to photodegradation, resulting in a change in appearance and/or mechanical properties. Photodegradation can be slowed through the addition of photostabilizers. This study examines the performance of wood flour/high-density polyethylene composites after accelerated weathering. Two $2^{4}$ factorial experimental designs were used to determine the effects of two hindered amine light stabilizers, an ultraviolet absorber, a colorant, and their interactions on the photostabilization of high-density polyethylene blends and wood flour/high-density polyethylene composites. Color change and flexural properties were determined after $250,500,1000$, and $2000 \mathrm{~h}$ of accelerated weathering. The results indicate that both colorant and ultraviolet absorber are more effective photostabilizers for wood flour/highdensity polyethylene composites than are hindered amine light stabilizers.

\subsection{Introduction}

Although inorganic fillers currently dominate the thermoplastic industry, woodderived fillers have become more accepted in recent years. The use of wood fibers in plastics is expected to increase by $50 \%$ through 2005 , to a great extent as a result of the recent acceptance of wood-plastic composites (WPC) into the construction industry for applications such as decking, siding, roofing tiles, and window frames (1).

The use of WPC by the construction industry has resulted in concern about the durability of these products exposed to outdoor environments. Outdoor durability may include thermal stability, moisture resistance, fungal resistance, and ultraviolet (UV) 
stability. Articles have been published about the susceptibility of WPC to moisture and fungal attack (2-4), the photodegradation of wood flour filled polyvinyl chloride composites $(5,6)$, and the photodegradation of wood flour filled polyethylene (WF/PE) composites $(7,8)$.

Falk et al. (7) investigated the color fade of WF/PE and polypropylene composites after accelerated weathering. The results indicated that polypropylene-based composites fade more than do polyethylene-based composites. These researchers also determined that colorants can be used effectively to lessen the color fade of WF/PE composites after accelerated weathering, but a hindered amine light stabilizer does not protect against color fade. However, the stabilization mechanism of the ineffective hindered amine light stabilizer added by itself was not addressed. In addition, the effect of combining a colorant and hindered amine light stabilizer is not known. Lundin (8) weathered photostabilized WF/PE composites and monitored the degradation of mechanical properties. The composites lost 33\% stiffness after $2000 \mathrm{~h}$ of weathering. However, because a composite without the photostabilizer was not monitored, the effect of the photostabilizer is not known. Despite this initial work, a fundamental understanding of the photostabilization of WF/PE composites is lacking.

The photodegradation of WPC is a difficult problem, complicated by the fact that each component may degrade via a different mechanism. The photodegradation of polyolefins originates from excited polymer-oxygen complexes (9) and is caused mainly by catalyst residues, hydroperoxide groups, carbonyl groups, and double bonds introduced during polymer manufacturing. Even in the absence of a significant amount of UV absorption, small amounts of these impurities can be sufficient to induce polymer 
degradation (10). Degradation of polymers as a result of photooxidation has undesirable effects, such as loss of strength, stiffness, and surface quality. Slowing down or stopping the reactions that are responsible for degradation is necessary for UV stabilization.

Photostabilizers are compounds developed to combat UV degradation. They are generally classified according to the degradation mechanism they hinder. Ultraviolet absorbers (UVAs), hydroperoxide decomposers, and free radical scavengers are all important photostabilizers for polyolefins. Commercial UVAs are readily available as benzophenones and benzotriazoles (10). A relatively new class of materials, hindered amine light stabilizers (HALS), has been extensively examined for polyolefin protection $(11,12)$ as free radical scavengers. Although hydroperoxides can act as photoinitiators, the concentration of hydroperoxides in polyethylene drops quickly upon UV exposure (10).

The individual components of wood-cellulose, hemicellulose, lignin, and extractives - are variously susceptible to photodegradation (13). Research has shown that the weathering of wood is confined to the wood surface and involves photo-induced breakdown of lignin to water-soluble reaction products, which leads to the generation of chromophoric functional groups such as carbonyls, carboxylic acids, quinones, and hydroperoxy radicals (13). Coating the wood surface inhibits photodegradation by limiting UV absorption.

Although the photodegradation of both polyethylene and wood have been extensively examined, little information is available on the photodegradation of woodflour-filled high-density polyethylene (WF/HDPE) composites $(7,8)$. In addition, much of the available information on photostabilizers covers solely the photostabilization of 
unfilled plastics (9-12). The results of the study reported here will aid in the development of an understanding of how photostabilizers affect the properties of WF/HDPE composites after weathering. This study has two main objectives: (a) to characterize the optical and mechanical properties of weathered HDPE blends and 50\% WF/HDPE composites and (b) to determine the effectiveness of various photostabilizers and their interactions on the weathering of WF/HDPE composites.

\subsection{Methods}

\subsubsection{Materials}

The materials used in this study are presented in Table 5.1. Combinations of wood flour (WF), a hydroxy benzotriazole UV absorber (UVA), a low molecular weight HALS (LS1), a high molecular weight HALS (LS2), and zinc ferrite in a carrier wax (Color) were added to HDPE. In each blend to which wood flour was added, the wood flour was maintained at $50 \%$ by weight of the composite, while the photostabilizers and HDPE constituted the remainder of the composite. The effects of each variable on color and flexural properties, as well as their interactions, were determined using a $2^{4}$ factorial experimental design.

\subsubsection{Processing}

The hydroscopic wood flour was dried for $24 \mathrm{~h}$ at $105^{\circ} \mathrm{C}$ to remove moisture before being dry-blended with the additives and HDPE. Compounding was accomplished using a 32-mm Davis Standard (Pawcatuck, CT) co-rotating twin-screw extruder to produce homogeneous composite pellets. The melt temperature varied between 385 and 
$400^{\circ} \mathrm{C}$. All composite pellets were dried at $105^{\circ} \mathrm{C}$ for at least $24 \mathrm{~h}$ prior to injection molding. Test specimens were molded in a 33-ton Cincinnati Milacron reciprocating screw injection molder (Batavia, $\mathrm{OH}$ ). The nozzle temperature was set to $400^{\circ} \mathrm{C}$. The American Society for Testing and Materials mold cavity used for the flexural samples was 120 by 3 by $12 \mathrm{~mm}(14)$.

Table 5.1. Materials and content of composite blends.

\begin{tabular}{|c|c|c|c|c|}
\hline Variable & & Supplier & Tradename & $\begin{array}{c}\text { Content } \\
(\%)\end{array}$ \\
\hline Wood flour & WF & American Wood Fibers & 4020 & 50 \\
\hline $\begin{array}{l}\text { Low molecular } \\
\text { weight light stabilizer }\end{array}$ & LS1 & Ciba Specialty Chemicals & $\begin{array}{l}\text { Tinuvin } \\
770 \mathrm{DF}\end{array}$ & $0,0.5$ \\
\hline $\begin{array}{l}\text { High molecular } \\
\text { weight light stabilizer }\end{array}$ & LS2 & Ciba Specialty Chemicals & $\begin{array}{c}\text { Chimassorb } \\
944 \text { FD }\end{array}$ & $0,0.5$ \\
\hline Ultraviolet absorber & UVA & Ciba Specialty Chemicals & $\begin{array}{l}\text { Tinuvin } \\
328\end{array}$ & $0,0.5$ \\
\hline Zinc ferrite colorant & Color & $\begin{array}{l}\text { Holland Colors } \\
\text { Americas, Inc. }\end{array}$ & $\begin{array}{c}\text { Cedar } \\
\text { TI-8536 }\end{array}$ & 0,1 \\
\hline $\begin{array}{l}\text { High-density } \\
\text { polyethylene }\end{array}$ & HDPE & Solvay Polymers, Inc. & $\begin{array}{c}\text { Fortiflex } \\
\text { A60-70-162 }\end{array}$ & $47.5-50$ \\
\hline
\end{tabular}

\subsubsection{Testing and Analysis}

\section{Weathering}

Twenty replicates of each of 32 formulations were placed in a xenon arc-type light exposure apparatus and operated according to ASTM D2565 (14). Samples were mounted in four rows on a drum that rotated around the xenon arc bulb at $1 \mathrm{rpm}$. The 
samples were rotated periodically to ensure that all were exposed to the same irradiance. The exposure cycle consisted of $108 \mathrm{~min}$ light exposure and $12 \mathrm{~min}$ simultaneous water spray and light exposure (14). To understand the initial effect of ultraviolet exposure, samples were removed for analysis after 250,500,1000, and $2000 \mathrm{~h}$ of exposure.

\section{Optical Properties}

A Minolta CR-200 Chroma Meter (Minolta Corporation, Ramsey, New Jersey) was used to measure color using the CIELAB color system. Lightness $(L)$ and chromaticity coordinates ( $a$ and $b$ ) were measured for five replicate samples, and the color change $\left(\Delta E_{a b}\right)$ was determined using the procedure outlined in ASTM D2244 (15):

$$
\Delta E_{a b}=\left(\Delta L^{2}+\Delta a^{2}+\Delta b^{2}\right)^{1 / 2}
$$

where $\Delta L, \Delta a$, and $\Delta b$ represent the difference between initial and final values of $L, a$, and $b$, respectively. In the CIELAB color system, the value $L$ can be thought of as a lightness factor. An increase in $L$ means the sample is lightening (i.e., $+\Delta L$ for lightening and $-\Delta L$ for darkening); $+\Delta a$ signifies a color shift towards red, $-\Delta a$ towards green, $+\Delta b$ towards yellow, and $-\Delta b$ towards blue.

\section{$\underline{\text { Mechanical Properties }}$}

Samples were oven dried at $105^{\circ} \mathrm{C}$ for $24 \mathrm{~h}$ before testing. This ensured the same conditioning for samples before and after exposure. Flexural tests were carried out according to ASTM D790 (16) on an Instron Universal Testing machine. The three-point loading system was utilized with a crosshead speed of $1.3 \mathrm{~mm} / \mathrm{min}$. The exposed surface 
was placed away from the center load to place that part of the sample in tension. At least four replicate specimens were tested for each formulation. The stress at maximum load and tangent modulus of elasticity (MOE) were calculated according to the standard.

\section{$\underline{\text { Statistics }}$}

To determine the effects of weathering on mechanical properties, a two-tailed $t$ test was carried out at an $\alpha$ value of 0.05 , comparing the exposed data to the unexposed data. An attempt was made to model each property in terms of LS1, LS2, UVA, and Color after $2000 \mathrm{~h}$ of exposure using a full factorial statistical analysis. This type of design results in a select variables run at different levels of which the experiments are run with all possible combinations (17). In this study, the effects of two levels (added or not added to the blend) on four variables resulted in 16 formulations for both HDPE blends and WF/HDPE composites. This was accomplished using the Design Expert 6.0.0 software by Stat-Ease, Inc. (Minneapolis, MN). If the data could be characterized using full factorial analysis, i.e., we were able to generate a model describing the data, then the derived equations are reported in terms of coded factors. Coding reduces the range of each factor to a common scale, -1 to +1 , regardless of its relative magnitude. In typical coding, -1 is the lower level of a factor and +1 the upper level (17).

\subsection{Results and Discussion}

Figures 5.1, 5.2, and 5.3 present the data obtained for the lightness value (L), flexural MOE, and flexural strength of the blends without photostabilizers at different exposure times. Each error bar corresponds to one standard deviation. In Tables 5.2 to 5.5, columns 1 through 4 indicate the types of photostabilizer added to each composite 
blend. A plus sign designates that the photostabilizer was included in the blend, and a minus sign designates the absence of the photostabilizer. The data in the first row are for the formulation without photostabilizers. Effects of individual photostabilizers are shown in rows 2 to 5 ; the effect of combining two to four photostabilizers is shown in rows 6 through 16. In Tables 5.4 and 5.5, boldfaced and underlined values represent no significant change in property from unexposed values at $\alpha=0.05$.

For each aspect of the study, the discussion is presented in two parts: (a) performance of unfilled HDPE blends and (b) performance of WF/HDPE composites.

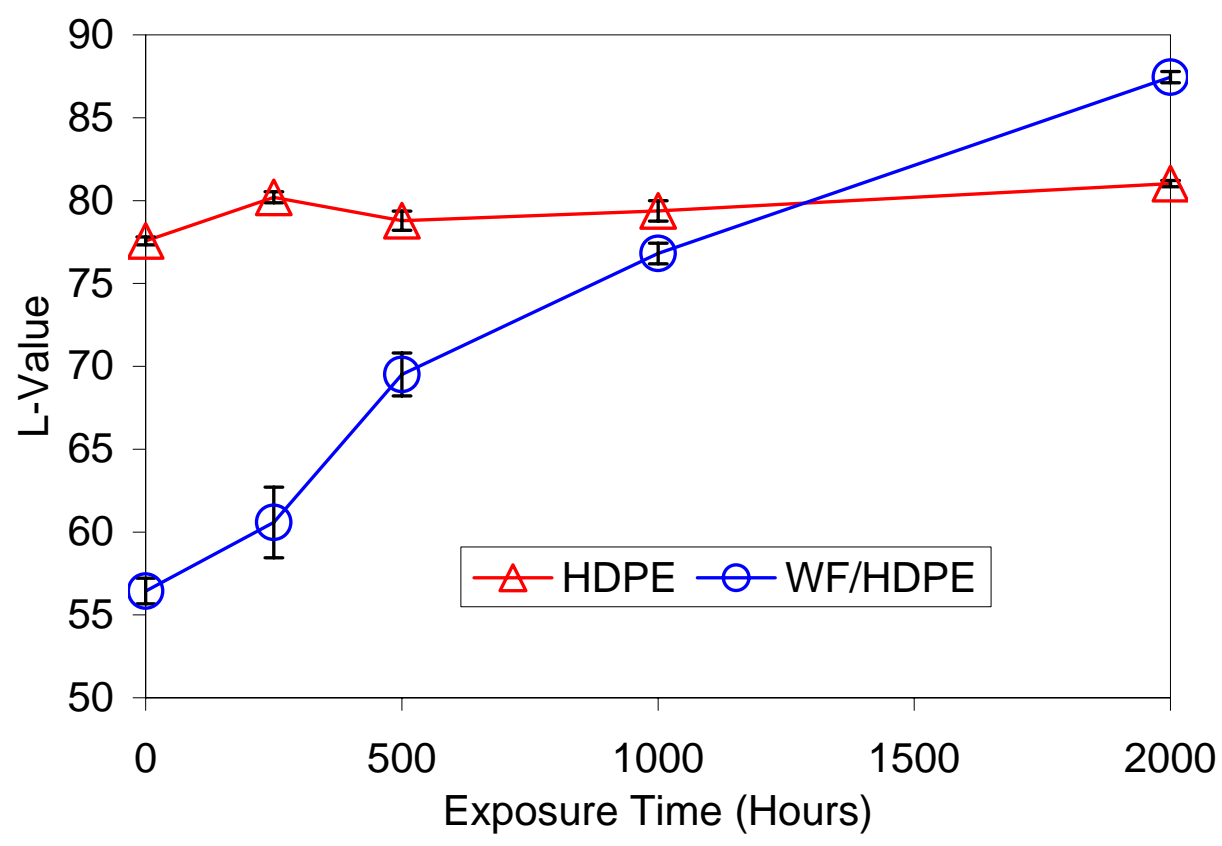

Figure 5.1. Effect of exposure time on lightness (L) of unfilled HDPE and WF/HDPE composites. 


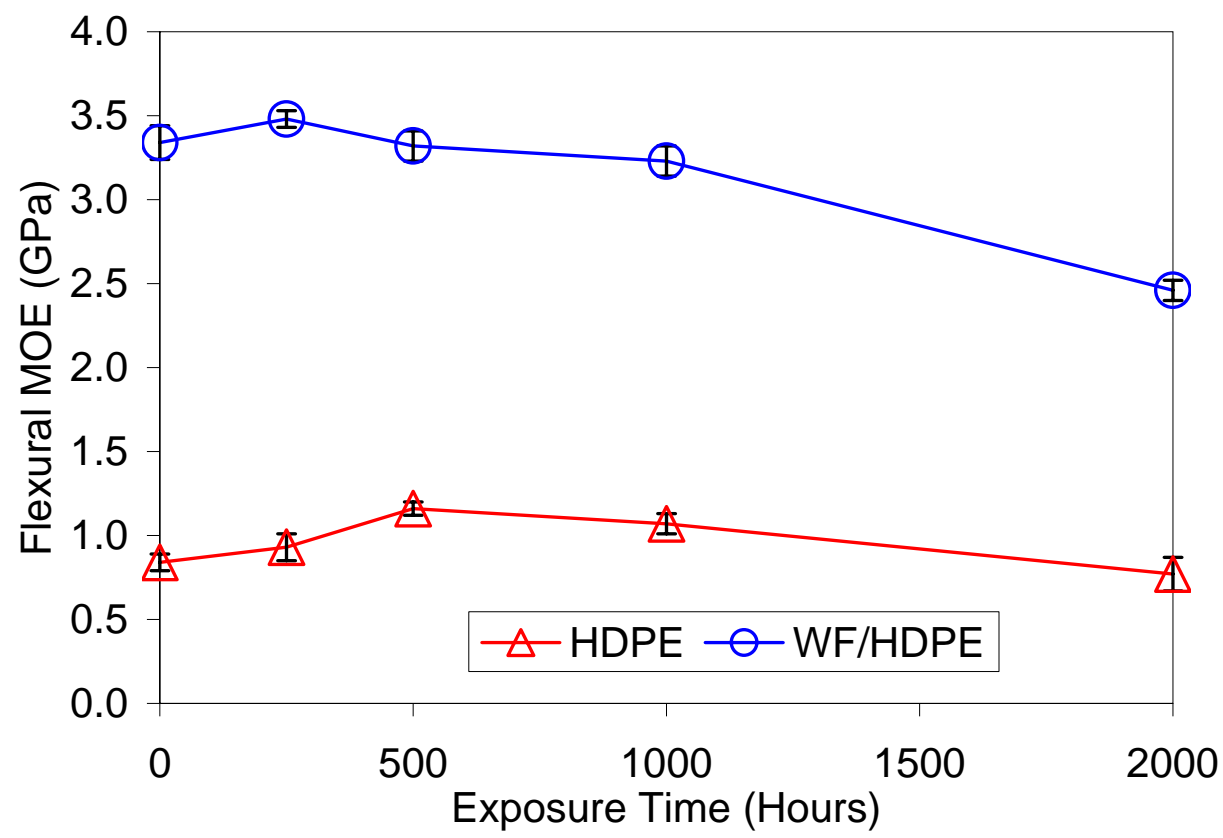

Figure 5.2. Effect of exposure time on flexural MOE of unfilled HDPE and WF/HDPE composites.

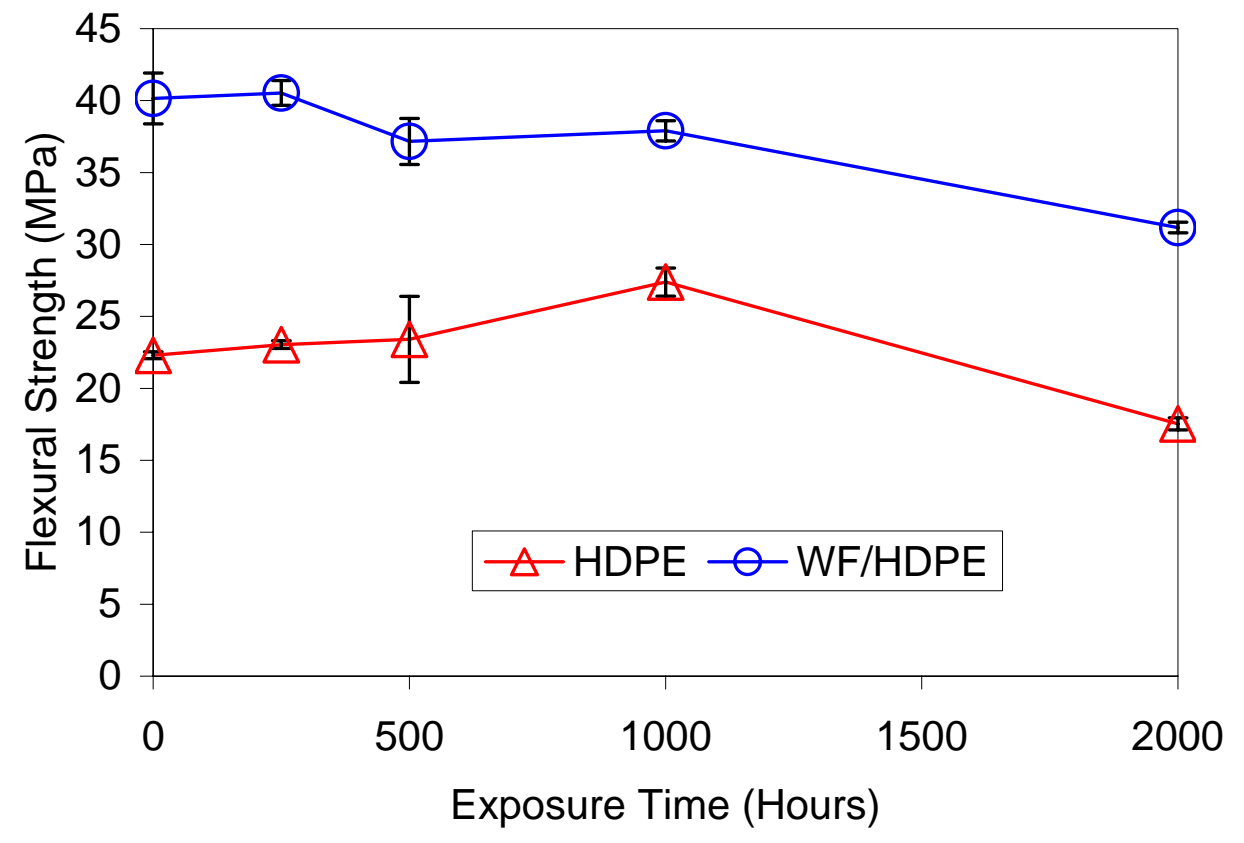

Figure 5.3. Effect of exposure time on flexural strength of unfilled HDPE and WF/HDPE composites. 


\subsubsection{Color Analysis}

Table 5.2. Change in color $\left(\Delta E_{a b}\right)$ and lightness $(\Delta L)$ at various exposure times for unfilled HDPE and photostabilizer blends after accelerated weathering.

\begin{tabular}{cccccccccccc}
\hline & \multicolumn{3}{c}{ Stabilizer } & \multicolumn{4}{c}{$\Delta E_{a b}$ exposure time $(\mathrm{h})$} & \multicolumn{5}{c}{$\Delta L$ exposure time ${ }^{\mathrm{a}}(\mathrm{h})$} \\
LS1 & LS2 & UVA & Color & 250 & 500 & 1000 & 2000 & 250 & 500 & 1000 & 2000 \\
\hline- & - & - & - & 4.6 & 4.5 & 4.5 & 4.9 & 2.6 & 1.2 & 1.8 & 3.5 \\
+ & - & - & - & 1.9 & 10.5 & 11.5 & 11.0 & 0.7 & 3.2 & 3.4 & 3.8 \\
- & + & - & - & 8.4 & 9.7 & 9.9 & 9.5 & -1.7 & 2.8 & 2.5 & 3.4 \\
- & - & + & - & 2.6 & 3.2 & 4.0 & 4.5 & 2.3 & 1.3 & 1.5 & 1.8 \\
- & - & - & + & 0.5 & 2.4 & 3.0 & 3.2 & -0.4 & 0.1 & -0.1 & 0.1 \\
+ & + & - & - & 4.0 & 11.4 & 11.9 & 11.4 & -0.6 & 3.5 & 3.7 & 4.2 \\
+ & - & + & - & 4.1 & 6.7 & 7.7 & 7.8 & -0.8 & 1.9 & 2.5 & 3.1 \\
- & + & + & - & 9.2 & 6.6 & 7.4 & 6.9 & -3.5 & 2.3 & 2.1 & 2.7 \\
+ & - & - & + & 0.3 & 1.4 & 1.8 & 2.7 & 0 & -0.2 & -0.4 & -0.1 \\
- & + & - & + & 0.5 & 2.7 & 2.8 & 3.4 & 0.1 & 0.3 & 0.3 & 0.3 \\
- & - & + & + & 0.9 & 1.7 & 2.0 & 1.6 & 0.3 & 0.1 & -0.3 & 0.3 \\
+ & + & + & - & 8.0 & 7.4 & 8.4 & 7.8 & -3.0 & 3.3 & 3.2 & 3.8 \\
+ & + & - & + & 0.5 & 2.9 & 3.7 & 4.3 & -0.4 & -0.2 & -0.3 & -0.2 \\
+ & - & + & + & 0.2 & 1.2 & 2.7 & 4.1 & 0.1 & -0.3 & -0.4 & -0.4 \\
- & + & + & + & 0.9 & 1.7 & 2.5 & 1.1 & 0.1 & -0.3 & -0.3 & 0.3 \\
+ & + & + & + & 0.2 & 2.5 & 3.6 & 3.8 & -0.2 & -0.1 & -0.1 & 0.2 \\
\hline
\end{tabular}

${ }^{a}$ One standard deviation for $L=0.3$.

Table 5.3. Change in color $\left(\Delta E_{a b}\right)$ and lightness $(\Delta L)$ at various exposure times for wood-flour-filled HDPE and photostabilizer blends after accelerated weathering.

\begin{tabular}{cccccccccccc}
\hline & \multicolumn{4}{c}{ Stabilizer } & \multicolumn{4}{c}{$\Delta E_{a b}$ exposure time $(\mathrm{h})$} & \multicolumn{4}{c}{$\Delta L$ exposure time ${ }^{\mathrm{a}}(\mathrm{h})$} \\
LS1 & LS2 & UVA & Color & 250 & 500 & 1000 & 2000 & 250 & 500 & 1000 & 2000 \\
\hline- & - & - & - & 4.4 & 16.7 & 25.4 & 35.8 & 4.1 & 13.1 & 20.4 & 31.0 \\
+ & - & - & - & 8.6 & 20.2 & 29.3 & 37.2 & 8.0 & 17.5 & 25.2 & 33.1 \\
- & + & - & - & 9.0 & 19.6 & 28.1 & 34.7 & 8.6 & 16.4 & 23.6 & 30.5 \\
- & - & + & - & 6.7 & 17.7 & 25.6 & 32.8 & 5.7 & 13.6 & 20.1 & 27.7 \\
- & - & - & + & 6.6 & 13.1 & 20.1 & 25.4 & 6.2 & 11.4 & 18.6 & 24.3 \\
+ & + & - & - & 7.9 & 19.4 & 27.6 & 34.8 & 7.7 & 17.2 & 24.2 & 31.5 \\
+ & - & + & - & 7.4 & 18.2 & 27.0 & 33.8 & 7.2 & 16.3 & 23.7 & 30.5 \\
- & + & + & - & 6.9 & 16.3 & 24.7 & 30.3 & 6.6 & 13.9 & 20.8 & 26.8 \\
+ & - & - & + & 7.1 & 13.3 & 18.7 & 23.6 & 6.9 & 12.6 & 17.9 & 22.7 \\
- & + & - & + & 9.6 & 16.4 & 21.6 & 26.1 & 9.4 & 15.6 & 20.8 & 25.2 \\
- & - & + & + & 5.7 & 11.1 & 16.0 & 20.8 & 5.5 & 9.8 & 14.7 & 19.7 \\
+ & + & + & - & 8.3 & 18.6 & 25.9 & 32.2 & 8.1 & 16.9 & 23.1 & 29.4 \\
+ & + & - & + & 11.7 & 17.8 & 23.6 & 27.5 & 11.4 & 17.1 & 22.8 & 26.7 \\
+ & - & + & + & 7.8 & 13.1 & 19.2 & 23.8 & 7.7 & 12.3 & 18.3 & 22.9 \\
- & + & + & + & 10.8 & 15.0 & 20.9 & 26.0 & 10.7 & 14.4 & 20.1 & 25.2 \\
+ & + & + & + & 7.1 & 14.4 & 19.6 & 23.8 & 6.9 & 13.8 & 18.8 & 22.9 \\
\hline
\end{tabular}

${ }^{a}$ One standard deviation for $L=1.1$ 


\section{$\underline{\text { Unfilled HDPE Blends }}$}

Table 5.2 shows the values of $\Delta E_{a b}$ and $\Delta L$ at different exposure times for HDPE blends without wood flour. The calculated total change in color, $\Delta E_{a b}$, typically increased with increasing exposure time. At $2000 \mathrm{~h}$, samples without colorant (Color) had larger $\Delta E_{a b}$ values than did samples with colorant. The determination of total change in color took into account the three color parameters: $L, a$, and $b$ (Eq. 5.1). If the change in lightness were the most important parameter influencing total color change, the trend of $\Delta L$ would follow that of $\Delta E_{a b}$. A diversion of the $\Delta L$ trend from the $\Delta E_{a b}$ trend would typically indicate a change resulting from yellowing of the sample $(+\Delta b)$ through the initial weathering stages. After $2000 \mathrm{~h}$ exposure, HDPE samples with colorant generally showed little, if any, lightening after UV exposure regardless of the presence of other photostabilizers. This trend is similar to that observed for $\Delta E_{a b}$. The derived equation (Eq. 5.2) describing the relationship between the change in lightness factor after $2000 \mathrm{~h}$ exposure and the various photostabilizers (in terms of coded factors) supports the relative importance of both colorant and UVA in preventing lightening of neat HDPE samples:

$$
\begin{gathered}
\Delta L_{2000 \mathrm{~h}}=1.66+0.12(\mathrm{LS} 1)+0.16(\mathrm{LS} 2)-0.21(\mathrm{UVA})-1.62(\text { Color }) \\
-0.31(\mathrm{LSl})(\text { Color })+0.23(\mathrm{UVA})(\text { Color })
\end{gathered}
$$

$$
\text { Predicted } \mathrm{r}^{2}=0.96
$$

Notice that all main effects (LS1, LS2, UVA, and Color) and the significant twofactor interaction (LS1/color and UVA/color) are included in Equation 5.2. The relative effect of each factor in this equation is expressed by its coefficient and algebraic sign 
(17). As Equation 5.2 clearly indicates, the colorant (Color) and UVA were the two most important photostabilizers that prevented lightening of HDPE blends (negative algebraic sign in Eq. 5.2). Color, however, had a more pronounced effect than did UVA, as suggested by its coefficient value (i.e., 1.62 for Color compared with 0.21 for UVA). In contrast, the addition of HALS (LS1 and LS2) did not prevent lightening (positive algebraic sign in Eq. 5.2).

Despite significant interactions (LS1/Color and UVA/Color), the colorant did not exert a large synergistic effect. This can clearly be seen in Figure 5.4, which shows $\Delta L$ as a function of the interactions between UVA and Color (Fig. 5.4a) and LS1 and Color (Fig. 5.4b). These graphs represent the data and model described in Equation 5.2. The strong dependence of $\Delta L$ on Color content is apparent. The value of $\Delta L$ significantly decreased when Color content increased at 0 or $0.5 \%$ of LS1 or UVA. These results imply that the colorant used in the formulation is the most effective photostabilizer for preventing the lightening of unfilled HDPE.
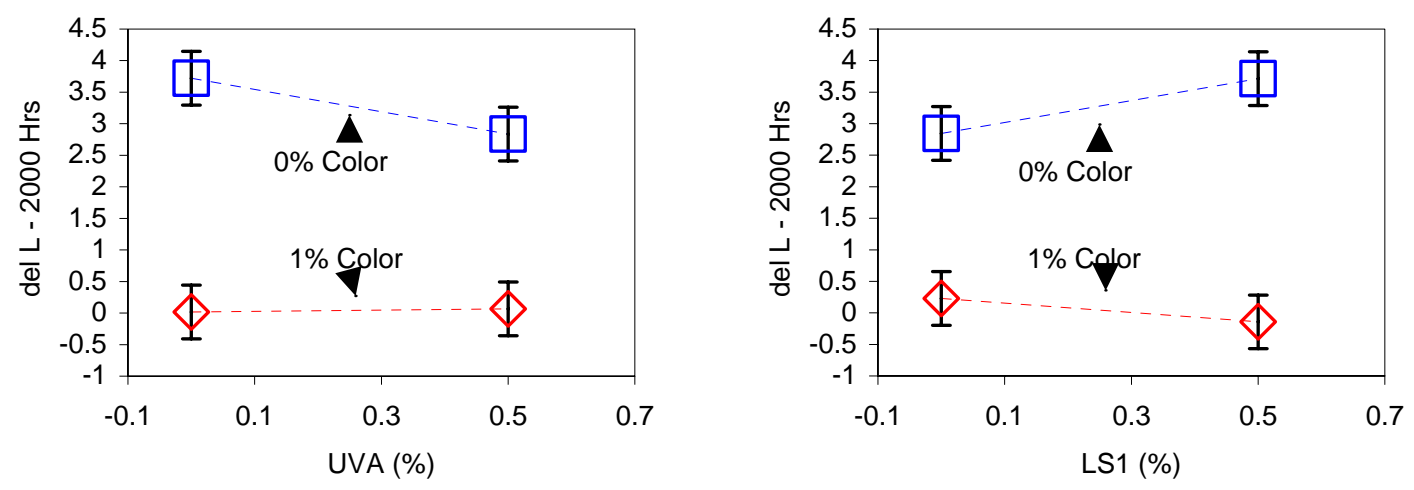

(5.4a)

Figure 5.4. Variation in $\Delta L$ as function of interactions between colorant and photostabilizer: (a) contents of LS1 and LS2 fixed at $0.25 \%$; (b) contents of LS2 and UVA fixed at $0.25 \%$. 


\section{Wood Flour/HDPE Composites}

For WF/HDPE composites, it is apparent that both $\Delta E_{a b}$ and $\Delta L$ increased with increasing exposure time (Table 5.3). Although all samples experienced a significant increase in lightness, the increase was less pronounced if the colorant was a component of the formulation. The only photostabilizers to significantly lower $\Delta L$ were UVA and Color (Eq. 5.3), as evidenced by the negative coefficients. As with the results for the unfilled HDPE composites, the most influential photostabilizer for color fade was the colorant (Color). Interestingly, Equation 5.3 contains neither an LS1 or LS2 term, implying that HALS alone or in combination does not have a significant effect on $\Delta L$ of the composites. This will be explained in the next section.

$$
\begin{gathered}
\Delta L_{2000 h}=26.86-1.26(\mathrm{UVA})-3.19(\text { Color }) \quad \text { [Equation 5.3] } \\
\text { Predicted } \mathrm{r}^{2}=0.75
\end{gathered}
$$

In comparing the color changes of the unfilled HDPE blends (Table 5.2) and the WF/HDPE composites (Table 5.3), it is clear that the magnitude of lightening was much greater for the composites (Fig. 5.1). At $2000 \mathrm{~h}, \Delta L$ ranged from -0.4 to 4.2 for unfilled polyethylene blends. The corresponding $\Delta L$ for WF/HDPE composites ranged from 19.7 to 33.1. Addition of wood flour to HDPE clearly had a negative effect on color fade.

These results suggest that the majority of color fade of composites may be due to a bleaching of the wood fibers. The addition of UVA can be used to absorb some UV radiation before the wood is exposed and bleached. However, UVAs are ineffective in protecting polymer films (18). In injection-molded fiber-filled samples, a polymer film is 
present at the surface (19). Although the addition of UVA to WF/HDPE composites significantly lowered $\Delta L$ from 31.0 to 27.7 , this value is nevertheless much higher than the value obtained for unfilled HDPE blends. The addition of a colorant, to block the penetration of UV radiation and to mask the bleaching of the wood flour, was more effective than the addition of UVA, lowering $\Delta L$ to 24.3. The combination of UVA and colorant provided the best protection, lowering $\Delta L$ to 19.7 .

\subsubsection{Flexural Property Analysis}

Tables 5.4 and 5.5 summarize the flexural properties of unfilled HDPE blends and WF/HDPE composites, respectively. Flexural MOE was calculated using the initial tangential slope of the load-displacement curve, and flexural strength was calculated using the maximum load sustained by the sample. All the samples failed on the tensile side during testing.

\section{Unfilled HDPE Blends}

For unfilled HDPE samples, flexural MOE and strength generally changed significantly upon exposure, after as little as $250 \mathrm{~h}$ (Table 5.4). For many formulations, MOE appeared to increase with increasing exposure time through $1000 \mathrm{~h}$. After $2000 \mathrm{~h}$, MOE was lower than that reported at $1000 \mathrm{~h}$, but nevertheless higher than that of unexposed samples for all the blends except unprotected HDPE. Although the full factorial analysis showed that no significant factors influenced MOE of HDPE after 2000 $\mathrm{h}$ of exposure, the data indicate that the photostabilizers provided some level of protection (Table 5.4). 
Table 5.4. Change in flexural modulus (MOE) and strength at various exposure times for unfilled HDPE and photostabilizer blends after accelerated weathering ${ }^{\text {a }}$

\begin{tabular}{|c|c|c|c|c|c|c|c|c|c|c|c|c|c|}
\hline \multirow{2}{*}{\multicolumn{4}{|c|}{$\begin{array}{l}\text { Stabilizer } \\
\text { LS UV Col }\end{array}$}} & \multicolumn{5}{|c|}{$\operatorname{MOE}(\mathrm{GPa})$} & \multirow{2}{*}{\multicolumn{5}{|c|}{ Strength (MPa) }} \\
\hline & & & & & & & & & & & & & \\
\hline LS1 & 2 & A & or & 0 & 250 & 500 & 1000 & 2000 & 0 & 250 & 500 & 1000 & 2000 \\
\hline- & - & - & - & 0.84 & 0.93 & 1.16 & 1.07 & $\underline{0.77}$ & 22.3 & 23.0 & 23.4 & 17.1 & 17.5 \\
\hline+ & - & - & - & 0.80 & 0.90 & 0.93 & 1.10 & 0.93 & 21.6 & 24.9 & 25.3 & 27.4 & 27.2 \\
\hline- & + & - & - & 0.89 & $\underline{0.96}$ & 1.00 & 1.14 & 1.03 & 22.7 & 26.1 & 26.6 & 28.9 & 28.1 \\
\hline- & - & + & - & 0.79 & 0.90 & 0.90 & 1.05 & 1.01 & 21.5 & 24.3 & 25.8 & 27.8 & 27.3 \\
\hline- & - & - & + & 0.81 & 1.00 & 0.98 & 1.12 & 0.97 & 21.3 & 25.1 & 25.9 & 27.4 & 25.6 \\
\hline+ & + & - & - & 0.81 & 0.98 & 0.94 & 1.12 & 1.03 & 21.5 & 24.9 & 25.7 & 28.0 & 26.7 \\
\hline+ & - & + & - & 0.78 & 0.91 & 0.91 & 1.07 & 0.88 & 20.9 & 23.9 & 24.9 & 27.4 & 26.5 \\
\hline- & + & + & - & 0.74 & 0.95 & 0.96 & 1.08 & 1.07 & 21.2 & 24.7 & 25.4 & 27.2 & 27.5 \\
\hline+ & - & - & + & 0.81 & 0.99 & 0.96 & 1.10 & 0.99 & 21.0 & 25.2 & 25.3 & 28.0 & 25.3 \\
\hline- & + & - & + & 0.87 & 1.01 & 1.01 & 1.16 & 1.03 & 22.3 & 25.7 & 26.3 & 28.7 & 26.8 \\
\hline- & - & + & + & 0.80 & 0.90 & 0.96 & 1.11 & 0.98 & 22.0 & 24.8 & 25.3 & 27.7 & 25.3 \\
\hline+ & + & + & - & 0.74 & 0.92 & 0.88 & 1.07 & 0.98 & 20.3 & 24.4 & 24.3 & 27.7 & 25.9 \\
\hline+ & + & - & + & 0.78 & 0.96 & 0.92 & 1.13 & 0.92 & 20.6 & 24.8 & 25.5 & 28.4 & 25.8 \\
\hline+ & - & + & + & 0.79 & 0.94 & 0.88 & 1.07 & 0.91 & 19.6 & 24.6 & 24.2 & 27.1 & 25.1 \\
\hline- & + & + & + & 0.85 & 0.98 & 1.03 & 1.14 & $\underline{0.97}$ & 21.8 & 25.7 & 26.7 & 28.6 & 24.6 \\
\hline+ & + & + & + & 0.72 & 0.92 & 0.90 & 1.07 & $\overline{0.96}$ & 19.9 & 24.0 & 24.7 & 27.4 & 25.0 \\
\hline
\end{tabular}

${ }^{\mathrm{a}}$ Boldfaced and underlined values represent no significant change in property from unexposed values at $\alpha$ $=0.05$.

Table 5.5. Change in flexural modulus (MOE) and strength at various exposure times for wood-flour-filled HDPE and photostabilizer blends after accelerated weathering ${ }^{\mathrm{a}}$.

\begin{tabular}{|c|c|c|c|c|c|c|c|c|c|c|c|c|c|}
\hline \multicolumn{4}{|c|}{ Stabilizer } & \multicolumn{5}{|c|}{$\operatorname{MOE}(\mathrm{GPa})$} & \multicolumn{5}{|c|}{ Strength (MPa) } \\
\hline & LS & UV & Col & & & & & & & & & & \\
\hline 1 & 2 & $\mathrm{~A}$ & or & 0 & 250 & 500 & 1000 & 2000 & 0 & 250 & 500 & 1000 & 2000 \\
\hline- & - & - & - & 3.34 & 3.48 & $\underline{3.32}$ & $\underline{3.23}$ & 2.46 & 40.1 & $\underline{40.5}$ & 37.2 & 37.9 & 31.2 \\
\hline+ & - & - & - & 3.35 & $\underline{3.40}$ & $\overline{3.29}$ & $\overline{3.32}$ & 2.49 & 41.1 & $\overline{40.4}$ & $\underline{39.0}$ & $\underline{39.3}$ & 34.0 \\
\hline - & + & - & - & 3.34 & 3.38 & 3.20 & 3.15 & 2.58 & 41.3 & $\overline{40.5}$ & 39.9 & 38.9 & 34.6 \\
\hline- & - & + & - & 3.01 & $\overline{3.19}$ & $\underline{\underline{3.11}}$ & 3.24 & 2.47 & 37.6 & $\overline{37.5}$ & $\overline{38.4}$ & $\underline{38.5}$ & 33.7 \\
\hline- & - & - & + & 3.51 & 3.91 & $\underline{3.37}$ & 3.60 & 2.98 & 38.3 & $\underline{38.2}$ & $\underline{37.4}$ & $\underline{37.1}$ & 34.4 \\
\hline+ & + & - & - & 3.42 & $\underline{3.48}$ & $\underline{3.33}$ & $\underline{3.33}$ & 2.71 & 41.0 & $\underline{40.8}$ & $\underline{40.7}$ & $\underline{39.9}$ & 35.8 \\
\hline+ & - & + & - & 3.34 & $\underline{3.33}$ & $\underline{3.24}$ & $\underline{3.42}$ & 2.42 & 39.7 & $\underline{39.1}$ & $\underline{39.0}$ & $\underline{39.9}$ & 34.9 \\
\hline- & + & + & - & 3.24 & $\underline{3.27}$ & $\underline{3.11}$ & $\underline{3.32}$ & 2.44 & 39.4 & 38.7 & $\underline{38.5}$ & $\underline{39.0}$ & 35.2 \\
\hline+ & - & - & + & 3.80 & $\underline{3.83}$ & $\underline{3.59}$ & $\underline{3.72}$ & 3.20 & 39.8 & 40.1 & $\underline{39.4}$ & $\underline{39.5}$ & 36.3 \\
\hline- & + & - & + & 3.81 & $\underline{\underline{3.82}}$ & $\underline{\underline{3.67}}$ & $\underline{\underline{3.73}}$ & 3.20 & 38.7 & $\overline{38.4}$ & $\overline{38.5}$ & $\overline{37.4}$ & 35.7 \\
\hline- & - & + & + & 3.41 & $\overline{3.45}$ & $\overline{3.38}$ & $\overline{3.66}$ & $\underline{3.31}$ & 36.2 & $\overline{37.5}$ & $\overline{37.3}$ & $\underline{37.6}$ & $\underline{34.2}$ \\
\hline+ & + & + & - & 3.28 & $\underline{\underline{3.33}}$ & $\overline{3.07}$ & $\underline{3.23}$ & $\overline{2.62}$ & 40.3 & $\overline{39.2}$ & $\overline{38.5}$ & $\overline{37.7}$ & $\overline{36.3}$ \\
\hline+ & + & - & + & 3.94 & $\overline{3.97}$ & $\underline{3.63}$ & $\overline{3.72}$ & 3.09 & 39.1 & $\underline{38.9}$ & $\overline{38.5}$ & $\underline{37.6}$ & 36.2 \\
\hline+ & - & + & + & 3.72 & 3.71 & 3.38 & 3.82 & 3.08 & 37.2 & 38.6 & 37.3 & $\underline{37.4}$ & 34.8 \\
\hline- & + & + & + & 3.45 & 3.64 & 3.36 & 3.69 & 3.11 & 37.5 & 36.2 & 38.0 & 38.4 & 34.9 \\
\hline+ & + & + & + & 3.76 & 3.57 & 3.35 & 3.59 & 3.08 & 37.6 & $\overline{38.3}$ & $\overline{37.7}$ & $\overline{38.7}$ & 36.2 \\
\hline
\end{tabular}

\footnotetext{
${ }^{a}$ Boldfaced and underlined values represent no significant change in property from unexposed values at $\alpha$
} $=0.05$. 
As with flexural MOE, the strength of unfilled HDPE blends increased through $1000 \mathrm{~h}$ of exposure and then dropped off slightly at $2000 \mathrm{~h}$ exposure (Fig. 5.2), irrespective of the addition of photostabilizer (Table 5.4). Despite this decrease, all UV exposed samples, except for unprotected HDPE, showed greater flexural strength values than did their unexposed counterparts, even after $2000 \mathrm{~h}$ exposure. The photostabilizers or combinations were not significantly different in regard to the change in strength of HDPE at $2000 \mathrm{~h}$ exposure.

This phenomenon is explained by changes in the polymer morphology. Tidjani $e t$ al. (2000) exposed low density polyethylene (LDPE) to both natural and accelerated weathering and examined the elongation at break in conjunction with the formation of carbonyl and vinyl groups after weathering. They determined that in the initial stages of accelerated weathering, the mechanisms of degradation result in a predominance of crosslinking reactions over chain scission (20). In a later study, Tidjani expanded upon this explanation (21), concluding that cross-linking that occurs after accelerated weathering reduces the concentration of radicals that take part in the oxidation process. This is supported by experimental evidence that a high elongation at break was retained during the initial stages of exposure. The author suggests that a relatively high level of oxidation is necessary to overcome cross-linking and decrease elongation (21).

A complementary explanation comes from Jabarin and Lofgren (22), who also examined the structural changes of HDPE after natural and accelerated weathering. They reported an increase in concentration of carbonyl and vinyl compounds, an increase in crystallinity, and a decrease in molecular weight after natural weathering (22). They determined that as polyethylene undergoes photooxidation during the course of UV 
exposure, chain scission occurs as evidenced by the increase in concentration of carbonyl and vinyl groups and the decrease in molecular weight. These authors conclude that shorter chains have higher mobility and crystallize readily, resulting in an apparent increase in crystallinity (22). As UV exposure continues, chain scission continues to affect molecular weight and crystallinity, leading to embrittlement of the polyethylene, which corresponds with a decreased elongation to break (22). Kaci et al. (2001) also reported an increase in crystallinity of LDPE after natural weathering (23).

In our case, the polyethylene blends were exposed to accelerated weathering. We think that cross linking and chain scission occur simultaneously at later stages, but cross linking initially dominates. Initial cross linking may hinder the chain mobility, resulting in an increase in strength and modulus. For the unprotected polyethylene blend, maximum properties were observed at approximately $500 \mathrm{~h}$ of exposure (Table 5.4). After $500 \mathrm{~h}$, chain scission became the more influential structural change, leading to a drop in mechanical properties. After $2000 \mathrm{~h}$, there was no net change in flexural MOE and a net drop in flexural strength. Photostabilizers and colorant may be effective in delaying the switch from cross linking to chain scission by absorbing or blocking UV radiation and scavenging free radicals. Therefore, the degradation of properties is delayed. Further research is being conducted to verify the proposed mechanisms of degradation. The maximum properties were observed around $1000 \mathrm{~h}$ after exposure. After $2000 \mathrm{~h}$ of exposure, a drop in properties became apparent, but there was still a net increase in properties relative to those of unexposed samples. We expect that the degradation of properties of all HDPE blends would continue with increasing exposure times. 


\section{Wood Flour/HDPE Composites}

The change in flexural MOE of weathered WF/HDPE composites compared with flexural MOE of unexposed composites was generally insignificant until the exposure time reached $2000 \mathrm{~h}$ (Fig. 5.3, Table 5.5). Others have indicated similar trends. After $4000 \mathrm{~h}$ of weathering, Lundin (8) found that WF/HDPE composites retained only $45 \%$ of pre-exposure MOE. However, more than 35\% of stiffness loss occurred in the first 1000 $\mathrm{h}$ of exposure. Unlike the flexural MOE of unfilled HDPE blends, flexural MOE values of most WF/HDPE composites exposed to $2000 \mathrm{~h} \mathrm{UV}$ were significantly lower than that of their unexposed counterparts. These results imply that addition of wood flour to polyethylene is detrimental to the retention of MOE after accelerated weathering. The only blend that did not experience a significant decrease in MOE was the WF/HDPE composite with UVA and colorant. The full factorial statistical analysis at $2000 \mathrm{~h}$, however, led us to conclude that the change in MOE is unaffected by photostabilizer type.

Similar to the trend observed for flexural MOE of WF/HDPE composites, flexural strength generally did not change significantly until the exposure time reached $2000 \mathrm{~h}$. At this point, a drop in strength occurred that was most extreme for the unprotected WF/HDPE composite. Both colorant and UVA significantly decreased the loss in strength compared with that of the unprotected composite (Eq. 5.4). The derived regression equation describing the relationship between the change in flexural strength after $2000 \mathrm{~h}$ of UV exposure and various photostabilizers (in terms of coded factors) is as follows: 


$$
\Delta \text { Strength }=\left(\begin{array}{l}
36.45+9.83(\mathrm{UVA}) \\
+15.53(\text { Color }) \\
\text { Predicted } \mathrm{r}^{2}=0.84
\end{array}\right)^{1 / 2}-9.87 \quad \text { [Equation 5.4] }
$$

An examination of Equations 5.3 and 5.4 shows that for the WF/HDPE composites, both LS1 and LS2 do not significantly change color fade or loss in flexural strength. The ineffectiveness of HALS may be attributed to the acid acceptor characteristic of wood. The amine group on each HALS acts as an electron donor (base). As a result, the basic HALS will react with any acidic component (18). The parameters $\mathrm{K}_{\mathrm{A}}$ (acceptor) and $\mathrm{K}_{\mathrm{D}}$ (donor) can be used to characterize a material as an electron acceptor and donor. These values have been determined for $60 / 80$-mesh size eastern white pine (Pinus strobus). It was reported that if extractives were removed from the wood, as might occur during composite processing, the $\mathrm{K}_{\mathrm{A}}$ and $\mathrm{K}_{\mathrm{D}}$ would be 0.15 and 0.11 , respectively (24). This leads to the conclusion that the surface of the wood acts as an electron acceptor and can undergo an acid-base interaction with the HALS, thus affecting the performance of the light stabilizer.

Unlike unfilled HDPE blends, WF/HDPE composites did not experience a change in properties immediately, but they did experience a net loss in properties after $2000 \mathrm{~h}$ of exposure (Table 5.5). This may have been due to moisture sorption during weathering. The samples cycle through environments of $35^{\circ} \mathrm{C}$ and $100 \%$ relative humidity during the water spray cycle, and $40^{\circ} \mathrm{C}$ and $30 \%$ relative humidity during the dry cycle. Moisture has been shown to affect the properties of wood-polymer composites. Stark (2) examined the effects of moisture on flexural properties of $40 \% \mathrm{WF} / \mathrm{PE}$ composites. Composites 
exposed to $30 \%$ relative humidity for $2000 \mathrm{~h}$ experienced no loss in flexural properties. However, composites exposed to a water bath for $2000 \mathrm{~h}$ experienced $39 \%$ loss in flexural modulus and $22 \%$ loss in flexural strength (2).

In the initial stages of weathering of HDPE/WF composites, the loss of properties caused by moisture exposure may cancel out the gain resulting from polymer crosslinking. This would explain the observed plateau during the first $1000 \mathrm{~h}$ of exposure. At $2000 \mathrm{~h}$, a substantial decrease in properties occurs. It is at this point that the HDPE properties may be degrading as a result of chain scission as well as moisture. For unprotected HDPE/WF composites, this corresponds with a 26\% drop in MOE and a $22 \%$ drop in strength, partly as a result of a loss in interfacial strength (2). Unlike unfilled HDPE composites, WF/HDPE composites experienced a net loss in flexural MOE and strength after weathering for $2000 \mathrm{~h}$. The ultraviolet absorber (UVA) and colorant provide some protection against strength loss (Eq. 5.4). However, they may protect the polymer only and may not influence the drop in strength properties due to moisture exposure.

In addition, wood flour undergoes photodegradation, resulting in the breakdown of lignin to form free radicals (13). The free radicals may attack the polyethylene chain, resulting in the deleterious effect of adding wood flour to polyethylene through an accelerated chain scission in the polyethylene. Indeed, the loss of flexural MOE of the WF/HDPE composite without additives was almost double that of the loss in MOE of the HDPE composite (26\% versus $12 \%)$. These results suggest that both the loss of interfacial quality and photodegradation of wood flour contribute to the loss of flexural strength and stiffness of WF/HDPE composites. 


\subsection{Conclusions}

As wood-plastic composites become increasingly used for outdoor applications, a need to understand their ultraviolet (UV) durability arises. There is little fundamental information available on the photostabilization of wood-flour-filled high-density polyethylene (WF/HDPE) composites. In this study, a full factorial experimental design was used to examine the effects of photostabilizers on both unfilled HDPE blends and WF/HDPE composites. Optical and flexural properties were examined for all formulations after they had been exposed to UV light in an accelerated weathering apparatus. Our analysis led to the following conclusions:

The lightening effect is decreased through the addition of an ultraviolet absorber and colorant for both unfilled HDPE blends and WF/HDPE composites. However, because of bleaching of the wood flour, WF/HDPE composites experience more dramatic lightening than do unfilled HDPE blends.

After $2000 \mathrm{~h}$ of laboratory UV exposure, unprotected HDPE blends experience a drop in flexural strength and modulus, which can be mitigated through the addition of a photostabilizer.

Flexural properties (both modulus of elasticity and strength) of HDPE blends are immediately affected by UV exposure, whereas flexural properties of WF/HDPE composites are not significantly affected until $2000 \mathrm{~h}$ of exposure. The addition of an ultraviolet absorber and colorant significantly decreases strength loss. Hindered amine light stabilizers did not have a significant effect on lightness and flexural properties of the WF/HDPE composite formulations tested. 


\subsection{References}

1. C. Eckert, "Opportunities for Natural Fibers in Plastic Composites," in Proceedings, Progress in Wood Fiber-Plastic Composites Conference, Toronto, Canada, May 25-26, 2000.

2. N.M. Stark, "Influence of Moisture Absorption on Mechanical Properties of WoodFlour-Polypropylene Composites," Journal of Thermoplastic Composite Materials, 14(5), 421-432, 2001.

3. S.A. Verhey, P.E. Laks and D.L. Richter, "Laboratory Decay Resistance of Woodfiber/Thermoplastic Composites," Forest Products Journal, 51(9), 44-49, 2001.

4. C.M. Clemons and R.E. Ibach, "Laboratory Tests on Fungal Resistance of Wood Filled Polyethylene Composites," in Proceedings ANTEC, 2219-2222, San Francisco, CA, May 6-10, 2002.

5. L.M. Matuana, D.P. Kamdem and J. Zhang, "Photoaging and Stabilization of Rigid PVC/Wood-Fiber Composites," Journal of Applied Polymer Science, 80(11), 19431950, 2001.

6. L.M. Matuana and D.P. Kamdem, "Accelerated Ultraviolet Weathering of PVC/Wood-Flour Composites, Polymer Engineering and Science," 42(8), 16571666, 2002.

7. R. H. Falk, C. Felton, and T. Lundin, "Effects of Weathering on Color Loss of Natural Fiber-Thermoplastic Composites," in Proceedings, $3^{\text {rd }}$ International Symposium on Natural Polymers and Composites, 382-385, São Paulo, Brazil, May $14-17,2000$.

8. T. Lundin, "Effect of Accelerated Weathering on the Physical and Mechanical Properties of Natural Fiber Thermoplastic Composites," M.S. Thesis, University of Wisconsin-Madison, 2001.

9. F. Gugumus, "Current Trends in Mode of Action of Hindered Amine Light Stabilizers," Polymer Degradation and Stability, 40(2), 167-215, 1993.

10. F. Gugumus, "Light Stabilizers," in Plastics Additives Handbook, Chapter 3, 129262, R. Gächter and H. Müller, Eds., Hanser Publishers, New York, 1990.

11. F. Gugumus, "The Performance of Light Stabilizers in Accelerated and Natural Weathering," Polymer Degradation and Stability, 50(1), 101-116, 1995.

12. P. Gijsman, J. Hennekens and D. Tummers, "The Mechanism of Action of Hindered Amine Light Stabilizers," Polymer Degradation and Stability, 39(2), 225-233, 1993.

13. D.N.-S. Hon, "Weathering and Photochemistry of Wood," in Wood and Cellulosic Chemistry, Chapter 11, 513-546, D.N.-S. Hon and N. Shiraishi, Eds, Marcel Dekker, Inc., New York, 2001.

14. American Society for Testing and Materials, "D2565 Standard Practice for XenonArc Exposure of Plastics Intended for Outdoor Applications," in Annual Book of ASTM Standards, 8.02, 2000.

15. American Society for Testing and Materials, "D2244 Standard Test Method for Calculation of Color Differences From Instrumentally Measured Color Coordinates," in Annual Book of ASTM Standards, 6.01, 2000. 
16. American Society for Testing and Materials, "D790 Standard Test Method for Flexural Properties of Unreinforced and Reinforced Plastics and Electrical Insulating Materials," in Annual Book of ASTM Standards, 8.01, 2000.

17. G. E. P. Box, W. G. Hunter and J. S. Hunter, Statistics for Experimenters, John Wiley \& Sons, New York, 1978.

18. G. Wypych, Handbook of Material Weathering, ChemTec Publishing, TorontoScarborough, 1995.

19. M. Kazayawoko, J.J. Balatinecz and L.M. Matuana, "Surface Modification and Adhesion Mechanisms in Woodfiber-Polypropylene Composites," Journal of Materials Science, 34(24), 6189-6199, 1999.

20. A. Tidjani, R. Arnaud and A. Dasilva, "Natural and Accelerated Photoaging of Low-Density Polyethylene: Changes of the Elongation at Break," Journal of Applied Polymer Science, 47(2), 211-216, 1993.

21. A. Tidjani, "Comparison of Formation of Oxidation Products During PhotoOxidation of Linear Low Density Polyethylene Under Different Natural and Accelerated Weathering Conditions," Polymer Degradation and Stability, 68(3), 465-469, 2000.

22. S.A. Jabarin and E.A. Lofgren, "Photooxidative Effects on Properties and Structure of High-Density Polyethylene," Journal of Applied Polymer Science, 53(4), 411423, 1994.

23. M. Kaci, T. Sadoun and S. Cimmino, "Crystallinity Measurements of Unstabilized and HALS-Stabilized LDPE Films Exposed to Natural Weathering by FT-IR, DSC, and WAXS Analyses," International Journal of Polymer and Analytical Characterization, 6(5), 455-464, 2001.

24. M.A. Tshabalala, "Determination of the Acid-Base Characteristics of Lignocellulosic Surfaces by Inverse Gas Chromatography," Journal of Applied Polymer Science, 65(5), 1013-1020, 1997. 


\section{Chapter 6 - Color Fade ANd Mechanical Properties of PHOTOSTABILIZED WOOD FLOUR/HDPE COMPOSITES EXPOSED TO ACCELERATED ULTRAVIOLET WEATHERING}

This chapter has been submitted to the Journal of Applied Polymer Science (September 2003). It is co-authored by N.M. Stark and L.M. Matuana. 


\subsection{Abstract}

Photodegradation of wood-plastic composites results in a change in appearance and/or mechanical properties. These changes can be slowed through an addition of ultraviolet absorbers and pigments. This study examined color fade and mechanical property degradation of photostabilized and/or pigmented wood flour filled high-density polyethylene composites after accelerated ultraviolet light weathering. Different concentrations of an ultraviolet absorber and/or pigment were added to the composites. Color change and flexural properties were determined after 1000, 2000, and $3000 \mathrm{~h}$ of accelerated weathering. The lightness of the composite after weathering was influenced by the concentration of both the ultraviolet absorber and pigment. The pigment exerted more of an influence than the ultraviolet absorber by masking the bleaching wood component as well as blocking UV light. Flexural modulus of elasticity (MOE) loss was influenced by an increase in ultraviolet absorber concentration, but increasing pigment concentration had little influence on MOE loss. However increasing both ultraviolet absorber and pigment concentration resulted in improved strength properties over unstabilized composites after $3000 \mathrm{~h}$ of weathering.

\subsection{Introduction}

Although inorganic fillers currently dominate the thermoplastic industry, woodderived fillers have become more accepted in recent years. Growth of wood-plastic composites (WPCs) has averaged more than 25\% a year since 1998, no segment of the plastics industry has grown faster (1). To a great extent, the use of wood fibers in plastics 
is due to a recent acceptance of WPCs into the construction industry for applications such as decking, siding, roof tiles, and window frames (2).

Wood-plastic composite lumber is promoted as being a low-maintenance highdurability product (3). However, their use by the construction industry has resulted in concern about exterior durability. Ultraviolet (UV) durability is of particular concern because it has been well documented that WPCs exposed to accelerated weathering experience color change affecting the aesthetic appeal of the product (4-9) and an extensive loss in mechanical properties that severely limit its performance $(4-6,8,10-14)$.

Enormous efforts have been put into the development of photostabilizers and other compounds to protect materials against UV degradation by preventing or delaying the formation of chromophoric functional groups and polyenes (double bonds) during processing $(15,16)$. Ultraviolet absorbers (UVAs) and hindered amine light stabilizers (HALSs) are two important photostabilizers $(15,16)$. In addition, pigments are often used as a photo-blocker. While pigments are not technically photostabilizers, they will be referred to as such in this paper. A large majority of the available information on photostabilizers covers solely the photostabilization of unfilled plastics. Relatively little in-depth work has been done on the photostabilization of WPCs $(4-6,10)$.

The effect of colorants on color fade and flexural properties of wood flour (WF) filled polyethylene (PE) and polypropylene composites after accelerated weathering has been investigated (4). The results indicated that polypropylene based composites fade more than PE based composites. In addition, it was found that colorants can be effectively used to lessen or inhibit the color fade and significantly increase the flexural property retention of WF/PE composites after accelerated UV weathering. While this 
study clearly showed the effectiveness of pigments in preventing color fade and mechanical property loss of WF/PE composites, the effect of pigment concentration on the durability of the composites exposed to UV radiation was not examined.

The effect of hindered amine light stabilizer (HALS) content on the color fade and mechanical property loss of 50\% WF filled PE composites weathered for $1500 \mathrm{~h}$ was investigated (5). The author reported that the addition of HALS $(0.25$ and $0.5 \%$ by weight) to the composite did not affect color change caused by accelerated weathering. The stiffness of the composites decreased between 26 and 30\% regardless of the addition of HALS. On the other hand, the loss in flexural strength of the composite was reduced by $3 \%$ when $0.5 \%$ HALS was added to the composite but the significance of this is not known.

A full-factorial experimental design was employed in our previous study to examine the effect of a low molecular weight HALS, high molecular weight HALS, an UVA, and a pigment on color fade and mechanical properties of WF/HDPE composites exposed up to $2000 \mathrm{~h}$ of accelerated UV weathering (6). Only the UVA and pigment significantly reduced color fade and loss in mechanical properties. Regardless of molecular weight, HALS was found ineffective in protecting the composite against surface discoloration and flexural property loss. Despite these results, prior research has not examined the effect of photostabilizer content on UV durability of WF/HDPE composites.

The main objective of the present study was to determine the effect of stabilizer concentration on color fade and mechanical property loss of WF/HDPE composites after accelerated UV weathering. The results reported in this paper will aid in development of 
an understanding of the efficiency of photostabilizers to protect WPCs against UV weathering.

\subsection{Methods}

\subsubsection{Materials}

The materials used in this study are listed in Table 6.1. Combinations of WF, a hydroxy benzotriazole UVA, and zinc ferrite pigment in a carrier wax $(\mathrm{P})$ were added to HDPE. The HDPE was a virgin material with a melt index of $0.72 \mathrm{~g} / 10$ min and density of $0.963 \mathrm{~g} / \mathrm{cm}^{3}$. The WF was maintained at $50 \%$ by weight of the composite. The manufacturer recommended concentration of UVA was $0.5 \%$ and of $\mathrm{P}$ was $1 \%$. UVA and $\mathrm{P}$ were added at either one or two times the recommended concentration. Table 6.2 shows the seven composite formulations manufactured.

Table 6.1. Materials used in composite blends.

\begin{tabular}{cccc}
\hline Variables & & Suppliers & Tradenames \\
\hline Wood flour & WF & American Wood Fibers & 4020 \\
Ultraviolet absorber & UVA & Ciba Specialty Chemicals & Tinuvin 328 \\
Zinc ferrite pigment & P & Holland Colors Americas, Inc. & $\begin{array}{c}\text { Cedar TI- } \\
8536\end{array}$ \\
$\begin{array}{c}\text { High-density } \\
\text { polyethylene }\end{array}$ & HDPE & Solvay Polymers, Inc. & Fortiflex A60- \\
& & & $70-162$ \\
\hline
\end{tabular}

\subsubsection{Processing}

WF was dried for $24 \mathrm{~h}$ at $105^{\circ} \mathrm{C}$ to remove moisture before being dry-blended with photostabilizers and HDPE. Compounding was accomplished using a 32-mm Davis 
Standard (Pawcatuck, CT) co-rotating twin-screw extruder to produce homogeneous composite pellets. The melt temperature varied between 385 and $400^{\circ} \mathrm{C}$. All composite pellets were dried at $105^{\circ} \mathrm{C}$ for at least $24 \mathrm{~h}$ prior to injection molding. Test specimens were molded in a 33-ton Cincinnati Milacron reciprocating screw injection molder (Batavia, OH). The nozzle temperature was set to $400^{\circ} \mathrm{C}$. The American Society for Testing and Materials mold cavity used for the flexural samples was 120 by 3 by $12 \mathrm{~mm}$ (17).

Table 6.2. Formulations of wood-plastic composites manufactured.

\begin{tabular}{ccccc}
\hline \multirow{5}{*}{ Formulations } & \multicolumn{4}{c}{ Contents } \\
& $\begin{array}{c}\text { WF } \\
(\%)\end{array}$ & $\begin{array}{c}\text { UVA } \\
(\%)\end{array}$ & $\begin{array}{c}\text { P } \\
(\%)\end{array}$ & $\begin{array}{c}\text { HDPE } \\
(\%)\end{array}$ \\
\hline 1 & 50 & 0 & 0 & 50 \\
2 & 50 & 0.5 & 0 & 49.5 \\
3 & 50 & 1 & 0 & 49 \\
4 & 50 & 0 & 1 & 49 \\
5 & 50 & 0 & 2 & 48 \\
6 & 50 & 0.5 & 1 & 48.5 \\
7 & 50 & 1 & 2 & 47 \\
\hline
\end{tabular}

\subsubsection{Testing and Analysis}

\section{Weathering}

The samples were placed in a xenon arc-type light exposure apparatus and operated according to ASTM D2565 (18). Samples were mounted in one row on a drum that rotated around the xenon arc bulb at $1 \mathrm{rpm}$. The exposure cycle consisted of $108 \mathrm{~min}$ light exposure and 12 min simultaneous water spray and light exposure. An irradiance 
sensor was used to measure light intensity for wavelengths from 300 to $400 \mathrm{~nm}$. The irradiance was monitored and voltage to the bulb was changed periodically in order to maintain a constant irradiance. The dosage or amount of light energy the samples were subjected to was calculated (irradiance $\mathrm{x}$ time). The dosage at 1000 hour time increments is shown in Table 6.3. We can be confident that samples were exposed to consistent energy dosages for each thousand hours of weathering. To understand the effect of exposure time on weathering, samples were removed for analysis after 1000, 2000, and $3000 \mathrm{~h}$ of exposure in the UV apparatus.

\section{Table 6.3. The amount of light energy between 300 and $400 \mathrm{~nm}$ the samples were exposed to for 1000- hour time increments.}

\begin{tabular}{cc}
\hline $\begin{array}{c}\text { Time Increment } \\
\text { (Hours) }\end{array}$ & $\begin{array}{c}\text { Dosage } \\
\left(\mathrm{kW}-\mathrm{hr} / \mathrm{m}^{2}\right)\end{array}$ \\
\hline $0-1000$ & 67.1 \\
$1000-2000$ & 67.5 \\
$2000-3000$ & 67.3 \\
\hline
\end{tabular}

\section{Optical Properties}

A Minolta CR-200 Chroma Meter (Minolta Corporation, Ramsey, NJ) was used to measure color using the CIELAB color system. The lightness coordinate $(L)$ was measured for five replicate samples following the approach described in previous work $(6,10,11)$. In the CIELAB color system, the value $L$ can be thought of as a lightness factor, ranging between 0 and 100. An increase in $L$ means the sample is lightening. 


\section{Mechanical Properties}

Samples were oven dried at $105^{\circ} \mathrm{C}$ for $24 \mathrm{~h}$ before testing. This ensured the same conditioning for samples before and after exposure. Flexural tests were carried out according to ASTM D790 (17) on an Instron Universal Testing machine. A three-point loading system was utilized with a crosshead speed of $1.3 \mathrm{~mm} / \mathrm{min}$, which corresponds with an outer fiber strain rate of $0.01 \mathrm{~mm} / \mathrm{mm} / \mathrm{min}$. The exposed surface was placed away from the center load to place that part of the sample in tension. At least four replicate specimens were tested for each formulation. The stress at maximum load and modulus of elasticity (MOE) were calculated according to the standard.

\subsection{Results and Discussion}

\subsubsection{Color Analysis}

Figure 6.1 shows the increase in $\mathrm{L}$ after weathering for all composite formulations. All of the formulations experienced a larger change in lightness after 1000 $\mathrm{h}$ of weathering than for each subsequent $1000 \mathrm{~h}$ of weathering. The formulation that was not stabilized lightened the most throughout weathering. After $1000 \mathrm{~h}$ of weathering a difference in lightening characteristic of stabilized composites was evident. The samples with UVA alone lightened slightly less than unstabilized composites. The composites that lightened the least throughout the exposure time all had P added. 


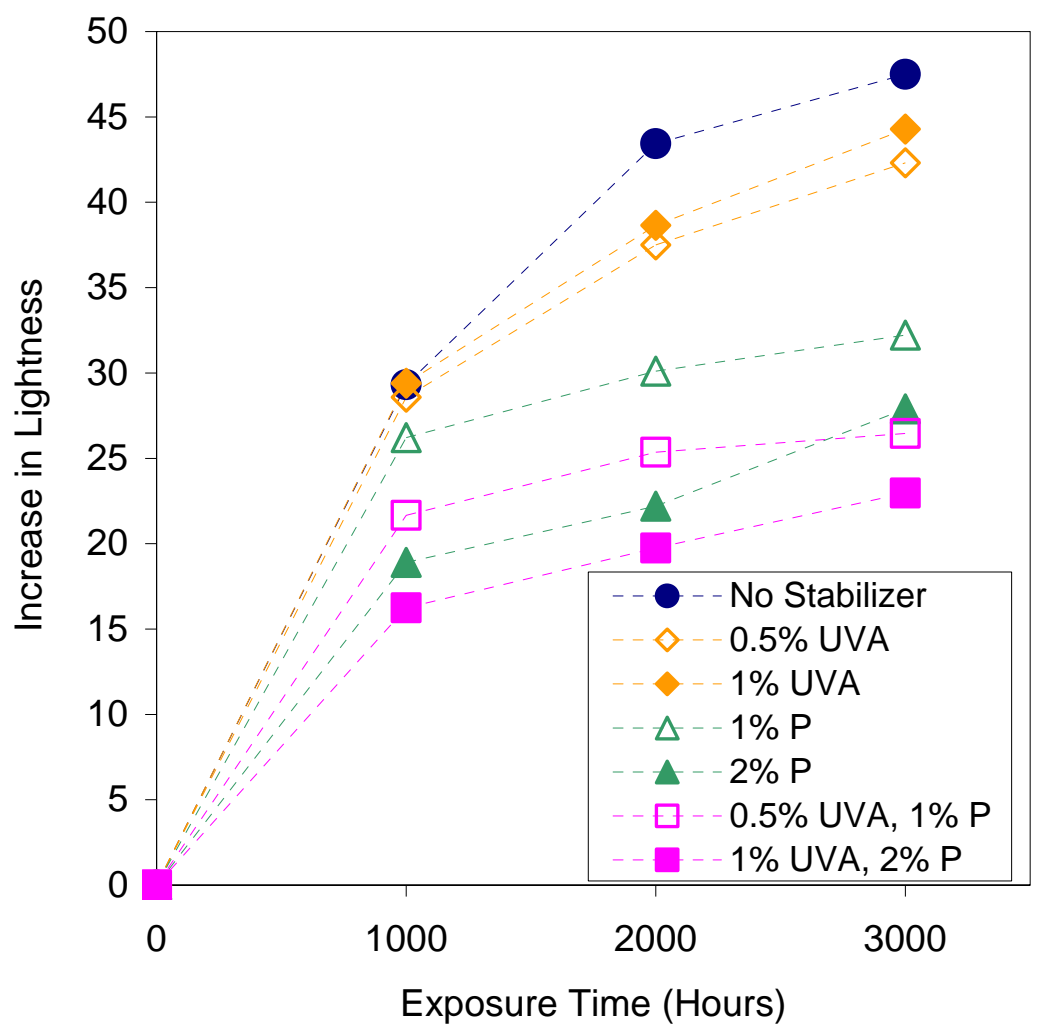

Figure 6.1. Effect of exposure time on the increase in lightness of $\mathrm{WF} / \mathrm{HDPE}$ composites. Average standard deviation $=0.6$.

The increase in lightness for each formulation on a percentage basis after $3000 \mathrm{~h}$ is summarized in Table 6.4. Composites with UVA or P did not lighten as much as the unstabilized composite. Adding either UVA or P had some effect on color change of the composites after weathering. However, adding 1\% P influenced color fade more than adding $1 \%$ UVA as expected. Therefore, $\mathrm{P}$ was more effective in preventing color fade than UVA. The composites that faded the least were those that had a combination of UVA and P. Surface discoloration was a strong function of the pigment content since the lightness did change significantly as the pigment content increased. By contrast, a relationship was not established between lightness and UVA content, although UVA reduced the lightning of the composites. 
Table 6.4. Changes in properties for $50 \%$ wood flour filled HDPE composites after $3000 \mathrm{~h}$ of accelerated weathering.

\begin{tabular}{cccc}
\hline \multirow{2}{*}{ Formulations } & $\begin{array}{c}\text { Increase in L } \\
(\%)\end{array}$ & $\begin{array}{c}\text { Loss in MOE } \\
(\%)\end{array}$ & $\begin{array}{c}\text { Loss in Strength } \\
(\%)\end{array}$ \\
\hline No Stabilization & 114.9 & 33.2 & 26.9 \\
$0.5 \%$ UVA & 97.5 & 31.7 & 20.2 \\
1\% UVA & 107.4 & 20.8 & 14.7 \\
1\% P & 73.4 & 18.4 & 13.4 \\
2\% P & 61.2 & 18.4 & 4.7 \\
$0.5 \%$ UVA, $1 \% \mathrm{P}$ & 58.9 & 15.4 & 9.2 \\
$1 \%$ UVA, $\%$ P & 49.6 & 15.9 & 2.3 \\
\hline
\end{tabular}

The change in surface discoloration of the composites was mainly due to the bleaching of wood components. The UVA reduced surface discoloration because once added into the HDPE matrix, UVA absorbs some of the UV radiation and dissipates it, therefore less is available to bleach the wood component. For the pigment, however, in addition to blocking some UV light from reaching the wood fiber, it also masks the bleaching effect, thus the pigment is more important for preventing color fade of the composite than the UVA.

\subsubsection{Flexural Property Analysis}

The loss in flexural MOE and strength during weathering is shown in Figures 6.2 and 6.3, respectively. It can be seen that loss in MOE and strength of the unstabilized composites increased as the exposure time increased. The unstabilized composites 
experienced higher losses in flexural properties throughout weathering than their counterparts with UVA and/or P added.

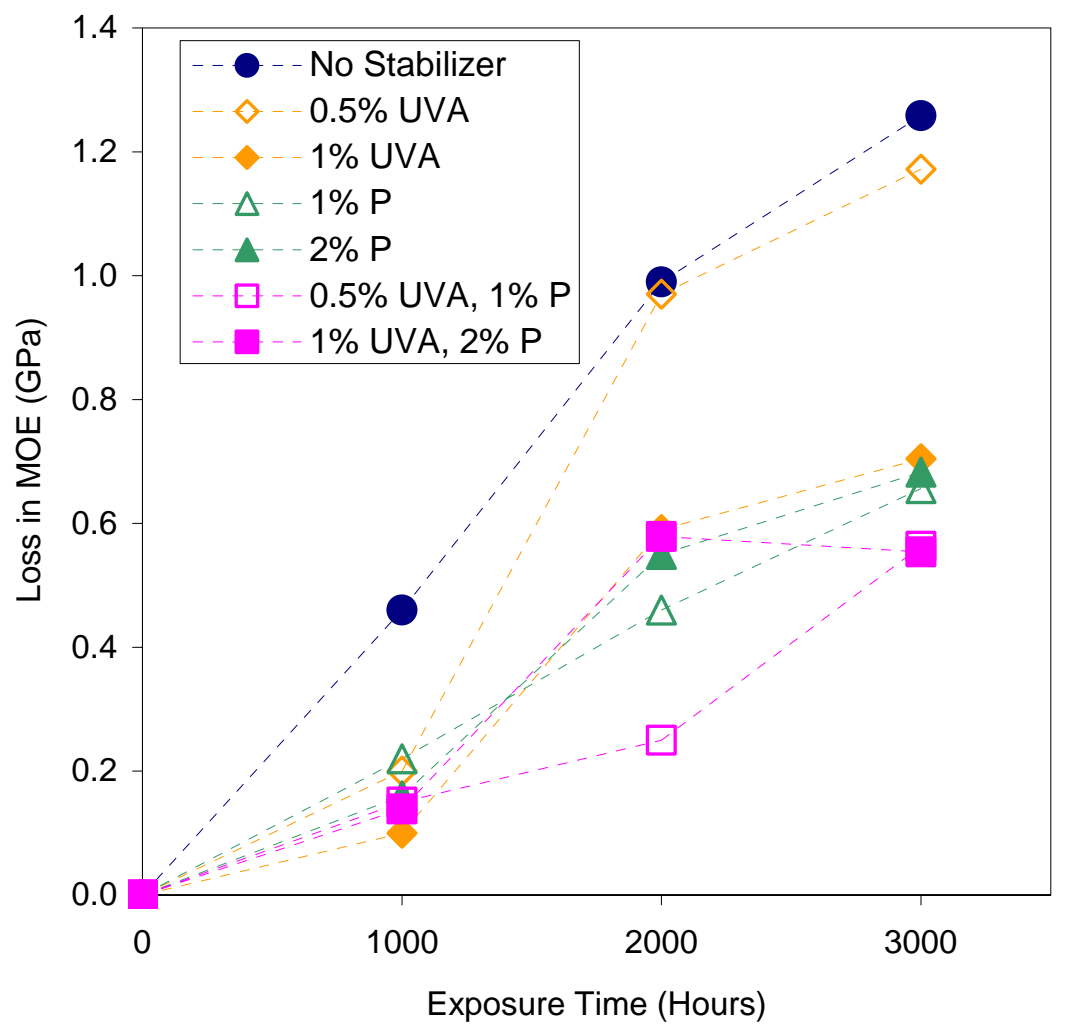

Figure 6.2. Effect of exposure time of the loss in MOE of WF/HDPE composites. Average standard deviation $=0.2$.

After $1000 \mathrm{~h}$ of weathering, both UVA and P appeared to aid in retention of flexural MOE, however the type or concentration of the stabilizer did not appear to tremendously influence MOE retention at this point (Fig. 6.2). After 2000 and $3000 \mathrm{~h}$ of weathering, UVA improved MOE retention only when added at the higher concentration of $1 \%$. The addition of $\mathrm{P}$ also resulted in $\mathrm{MOE}$ retention but increasing concentration from 1 to $2 \%$ did not seem to have a large effect on MOE retention. 


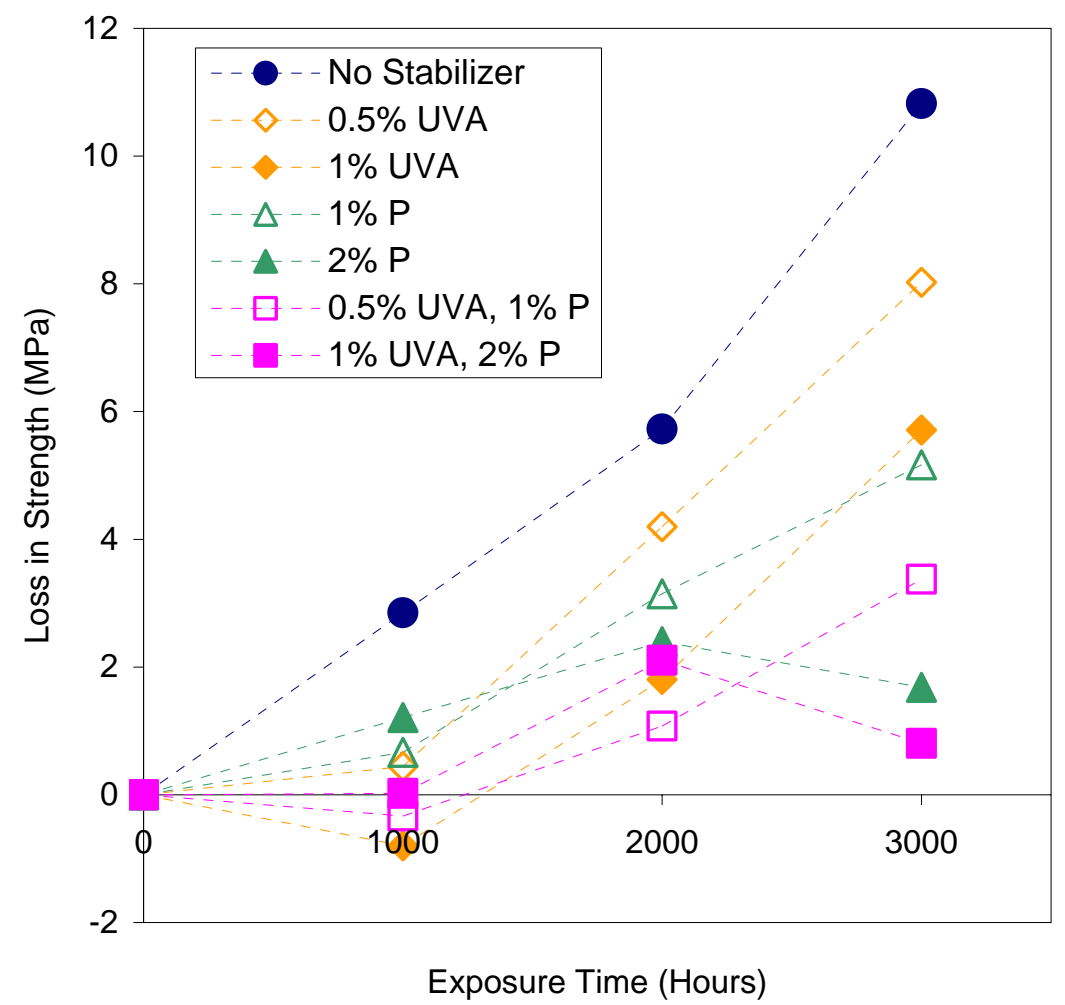

Figure 6.3. Effect of exposure time of the loss in MOE of WF/HDPE composites. Average standard deviation $=1.1$.

After $1000 \mathrm{~h}$ of weathering, all of the photostabilized composites resulted in greater strength retention than the unstabilized composites (Fig. 6.3). As weathering time continued through $3000 \mathrm{~h}$ of weathering it was found that composites with $\mathrm{P}$ added generally performed better than composites with UVA added.

Table 6.4 shows percent loss in flexural properties after $3000 \mathrm{~h}$ of weathering. It is apparent that adding only $0.5 \%$ UVA did not greatly influence the loss in MOE. Although adding $\mathrm{P}$ at $1 \%$ affected the loss in MOE, increasing $\mathrm{P}$ from 1 to $2 \%$ did not further affect the loss in MOE. Adding either 1\% UVA or 1\% P provided the same level of protection to the composites. However, the loss in strength was significantly reduced 
as the photostabilizer content increased. Increasing P from 1 to $2 \%$ and UVA from $0.5 \%$ to $1 \%$ did improve the flexural strength retention.

Theoretically, UVAs are not exhausted during the course of photodegradation. They return to their original stage after releasing UV radiation that has been absorbed. However, UVAs have been shown to degrade with time (19). This may explain why mechanical property losses between composites with $0.5 \%$ and $1 \%$ UVA added were not very different after $1000 \mathrm{~h}$ of weathering. Because composites with $1 \%$ UVA performed much better than those with $0.5 \%$ UVA after $3000 \mathrm{~h}$ of weathering, it is likely that some UVA was consumed.

During accelerated weathering, samples are exposed to both UV radiation and water spray. Moisture can also degrade mechanical properties of WPCs. Swelling of the wood particles can cause a loss in integrity of the wood particle/matrix interphase (20), leading to a reduction in mechanical properties. For example, after $3000 \mathrm{~h}$ of soaking, $40 \%$ WF filled polypropylene composites lost $36 \%$ of their initial MOE and $22 \%$ of their initial strength (21). Increasing wood content further increases the sensitivity to moisture. HDPE composites containing $55-70 \%$ WF lost approximately $40 \%$ of their initial MOE and $30 \%$ of their initial strength after being saturated with water (20).

While part of the loss in MOE after weathering is likely a result of moisture exposure, part of the loss in MOE after weathering may be attributed to a loss in crystallinity of the HDPE matrix. Decreasing crystallinity of HDPE results in a drop in MOE. It has been shown that crystallinity of WF/HDPE composites initially increases during accelerated weathering, and then as weathering continues decreases (10). Adding both UVA and P delay the drop in crystallinity resulting in a retention of MOE (10). 
Adding $\mathrm{P}$ at $1.0 \%$ is sufficient enough to block UV radiation and protect against MOE loss resulting from a decrease in crystallinity. However, increasing UVA concentration may initially prevent some loss in crystallinity, and may also counteract consumption of UVA during longer weathering times.

Decreasing crystallinity of HDPE also results in a decrease in strength. Therefore, part of the loss in strength is likely also a result of a loss in crystallinity of the HDPE matrix after weathering. Again, adding both UVA and P delay the drop in crystallinity and the result is increased retention of strength after weathering over that of unstabilized composites. Unlike the trend observed with $\mathrm{MOE}$, increasing P content from $1 \%$ to $2 \%$ results in a dramatic improvement in strength retention. This may be a result of the nature of the pigment, a zinc ferrite in a carrier wax. Wax aids in dispersing the pigment, but may also find its way to the wood/polymer interface. The wax may be protecting WF, causing a hydrophobic surface, resulting in less degradation of the interface. The strength of a composite is largely dependent upon interfacial quality to transfer stress from matrix to the fiber. As P concentration increases, protection from UVA becomes less important in preventing strength loss.

\subsection{Conclusions}

Wood-plastic composites experience both color fade and mechanical property loss after weathering. Adding ultraviolet absorbers (UVAs) and/or pigments (Ps) has been shown to protect against color fade and mechanical property loss. This study investigated the influence of concentration changes of UVA and $\mathrm{P}$ on the photostabilization of WF/HDPE composites. 
Adding UVA or P resulted in the composites lightening less after all weathering times. Increasing the concentration of UVA from 0.5 to $1 \%$ resulted in less lightening, as did increasing P concentration from $1 \%$ to $2 \%$. After $3000 \mathrm{~h}$ of weathering, the samples that lightened least were the combinations of UVA and P. If P and UVA are added at the same concentration, $\mathrm{P}$ is more efficient for preventing lightening than UVA. Both UVA and $\mathrm{P}$ absorb UV radiation to prevent WF bleaching, however adding $\mathrm{P}$ also masks bleaching.

Mechanical properties generally decreased after weathering. Adding UVA at low percentages likely results in a consumption of a majority of UVA after $1000 \mathrm{~h}$ of weathering. When either UVA or P were added, the composites retained flexural properties better than the unstabilized composites. Increasing the amount of UVA from 0.5 to $1 \%$ did affect flexural MOE but increasing P from 1 to $2 \%$ did not affect flexural MOE. Adding P at the lower level may be sufficient enough to prevent MOE loss due to a decrease in crystallinity. Increasing both UVA and P affected flexural strength loss. The more $\mathrm{P}$ in the system the less important UVA becomes for retaining flexural strength. This may be attributable to the carrier wax the pigment is in. The wax may protect the composites by making the WF surface more hydrophobic, thereby protecting the interface.

\subsection{References}

1. J. Morton, "Current and Emerging Applications for Natural \& Wood Fiber Composites," in Proceedings, $7^{\text {th }}$ International Conference on Woodfiber-Plastic Composites, Madison, WI, May 19-20, 2003.

2. C. Eckert, "Opportunities for Natural Fibers in Plastic Composites," in Proceedings, Progress in Wood Fiber-Plastic Composites Conference, Toronto, May 25-26, 2000. 
3. C. Clemons, "Wood-Plastic Composites in the United States, The Interfacing of Two Industries," Forest Products Journal, 52(6), 10-18, 2002.

4. R.H. Falk, T. Lundin and C. Felton, "The Effects of Weathering on WoodThermoplastic Composites Intended for Outdoor Applications," in Proceedings, Durability and Disaster Mitigation in Wood-Frame Housing, 175-179, Madison, WI, Nov. 6-8, 2000.

5. T. Lundin, "Effect of Accelerated Weathering on the Physical and Mechanical Properties of Natural-Fiber Thermoplastic Composites," M.S. Thesis, University of Wisconsin-Madison, 2001.

6. N.M. Stark and L.M. Matuana, "Ultraviolet Weathering of Photostabilized Wood Flour-HDPE Composites," accepted in Journal of Applied Polymer Science, February 2003.

7. L.M. Matuana, D.P. Kamdem and J. Zhang, "Photoaging and Stabilization of Rigid PVC/Wood-Fiber Composites," Journal of Applied Polymer Science, 80(11), 19431950, 2001.

8. L.M. Matuana and D.P. Kamdem, "Accelerated Ultraviolet Weathering of PVC/Wood-Flour Composites," Polymer Engineering and Science, 42(8), 16571666, 2002.

9. R.M. Rowell, S.E. Lange and R.E. Jacobson, "Weathering Performance of PlantFiber/Thermoplastic Composites," Molecular Crystals And Liquid Crystals, 353, 85-94, 2000.

10. N.M. Stark and L.M. Matuana, "Structural and Mechanical Property Changes of Wood-Flour/HDPE Composites After Accelerated Weathering," submitted to Journal of Applied Polymer Science, August 2003.

11. N.M. Stark and L.M. Matuana, "Surface Chemistry Changes of Weathered HDPE/Wood-Flour Composites Studied by XPS and FTIR Spectroscopy," submitted to Polymer Degradation and Stability, August 2003.

12. P. Pagès, F. Carrasco, J. Saurina and X. Colom, "FTIR and DSC Study of HDPE Structural Changes and Mechanical Properties Variation when Exposed to Weathering Aging During Canadian Winter," Journal of Applied Polymer Science, 60(2), 153-159, 1996.

13. X. Colom, J. Cañavate, P. Pagès, J. Saurina and F. Carrasco, "Changes in Crystallinity of the HDPE Matrix in Composites with Cellulosic Fiber Using DSC and FTIR," Journal of Reinforced Plastics and Composites, 19(10), 818-830, 2000.

14. J.J. Suñol and J. Saurina, "Thermal Analysis of Aged HDPE Based Composites," Journal of Thermal Analysis and Calorimetry, 70, 2002, 57-62.

15. F. Gugumus, "Light Stabilizers," in Plastics Additives Handbook, Chapter 3, 129262, R. Gächter and H. Müller, Eds., Hanser Publishers, New York, 1990.

16. G. Wypych, Handbook of Material Weathering, ChemTec Publishing, TorontoScarborough, 1995.

17. American Society for Testing and Materials, "D790 Standard Test Method for Flexural Properties of Unreinforced and Reinforced Plastics and Electrical Insulating Materials," in Annual Book of ASTM Standards, 8.01, 2000.

18. American Society for Testing and Materials, "D2565 Standard Practice for XenonArc Exposure of Plastics Intended for Outdoor Applications," in Annual Book of ASTM Standards, 8.02, 2000. 
19. J.E. Picket, "Permanence of UV Absorbers in Plastics and Coatings," in Service Life Prediction, Methodology and Metrologies, Chapter 12, 250-265, J.W. Martin and D.R. Bauer, Eds, Oxford University Press, Washington D.C., 2002.

20. S.V. Rangaraj and L.V. Smith, "Effects of Moisture on the Durability of a Wood/Thermoplastic Composite," Journal of Thermoplastic Composite Materials, 13(3), 140-161, 2000.

21. N. Stark, "Influence of Moisture Absorption on Mechanical Properties of Wood Flour-Polypropylene Composites," Journal of Thermoplastic Composite Materials, 14(5), 421-432, 2001. 


\section{Chapter 7 - Structural AND MEChanical PROPERTY CHANGES OF WOOD FLOUR/HDPE COMPOSITES AFTER ACCELERATED WEATHERING}

This chapter is in preparation for publication in Journal of Applied Polymer Science. It is co-authored by N.M. Stark and L.M. Matuana. 


\subsection{Abstract}

It has been shown that wood-plastic composites exposed to accelerated weathering may experience a color change and/or loss in mechanical properties. In this study, high density polyethylene (HDPE) and wood flour filled HDPE composites underwent accelerated weathering. The materials were left unstabilized, or were stabilized with either an ultraviolet absorber or pigment. After 1000 and $2000 \mathrm{~h}$ of accelerated weathering the samples were tested for loss in modulus of elasticity. Fourier transform infrared (FTIR) spectroscopy was employed to monitor carbonyl and vinyl group formation at the surface. The change in HDPE crystallinity was also determined using FTIR techniques. It was determined that structural changes in the samples; carbonyl group formation, terminal vinyl group formation, and crystallinity changes cannot reliably be used to predict changes in modulus of elasticity using a simple linear relationship. This indicates that the effect of cross-linking, chain scission, and crystallinity changes due to ultraviolet exposure as well as the interfacial degradation due to moisture exposure are inter-related factors when weathering HDPE and wood flour/HDPE composites.

\subsection{Introduction}

Although inorganic fillers currently dominate the thermoplastic industry, woodderived fillers have become more accepted in recent years and have made significant inroads into specialty markets. Construction, transportation, industrial and consumer applications are all on the rise. However, building products comprise the largest portion 
of the wood-plastic composite market (1). Exterior non-structural or semi-structural building products such as decking, fencing, siding, and roof tiles are being introduced into the marketplace. It is predicted that for building products alone, approximately 1.1 billion $\mathrm{lb}(500,000$ tons) of wood-plastic composites will be used in North America in 2006 (1). Although wood-plastic lumber is promoted as being a low-maintenance and high-durability product (2), ultraviolet (UV) durability is a concern. It has been shown that wood-plastic composites exposed to accelerated weathering experience a color change (3-8) and a loss in mechanical properties (3-6).

Although the photodegradation of polyethylene has been extensively examined (9-19), little information is available on the photodegradation of wood-flour-filled highdensity polyethylene (WF/HDPE) composites $(3-6,20)$. Much of the research conducted to date reports solely on color fade and mechanical property loss after accelerated weathering (3-6). Some work has been done examining surface chemistry changes of wood flour filled poly-vinyl chloride $(7,8)$, and others have examined the crystallinity changes of aspen fiber filled polyethylene after weathering $(21,22)$ but the information available on the surface chemistry changes of WF/HDPE composites after weathering is sparse $(20,22)$.

The degradation of polyethylene exposed to UV light (photodegradation) has been extensively studied (9-19). It has been postulated that carbonyl groups are the main light absorbing species responsible for the photochemical initiation reactions of UV exposed polyethylene (9). The degradation reactions proceed from carbonyl group precursors according to Norrish type I and II reactions (9-11). If degradation of the carbonyl groups proceeds according to Norrish I, the resulting free radicals formed can attack the polymer 
(Fig. 7.1a). Free radical attack may lead to termination via cross-linking or chain scission (10). If the degradation proceeds according to Norrish II, carbonyl groups and terminal vinyl groups are produced (Fig. 7.1b) and chain scission occurs. In addition, the carbonyl group formed is capable of further degradation. During the course of polyethylene photodegradation the two mechanisms, chain scission and cross-linking, are competing (9-11). While chain scission occurs in the amorphous phase of the polymer, imperfect crystalline regions degrade due to cross-linking (12). Tie molecules, chains traversing the amorphous phase from one crystalline lamella to another, can also be affected during photodegradation (13). Decreasing the tie molecule density can increase environmental stress cracking (23).

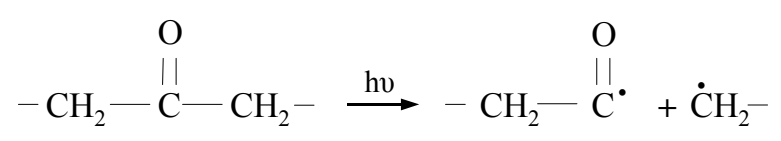

$$
\begin{aligned}
& \stackrel{\stackrel{\mathrm{O}}{\mathrm{Il}} \cdot \mathrm{CH}-\mathrm{C}}{\longrightarrow}--\dot{\mathrm{C}}_{2}+\mathrm{CO} \\
& \text { (7.1a) Norrish I }
\end{aligned}
$$

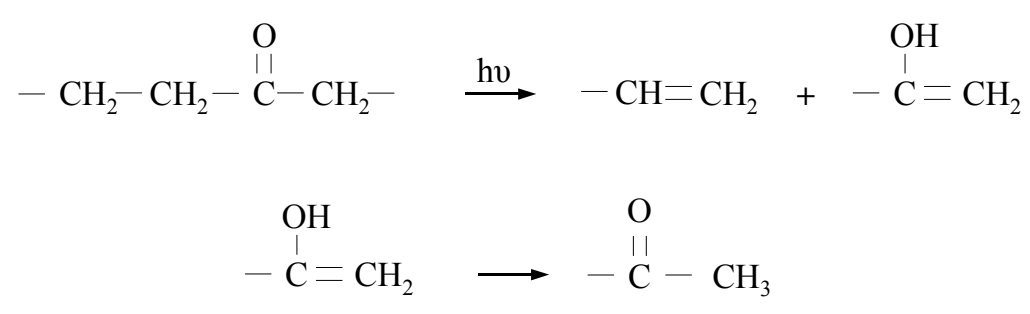$$
\text { (7.1b) Norrish II }
$$

Figure 7.1. Norrish degradation mechanisms from carbonyl precursors: (a) Norrish I, and (b) Norrish II. 
The formation of carbonyl groups and vinyl groups indicate main chain scission (14-16). An increase in polyethylene crystallinity after weathering also indicates that chain scission has occurred. The shorter chains produced during chain scission are more mobile and are able to crystallize more readily, resulting in an increased crystallization and associated embrittlement $(9,10)$. The crystalline component of polyethylene has a higher modulus than the amorphous component therefore increasing the crystallinity increases the modulus of elasticity (MOE) of polyethylene (24).

Recently Fourier Transform Infrared (FTIR) spectroscopy has been employed to study the changes in surface chemistry of polyethylene after weathering. FTIR spectroscopy has been used to monitor carbonyl group formation (9,11-16), vinyl group formation $(9,11,12,14)$, and changes in crystallinity $(19,25,26)$ of weathered polyethylene.

The mechanical properties of wood flour filled polymer composites are negatively affected by moisture (27-32). When the composite is exposed to moisture, the hydrophilic fiber swells. Cracks may form in the polymer matrix, which can also contribute to the penetration of water into the composite (28). Exposing wood filled polymer composites to moisture results in a drop in flexural modulus of elasticity and strength by degrading the wood-polymer interfacial quality (28-30). The amount of moisture absorbed can be influenced by wood flour content and wood particle size $(28,31)$.

Photostabilizers are compounds developed to protect polymers and combat UV degradation. These photostabilizers are generally classed according to the degradation mechanism they hinder. The three main types of photostabilizers are UV absorbers (UVAs), quenchers, and free radical scavengers. In addition, pigments, while not 
technically photostabilizers, are often used as photo-blockers to inhibit the photodegradation of polymers (33).

Much of the available information on photostabilizers covers solely the photostabilization of unfilled plastics $(10,11,17,18,33)$. The hindered amine light stabilizers studied to date have been shown to be ineffective stabilizers for WF/HDPE composites (3-6). It is suggested that this is due to acid-base interactions between the hindered amine and the wood particles (6). In a previous study it was determined that UVAs and pigments are the most effective photostabilizers for WF/HDPE composites, protecting against both color fade and mechanical property loss $(5,6)$. Others have also shown that pigments are able to prevent some mechanical property loss after accelerated weathering (3-6).

The results of the study reported here will aid in the development of an understanding of how photostabilizers affect the mechanical properties and structural changes of WF/HDPE composites after weathering. This study has three main objectives: 1) to characterize loss in modulus of elasticity (MOE) of photostabilized HDPE blends and WF/HDPE composites, 2) to understand how weathering changes the structure and surface chemistry of photostabilized HDPE blends and WF/HDPE composites, and 3) to relate changes in the MOE to changes in the surface chemistry.

\subsection{Methods}

\subsubsection{Materials}

The materials used in this study were wood flour (WF) and high-density polyethylene (HDPE). The WF was a 40 mesh ponderosa pine supplied by American 
Wood Fibers (Schofield, WI). The HDPE was a virgin material with a melt index of 0.72 $\mathrm{g} / 10 \mathrm{~min}$ and density of $0.963 \mathrm{~g} / \mathrm{cm}^{3}$ supplied by Solvay Polymers, Inc. (Fortiflex A6070-162, Houston, TX). A hydroxy benzotriazole UV absorber (UVA) supplied by Ciba Specialty Chemicals (Tinuvin 328, Tarrytown, NY) and zinc ferrite pigment in a carrier wax (P) supplied by Holland Colors Americas Inc. (Cedar TI-8536, Richmond, IN) were used as photostabilizers. The formulations of neat HDPE and WF/HDPE composite blends are shown in Table 7.1.

Table 7.1. Formulations of neat HDPE and WF/HDPE composite blends.

\begin{tabular}{lcccc}
\hline Formulations & $\mathrm{wt} \% \mathrm{HDPE}$ & $\mathrm{wt} \% \mathrm{WF}$ & $\mathrm{wt} \% \mathrm{UVA}$ & $\mathrm{wt} \% \mathrm{P}$ \\
\hline HDPE & 100 & 0 & 0 & 0 \\
HDPE/UVA & 99.5 & 0 & 0.5 & 0 \\
HDPE/P & 99 & 0 & 0 & 1 \\
WF/HDPE & 50 & 50 & 0 & 0 \\
WF/HDPE/UVA & 49.5 & 50 & 0.5 & 0 \\
WF/HDPE/P & 49 & 50 & 0 & 1 \\
\hline
\end{tabular}

\subsubsection{Processing}

The neat HDPE samples were molded into flexural bar test samples using a 33ton Cincinnati Milacron (Batavia, OH) injection molder. The mold nozzle temperature was $204^{\circ} \mathrm{C}\left(400^{\circ} \mathrm{F}\right)$ and the injection pressure reached a peak of $12.4 \mathrm{MPa}(1800 \mathrm{psi})$. The American Society for Testing and Materials mold cavity used for the flexural samples is $120 \times 3 \times 12 \mathrm{~mm}(34)$. 
The WF was dried for $24 \mathrm{~h}$ at $105^{\circ} \mathrm{C}\left(221^{\circ} \mathrm{F}\right)$, and then the composites were dryblended according to the formulations in Table 7.1. Compounding was accomplished using a 32-mm Davis Standard (Pawcatuck, CT) twin-screw extruder to produce homogeneous $\mathrm{WF} / \mathrm{HDPE}$ composite pellets. The melt temperature at the die was $200^{\circ} \mathrm{C}$ $\left(392^{\circ} \mathrm{F}\right)$ and the melt pressure was $2.96 \mathrm{MPa}(430 \mathrm{psi})$. The pellets were dried at $105^{\circ} \mathrm{C}$ $\left(221^{\circ} \mathrm{F}\right)$ for at least $24 \mathrm{~h}$ prior to injection molding into flexural bar test samples. The injection molding conditions were the same as for the neat HDPE manufacture.

\subsubsection{Testing And Analysis}

\section{Weathering}

The samples were placed in a xenon arc-type light exposure apparatus and operated according to ASTM D2565 (35). Samples were mounted in four rows on a drum that rotated around the xenon arc bulb at $1 \mathrm{rpm}$. The samples were rotated every $250 \mathrm{~h}$ to ensure that all were exposed to the same irradiance. The weathering cycle consisted of 108 min UV exposure and 12 min simultaneous water spray and light exposure (35). To understand the effect of weathering, samples were removed for analysis after 1000 and $2000 \mathrm{~h}$ of weathering and compared to unexposed samples.

\section{Scanning Electron Microscopy}

Molded surfaces were sputter-coated with gold and analyzed with a scanning electron microscope (SEM) (JSM-840, JEOL USA, Inc., Peabody, MA) at a working distance of approximately $25 \mathrm{~mm}$, a voltage of $15 \mathrm{kV}$, and a probe current of $6 \times 10^{-10}$ amps. 


\section{Mechanical Properties}

Samples were oven dried at $105^{\circ} \mathrm{C}$ for $24 \mathrm{~h}$ before testing. This ensured the same conditioning for samples before and after weathering. Flexural tests were carried out according to ASTM D790 (34) on an Instron Universal Testing machine. The three-point loading system was utilized with a crosshead speed of $1.3 \mathrm{~mm} / \mathrm{min}$ corresponding with a strain rate of $0.01 \mathrm{~mm} / \mathrm{mm} / \mathrm{min}$. The exposed surface was placed away from the center load to place that part of the sample in tension. At least four replicate specimens were tested for each formulation. The tangent modulus of elasticity (MOE) was calculated by fitting a line to the initial slope of the stress-strain curve.

\section{Fourier Transform Infrared Microscopy}

FTIR spectroscopy was conducted on a Mattson Genesis II spectrophotometer to provide a detailed knowledge of the functional groups present at the surface of the samples. Scans were run at a resolution of $4 \mathrm{~cm}^{-1}$. Each sample recorded consisted of 100 scans recorded in absorbance units from 4000-700 $\mathrm{cm}^{-1}$. The spectra were obtained using attenuated total reflectance (ATR). The surfaces of the samples analyzed were in contact with a $\mathrm{ZnSe}$ crystal that has a $45^{\circ}$ angle of incidence. At least five replicate specimens were analyzed for each formulation. Both a carbonyl index and a vinyl index were calculated using the following equations:

$$
\begin{gathered}
\text { Carbonyl Index }=\frac{I_{1715}}{I_{2912}} \times 100 \\
\text { Vinyl Index }=\frac{I_{908}}{I_{2912}} \times 100
\end{gathered}
$$


where I represents the peak intensity. The peak intensities were normalized using the peak at $2912 \mathrm{~cm}^{-1}$, which corresponds to methyl group vibrations.

The crystallinity of the HDPE was determined using the method described by Zerbi et al. (25). The doublet peaks observed at $1474-1464 \mathrm{~cm}^{-1}$ and $730-720 \mathrm{~cm}^{-1}$ correspond to polyethylene crystalline content $\left(1474 \mathrm{~cm}^{-1}\right.$ and $\left.730 \mathrm{~cm}^{-1}\right)$ and amorphous content $\left(1464 \mathrm{~cm}^{-1}\right.$ and $\left.720 \mathrm{~cm}^{-1}\right)$. The percentage of the crystalline content, $\mathrm{X}$, can be calculated using Equation 7.3:

$$
X=100-\frac{\frac{1-I_{a} / I_{b}}{1.233}}{1+I_{a} / I_{b}} \times 100
$$

where $I_{a}$ and $I_{b}$ can be determined from either the bands at $1474 \mathrm{~cm}^{-1}$ and $1464 \mathrm{~cm}^{-1}$, or 730 $\mathrm{cm}^{-1}$ and $720 \mathrm{~cm}^{-1}$, respectively (25).

Colom et al. (21) examined the crystallinity changes of aspen fiber filled HDPE composites using the FTIR method and differential scanning calorimetry (DSC). They determined that the bands at $730 \mathrm{~cm}^{-1}$ and $720 \mathrm{~cm}^{-1}$ were the most appropriate bands to study as a peak from cellulose fibers at $1430 \mathrm{~cm}^{-1}$ interferes with the $1474 \mathrm{~cm}^{-1}$ and 1464 $\mathrm{cm}^{-1}$ peaks (21). In addition Kaci et al. (19) studied the crystallinity changes of lowdensity polyethylene films after weathering using FTIR and DSC. They concluded that using the bands at $1474 \mathrm{~cm}^{-1}$ and $1464 \mathrm{~cm}^{-1}$ to determine crystallinity leads to unreliable results because they are asymmetric (19). In this paper, the crystallinity was calculated using the doublet peaks at $730 \mathrm{~cm}^{-1}$ and $720 \mathrm{~cm}^{-1}$. 


\section{$\underline{\text { Statistics }}$}

To determine the effects of weathering on properties, Student's two-tailed $t$-tests were carried out at $\alpha=0.05$ for each blend, testing the data for significant differences within a blend due to weathering. Statistical analysis was done separately for each HDPE blend or WF/HDPE composite.

One of the objectives of this study was to understand how weathering affected the properties of HDPE blends and WF/HDPE blends. Therefore comparisons were only performed within each blend between unweathered and weathered samples. Comparisons between unstabilized and stabilized samples were not performed. In Figures 7.4-7.11 (see results and discussion) statistically significant differences within each group are represented with separate letters. Means with different letters indicate statistically significant changes after weathering. Otherwise, the changes are not statistically significant.

To relate the change in carbonyl index, vinyl index, or crystallinity with changes in MOE after $2000 \mathrm{~h}$ of weathering, linear regressions were performed from plots where flexural MOE was on the y-axis and carbonyl index, vinyl index, or crystallinity was on the $\mathrm{x}$-axis. This was carried out for the HDPE blends and WF/HDPE blends independently. In each case, the samples with and without photostabilizers were included in the analysis. 


\subsection{Results and Discussion}

\subsubsection{Scanning Electron Microscopy}

The micrographs of the exposed neat HDPE blends and WF/HDPE composites are shown in Figures 7.2 and 7.3, respectively. The surface of the unstabilized neat HDPE without weathering was initially smooth (Fig. 7.2a), however after $2000 \mathrm{~h}$ of accelerated weathering surface cracks were readily apparent (Fig. 7.2b). Adding either UVA or P to HDPE as a photostabilizer prevented the appearance of surface cracks after $2000 \mathrm{~h}$ of accelerated weathering (Figs. 7.2c and 7.2d, respectively).

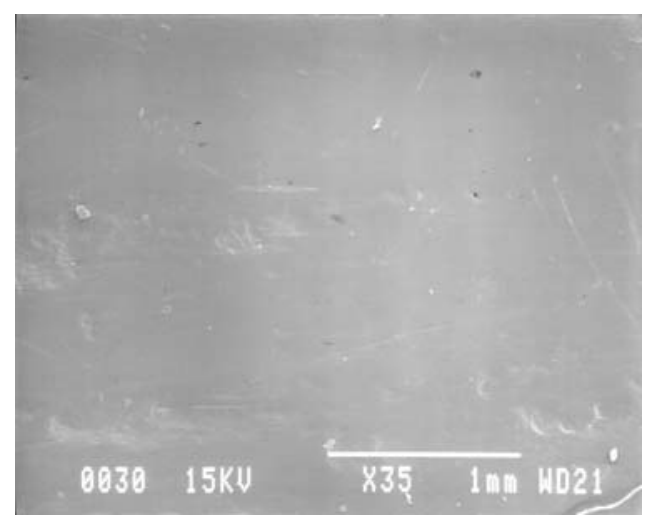

(7.2a)

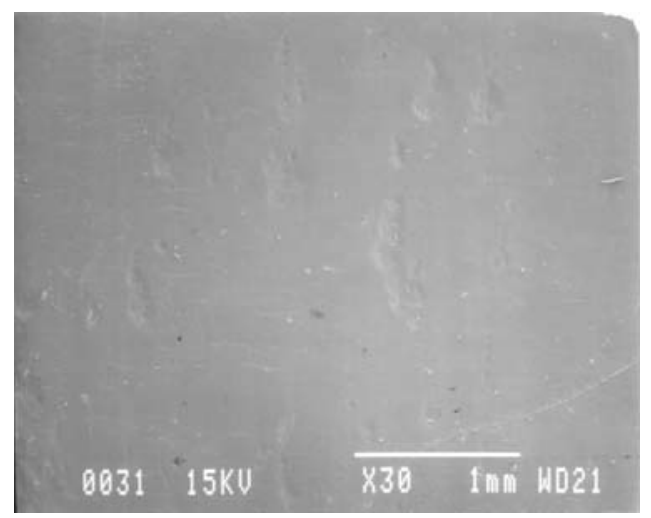

$(7.2 \mathrm{c})$

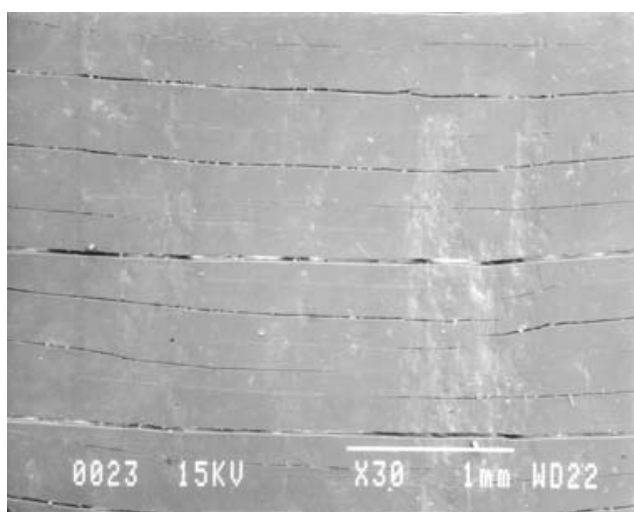

$(7.2 b)$

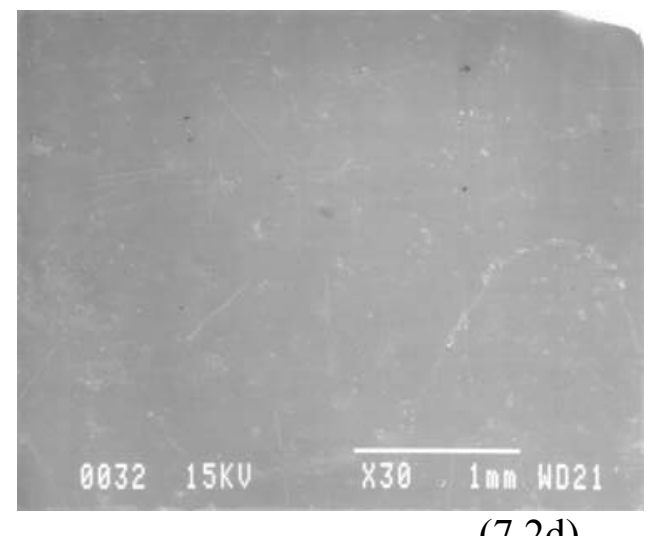

(7.2d)

Figure 7.2. Micrographs of neat HDPE: (a) unstabilized without weathering, (b) unstabilized-exposed to $2000 \mathrm{~h}$ of weathering, (c) stabilized with UVA-exposed to $2000 \mathrm{~h}$ of weathering, (d) stabilized with pigment-exposed to $2000 \mathrm{~h}$ of weathering. 
The micrograph of the unstabilized and unexposed WF/HDPE composite (Fig. 7.3a) also shows a relatively smooth surface. However, after weathering two distinct phenomenon occurred to the composite (Fig. 7.3b): (i) the WF particles had risen from the surface and (ii) the HDPE matrix had apparent surface cracks. The addition of UVA or P did not prevent the WF particles from protruding through the sample surface after weathering (Figs. 7.3c and 7.3d), however there appeared to be fewer surface cracks in the HDPE matrix when compared to the unstabilized samples (Fig. 7.3b).

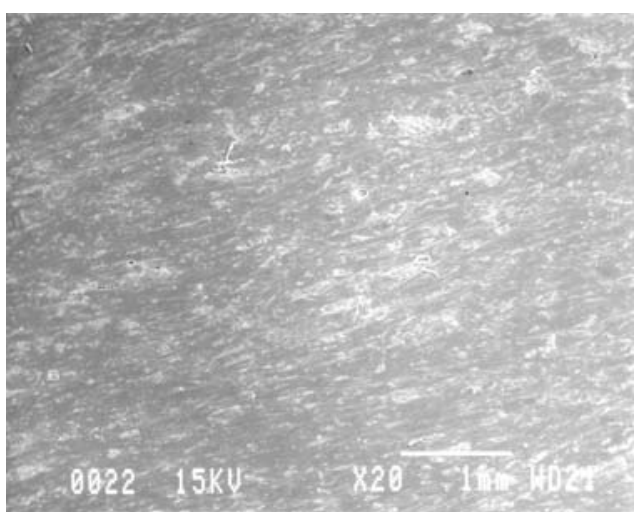

(7.3a)

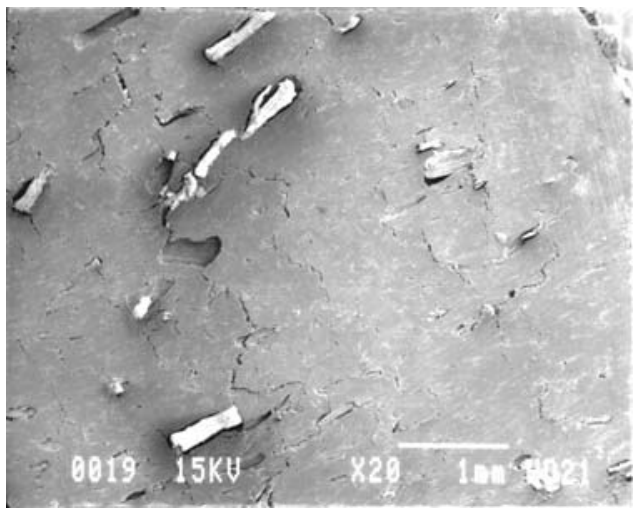

$(7.3 \mathrm{c})$

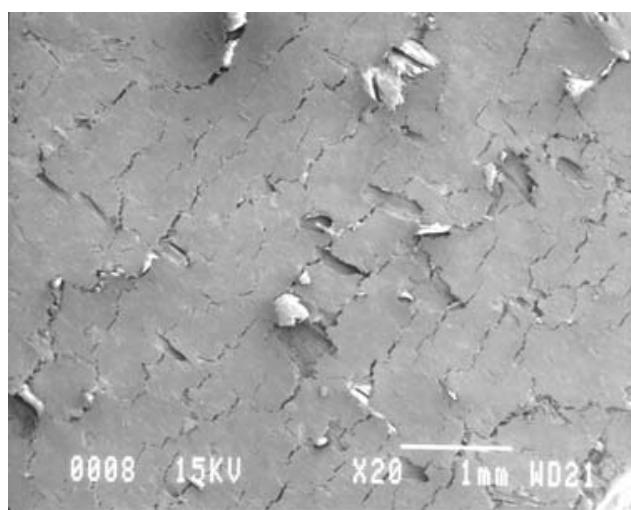

$(7.3 b)$

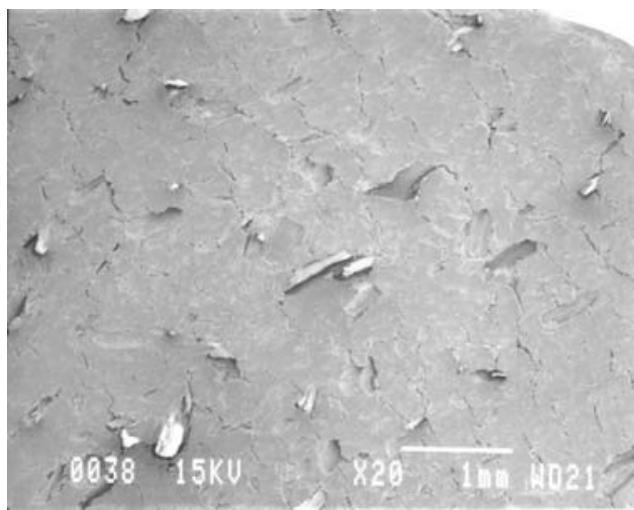

$(7.3 \mathrm{~d})$

Figure 7.3. Micrographs of WF/HDPE composites: (a) unstabilized without weathering, (b) unstabilized-exposed to $2000 \mathrm{~h}$ of weathering, (c) stabilized with UVA-exposed to $2000 \mathrm{~h}$ of weathering, (d) stabilized with pigment-exposed to $2000 \mathrm{~h}$ of weathering. 


\subsubsection{Flexural Modulus}

Figures 7.4 and 7.5 illustrate the flexural modulus of elasticity (MOE) of unfilled HDPE blends and WF/HDPE composites, respectively. Flexural MOE was calculated using the initial tangential slope of the load-displacement curve. All the samples failed on the tensile side during testing.

For unstabilized neat HDPE, flexural MOE increased significantly upon weathering after $1000 \mathrm{~h}$ (Fig. 7.4). An increase in modulus can be a sign of an increase in crystallinity or cross-linking. After $2000 \mathrm{~h}$ of weathering the MOE decreased to a level that was not significantly different from the initial MOE. The loss of MOE was consistent with the appearance of surface cracks. Environmental stress cracking in polyethylene increases with a decrease in tie molecule density (23).

HDPE stabilized with UVA or $\mathrm{P}$ also resulted in an initial increase in flexural MOE after $1000 \mathrm{~h}$ of weathering. However, the addition of UVA prevented a drop in MOE between 1000 and $2000 \mathrm{~h}$ of weathering. The addition of $\mathrm{P}$ resulted in significant drop in MOE during the second thousand hours of exposure, but the drop was not large enough to return to the level of the initial MOE. The addition of the photostabilizers UVA and P may have delayed the chain scission process that led to the degradation of MOE. It is expected that further exposure would lead to a drop in MOE for the photostabilized HDPE as well as the formation of surface cracks.

The flexural MOE of unstabilized WF/HDPE decreased slightly but significantly between 0 and $1000 \mathrm{~h}$ of weathering, and experienced a larger drop between 1000 and $2000 \mathrm{~h}$ (Fig. 7.5). The addition of UVA and $\mathrm{P}$ to the WF/HDPE composite resulted in a small increase in MOE between 0 and $1000 \mathrm{~h}$ of weathering. The stabilized composites 
also experienced a drop in MOE between 1000 and $2000 \mathrm{~h}$ of weathering. There was a net drop in MOE after $2000 \mathrm{~h}$ of weathering for all WF/HDPE blends, however the loss in MOE was $26 \%$ for the unstabilized WF/HDPE and was $18 \%$ and $15 \%$ for composites with UVA and P stabilizers, respectively. Clearly the photostabilizers UVA and P prevent some loss in MOE of WF/HDPE composites after weathering. Falk et. al. (4) have also found that red and black pigments can protect WF/HDPE composites from a loss in MOE after weathering.

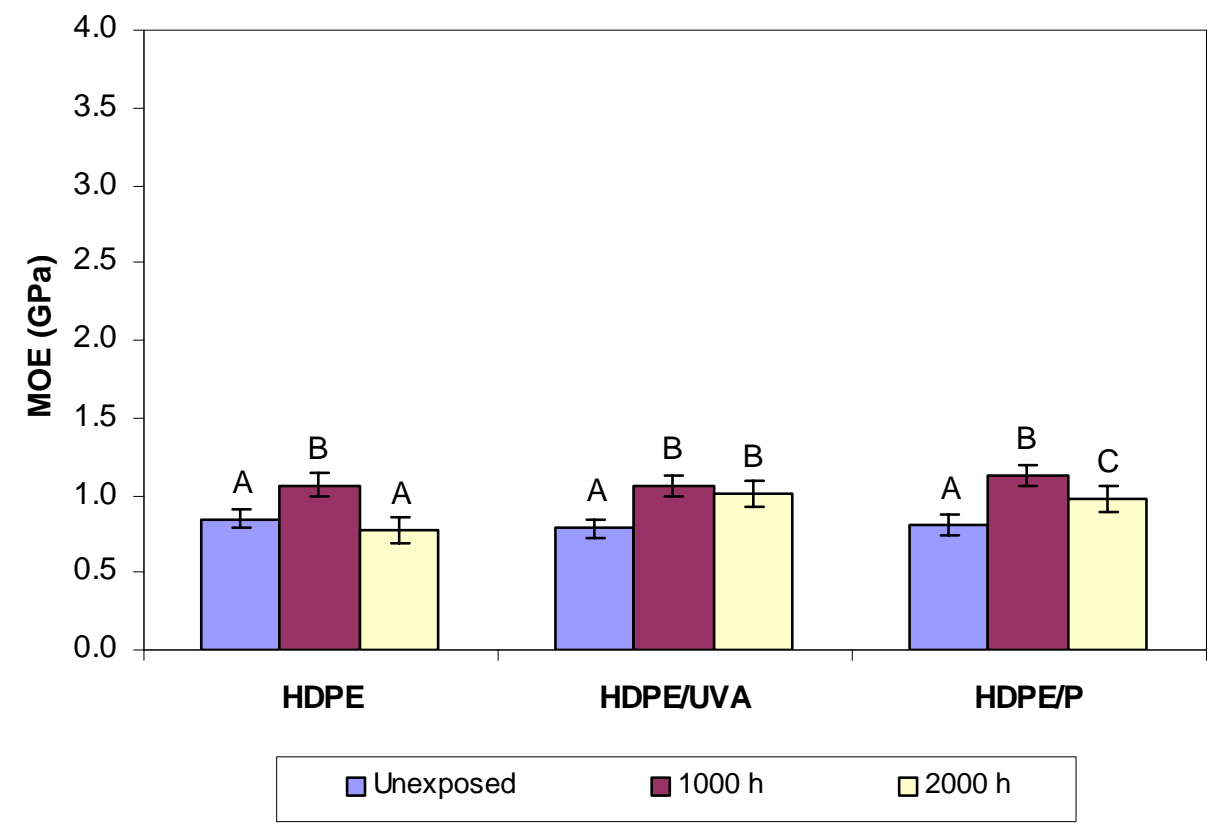

Figure 7.4. Flexural MOE of neat HDPE blends before and after accelerated weathering. Statistically significant differences within each group are represented with different letters. 


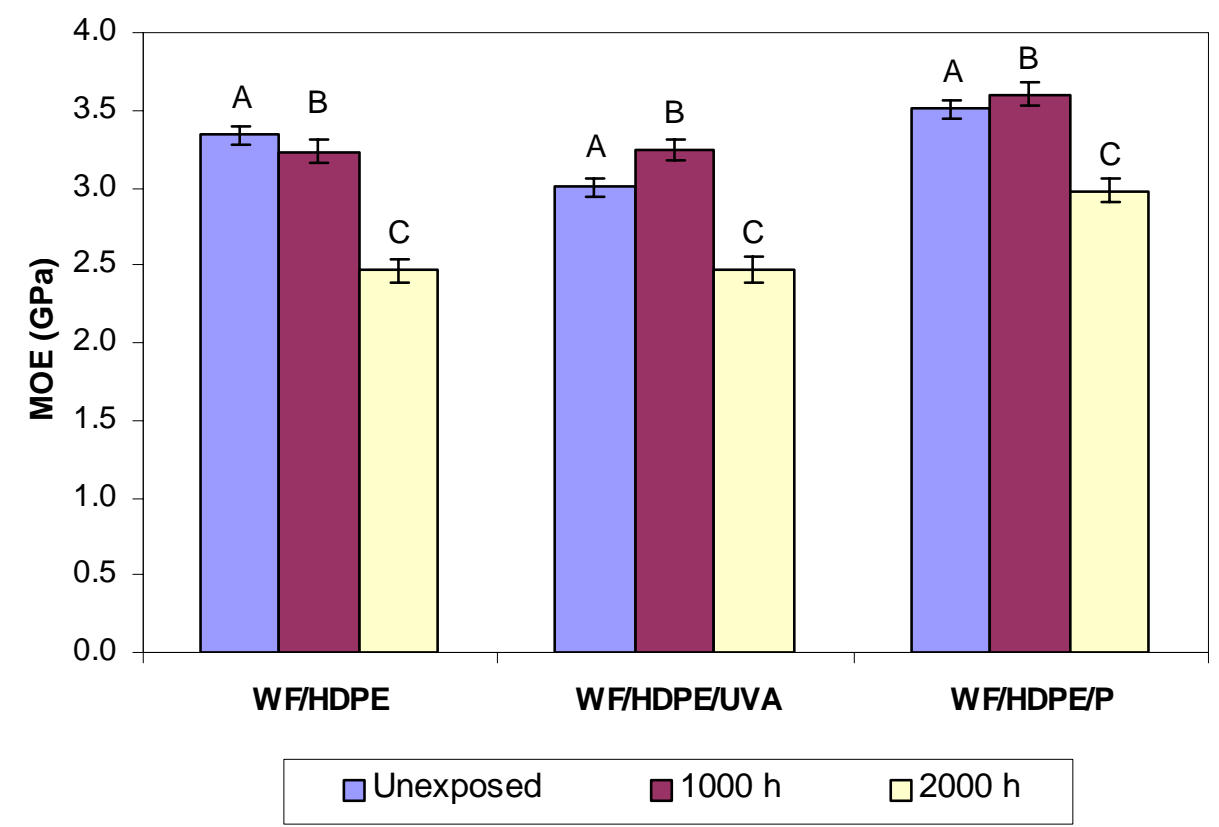

Figure 7.5. Flexural MOE of WF/HDPE composites before and after accelerated weathering. Statistically significant differences within each group are represented with different letters.

\subsubsection{Fourier Transform Infrared Spectroscopy}

FTIR spectroscopy was used to determine structural changes in the HDPE and WF/HDPE surface chemistry after weathering. Carbonyl group formation indicates surface oxidation has occurred. The formation of terminal vinyl groups indicates that photodegradation has occurred via Norrish II reactions, resulting in chain scission. The method does not differentiate between carbonyl and vinyl functional groups at the HDPE or WF surface. While increases in crystallinity due to recrystallization of shorter chains suggest chain scission has occurred, decreases in crystallinity due to the breakage of a sufficient number of tie molecules can also be an indication of chain scission (23). The peaks examined for changes in crystallinity are characteristic of HDPE only. The changes 
in carbonyl index are shown in Figures 7.6-7.7, the change in vinyl index in Figures 7.87.9, and the change in crystallinity in Figures 7.10-7.11.

\section{Carbonyl Group Formation}

After 1000 and $2000 \mathrm{~h}$ of weathering, the carbonyl index for unstabilized HDPE increased significantly (Fig. 7.6). When HDPE was stabilized with either UVA or P, there was still a significant increase in carbonyl formation through $1000 \mathrm{~h}$ of weathering, however between 1000 and $2000 \mathrm{~h}$ of weathering the increase was not statistically significant. Overall, UVA and P stabilized samples showed lower carbonyl index values than unstabilized counterparts, regardless of exposure time. These results indicate that both UVA and P are effective stabilizers for preventing HDPE oxidation that occurs as a result of UV exposure.

A similar trend in carbonyl group formation was seen for the WF/HDPE composites (Fig. 7.7). The WF/HDPE composite without any photostabilizer added experienced a significant increase in carbonyl index after the first 1000 and second 1000 $\mathrm{h}$ of weathering. When UVA or P was added to protect the composite, the increase in the carbonyl index was significant only during the first $1000 \mathrm{~h}$ of weathering. This confirms that both UVA and P are effective at preventing some oxidation of the composite that occurs as a result of UV exposure.

The carbonyl index was consistently higher for WF/HDPE composites than for their HDPE counterparts. This is explained by the fact that carbonyl groups are present in lignin, a component of WF, i.e., WF has more chromophores than HDPE. Therefore the addition of WF to an HDPE matrix is detrimental to weathering as increases in carbonyl 
groups in the composite compared to neat HDPE make it more susceptible to attack by UV light.

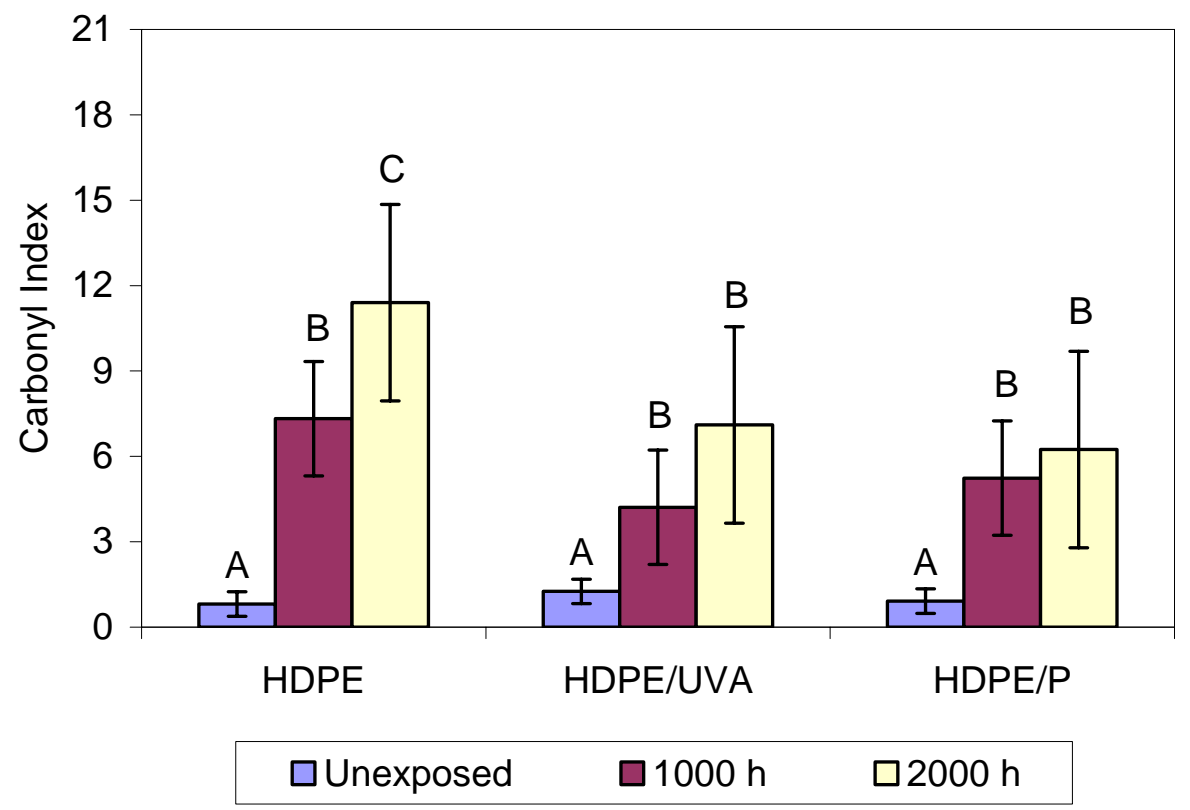

Figure 7.6. Carbonyl index of HDPE blends before and after accelerated weathering. Statistically significant differences within each group are represented with different letters.

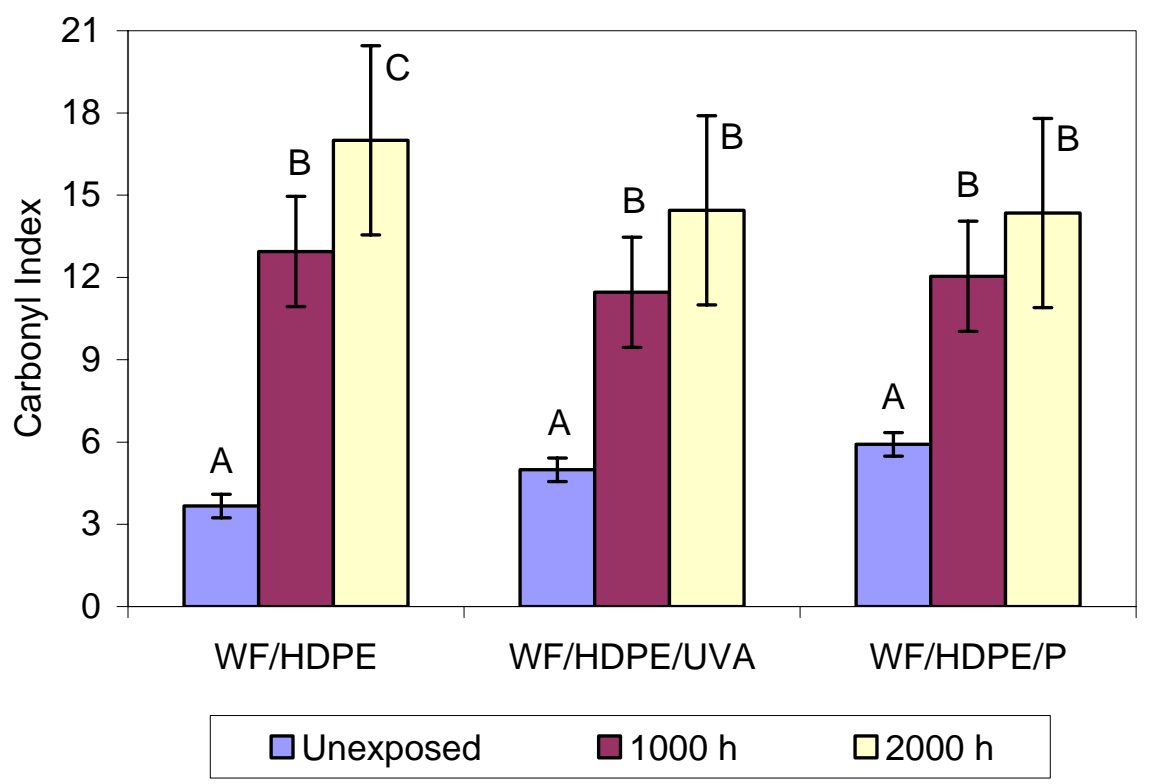

Figure 7.7. Carbonyl index of WF/HDPE composites before and after accelerated weathering. Statistically significant differences within each group are represented with different letters. 


\section{Vinyl Group Formation}

The vinyl index appeared to increase for unstabilized neat HDPE after $1000 \mathrm{~h}$ of weathering and then did not significantly change between 1000 and $2000 \mathrm{~h}$ of weathering (Fig. 7.8). The formation of vinyl groups during photodegradation via Norrish II may be followed by a slower formation of secondary carbonyl groups, which could lead to a plateau during later exposure times (9). When the photostabilizers UVA and P were added to HDPE, a significant increase in vinyl index also occurred between 1000 and $2000 \mathrm{~h}$ of weathering. When the photostabilizer is added the formation of secondary carbonyl groups may be delayed, resulting in a continued formation of vinyl groups. This would explain the lack of change in vinyl index coupled with the significant increase in carbonyl index for unstabilized HDPE between 1000 and $2000 \mathrm{~h}$ (Fig. 7.6). The delay of secondary carbonyl group formation also explains the significant increase in vinyl index between 1000 and $2000 \mathrm{~h}$ coupled with no significant increase in carbonyl index for the photostabilized HDPE (Fig. 7.6).

For WF/HDPE composites the vinyl index remained relatively unchanged through $2000 \mathrm{~h}$ of weathering regardless if a photostabilizer is added or not (Fig. 7.9). This combined with the fact that the carbonyl index increased after weathering may indicate that the formation in the carbonyl index stems primarily from the Norrish I reaction. This may mean that the Norrish II reaction is not as important mechanism in the photodegradation of WF/HDPE as Norrish I. 


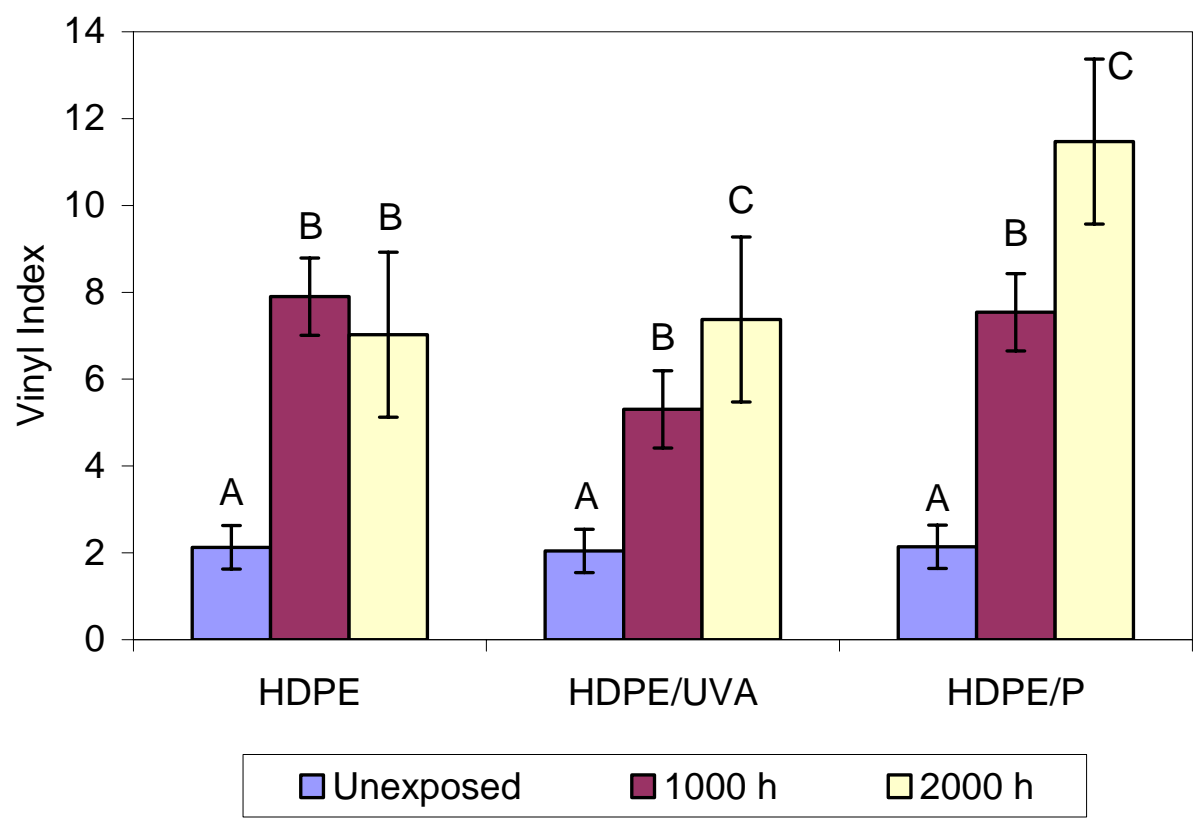

Figure 7.8. Vinyl index of HDPE blends before and after accelerated weathering. Statistically significant differences within each group are represented with different letters.

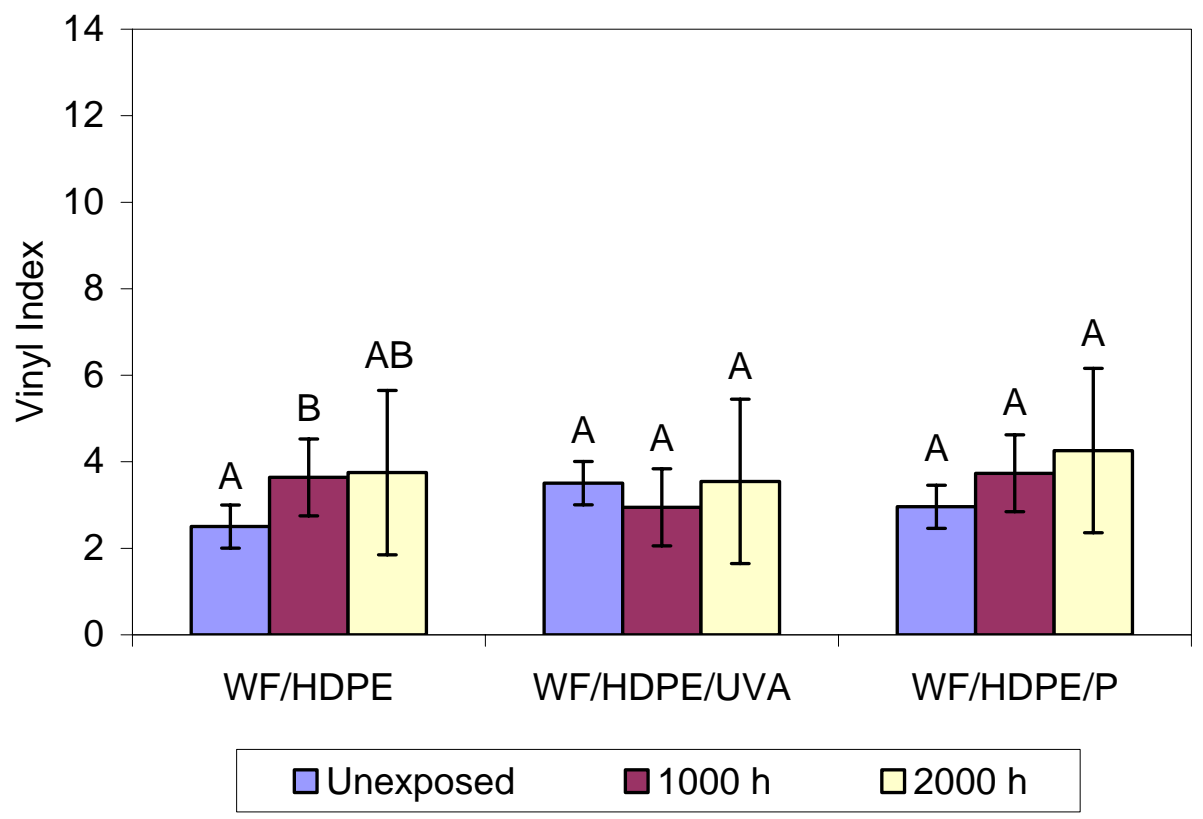

Figure 7.9. Vinyl index of WF/HDPE composites before and after accelerated weathering. Statistically significant differences within each group are represented with different letters. 


\section{Crystallinity Changes}

Crystallinity increases are an indication of chain scission as the smaller molecules undergo recrystallization. However, as chain scissions continue to occur they can affect tie molecules, which results in a decrease in crystallinity. The percentage crystallinity of unstabilized neat HDPE dropped after 1000 and $2000 \mathrm{~h}$ of weathering (Fig. 7.10). Between 1000 and $2000 \mathrm{~h}$ of weathering this drop was significant. The drop in crystallinity corresponds with the formation of surface cracks (Fig. 7.2). Therefore chain scission had affected a sufficient number of tie molecules to result in a degradation of crystallinity and the appearance of surface cracks. After $2000 \mathrm{~h}$ of weathering the net change in crystallinity for HDPE protected with UVA or P was not significant. This confirms that UVA and P both have the ability to delay some chain scission.

For WF/HDPE composites, the crystallinity increased after $1000 \mathrm{~h}$ of weathering, regardless of the use of stabilizers (Fig. 7.11). This may be evidence for the domination of chain scission versus cross-linking in WF/HDPE composites. The crystallinity did not significantly change during the second $1000 \mathrm{~h}$ of weathering regardless of the absence or presence of a photostabilizer.

The addition of $50 \%$ wood flour to the HDPE matrix hinders the ability of the HDPE to crystallize (20). As a result, the crystallinity before weathering is generally higher for the HDPE blends than for the WF/HDPE composites. 


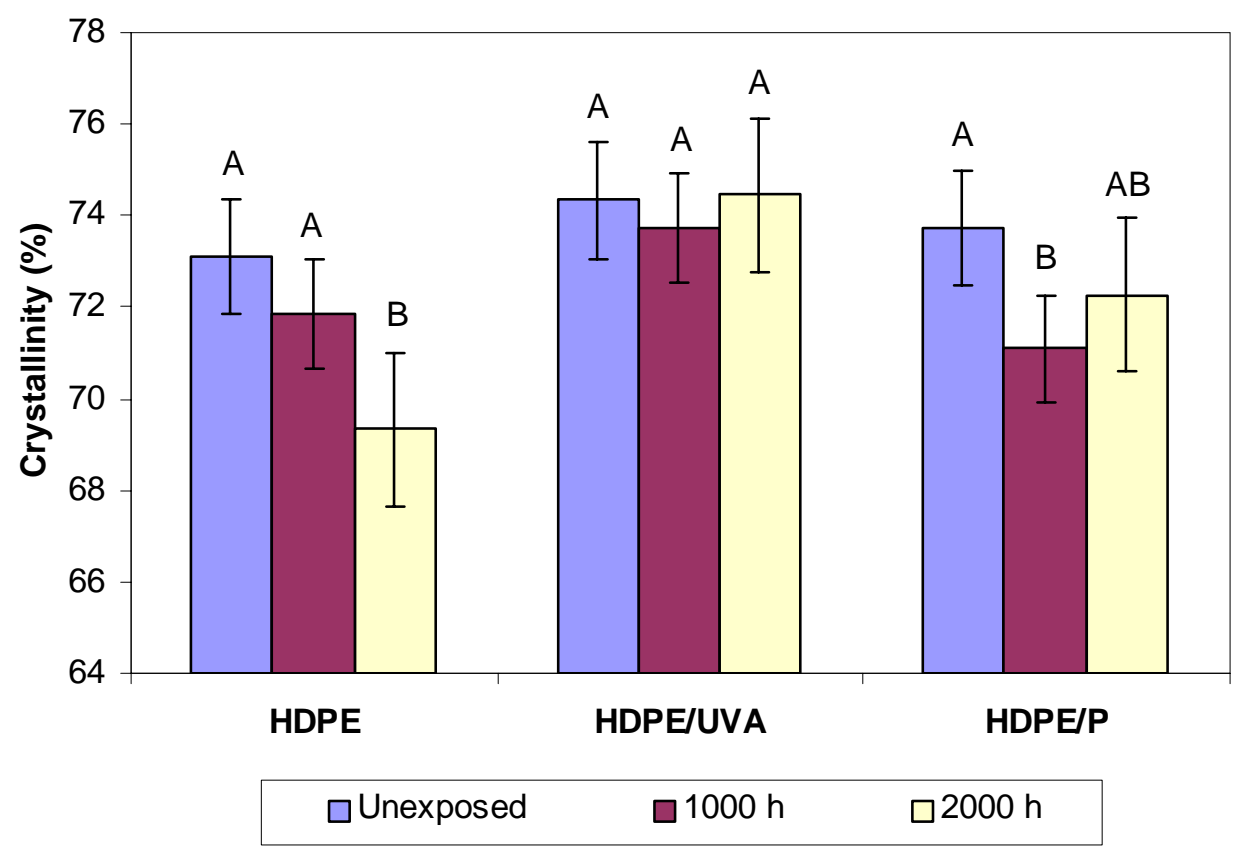

Figure 7.10. Crystallinity of HDPE blends before and after accelerated weathering. Statistically significant differences within each group are represented with different letters.

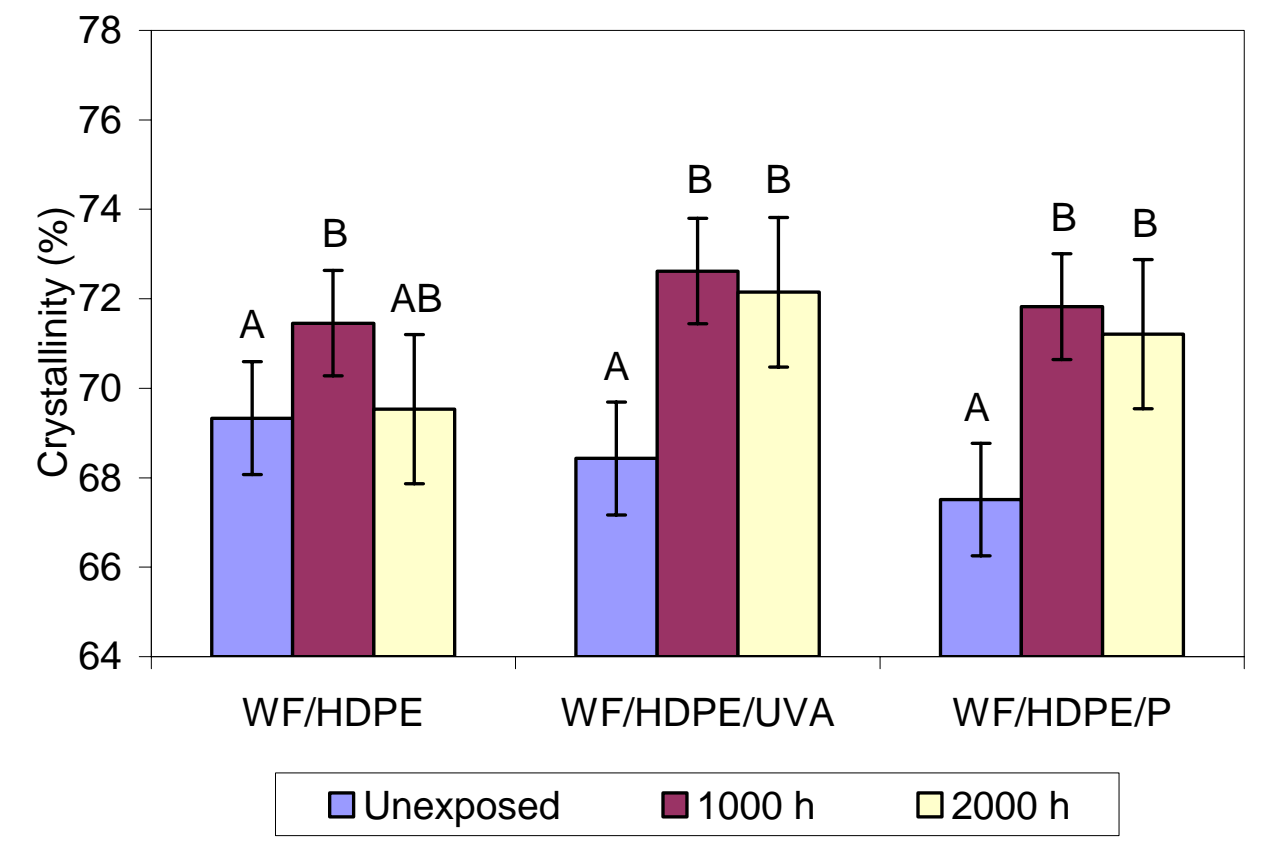

Figure 7.11. Crystallinity of WF/HDPE composites before and after accelerated weathering. Statistically significant differences within each group are represented with different letters. 


\subsubsection{Structure-Property Relationships}

\section{HDPE Blends}

First consider the unstabilized neat HDPE. The MOE (Fig. 7.4), carbonyl index (Fig. 7.6), and vinyl index (Fig. 7.8) all increased after $1000 \mathrm{~h}$ of weathering. The crystallinity, however, did not significantly change (Fig. 7.10). While the increases in carbonyl index and vinyl index confirm that some chain scission has occurred, the shorter chains have not recrystallized. Therefore, cross-linking is likely the structural change responsible for the increase in MOE. Initial cross-linking may hinder the chain mobility, resulting in an increased MOE and interrupting the recrystallization process. Carbonyl and vinyl index results have clearly showed that chain scission is occurring, however the effects could have been masked by the domination of cross-linking reaction.

Between 1000 and $2000 \mathrm{~h}$ of weathering there was a significant loss in MOE and crystallinity while the vinyl index remained the same. Chain scission has continued as the carbonyl index has increased. Therefore, the number of chain scissions may be sufficient to begin to affect the tie molecules. Torikai et al. (13), have shown that a small amount of oxidation products in polyethylene can cause great damage to the tie molecules, resulting in a breakdown of crystallization. This explains the significant loss in MOE, the drop in crystallinity, and the surface cracking apparent in the micrograph (Fig. 7.2b).

Next consider the stabilized neat HDPE. The addition of UVA or P to HDPE appeared to delay the degradation. The MOE increased after $1000 \mathrm{~h}$ of weathering for HDPE blends stabilized with either UVA or P (Fig. 7.4). As with the unstabilized HDPE the carbonyl index also increased (Fig. 7.6) for the stabilized blends but the crystallinity did not (Fig. 7.10). As a result, cross-linking is likely occurring in the first $1000 \mathrm{~h}$ of 
weathering for the stabilized HDPE blends. However, a drop in MOE and a drop in crystallinity were not apparent after $2000 \mathrm{~h}$ of weathering. This confirms that the stabilizers aid in protecting against chain scission. Indeed, the carbonyl index did not significantly increase for the stabilized HDPE blends between 1000 and $2000 \mathrm{~h}$ of exposure. The number of chain scissions may not be sufficient to affect the tie molecules. The absence of surface cracks after weathering validates this assumption (Figs 7.2c, 7.2d). The degradation of MOE is effectively delayed and the degradation would be expected to continue with increased weathering times.

Other researchers have studied the structure-property relationships of polyethylene after weathering and found similar results. While chain scission may be an important mode of degradation, crosslinking begins to predominate as the temperature increases $(10,15)$. In accelerated weathering, the temperatures are elevated above that of the exposure temperatures of natural weathering. Hamid et al. (12) studied both natural and accelerated weathering of LDPE. They concluded that the cross-linking and chain scission reactions take place simultaneously. Tidjani (14) adds that under accelerated weathering, cross-linking reactions occur that decrease the concentration of free radicals taking part in the oxidation process. In the initial stages of weathering, the mechanisms of degradation result in a predominance of cross-linking reactions over chain scission (14). A relatively high level of oxidation is necessary to overcome cross-linking (16).

\section{WF/HDPE Composites}

The WF/HDPE composite without any stabilizer experienced a small drop in MOE after $1000 \mathrm{~h}$ of weathering (Fig. 7.5). During that time, an increase in composite carbonyl index (Fig. 7.7) and corresponding increase in HDPE crystallinity occurred (Fig. 
7.11). While we do not know the reasons for this difference in the degradation mechanism, we believe that the WF particles may physically hinder cross-linking in the composite during the initial stages of accelerated weathering. This would allow for more chain scission, and a corresponding increase in crystallinity. As a result, secondary crystallization of the shorter chains takes place and the crystallinity increases. Crosslinking does not appear to be as important in the initial stages of weathering WF/HDPE composites as for the HDPE. Between 1000 and $2000 \mathrm{~h}$ of weathering a larger drop in MOE occurred, the composite carbonyl index continued to increase, and the HDPE crystallinity did not significantly change. The increase in carbonyl index is most likely due to degradation via Norrish I because the vinyl index did not increase (Fig 7.9). At this point the oxidation is sufficient to affect the tie molecules, which explains a portion of the loss in MOE.

During the first $1000 \mathrm{~h}$ of weathering the HDPE crystallinity increased yet the WF/HDPE composite MOE decreased. This is not what would be expected and is most likely due to a degradation of interfacial properties as a result of exposure to moisture. During weathering the samples cycle through environments of $35^{\circ} \mathrm{C}$ and $100 \%$ relative humidity during the water spray cycle, and $40^{\circ} \mathrm{C}$ and $30 \%$ relative humidity during the dry cycle. Moisture has been shown to adversely affect the properties of wood-plastic composites (27-32). HDPE composites filled with $40 \%$ wood fiber exposed to $30 \%$ relative humidity for $2000 \mathrm{~h}$ experienced no loss in flexural MOE. However, composites exposed to a water bath for $2000 \mathrm{~h}$ experienced 39\% loss in flexural MOE (29). Similarly, 65\% wood filled HDPE lost approximately $40 \%$ tensile modulus after being saturated with water (30). 
In the initial stages of weathering of WF/HDPE composites, the loss of properties caused by moisture exposure may cancel out the gain resulting from increasing crystallinity. This would explain the modest loss after $1000 \mathrm{~h}$ of weathering. At $2000 \mathrm{~h}$, a substantial decrease in properties occurs. It is at this point that the HDPE matrix properties may be degrading as a result of chain scission, as well as the composite properties degrading due to moisture effects. For unprotected WF/HDPE composites, this corresponds with a $26 \%$ drop in MOE after $2000 \mathrm{~h}$ of weathering. The UVA and P provided some protection against MOE loss, resulting in an 18\% and 15\% loss in MOE, respectively. Similar to the trends with photostabilized HDPE blends, the photostabilizers effectively delay some degradative properties of weathering WF/HDPE blends. However, photostabilizers may protect the HDPE matrix only and may not influence the drop in MOE due to moisture.

In addition, wood flour undergoes photodegradation, resulting in the breakdown of lignin to form free radicals (36). The free radicals may attack the polyethylene chain, resulting in a deleterious effect of adding wood flour to polyethylene through accelerated chain scission in the polyethylene. Further research needs to be done to ascertain if both the loss of interfacial quality due to moisture sorption and photodegradation of wood flour due to UV radiation contribute to the MOE loss of WF/HDPE composites.

To determine if any of the structural changes monitored directly influence the flexural MOE, three linear regressions were performed. These relate the carbonyl index, vinyl index, or crystallinity (x-axis) to the flexural MOE (y-axis). Table 7.2 shows the slope (m) and intercept (b) values of these regressions as well as the coefficient of determination $\left(\mathrm{r}^{2}\right)$. The low coefficients of determination clearly indicate that the 
carbonyl index, vinyl index, or crystallinity are not linearly related to MOE independently. This confirms that for polyethylene, the changes in vinyl and carbonyl index cannot be easily correlated with mechanical property reductions (9). This appears to also be true for unfilled HDPE composites as well as WF/HDPE composites. The difficulty of developing a correlation relating structural changes to MOE may lie in the fact that the structural changes are a surface phenomena, while the experimentally determined MOE is calculated for the whole thickness of the sample. There is probably a gradient in the sample ranging from undegraded material to degraded material.

Table 7.2. Linear regression parameters relating surface chemistry changes to MOE.

\begin{tabular}{lcccc}
\hline Formulations & $\begin{array}{c}\text { Regression } \\
\text { Parameters }\end{array}$ & $\begin{array}{c}\text { Vinyl } \\
\text { Index }\end{array}$ & $\begin{array}{c}\text { Carbonyl } \\
\text { Index }\end{array}$ & Crystallinity \\
\hline HDPE Blends & $\mathrm{m}$ & 0.024 & 0.0085 & -0.0013 \\
& $\mathrm{~b}$ & 0.080 & 0.90 & 1.0 \\
& $\mathrm{r}^{2}$ & 0.33 & 0.05 & 0.00027 \\
WF/HDPE Composites & $\mathrm{m}$ & -0.30 & -0.049 & -0.027 \\
& $\mathrm{~b}$ & 4.1 & 3.6 & 5.0 \\
& $\mathrm{r}^{2}$ & 0.15 & 0.32 & 0.015 \\
\hline
\end{tabular}

Regression parameters satisfy: $\mathrm{y}=\mathrm{mx}+\mathrm{b}$ where $\mathrm{x}$ is the vinyl index, carbonyl index, or crystallinity and $y$ is the MOE.

\subsection{Summary and Conclusions}

Two main structural changes occur in the HDPE after weathering. The HDPE may undergo cross-linking due to carbonyl degradation via Norrish I, or the HDPE may undergo chain scission due to carbonyl degradation via Norrish I or II. If chain scission occurs the HDPE can undergo secondary crystallization resulting in an increased crystallinity. However, after sufficient photodegradation the chain scissions become 
numerous enough to affect the tie molecules and the crystallinity decreases. Both an increase in cross-linking and increase in crystallinity result in an increase in modulus of elasticity.

In the initial stages of exposure of HDPE to accelerated weathering, the structure of HDPE changes predominantly through cross-linking. This leads to an increase in MOE. As the exposure continues, chain scission becomes more important and photodegradation of the polymer continues to the point at which the tie molecules are affected. This leads to environmental stress cracking and a decrease in MOE. The addition of photostabilizers such as ultraviolet absorbers or pigments prevents a significant loss in crystallinity after $2000 \mathrm{~h}$ of exposure, which in turn delays the appearance of surface cracking and consequent loss in MOE.

In the initial stages of exposure of WF/HDPE composites to accelerated weathering, cross-linking in the matrix does not predominate. It may be that the wood flour particles physically prevent the formation of cross-linked networks. Instead, the crystallinity of the polymer increases as chain scission occurs. However, the increased HDPE crystallinity does not translate into MOE increases for the WF/HDPE composites. It is suspected that loss in MOE is due mainly to the effect of moisture. The MOE decreases during the second one thousand hours of weathering, possibly due to a combination of chain scission of the tie molecules in the matrix, photodegradation of the WF, and degradation of the interface due to moisture. The addition of photostabilizers prevents a significant loss in crystallinity between 1000 and $2000 \mathrm{~h}$ of exposure. However, the MOE decreases during this time for the photostabilized composites, further 
indicating that the MOE loss is due to the degradative effect of moisture on the wood flour-HDPE interface.

Structural changes in the samples, carbonyl group formation, terminal vinyl group formation, and crystallinity changes cannot be reliably used to predict changes in $\mathrm{MOE}$ using a simple linear relationship. This indicates that the effect of cross-linking, chain scission, and crystallinity changes due to ultraviolet exposure as well as the interfacial degradation due to moisture exposure are all important factors to consider when weathering WF/HDPE composites.

\subsection{References}

1. M. DeFosse, "Wood Composites Are Expanding Among Sectors," Modern Plastics, 80(1), 25-30, 2003.

2. C. Clemons, "Wood-Plastic Composites in the United States, The Interfacing of Two Industries," Forest Products Journal, 52(6), 10-18, 2002.

3. T. Lundin, "Effect of Accelerated Weathering on the Physical and Mechanical Properties of Natural Fiber Thermoplastic Composites," M.S. Thesis, University of Wisconsin-Madison, 2001.

4. R. H. Falk, C. Felton and T. Lundin, "Effects of Weathering on Color Loss of Natural Fiber-Thermoplastic Composites," in Proceedings, $3^{\text {rd }}$ International Symposium on Natural Polymers and Composites, 382-385, São Paulo, Brazil, May 14-17, 2000.

5. N. M. Stark and L. M. Matuana, "Photostabilization of Wood Flour Filled HDPE Composites," in Proceedings, ANTEC, 2, 2209-2213, San Francisco, CA, May 610, 2002.

6. N.M. Stark and L.M. Matuana, "Ultraviolet Weathering of Photostabilized HDPE/Wood Flour Composites," accepted in Journal of Applied Polymer Science, February 2003.

7. L.M. Matuana, D.P. Kamdem and J. Zhang, "Photoaging and Stabilization of Rigid PVC/Wood-Fiber Composites," Journal of Applied Polymer Science, 80(11), 19431950, 2001.

8. L.M. Matuana and D.P. Kamdem, "Accelerated Ultraviolet Weathering of PVC/Wood-Flour Composites," Polymer Engineering and Science, 42(8), 16571666, 2002.

9. S.A. Jabarin and E.A. Lofgren, "Photooxidative Effects on Properties and Structure of High-Density Polyethylene," Journal of Applied Polymer Science, 53(4), 411423, 1994. 
10. G. Wypych, Handbook of Material Weathering, ChemTec Publishing, TorontoScarborough, 1995.

11. M. Kaci, T. Sadoun and S. Cimmino, "HALS Stabilization of LDPE Films Used in Agricultural Applications," Macromolecular and Materials Engineering, 278(1), 36-42, 2000.

12. S.H. Hamid and M.B. Amin, "Lifetime Prediction of Polymers," Journal of Applied Polymer Science, 55(1), 1385-1394, 1995.

13. A. Torikai, H. Shirakawa, S. Nagaya and K. Fueki, "Photodegradation of Polyethylene: Factors Affecting Photostability," Journal of Applied Polymer Science, 40(9-10), 1637-1646, 1990.

14. A. Tidjani, "Comparison of Formation of Oxidation Products During PhotoOxidation of Linear Low Density Polyethylene Under Different Natural and Accelerated Weathering Conditions," Polymer Degradation and Stability, 68(3), 465-469, 2000.

15. C. David, M. Trojan, A. Daro and W. Demarteau, "Photodegradation of polyethylene: Comparison of Various Photoinitiators in Natural Weathering Conditions," Polymer Degradation and Stability, 37(3), 233-245, 1992.

16. A. Tidjani, R. Arnaud and A. Dasilva, "Natural and Accelerated Photoaging of Low-Density Polyethylene: Changes of the Elongation at Break," Journal of Applied Polymer Science, 47(2), 211-216, 1993.

17. F. Gugumus, "The Performance of Light Stabilizers in Accelerated and Natural Weathering," Polymer Degradation and Stability, 50(1), 101-116, 1995.

18. F. Gugumus, "Current Trends in Mode of Action of Hindered Amine Light Stabilizers," Polymer Degradation and Stability, 40(2), 167-215, 1993.

19. M. Kaci, T. Sadoun and S. Cimmino, "Crystallinity Measurements of Unstabilized and HALS-Stabilized LDPE Films Exposed to Natural Weathering by FT-IR, DSC, and WAXS Analyses," International Journal of Polymer and Analytical Characterization, 6(5), 455-464, 2001.

20. N.M. Stark and L.M. Matuana, "Surface Chemistry Changes of Weathered HDPE/Wood Flour Composites Studied by XPS and FTIR," submitted to Polymer Degradation and Stability, August 2003.

21. X. Colom, J. Canavate, P. Pagès, J. Saurina and F. Carrasco, "Changes in Crystallinity of the HDPE Matrix in Composites with Cellulosic Fiber using DSC and FTIR," Journal of Reinforced Plastics and Composites, 19(10), 818-830, 2000.

22. P. Pagès, F. Carrasco, J. Saurina and X. Colom, "FTIR and DSC Study of HDPE Structural Changes and Mechanical Properties Variation When Exposed to Weathering Aging During Canadian Winter," Journal of Applied Polymer Science, 60(2), 153-159, 1996.

23. J. Schellenberg and G. Fienhold, "Environmental Stress Cracking Resistance of Blends of High-Density Polyethylene with Other Polyethylenes," Polymer Engineering and Science, 38(9), 1413-1419, 1998.

24. R. J. Young and P. A. Lovell, Introduction to Polymers, Chapman \& Hall, London, 1991.

25. G. Zerbi, G. Gallino, N. Del Fanti and L. Baini, "Structural Depth Profiling in Polyethylene Films by Multiple Internal Reflection Infra-Red Spectroscopy," Polymer, 30(12), 2324-2327, 1989. 
26. W. Camacho and S. Karlsson, "Simultaneous Determination of Molecular Weight and Crystallinity of Recycled HDPE by Infrared Spectroscopy and Multivariate Calibration," Journal of Applied Polymer Science, 85(2), 321-327, 2002.

27. C.M. Clemons and R.E. Ibach, "The Effects of Processing Method and Moisture History on the Laboratory Fungal Resistance of Wood-HDPE Composites," submitted to Forest Products Journal, December 2002.

28. K. Joseph, S. Thomas and C. Pavithran, "Effect of Ageing on the Physical and Mechanical Properties of Sisal-Fiber-Reinforced Polyethylene Composites," Composites Science and Technology, 53(1), 99-110, 1995.

29. N. Stark, "Influence of Moisture Absorption on Mechanical Properties of Wood Flour-Polypropylene Composites," Journal of Thermoplastic Composite Materials, 14(5), 421-432, 2001.

30. S.V. Rangaraj and L.V. Smith, "Effects of Moisture on the Durability of a Wood/Thermoplastic Composite," Journal of Thermoplastic Composite Materials, 13(3), 140-161, 2000.

31. Q. Lin, X. Zhou and G. Dai, "Effect of Hydrothermal Environment on Moisture Absorption and Mechanical Properties of Wood Flour-Filled Polypropylene Composites," Journal of Applied Polymer Science, 85(14), 2824-2832, 2002.

32. J.J. Balatinecz and B.-D. Park, "The Effects of Temperature and Moisture Exposure on the Properties of Wood-Fiber Thermoplastic Composites," Journal of Thermoplastic Composite Materials, 10(9), 476-487, 1997.

33. F. Gugumus, "Light Stabilizers," in Plastics Additives Handbook, Chapter 3, 129262, R. Gächter and H. Müller, Eds., Hanser Publishers, New York, 1990.

34. American Society for Testing and Materials, "D790 Standard Test Method for Flexural Properties of Unreinforced and Reinforced Plastics and Electrical Insulating Materials," in Annual Book of ASTM Standards, 8.01, 2000.

35. American Society for Testing and Materials, "D2565 Standard Practice for XenonArc Exposure of Plastics Intended for Outdoor Applications," in Annual Book of ASTM Standards, 8.02, 2000.

36. D.N.-S. Hon, "Weathering and Photochemistry of Wood," in Wood and Cellulosic Chemistry, Chapter 11, 513-546, D.N.-S. Hon and N. Shiraishi, Eds, Marcel Dekker, Inc., New York, 2001. 


\section{SUMMARY OF FINDINGS}

As wood-plastic composites become increasingly popular for outdoor applications, a need to fundamentally understand their ultraviolet durability arises. The goal of the work reported here was to characterize the changes in color fade, mechanical properties, and surface chemistry of weathered WF/HDPE composites and to determine the effects of photostabilizers on weathering WF/HDPE composites. The following summarizes the findings relating to the six specific objectives presented at the beginning of this thesis.

\section{i. Characterize the surface of WF/HDPE composites produced using different manufacturing methods.}

FTIR spectroscopy can be used to examine the surface characteristics of woodplastic composites manufactured using different processing techniques. By following peaks associated with functional groups present in polyethylene and cellulose, the differences in surface chemistries between manufacturing methods became apparent. By using FTIR spectroscopy technique to characterize the surface of injection molded, extruded, and planed-extruded samples, it was found that injection molded samples had less wood component at the surface than the extruded and planed samples, respectively. The planed samples exhibited more wood component as a result of removing polymer rich surface layer to expose the wood particles. 


\section{ii. Understand how manufacturing methods affect the weathering of WF/HDPE composites.}

The manufacturing method of WF/HDPE composites greatly influences their durability. Injection molded samples have more polymer on the surface layers than extruded and planed samples. This resulted in increased color fade for the extruded and planed samples during the initial stages of weathering, which was attributed to a bleaching of the wood fiber. After a sufficient weathering time period, however, the depth of the lightened degradation layer was more than the depth of the polymer rich layer. Therefore, manufacturing method did not influence the lightening of the composite after long weathering times.

The retention of flexural properties was greatly influenced by processing method. Generally, the molded samples showed an improved retention of flexural MOE and strength over extruded and planed samples after $3000 \mathrm{~h}$ of weathering. In addition, the extruded and planed samples lost a larger percentage of their total mechanical property loss during the first $1000 \mathrm{~h}$ of exposure than molded samples. This behavior was likely due directly to the loss in properties due to moisture exposure. The planed samples provided a pathway for the absorption of moisture because of the strong hydrophilic wood characteristic at the surface. 


\section{iii. Study how weathering changes the structure and surface chemistry of HDPE blends and WF/HDPE composites.}

Both XPS and FTIR spectroscopy techniques can be used to effectively study the surface oxidation of weathered WF/HDPE composites. A low-resolution XPS scan quickly demonstrated an increase in oxygen atoms at the surface of both HDPE samples and WF/HDPE composites after $2000 \mathrm{~h}$ of weathering. A high-resolution scan was used to determine the types and amounts of carbon-oxygen bonds present at the surface. After weathering, the oxidized-to-unoxidized carbon ratio increased dramatically more for the WF/HDPE composites versus unfilled HDPE (80\% versus 5\%, respectively). These results are evidence of the damaging effect of adding wood to HDPE matrix, which effectively increases the surface oxidation of composite samples after weathering.

FTIR spectroscopy was used to determine carbonyl group formation, vinyl group formation, and crystallinity changes during weathering. An increase in the calculated carbonyl index, vinyl index, and/or crystallinity can signify an increase in polymer chain scission. Initially, the carbonyl index was higher for the WF/HDPE composites but increased at approximately the same rate for both WF/HDPE composites and neat HDPE. The vinyl index remained constant through $250 \mathrm{~h}$ of exposure time, increased through $1000 \mathrm{~h}$, and then reached a plateau for both WF/HDPE composites and neat HDPE. The concentration of vinyl groups was much larger for neat HDPE than for WF/HDPE composites, suggesting that vinyl group formation takes place mainly in the polymer component of the composite. Crystallinity of the HDPE samples remained statistically unchanged through $1000 \mathrm{~h}$ of exposure then decreased. Conversely, the crystallinity of 
the HDPE matrix in the WF/HDPE composites increases with exposure time through $1000 \mathrm{~h}$ before decreasing.

The experimental results indicated that neat HDPE samples may have predominantly undergone cross-linking as opposed to chain scission during the initial stages of accelerated weathering. While some chain scission occurs initially, the delay in vinyl group formation suggests that early in weathering the Norrish II degradation mechanism is not as important as the Norrish I mechanism. However, as exposure increases the vinyl group formation increases, confirming an increase in polymer chain scission. Although favoring cross-linking over chain scission does not change overall crystallinity, at longer weathering times chain scission begins to affect the tie molecules, resulting in a net decrease in crystallinity.

The WF/HDPE composites initially had a higher surface oxygen concentration compared to that of unfilled HDPE as a result of hydroxyl groups on the wood surface. The rate of carbonyl group formation was similar for WF/HDPE composites and unfilled HDPE samples; suggesting that each component of the WF/HDPE composite is oxidizing. Although initial crystallinity in the polymer matrix of the WF/HDPE composites was lower than the crystallinity of the neat HDPE because the wood fiber hindered crystal growth, crystallinity increased through $1000 \mathrm{~h}$ of exposure time. At 2000 h of exposure, crystallinity declined somewhat. This behavior implied that chain scission in the polymer phase may predominate over cross-linking almost immediately, possibly because the wood fiber hinders crosslinking of the matrix as well as crystal growth. 


\section{iv. Determine the effectiveness of various photostabilizers and their interactions on the weathering of WF/HDPE composites.}

A full factorial experimental design was used to examine the effects of photostabilizers on both unfilled HDPE blends and WF/HDPE composites. Two hindered amine light stabilizers, an ultraviolet absorber (UVA), and pigment (P) were chosen as photostabilizers. Optical and flexural properties were examined for all formulations after they had been weathered in an accelerated weathering apparatus.

Color fade was decreased through the addition of an ultraviolet absorber and colorant for both unfilled HDPE blends and WF/HDPE composites. However, because of bleaching of the wood flour, WF/HDPE composites experienced more dramatic lightening than unfilled HDPE blends.

After $2000 \mathrm{~h}$ of weathering, unprotected HDPE blends experienced a drop in flexural strength and modulus, which could be mitigated through the addition of a photostabilizer. Only the addition of an UVA and P significantly decreased strength loss of WF/HDPE composites.

Hindered amine light stabilizers did not have a significant effect on lightness and flexural properties of the WF/HDPE composite formulations tested.

\section{v. Determine the effect of stabilizer concentration on the color fade and mechanical property loss of WF/HDPE composites after weathering.}

WF/HDPE composites were stabilized with UVA, added at $0 \%, 0.5 \%$, and $1 \%$, and/or $\mathrm{P}$, added at $0 \%, 1 \%$, and $2 \%$ by weight of the composite. The influence of 
concentration changes of UVA and P on the color fade and mechanical property loss of WF/HDPE composites was determined.

Adding UVA or P resulted in the composites lightening less after all weathering times. Increasing the concentration of UVA from 0.5 to $1 \%$ resulted in less lightening, as did increasing the $\mathrm{P}$ concentration from $1 \%$ to $2 \%$. After $3000 \mathrm{~h}$ of weathering, the samples that lightened the least were the combinations of UVA and P. Both the UVA and $\mathrm{P}$ absorb UV radiation to prevent WF bleaching, however adding $\mathrm{P}$ also masks the bleaching.

The mechanical properties generally decreased after weathering. Adding UVA at low percentages likely results in a consumption of a majority of the UVA after $1000 \mathrm{~h}$ of weathering. When either UVA or P were added, the composites retained flexural properties better than the unstabilized composites. Increasing the amount of UVA from 0.5 to $1 \%$ did affect flexural MOE but increasing P from 1 to $2 \%$ did not affect flexural MOE. Adding P at the lower level may be sufficient enough to prevent MOE loss due to a decrease in crystallinity. Increasing both UVA and P prevented some flexural strength loss. The more $\mathrm{P}$ in the system the less important UVA became for retaining flexural strength probably because of the carrier wax the pigment is in. The wax may protect the composites by making the surface of the WF more hydrophobic, thereby protecting the interface. 


\section{vi. Characterize the mechanical properties and surface chemistry change of stabilized HDPE blends and WF/HDPE composites after weathering.}

In the initial stages of exposure of HDPE to accelerated weathering, the structure of HDPE changed predominantly through cross-linking. This led to an increase in MOE. As the exposure continued, chain scission became more important and photodegradation of the polymer continued to the point at which the tie molecules were affected. This led to environmental stress cracking and a decrease in MOE. The addition of an UVA and P prevented a significant loss in crystallinity after $2000 \mathrm{~h}$ of exposure, which in turn delayed the appearance of surface cracks and consequent loss in MOE.

In the initial stages of weathering WF/HDPE composites, cross-linking in the matrix did not predominate. It may be that the wood flour particles physically prevented the formation of cross-linked networks. Instead, the crystallinity of the polymer increased as chain scission occurred. However, the increased HDPE crystallinity did not translate into an increased MOE for the WF/HDPE composites. It is suspected that loss in MOE was mainly due to the effect of moisture. The MOE decreased during the second one thousand hours of weathering, possibly because of a combination of chain scission of the tie molecules in the matrix, photodegradation of the WF, and degradation of the interface due to moisture. The addition of photostabilizers prevented a significant loss in crystallinity between 1000 and $2000 \mathrm{~h}$ of exposure. However, the MOE decreased during this time for the stabilized composites, further indicating that the MOE loss was caused by the degradative effect of moisture on the wood flour-HDPE interface. 


\section{FUTURE RESEARCH}

This thesis contains baseline information on how to manipulate composite performance after weathering by changing the manufacturing method and adding photostabilizers. There are many opportunities for using these techniques to improve the durability of wood-plastic composites. To add to this information additional work may answer the following questions in the future:

1) How does changing the variables in a single processing method (for example, injection molding) influence the surface of the composite sample? How will this affect durability?

2) Do all pigments influence the durability of wood-plastic composites in the same manner?

3) Can a central composite experimental design be used to find a response surface that can be used to predict the effects of stabilizers on the weathering properties of wood-plastic comsites?

This thesis also provides insight into the degradation mechanism of wood-plastic composites exposed to UV light. Spectroscopic methods were useful for providing information on structural changes in the composite, such as chain scission, cross-linking, and crystallinity differences as a result of weathering. In future research, these methods can be used to answer the following question:

1) Can following the structural changes be used to correlate natural weathering with accelerated weathering? 
2) Can FTIR be used to determine the degradation depth as a function of dosage? Can this be correlated with mechanical properties using beam theory?

3) How does weathering temperature and moisture cycles separately influence weathering of wood-plastic composites?

The understanding of the weathering of wood and polymers has been facilitated through the use of accelerated weathering tests. However, it is difficult to correlate accelerated weathering results with natural weathering results. While accelerated weathering tests result in a controlled environment, exposure to natural weathering is complicated by variations in climate, time of year, industrial atmosphere, and annual variations in weather. In addition, accelerated artificial UV-weathering tests exclude any biological influence that may occur in a natural environment. It is recommended that natural weathering be carried out for more than one year, and at several latitudes, to minimize these variations. While accelerated weathering gives good information about the comparative behavior of WPCs, natural weathering is necessary to minimize errors in the prediction of life service. 


\section{LIST OF TABLES}

\section{Chapter 3}

Table 3.1 The amount of light energy between 300 and $400 \mathrm{~nm}$ the samples were exposed to for 500-hour time increments.

Table 3.2 Physical properties of unexposed 50\% wood flour filled HDPE composites.

Table 3.3 Wood Index determined from the cellulose peak at $1023 \mathrm{~cm}^{-1}$.

Table 3.4 Loss in MOE and loss in strength after accelerated weathering for 1000, 2000, and $3000 \mathrm{~h}$ for 50\% WF filled HDPE composites compared with values found in the literature.

\section{Chapter 4}

Table 4.1 The relative amount of atoms present at the surface of the sample determined using low-resolution XPS scan and the calculated oxygen-tocarbon atomic ratio.

Table 4.2 Deconvoluted peak assignments with corresponding theoretical binding energy and bond type for a high-resolution XPS scan of the $\mathrm{C}_{1 \mathrm{~s}}$ region.

Table 4.3 The relative amount of different carbon-to-oxygen bonds present at the surface of the sample determined using high-resolution XPS.

Table 4.4 Wavenumbers of the peaks used for FTIR analysis and the corresponding functional groups and vibrational types.

\section{Chapter 5}

Table 5.1 Materials and content of composite blends.

Table 5.2 Change in color $\left(\Delta E_{a b}\right)$ and lightness $(\Delta L)$ at various exposure times for unfilled HDPE and photostabilizer blends after accelerated weathering.

Table 5.3 Change in color $\left(\Delta E_{a b}\right)$ and lightness $(\Delta L)$ at various exposure times for wood-flour-filled HDPE and photostabilizer blends after accelerated weathering.

Table 5.4 Change in flexural modulus (MOE) and strength at various exposure times for unfilled HDPE and photostabilizer blends after accelerated weathering. 
Table 5.5 Change in flexural modulus (MOE) and strength at various exposure times for wood-flour-filled HDPE and photostabilizer blends after accelerated weathering.

\section{Chapter 6}

Table 6.1 Materials used in composite blends.

Table 6.2 Formulations of wood-plastic composites manufactured.

Table 6.3 The amount of light energy between 300 and $400 \mathrm{~nm}$ the samples were exposed to for 1000-hour time increments.

Table 6.4 Changes in properties for 50\% wood flour filled HDPE composites after $3000 \mathrm{~h}$ of accelerated weathering.

\section{Chapter 7}

Table 7.1 Formulations of neat HDPE and WF/HDPE composite blends.

Table 7.2 Linear regression parameters relating surface chemistry changes to MOE.

\section{Appendix}

Table A.1 Compounding extrusion settings for 32-mm twin-screw extruder.

Table A.2 Injection molding conditions for 33-ton injection molder.

Table A.3 Compounding extrusion settings for 94-mm twin-screw extruder at the University of Maine.

Table A.4 Factorial design used to determine main effects and interaction of photostabilizers on weathering of HDPE and WF/HDPE composites. 


\section{LIST OF FIGURES}

\section{Chapter 2}

Figure 2.1 A combination of four cellulose building blocks.

Figure 2.2 Cellulose molecular arrangement.

Figure 2.3 Lignin precursors for (a) syringyl, (b) guaiacyl, (c) p-hydroxyphenyl lignin.

Figure 2.4 Structural scheme of spruce lignin.

Figure 2.5 Transverse section showing earlywood and latewood cells for a softwood.

Figure 2.6 Wood cell wall structure.

Figure 2.7 Polyethylene repeating unit.

Figure 2.8 Norrish degradation mechanisms from carbonyl precursors: (a) Norrish I, and (b) Norrish II.

Figure 2.9 UVA mechanism of photostabilization.

Figure 2.10 Protection mechanisms of HALS: (a) formation of nitroxyl radical in the presence of oxygen and (b) deactivation of polymer free radical by nitroxyl radical.

Figure 2.11 CIE L*a*b* color space.

Figure 2.12 Three-point bending set-up.

Figure 2.13 Representative stress-strain curves for an unfilled HDPE sample and a WF/HDPE composite.

Figure 2.14 Schematic of attenuated total reflectance FTIR set-up.

\section{Chapter 3}

Figure 3.1 Extruded profile showing where extruded and planed samples were cut from.

Figure 3.2 FTIR spectra of HDPE and SYP. 
Figure 3.3 FTIR spectra of molded, extruded, and planed WF/HDPE composites.

Figure 3.4 Micrographs of molded WF/HDPE composites (a) before weathering and after (b) 1000, (c) 2000 , and (d) $3000 \mathrm{~h}$ of weathering.

Figure 3.5 Micrographs of extruded WF/HDPE composites (a) before weathering and after (b) 1000, (c) 2000 , and (d) $3000 \mathrm{~h}$ of weathering.

Figure 3.6 Micrographs of planed WF/HDPE composites (a) before weathering and after (b) 1000, (c) 2000, and (d) $3000 \mathrm{~h}$ of weathering.

Figure 3.7 L value for molded, extruded, and planed WF/HDPE composites before and after 1000, 2000 and $3000 \mathrm{~h}$ of weathering.

Figure 3.8 Flexural modulus of molded, extruded, and planed WF/HDPE composites before and after 1000, 2000 and $3000 \mathrm{~h}$ of weathering.

Figure 3.9 Flexural strength of molded, extruded, and planed WF/HDPE composites before and after 1000, 2000 and $3000 \mathrm{~h}$ of weathering.

\section{Chapter 4}

Figure 4.1 Norrish degradation mechanisms from carbonyl precursors: (a) Norrish I and (b) Norrish II.

Figure 4.2 XPS Scan of $\mathrm{C}_{1 \mathrm{~s}}$ region for neat HDPE: (a) unexposed samples and (b) samples subjected to $2000 \mathrm{hrs} \mathrm{UV} /$ water spray cyclic exposures.

Figure 4.3 XPS Scan of $\mathrm{C}_{1 \mathrm{~s}}$ region for $\mathrm{WF} / \mathrm{HDPE}$ composites: (a) unexposed samples and (b) samples subjected to $2000 \mathrm{hrs} \mathrm{UV} /$ water spray cyclic exposures.

Figure 4.4 Size, shape and location of FTIR spectra of WF/HDPE composite samples exposed to various weathering times: (a) methyl group and (b) carbonyl group region.

Figure 4.5 Carbonyl group formation versus exposure time for both neat HDPE and WF/HDPE composite samples.

Figure 4.6 Vinyl group formation versus exposure time for both neat HDPE and WF/HDPE composite samples.

Figure 4.7 Crystallinity versus exposure time for both neat HDPE and WF/HDPE composite samples. 


\section{Chapter 5}

Figure 5.1 Effect of exposure time on lightness $(L)$ of unfilled HDPE and WF/HDPE composites.

Figure 5.2 Effect of exposure time on flexural MOE of unfilled HDPE and WF/HDPE composites.

Figure 5.3 Effect of exposure time on flexural strength of unfilled HDPE and WF/HDPE composites.

Figure 5.4 Variation in $\Delta L$ as function of interactions between colorant and photostabilizer: (a) contents of LS1 and LS2 fixed at $0.25 \%$; (b) contents of LS2 and UVA fixed at $0.25 \%$.

\section{Chapter 6}

Figure 6.1 Effect of exposure time on the increase in lightness of WF/HDPE composites.

Figure 6.2 Effect of exposure time of the loss in MOE of WF/HDPE composites.

Figure 6.3 Effect of exposure time on the loss in strength of WF/HDPE composites.

\section{Chapter 7}

Figure 7.1 Norrish degradation mechanisms from carbonyl precursors: (a) Norrish I, and (b) Norrish II.

Figure 7.2 Micrographs of neat HDPE: (a) unstabilized without weathering, (b) unstabilized-exposed to $2000 \mathrm{~h}$ of weathering, (c) stabilized with UVAexposed to $2000 \mathrm{~h}$ of weathering, (d) stabilized with pigment-exposed to $2000 \mathrm{~h}$ of weathering.

Figure 7.3 Micrographs of WF/HDPE composites: (a) unstabilized without weathering, (b) unstabilized-exposed to $2000 \mathrm{~h}$ of weathering, (c) stabilized with UVA-exposed to $2000 \mathrm{~h}$ of weathering, (d) stabilized with pigment-exposed to $2000 \mathrm{~h}$ of weathering.

Figure 7.4 Flexural MOE of neat HDPE blends before and after accelerated weathering. Statistically significant differences within each group are represented with different letters. 
Figure 7.5 Flexural MOE of WF/HDPE composites before and after accelerated weathering. Statistically significant differences within each group are represented with different letters.

Figure 7.6 Carbonyl index of HDPE blends before and after accelerated weathering. Statistically significant differences within each group are represented with different letters.

Figure 7.7 Carbonyl index of WF/HDPE composites before and after accelerated weathering. Statistically significant differences within each group are represented with different letters.

Figure 7.8 Vinyl index of HDPE blends before and after accelerated weathering. Statistically significant differences within each group are represented with different letters.

Figure 7.9 Vinyl index of WF/HDPE composites before and after accelerated weathering. Statistically significant differences within each group are represented with different letters.

Figure 7.10 Crystallinity of HDPE blends before and after accelerated weathering. Statistically significant differences within each group are represented with different letters.

Figure 7.11 Crystallinity of WF/HDPE composites before and after accelerated weathering. Statistically significant differences within each group are represented with different letters.

\section{Appendix}

Figure A.1 Characteristic stress-strain curves for 50\% WF/HDPE composites that were injection molded, extruded, and planed.

Figure A.2 Characteristic stress-strain curves for injection molded WF/HDPE composites, both unweathered and weathered $2000 \mathrm{~h}$.

Figure A.3 Characteristic stress-strain curves for extruded WF/HDPE composites, both unweathered and weathered $2000 \mathrm{~h}$.

Figure A.4 Characteristic stress-strain curves for planed WF/HDPE composites, both unweathered and weathered $2000 \mathrm{~h}$.

Figure A.5 Characteristic stress-strain curves for HDPE and WF/HDPE composites, both unweathered and weathered $2000 \mathrm{~h}$. 
Figure A.6 Characteristic stress-strain curves for WF/HDPE composites, both unweathered and weathered $3000 \mathrm{~h}$.

Figure A.7 Characteristic stress-strain curves for WF/HDPE composites with $1 \%$ UVA added, both unweathered and weathered $3000 \mathrm{~h}$.

Figure A.8 Characteristic stress-strain curves for WF/HDPE composites with $2 \%$ Pigment added, both unweathered and weathered $3000 \mathrm{~h}$.

Figure A.9 Characteristic FTIR spectra for HDPE, both unweathered and weathered for $2000 \mathrm{~h}$.

Figure A.10 Characteristic FTIR spectra for WF/HDPE, both unweathered and weathered for $2000 \mathrm{~h}$. 


\section{APPENDIX}

Table A.1. Compounding extrusion settings for 32-mm twin-screw extruder.

\begin{tabular}{cccc}
\hline & Settings & HDPE Blends & $\begin{array}{c}\text { WF/HDPE } \\
\text { Composites }\end{array}$ \\
\hline Temperatures & Zone 1 $\left({ }^{\circ} \mathrm{F}\right)$ & 380 & 380 \\
& Zone 2 $\left({ }^{\circ} \mathrm{F}\right)$ & 370 & 370 \\
& Zone 3 $\left({ }^{\circ} \mathrm{F}\right)$ & 350 & 350 \\
& Zone 4 $\left({ }^{\circ} \mathrm{F}\right)$ & 340 & 340 \\
& Zone 5 $\left({ }^{\circ} \mathrm{F}\right)$ & 340 & 340 \\
& Zone 6 $\left({ }^{\circ} \mathrm{F}\right)$ & 340 & 340 \\
Processing & Zone 7 $\left({ }^{\circ} \mathrm{F}\right)$ & 340 & 340 \\
Parameters & Melt Temperature $\left({ }^{\circ} \mathrm{F}\right)$ & $375-385$ & 360 \\
& Te Load & $75-80$ & $370-390$ \\
& Melt Pressure (psi) & 230 & $65-80$ \\
& Screw RPM & 300 & $340-440$ \\
\hline
\end{tabular}

Table A.2. Injection molding conditions for 33-ton injection molder.

\begin{tabular}{cccc}
\hline & Settings & HDPE Blends & $\begin{array}{c}\text { WF/HDPE } \\
\text { Composites }\end{array}$ \\
\hline Temperatures & Zone 1 ( $\left.{ }^{\circ} \mathrm{F}\right)$ & 400 & 400 \\
& Zone 2 ( $\left.{ }^{\circ} \mathrm{F}\right)$ & 400 & 400 \\
& Zone 3 ( $\left.{ }^{\circ} \mathrm{F}\right)$ & 400 & 400 \\
& Nozzle ( $\left.{ }^{\circ} \mathrm{F}\right)$ & 400 & 400 \\
\hline Processing & Shot Size (in) & 1.50 & 2.00 \\
Parameters & High Limit (psi) & 2300 & 2300 \\
& Hydraulic Transfer (psi) & 1500 & 1100 \\
& Pack Pressure (psi) & 1200 & 1200 \\
& Hold Pressure (psi) & 1200 & 1200 \\
\hline Cycle Times & Injection (s) & 25.0 & 25.0 \\
& Pack (s) & 10.0 & 10.0 \\
& Hold (s) & 4.0 & 4.0 \\
& Cooling (s) & 20.0 & 20.0 \\
\hline
\end{tabular}


Table A.3. Compounding extrusion settings for 94-mm twinscrew extruder at the University of Maine.

\begin{tabular}{ccc}
\hline & Settings & $\begin{array}{c}\text { WF/HDPE } \\
\text { Composites }\end{array}$ \\
\hline Temperatures & Zone $1\left({ }^{\circ} \mathrm{C}\right)$ & 200 \\
& Zone $2\left({ }^{\circ} \mathrm{C}\right)$ & 200 \\
& Zone $3\left({ }^{\circ} \mathrm{C}\right)$ & 190 \\
& Zone $4\left({ }^{\circ} \mathrm{C}\right)$ & 185 \\
& Zone $5\left({ }^{\circ} \mathrm{C}\right)$ & 185 \\
& Zone $6\left({ }^{\circ} \mathrm{C}\right)$ & 183 \\
& Zone $7\left({ }^{\circ} \mathrm{C}\right)$ & 169 \\
& Zone $8\left({ }^{\circ} \mathrm{C}\right)$ & 164 \\
Processing & Die $\left({ }^{\circ} \mathrm{C}\right)$ & 180 \\
Parameters & Melt Temperature $\left({ }^{\circ} \mathrm{C}\right)$ & 154 \\
& \% Load & 42 \\
& Melt Pressure $(\mathrm{psi})$ & 250 \\
Screw RPM & 30 \\
\hline
\end{tabular}

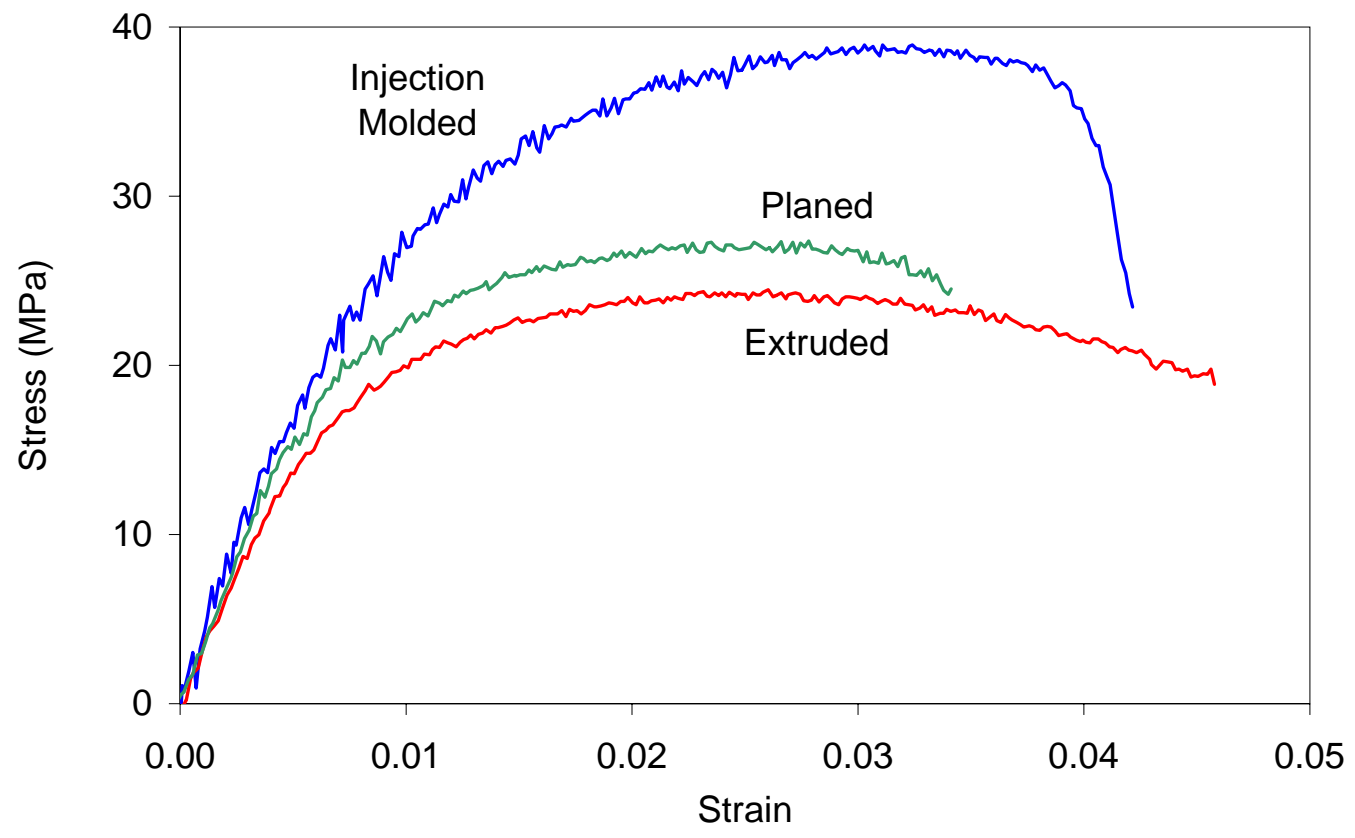

Figure A.1. Characteristic stress-strain curves for 50\% WF/HDPE composites that were injection molded, extruded, or planed. 


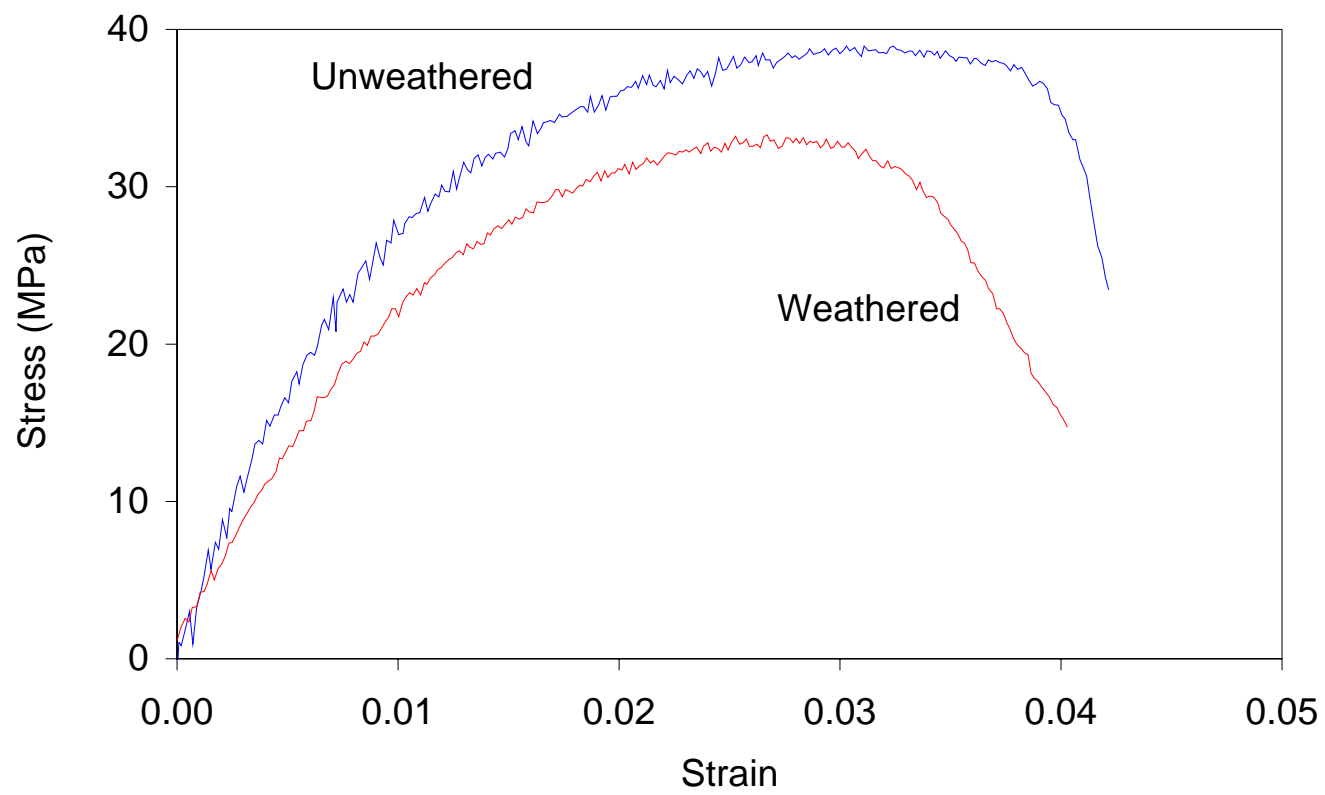

Figure A.2. Characteristic stress-strain curves for injection molded WF/HDPE composites, both unweathered and weathered $2000 \mathrm{~h}$.

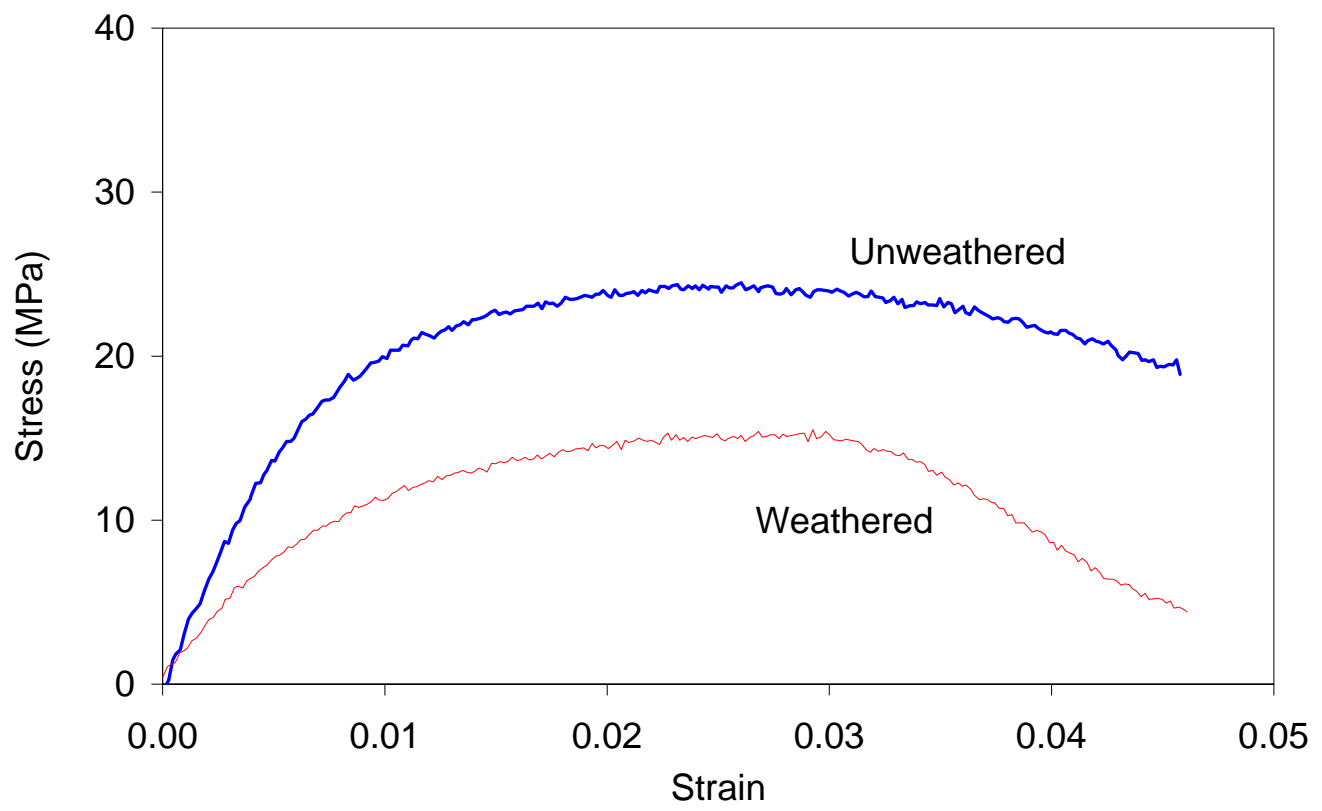

Figure A.3. Characteristic stress-strain curves for extruded WF/HDPE composites, both unweathered and weathered $2000 \mathrm{~h}$. 


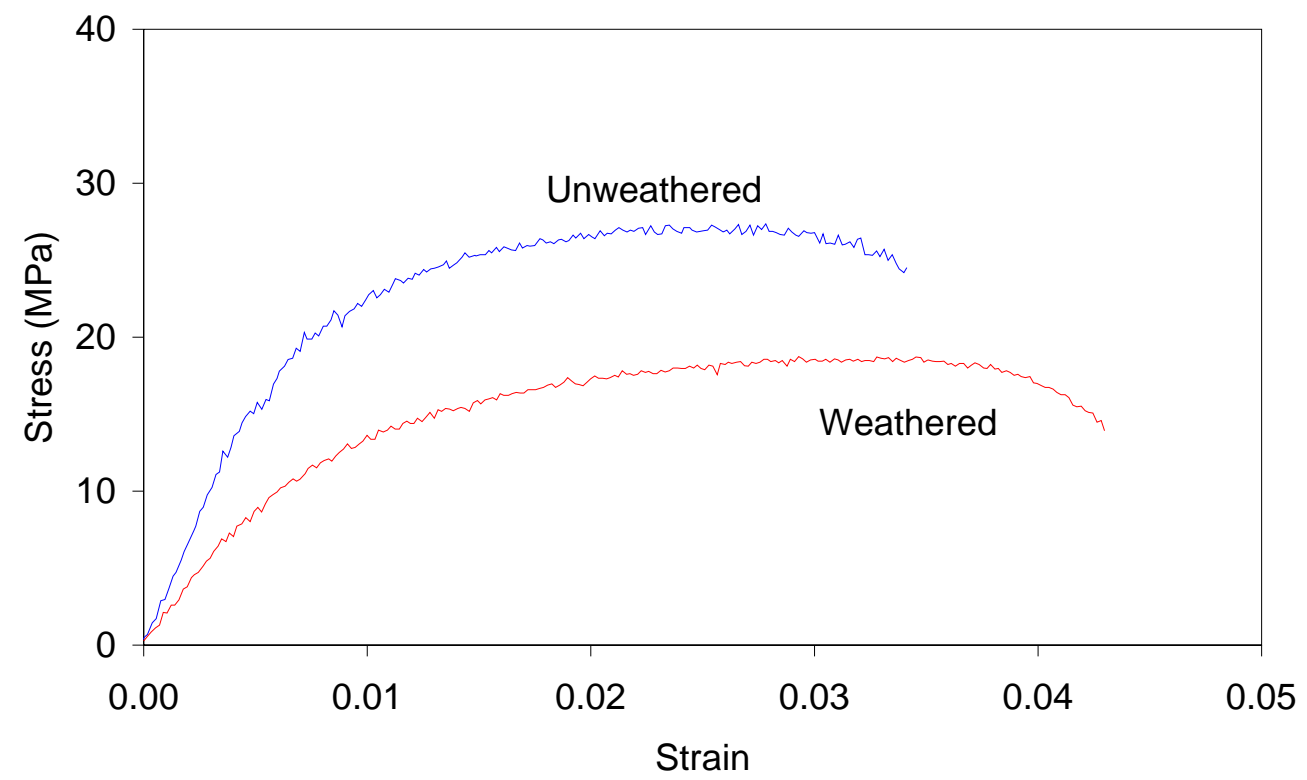

Figure A.4. Characteristic stress-strain curves for planed WF/HDPE composites, both unweathered and weathered $2000 \mathrm{~h}$.

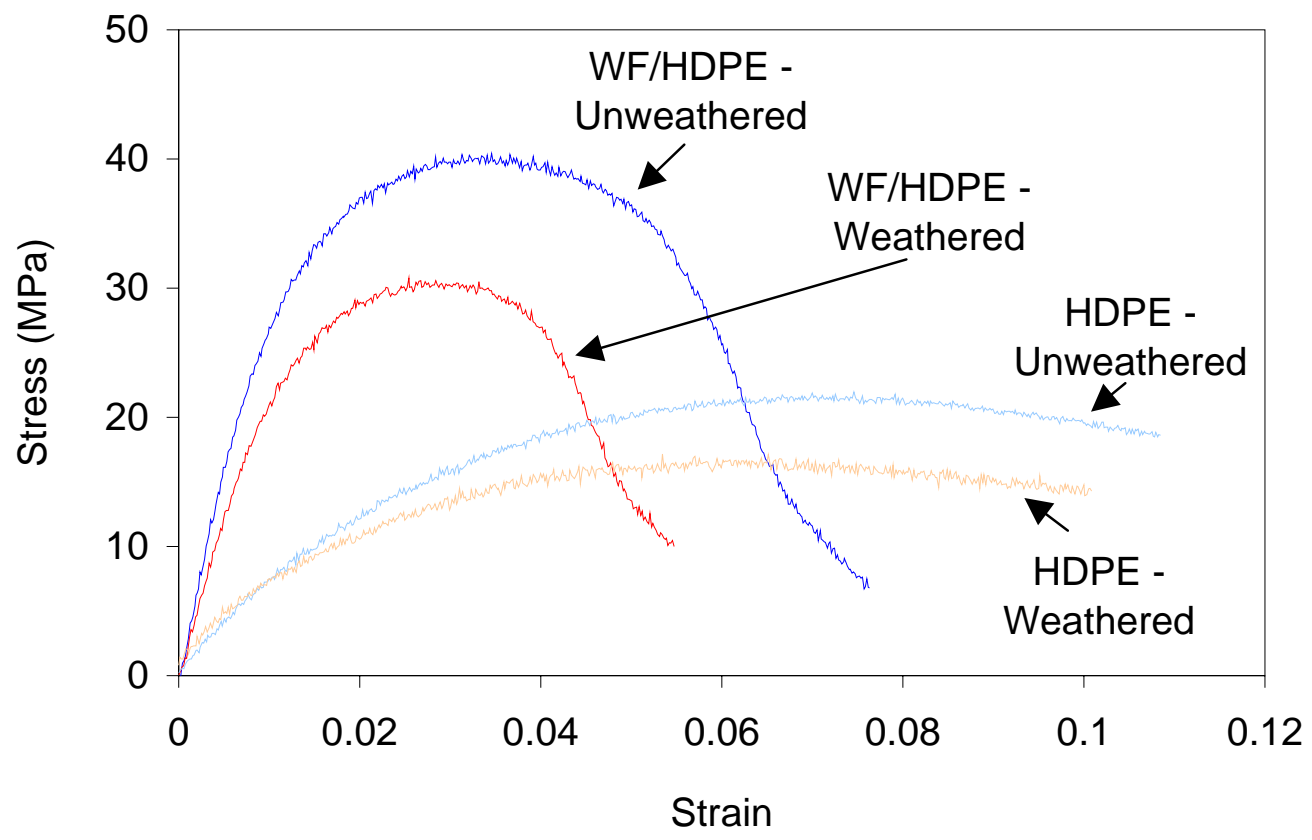

Figure A.5. Characteristic stress-strain curves for HDPE and WF/HDPE composites, both unweathered and weathered $2000 \mathrm{~h}$. 


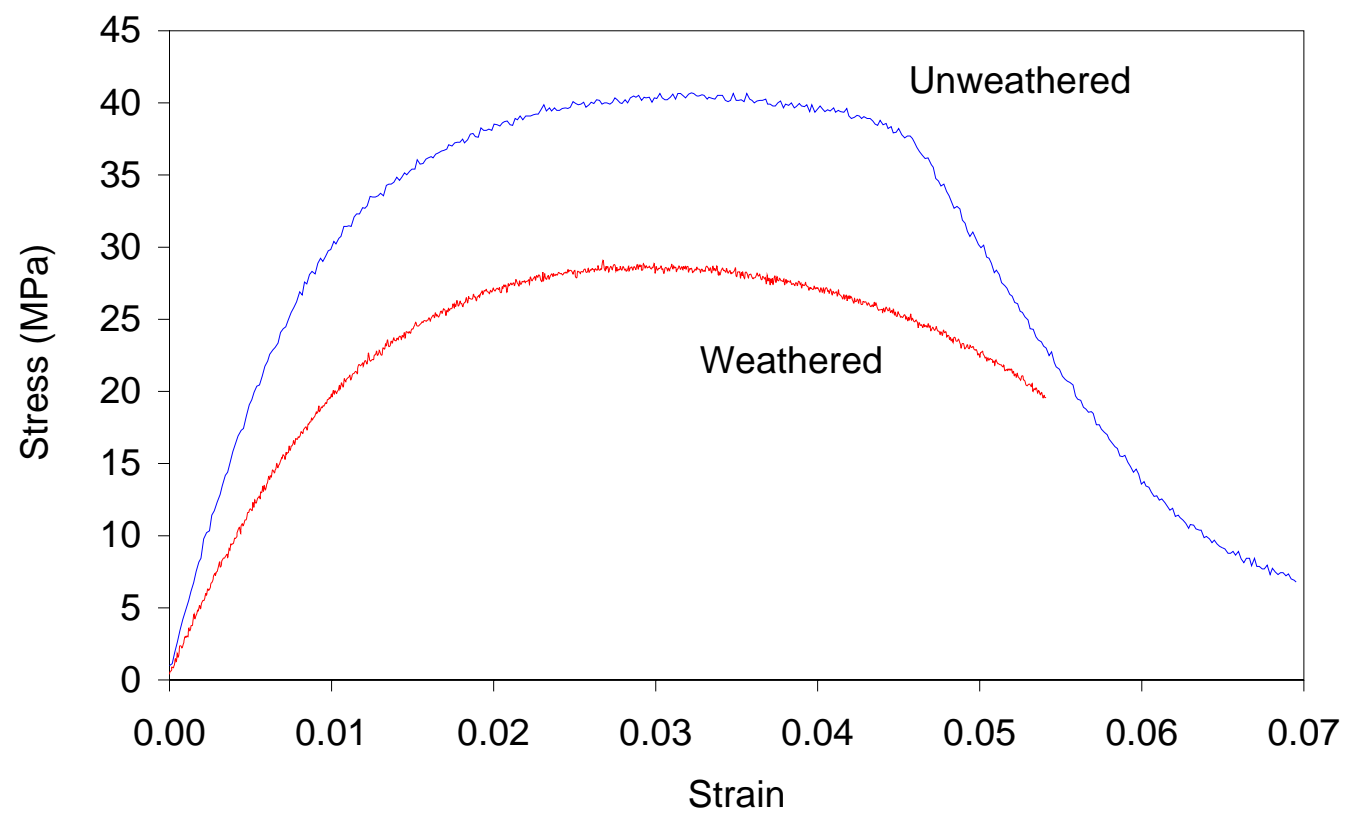

Figure A.6. Characteristic stress-strain curves for WF/HDPE composites, both unweathered and weathered $3000 \mathrm{~h}$.

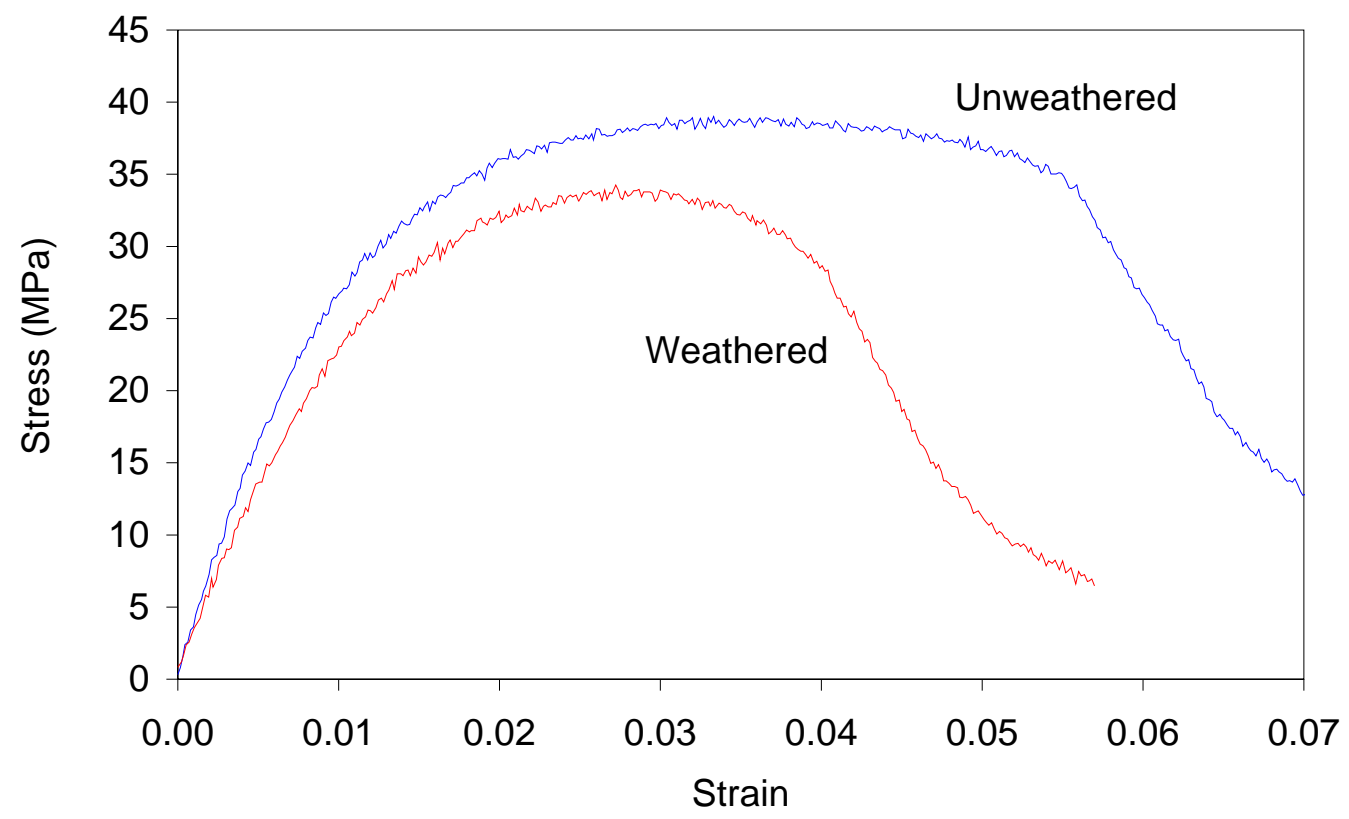

Figure A.7. Characteristic stress-strain curves for WF/HDPE composites with $1 \%$ UVA added, both unweathered and weathered $3000 \mathrm{~h}$. 


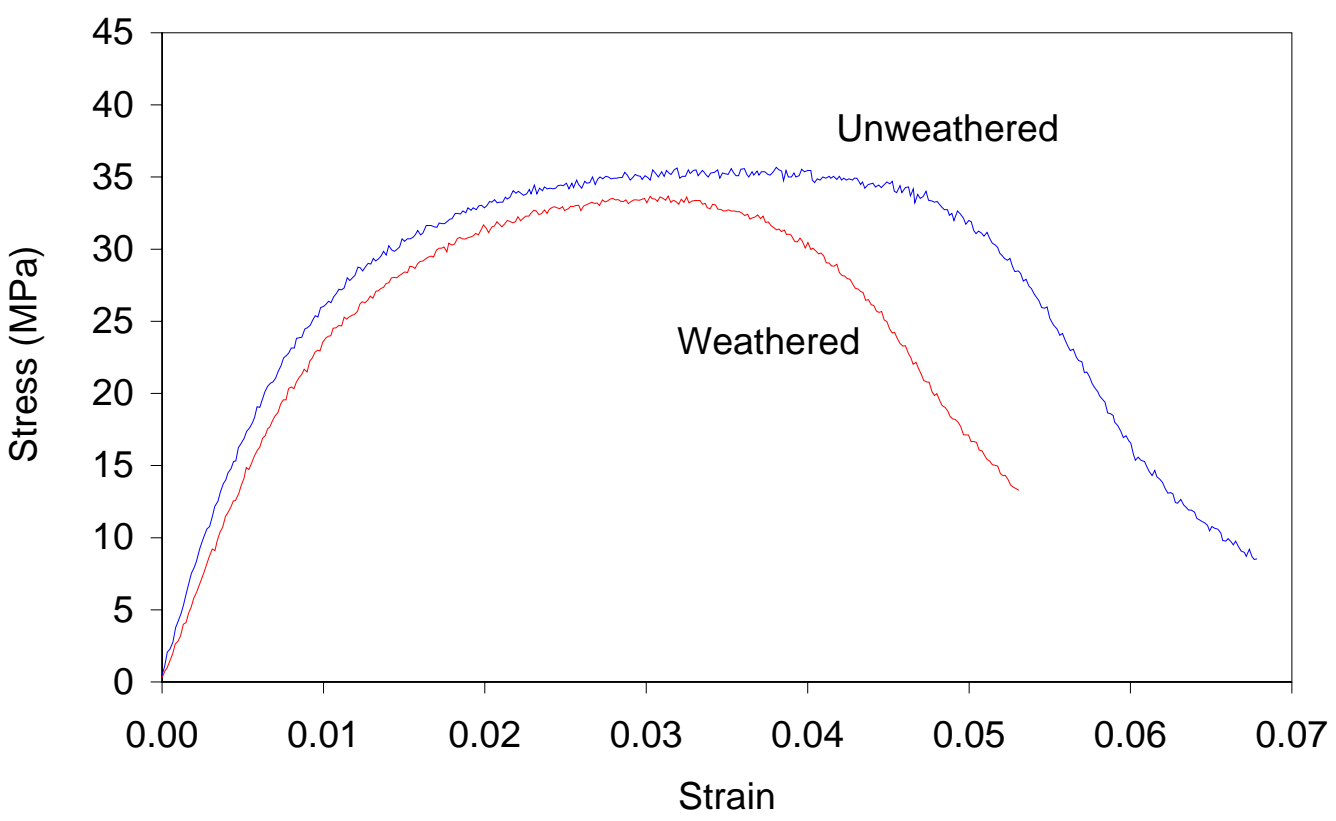

Figure A.8. Characteristic stress-strain curves for WF/HDPE composites with $2 \%$ pigment added, both unweathered and weathered $3000 \mathrm{~h}$. 


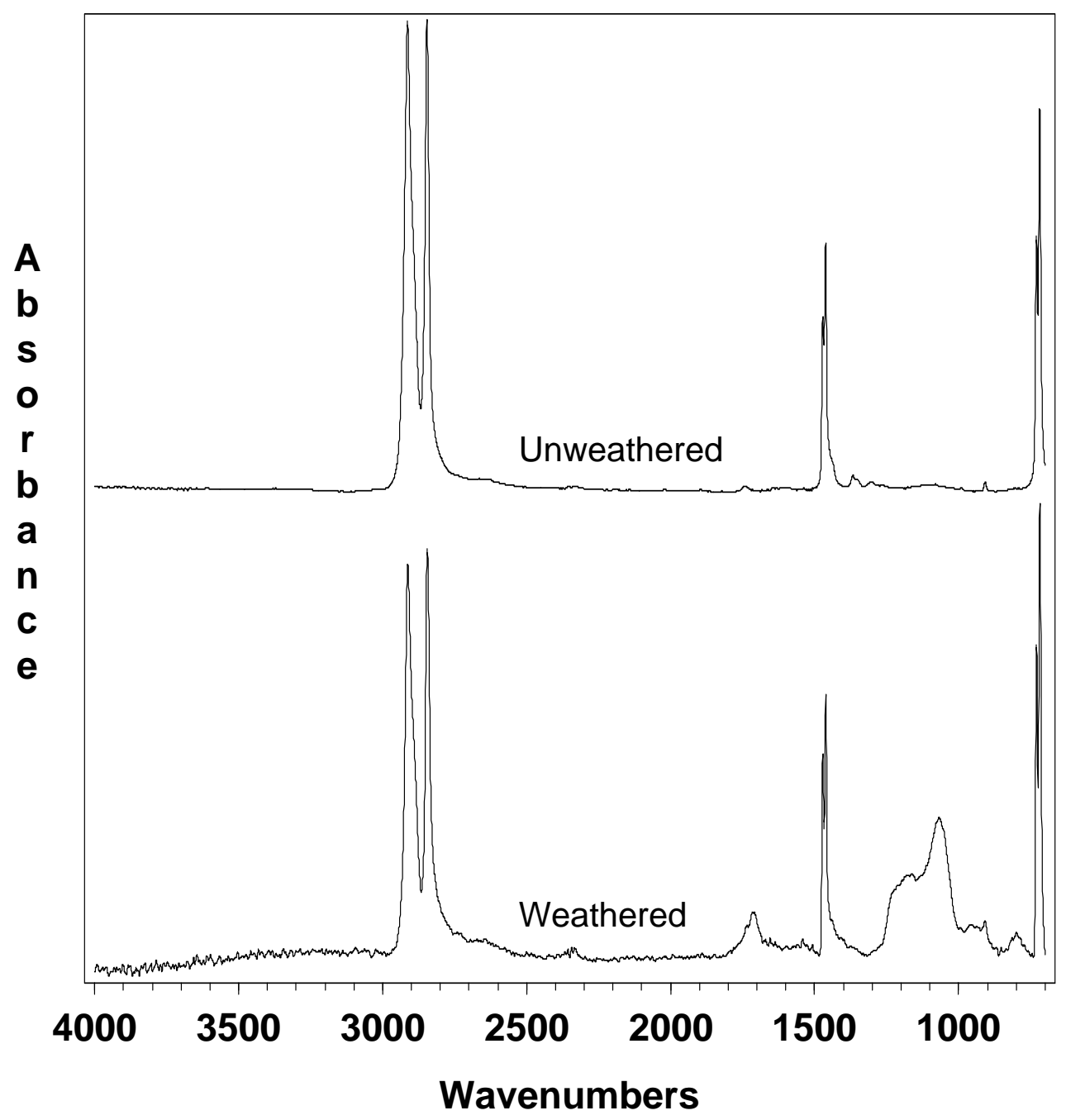

Figure A.9. Characteristic FTIR spectra for HDPE, both unweathered and weathered for $2000 \mathrm{~h}$. 


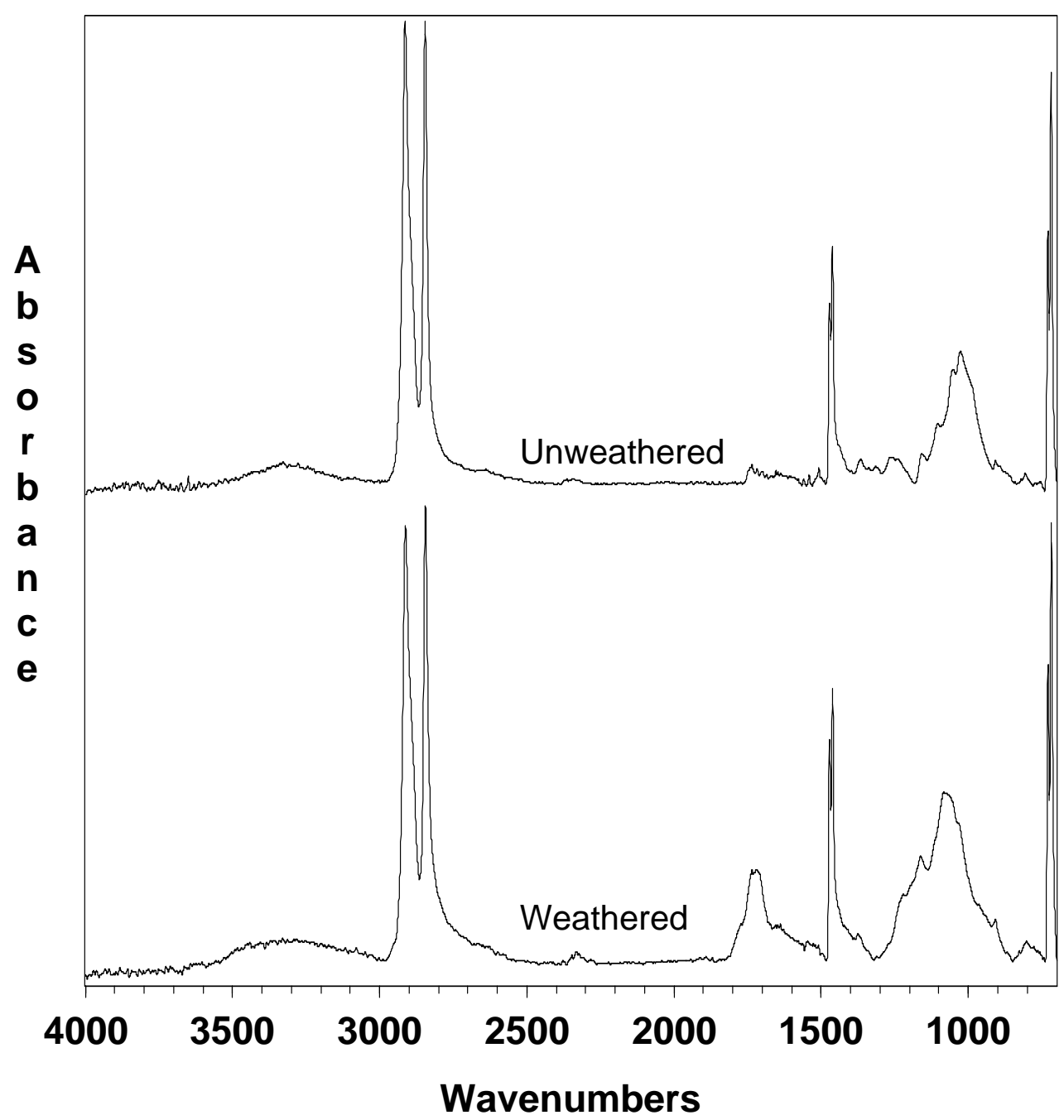

Figure A.10. Characteristic FTIR spectra for WF/HDPE, both unweathered and weathered for $2000 \mathrm{~h}$. 
Table A.4. Factorial design used to determine main effects and interaction of photostabilizers on weathering of HDPE and WF/HDPE composites.

\begin{tabular}{|c|c|c|c|c|}
\hline \multirow{3}{*}{$\begin{array}{c}\text { Standard } \\
\text { Order }\end{array}$} & \multicolumn{4}{|c|}{ Factors } \\
\hline & A & B & $\mathrm{C}$ & $\mathrm{D}$ \\
\hline & LS1 & LS2 & UVA & Pigment \\
\hline 1 & - & - & - & - \\
\hline 2 & + & - & - & - \\
\hline 3 & - & + & - & - \\
\hline 4 & + & + & - & - \\
\hline 5 & - & - & + & - \\
\hline 6 & + & - & + & - \\
\hline 7 & - & + & + & - \\
\hline 8 & + & + & + & - \\
\hline 9 & - & - & - & + \\
\hline 10 & + & - & - & + \\
\hline 11 & - & + & - & + \\
\hline 12 & + & + & - & + \\
\hline 13 & - & - & + & + \\
\hline 14 & + & - & + & + \\
\hline 15 & - & + & + & + \\
\hline 16 & + & + & + & + \\
\hline
\end{tabular}

